\title{
I. Auferstanden aus Ruinen - Chaos und Verwaltungsbruch
}

Mit der Besetzung Deutschlands und dem Ende der Kriegshandlungen standen die Besatzungsmächte vor der schwierigen Aufgabe der Reorganisation des sozialen Lebens. Dazu bauten sie neue Verwaltungsstrukturen auf und installierten neue Verantwortungsträger. In der Sowjetischen Besatzungszone (SBZ) vollzog sich dieser Prozeß bis zur Gründung der fünf Landes- und Provinzialverwaltungen Anfang Juli 1945 auf gesamtzonaler und lokaler Ebene. Zuerst wurden in jeder militärisch eingenommenen Stadt sowjetische Kommandanturen eingerichtet. Gemeinsam mit den seit Kriegsende aus der Sowjetunion eingeflogenen Initiativgruppen der KPD, die aus speziell geschulten deutschen Exilanten und Kriegsgefangenen bestanden, setzten die Kommandanten neue Bürgermeister, Landräte und Leiter der einzelnen Verwaltungsabteilungen ein. Diese waren die ersten Stützen für die Wiederherstellung des zivilen Lebens und bildeten gleichzeitig ein personelles Reservoir für das neue politische System. Die Entwicklung auf lokaler Ebene gestaltete sich unterschiedlich, weil die Besatzungsmacht sie nur durch allgemeine Vorgaben lenkte. Wie der Oberbürgermeister von Güstrow und spätere Innenminister Mecklenburg-Vorpommerns, Johannes Warnke, ${ }^{1}$ es den Bürgermeistern und Gemeindevorstehern seines Kreisgebietes schon Ende Mai 1945 verkündete, ist jede Stadt und jeder Kreis eine eigene Untersuchung wert: „Die Geschichte von diesen Männern und Frauen niederzuschreiben, wird einmal eine Doktorarbeit sein. " 2

Die vorliegende Arbeit konzentriert sich zwar auf die Landesebene, es werden jedoch beispielhaft anhand des Kreises Güstrow allgemeine lokale Entwicklungslinien nachgezeichnet, die auch Einblick in die sozialen und mentalen Umstände geben, die die Grundlage für die schnellen und tiefgreifenden Veränderungen im ersten Besatzungsjahr bilden. ${ }^{3}$ Für die Auswahl der Barlach-Stadt spricht neben der guten Aktenüberlieferung, daß hier zwei Männer die zentrale Rolle spielten, die in den folgenden Jahren im Zen-

\footnotetext{
'Johannes Warnke (1896-1984); geboren in Hamburg; 1911 Lehrbeginn als Dachdecker; 1914 SPD-Eintritt; 1918 Übertritt zur USPD und Mitglied der USPD-Sicherheitswehr (Wachdienst); 1919 Umzug nach Güstrow; nach dem Kapp-Putsch von der KPD-Bezirksleitung zum Aufbau eines illegalen militärischen Parteiapparates bestimmt; 1924-1926 Zuchthaus wegen Vorbereitung zum Hochverrat; Landtagsabgeordneter in Schwerin; seit 1926 Vorsitzender der KPD-Landtagsfraktion; hauptamtlicher Politischer Sekretär der KPD-Bezirksleitung Rostock; April 1932 Kur im Kaukasus; 1933-1935 Zuchthaus Dreibergen-Bützow; seitdem unter Polizeiaufsicht; danach erneute Verhaftungen, zwischenzeitlich im KZ Sachsenhausen; 1944 mit Carl Moltmann (SPD) in einer Zelle in Dreibergen-Bützow; 1945 Oberbürgermeister des erweiterten Kreises Güstrow; seit Juli 1945 Leiter der Abteilung Innere Verwaltung der Landesverwaltung Mecklenburg-Vorpommern; Ende 1946-1949 Landesinnenminister; Oktober 1949-1952 Staatssekretär im DDR-Innenministerium; 1952-1959 Vorsitzender des Rates des Bezirkes Rostock; 1959-1966 Leiter der Hafenbehörde; langiähriges Mitglied der Volkskammer (MdV).

${ }^{2}$ MLHA, MdI 30, Bl, 87.

${ }^{3}$ Fulbrook, Herrschaft, S. 84f.
} 
trum der Landespolitik stehen sollten: Mit dem Sozialdemokraten Wilhelm Höcker ${ }^{4}$ und dem Kommunisten Warnke standen zwei alte Landespolitiker zur Verfügung, die auf einen umfangreichen politischen Erfahrungsschatz und intime Kenntnisse ihres Landes und Kreises zurückgreifen konnten. Daß die personelle Konstellation und die politische Arbeit dieser Leitungsgruppe den Vorstellungen der Besatzungsmacht und der Initiativgruppe Sobottka ${ }^{5}$ entsprachen, zeigte sich im Juli 1945, als drei Politiker dieser Stadt in das vierköpfige Landespräsidium berufen wurden. ${ }^{6}$

${ }^{4}$ Wilhelm Höcker (1886-1955); in Hozendorf im Kreis Neubrandenburg geboren; gelernter Kaufmann; 1911 SPD-Eintritt; 1914-1918 Soldat; 1920-1932 Amtshauptmann des Kreises Güstrow; 1920-1932 Mitglied und zeitweise Präsident des Landtags; 1933-1945 Tabakwarenhändler; 1944 verhaftet; 1945 Präsident der Landesverwaltung Mecklenburg-Vorpommern; 1945-1946 Landesvorstand SPD Mecklenburg; 1946 bis Juli 1951 Ministerpräsident des Landes Mecklenburg; ab 1946 MdL; 1948-1950 MdVR/MdV; 1954 Mitglied DDR-Länderkammer.

${ }^{5}$ Gustav Sobottka leitete ebenso wie Walter Ulbricht und Anton Ackermann eine von drei Initiativgruppen, die die Sowjetunion kurz vor Kriegsende nach Deutschland schickte. Die ehemaligen Kriegsgefangenen und Exilanten unterstützten die Rote Armee und dienten der Durchsetzung der kommunistischen Hegemonie im sowjetischen Besatzungsgebiet. Die Initiativgruppe Sobottka wurde am 6. 5. 1945 von Moskau nach Warsow bei Stettin geflogen, wo sich die Politische Verwaltung der Zweiten Belorussischen Front befand; am 28. 5. 1945 kamen weitere Personen hinzu. Bis zum 6. 6. 1945 hatte die Gruppe ihren Sitz in Stettin-Kreckow, danach in Waren; zu ihr gehörten unter anderem Gerda Baum, Willi Bredel, Kurt Bürger, Otto Faust, Gottfried Grünberg, Herbert Hentschke, Rudolf Herrnstadt, Willi Keller, Aenne Kundermann, Frieda und Jonny Löhr, Lore Pieck, Anton bzw. Stanislaw Switalla (SAPMO-BA, NY 4182 [NL Ulbricht], 851, B1. 42f.; Geschichte der Landesparteiorganisation, S. 74, 86f.). Zur Tätigkeit der Initiativgruppen siehe Erler/Laude/Wilke, Hitler, S. 117-120; Fischer, Außenpolitik, S. 146-153; Grünberg, Mitglied; Kornow, Arbeiterklasse, S. 36ff.; Krüger, Initiativgruppe; Leonhard, Revolution, S. 296359; Müller, KPD, S. 442f.; Podewin, Ulbricht, S. 167-174; Voßke, Initiativgruppe; Voßke, Tätigkeit; Keiderling, Gruppe, enthält eine umfangreiche Dokumentensammlung zur Tätigkeit der nach ihrem Leiter Ulbricht benannten zentralen Initiativgruppe in Berlin. Gustav Sobottka (18861953); 1909 Mitglied des Bergarbeiterverbands; seit 1910 SPD-Mitglied; 1918 USPD; 1921-1932 KPD-Abgeordneter im Preußischen Landtag; international tätiger Gewerkschaftsfunktionär; 1933 Emigration Frankreich; 1935 Moskau; Journalist und Lehrer in Kriegsgefangenenlagern; Gründungsmitglied des NKFD; 1945 1. Sekretär der Landesleitung der KPD-Mecklenburg-Vorpommern; seit 1945 (Vize-)Präsident der Deutschen Zentralverwaltung für Brennstoffindustrie; 1949-1951 Leiter der Hauptverwaltung Kohle der DWK bzw. im Ministerium für Schwerindustrie der DDR.

6 Neben Höcker und Warnke noch Otto Möller (1892-1978); Agrartechniker; Mitglied der Demokratischen Partei; 1932-1933 (Austritt) Stahlhelm; Arbeit im ,Reichsnährstand'; Landwirtschaftsrat; 1945 CDU; 1948 National-Demokratische Partei Deutschlands (NDPD); 1948-1950 Professor für Kulturtechnik an der Universität Rostock; 1949-1950 stellvertretender Vorsitzender des Landesvorstands NDPD Mecklenburg, ab 1949 Hauptvorstand NDPD; 1950-1963 MdV; $1952-$ 1955 Leiter des Amtes für Wasserwirtschaft DDR, ab 1955 Professor an der Universität Rostock. Der zweite Vizepräsident war Gottfried Grünberg (1899-1985); geboren in Beuthen (Oberschlesien); 13jährig verläßt er die Dorfschule und arbeitet in einer Klemmplattenfabrik; danach im Bergbau; Soldat im Ersten Weltkrieg; danach Bergmann im Ruhrgebiet; in den zwanziger Jahren Verhaftung unter anderem wegen prosowjetischer Aktivitäten; 1928 KPD-Eintritt; Mitarbeit beim Aufbau der Kohlenindustrie im Donbaß in der Sowjetunion; 1933 Studienbeginn in Moskau; 1936 Spanienkämpfer; danach über Frankreich zurück in die SU; Industrie-Instrukteur in Gorki; 1941 Soldat der Roten Armee; seit 1942 Schulung deutscher Kriegsgefangener in Krasnogorsk und Taliza; Gründungsmitglied des NKFD; 1945 Initiativgruppe Sobottka; 1947 Mitbegründer und erster Landesvorsitzender der Gesellschaft zum Studium der Sowjetunion; später NVA und Militärattaché in Moskau. 
Nach der Übernahme der bis Ende Juni 1945 US-amerikanisch und britisch besetzten Gebiete Westmecklenburgs und Thüringens durch die Rote Armee installierte die Sowjetische Militäradministration Deutschlands (SMAD) Anfang Juli in der SBZ fünf Provinzial- und Landesverwaltungen. ${ }^{7}$ Die Verwaltungsspitze in Schwerin, die sich vorwiegend aus alten mecklenburgischen Politikern und aus in der Sowjetunion politisch geschulten Remigranten und ehemaligen Kriegsgefangenen zusammensetzte, war anfangs vor allem mit der eigenen Konstituierung beschäftigt und übernahm dann sukzessive Kompetenzen, die bis dahin nur auf lokaler Ebene verwaltet und geregelt worden waren. Dabei mußten auch die Strukturen und Kompetenzen im Bereich der Entnazifizierungsund Personalpolitik bestimmt werden. Weil diese für die Zusammensetzung des Verwaltungsapparates entscheidend war, kam ihr eine herausragende Bedeutung bei der Gestaltung der neuen Herrschaft zu.

\section{Herrschaft im Zusammenbruch - Mecklenburg im Sommer 1945}

\section{Die Stunde Eins}

Vier Tage nach dem Einmarsch sowjetischer Truppen in die größte Stadt Mecklenburgs erließ der Stadtkommandant von Rostock, Oberst Prjadko, seinen ersten schriftlichen Befehl: ${ }^{8}$ Er erklärte den „gesamte[n] vom Hitlerregime geschaffene[n] Staats- und Verwaltungsapparat" sowie die NSDAP mit allen ihr angeschlossenen Organisationen für aufgelöst und setzte den im Nationalkomitee Freies Deutschland (NKFD) ausgebildeten ehemaligen Kriegsgefangenen Christoph Seitz zum Bürgermeister ein. Damit einher ging die Aufforderung an alle Leiter der NSDAP und ihrer Gliederungen sowie an alle Mitglieder von SS, Gestapo, SD, Feldgendarmerie, Polizei, Wehrmacht, Volkssturm, Arbeitsdienst und der Organisation Todt, sich sofort bei der Kommandantur zur Registrierung zu melden. Nichtbefolgung sei „Spionage und Sabotagetätigkeit“ und werde „als eine gegen die Rote Armee feindlich gerichtete Handlung geahndet" werden. Der Befehl drohte hierfür drastische Strafmaßnahmen an. ${ }^{9}$ Dabei ging es nicht nur darum, in der chaotischen Situation am Ende des Krieges einen Überblick zu gewinnen, sondern dies

\footnotetext{
7 Kurz darauf wurden Generaloberst Iwan Iwanowitsch Fedjuninski als Chef der Sowjetischen Militäradministration Mecklenburgs (SMAM) und sein Stellvertreter Generaloberst Michail Alexandrowitsch Skossyrew ernannt; der ehemalige Funktionär der Kommunistischen Partei der Sowjetunion (KPdSU) Skossyrew verantwortete alle Zivilangelegenheiten und war daher für die meisten Fragen im Zusammenhang mit den deutschen Organen entscheidend (Befehle des Obersten Chefs, S. 13f.; Foitzik, Sowjetische Militäradministration, S. 24f., 57; Errichtung, S. 51; Fait, Mecklenburg, S. 109).

${ }^{8}$ Sowjetische Truppen erreichten Rostock am 1. 5. 1945; militärische Auseinandersetzungen fanden in Mecklenburg und Vorpommern vom 28. 4. 1945 bis zum 3. 5. 1945 statt; 57 der 73 von der Roten Armee eingenommenen Städte wurden "kampflos oder nahezu kampflos befreit“ (Kornow, Arbeiterklasse, S. 29; siehe auch ebenda, Anhang I, Bl. 1 und S. 22-30; Fenske, Verwaltung, S. 165f.; Jahnke, Ende; Krüger, Haff; Mai, Quellen; Mai, Sieg; Menger, 1945; Murawski, Eroberung, besonders S. 314-362; Rönsch, Übergabe; Schultz-Naumann, Mecklenburg).

9 Rackow, Kampf, Anlage 6.
} 
war gleichzeitig der Beginn der Entnazifizierung: Entlassungen, Verpflichtungen zum Arbeitseinsatz und zahlreiche Internierungen waren die Folgen, die die NS-Funktionäre zu gewärtigen hatten.

Schon zwei Tage vor dem ersten sowjetischen Befehl hatte sich das aus fünf Kommunisten, drei Sozialdemokraten und vier parteilosen Bürgern bestehende „Rostocker Ordnungskomitee" an die Bevölkerung ihrer Stadt gewandt, um erste Schritte zur Regelung wichtiger Bereiche des kommunalen Lebens festzulegen:10 „1. Sämtliche Lebensmittel, gleich welcher Art, in vorhandenen Läden und Lebensmittelgeschäften werden für die Bevölkerung sichergestellt. Für diesen Zweck sind vorläufig Rostocker Arbeiter, die mit der roten Armbinde gekennzeichnet sind, und in deren Begleitung sich Soldaten der russischen Wehrmacht befinden, eingesetzt. "Bezeichnend für die Lage am Kriegsende war, welche Berufsgruppe als erste konkret benannt wurde: „Die Friedhofsarbeiter, Leichenfrauen haben sofort die Arbeit wiederaufzunehmen. Ein Tischlermeister wird beauftragt, vorkommende Todesfälle sofort zu erledigen. Es wird dafür gesorgt werden, gestorbene Menschen beerdigen zu können“. Erst danach wurden Müllabfuhr, Elektrizitäts- und Wasserwerk angesprochen. Ferner hätten Ärzte, Hebammen und Apotheken ihre Arbeit „sofort wieder aufzunehmen “. Für weitere Angelegenheiten, so hieß es, „erfolgt in den nächsten Tagen nähere Anweisung“.

Diese Verteilung von Aufgaben war für die ersten Wochen symptomatisch: Während die sowjetischen Stellen offensichtlich bemüht waren, Deutsche schon früh in die Verantwortung für die Reorganisation des öffentlichen Lebens zu integrieren, wird nirgends davon berichtet, daß Deutsche entscheidende Funktionen bei der Entnazifizierung übernahmen. Die frühen Formen der Abrechnung waren vielmehr von Kriegsende, Siegereuphorie und spontanen Übergriffen seitens der kämpfenden Truppen, befreiter Zwangsarbeiter und ehemaliger Kriegsgefangener geprägt und sollten zudem dem sowjetischen Hauptanliegen dienen, in den besetzten Gebieten Ruhe und Ordnung herzustellen. Generell sind Ausmaß und Formen der Entnazifizierung in den ersten Besatzungswochen in allen Besatzungszonen nur schwer einzuschätzen, da es sich ausschließlich um lokale Aktionen handelte. ${ }^{11}$

Übergriffe und Abrechnungen. Die ersten Tage nach Zusammenbruch und Besetzung waren in starkem Maße durch spontane Aktionen gegen vermeintliche Repräsentanten des Faschismus geprägt: „Am 23. Mai wurde in Kirch Kogel (Bezirk Krakow) die Ehefrau des bald nach dem Einzug der Russen erschossenen Gutspächters Burchard, der selbst längere Zeit durch die Hitler-Regierung eingesperrt war und niemals der NSDAP angehört hatte, ebenso wie ihre Tochter entkleidet und mit Stockschlägen bearbeitet. In gleicher Weise erging es dem Sohn Burchard. In der Nacht vom 21. auf 22. Mai wurde scheinbar von 3 russischen Soldaten in Goldewin ein Feuer angelegt, und zwar wurden die strohgedeckten Dächer des Gehöftes des Bürgermeisters Levihn mit Leuchtspurmunition in Brand geschossen. Die 20jährige und die 23jährige Tochter des Bürgermeisters verbrannten. Diese Fälle können leider noch ergänzt werden. “12 Dieser Bericht eines

\footnotetext{
10 Rackow, Kampf, Anlage 5.

11 Siehe Kapitel I.2, S. 68-76.

12 „Programm für die Rücksprache mit den Kommandanten der einzelnen Städte am 30. Mai 1945“ (MLHA, MdI 2078).
} 
nach Kriegsende eingesetzten deutschen Politikers diente als Grundlage für eine Aussprache mit dem sowjetischen Kommandanten und steht im Einklang mit vielen anderen Erinnerungsberichten über das Verhalten sowjetischer Soldaten. Er zeugt beispielhaft von der Mischung aus sowjet-marxistischer Faschismustheorie, der innerhalb der Roten Armee bis zum Frühjahr 1945 massiv propagierten Kollektivschuld aller Deutschen und einer militärischen Siegerpose: Diese antifaschistische Grundauffassung erkannte den politischen Gegner besonders im ,Klassenfeind', hier im Gutspächter, und die traditionell soldatische Siegerpose äußerte sich neben materieller Bereicherung vor allem in Demütigungen und Brutalität gegenüber Frauen und Mädchen. Die Übergriffe der Militärs und zahlreicher befreiter Zwangsarbeiter betrafen viele Unschuldige, richteten sich aber auch gegen tatsächliche Repräsentanten und Träger des NS-Regimes, wie das Gefängnispersonal in Bützow-Dreibergen und ,Sklavenhalter" der Zwangsarbeiter. Aufgrund der mehrere Wochen andauernden allgemeinen Unsicherheit vor allem auf dem Land und nur zufällig festgehaltener Zahlen über die Ausschreitungen sowjetischer und anderer ausländischer ,Sieger` sind Opfer und Täter hier nicht genauer zu differenzieren und zu quantifizieren. ${ }^{13}$

Das Chaos wurde durch die Vielzahl der Suizide ${ }^{14}$ vergrößert; bei der Erstellung einer Vermögensliste nannte es der Stadtkämmerer von Güstrow in einigen Fällen „zweifelhaft [...], ob Freitod oder Erschießen durch Polen oder Angehörige der Roten Armee vorliegt" ${ }^{15}$ Während sich viele bereits vor dem Einmarsch der sowjetischen Truppen umbrachten, wurde im Zusammenhang mit Vergewaltigungen durch Besatzungssoldaten auch auf den Tod aller Familienangehörigen hingewiesen: „Vernichtung ganzer Familien durch Ehemänner ist die Folge dessen, daß ,er diese Schande nicht ertragen kann. “ ${ }^{16}$ Im Begräbnisregister Teterow ${ }^{17}$ wurden unter der Überschrift: „Fortsetzung des Nachtrages aus der Selbstmordperiode Anfang Mai 1945“ insgesamt über 120 Tote mit Angaben darüber aufgezählt, wie der Suizid durchgeführt wurde: „Selbstmord durch Erhängen“, „Selbstmord durch Ertrinken“, „Selbstmord durch Schuß“, „Selbstmord durch Vergiftung“, „Selbstmord durch Gasvergiftung“; andere Sterbefälle - „erschossen“, „tot aufgefunden“ - wurden zusätzlich genannt. In vielen Berichten von Zeitgenossen finden sich Hinweise, daß Väter ihre ganzen Familien und daraufhin sich selbst umbrachten: „Der Ehemann hat mit ihrem vollen Einverständnis Frau und Kinder

${ }^{13} \mathrm{Zu}$ den Schwierigkeiten der Quantifizierung siehe den Bericht des Landrats „über die Lage im Kreisgebiet Güstrow" vom 28. 5. 1945, der zudem davon berichtet, daß mehrere $Z$ wangsarbeiter und sowjetische Soldaten wegen solcher Übergriffe erschossen worden seien (MLHA, MdI 2078).

${ }^{14}$ Johr, Ereignisse, S. 55f. Einen Hinweis auf die öffentliche Bedeutung der Selbstmorde im Jahr 1945 enthält einer der in Mecklenburg-Vorpommern kursierenden, anonym mit „SchmitzDeutschland" unterzeichneten nationalistischen und antialliierten Briefe, in dem gefordert wird, statt der „Lügereien“ über die KZ-Toten „lieber mal die Selbstmordzahlen in Deutschland, die durch Eure Gemeinheiten vorgekommen sind und noch weiter vorkommen werden", zu veröffentlichen (Landeskirchliches Archiv, Bestand Oberkirchenrat, II 1/O, 1, Bl.6).

15 MLHA, MdI 2928.

${ }^{16}$ Schmidt-Harzbach, Woche, S. 31, 17.

${ }^{17}$ Alle im folgenden zitierten Begräbnisregister in: Landeskirchliches Archiv, Schwerin. Die Stadt Teterow hatte 19469705 Einwohner (Statistisches Landesamt, Gemeindeverzeichnis). 
vergiftet und dann sich selbst erhängt." Diese Angabe bezog sich auf einen Sparkassenleiter bei Teterow, seine Frau und drei Kinder. ${ }^{18}$

Die Selbstmorde können nicht unbedingt als Schuldeingeständnisse oder als Flucht vor der Rechenschaftsablegung verstanden werden. Es handelte sich keineswegs nur um Nazis, die die Ahndung politischer oder strafrechtlicher Vergehen fürchteten, sondern um viele national Gesinnte, die die Kriegsniederlage, Besetzung und Kapitulation Deutschlands nicht ertrugen, und vor allem um Menschen, die Angst vor der kommenden Unsicherheit unter sowjetischer Besatzung hatten, die durch die NS-Propaganda und durch Augenzeugenberichte über die Eroberung der ostdeutschen Gebiete gefördert wurde. Ein Beispiel für den Selbstmord eines politisch Unbelasteten ist der des bürgerlich-demokratischen Kommunalpolitikers Robert Grabow, der von 1930 bis 1935 Rostocker Oberbürgermeister gewesen war: Der Verdacht, daß Grabow sich vor der Ahndung faschistischer Taten fürchtete, kann weitgehend ausgeschlossen werden, da er vom kommunistisch dominierten Rostocker "Ordnungskomitee“ nach dem Einzug der Sowjets als Oberbürgermeister vorgeschlagen wurde. ${ }^{19}$

Internierungen und Militärtribunale. Nach der Besetzung war alle öffentliche Gewalt auf die Befehlshaber der kämpfenden Truppen übergegangen. Diese setzten in Städten, Kreisen und Gemeinden ranghohe Soldaten als Kommandanten ein, die nach den Richtlinien und Vorgaben ihrer Oberkommandos zu handeln hatten ${ }^{20}$ und für die Wiederherstellung gesellschaftlicher Ordnung verantwortlich waren. Nach einem Jahre währenden Bewegungskrieg, der sie durch das eigene Land und weitere besetzte Länder geführt hatte, konnten sie - ebenso wie die ersten westalliierten Besatzungssoldaten - für diese neuen Tätigkeiten nur auf wenig Erfahrungen und Vorbereitungen zurückgreifen. Das führte zu Differenzen zwischen den einzelnen Kommandanten, die schon bald von den neuen deutschen Funktionsträgern bemerkt wurden und die sich vor allem in unterschiedlichen Erfolgen bei der Beseitigung des Nachkriegschaos zeigten.

${ }^{18}$ Bei vielen in den Tagen vor und nach dem sowjetischen Einmarsch gestorbenen Frauen finden sich Angaben, die auf den gemeinsamen Tod mit ihren Ehemännern hinweisen, wie z. B. bei einer Toten mit der Registernummer 78: „Ehefrau von 77.“

${ }^{19}$ Rackow, Kampf, S. 93; auch der ehemalige sozialdemokratische Finanzminister, Hans Hennecke, ging mit der ganzen Familie in den Freitod (Schwabe, Krone, S. 193). Nach einem Bericht des Güstrower Landrats Wilhelm Beltz vom 28. 5. 1945 brachten sich überdurchschnittlich viele Gutsbesitzer um; sie bildeten aber keineswegs den größten Teil der Toten: „Die mir bisher bekanntgewordenen Fälle der Selbstmorde auf dem platten Lande betragen etwa 25 Guts- und Hofbesitzer einschließlich der Familienmitglieder. Die angegebenen Zahlen dürften sich aber noch etwas erhöhen" (MLHA, MdI 2078). Die kirchlichen Begräbnisbücher geben einen Eindruck vom nicht exakt quantifizierbaren Ausmaß der Todesfälle. Manche Pfarrer unterbrachen in den Tagen vor und nach dem Einmarsch der Sowjets die lange Tradition der namentlichen Nennung der Beerdigten. Im Begräbnisbuch der lutherischen St. Marien-Gemeinde in Parchim heißt es beispielsweise: „Genaue Beerdigung unbekannt: Massenbeerdigung". Am Ende des Buches wurde ohne Datum nachgetragen: „Durch Kriegseinwirkung sind folgende Personen ums Leben gekommen mit unvollständigen Angaben." Von den genannten 160 wurde bei 45 Selbstmord, bei 14 (von Russen) erschossen“, bei 2 „unter Trümmern“, bei 3 „durch Beschuß ${ }^{\text {“ }}$, bei 1 "durch Brand" als Sterbeursache angegeben. In der Parchimer Nachbargemeinde St. Georg wurden die vielen Toten zwischen dem 7. und 10. 5. 1945 nur noch in langen Listen ohne weitere Angaben über Verwandte, Geburtsdatum etc. aufgezählt.

20 Fricke, Politik, S. 13f.; Mai, Sieg. 
Schon am 1. März 1945 war eine Direktive der Ersten Belorussischen Front an die Kommandeure der Verbände und Truppenteile in den besetzten Gebieten Deutschlands ergangen, in der ihnen als Hauptaufgabe aufgetragen wurde, „geordnete Zustände allerorts herzustellen, die schlimmsten Kriegsfolgen zu überwinden, die Gefahr von Seuchen und von Hungersnot zu bannen, versprengte Einheiten der faschistischen Wehrmacht, der SS und der Polizei zu entwaffnen und untergetauchte Kriegsverbrecher ausfindig zu machen". ${ }^{21} \mathrm{Da}$ es zunächst galt, die besetzten Gebiete zu sichern, wurde nicht sofort systematisch nach Nazis gesucht. Um Ruhe und Ordnung herzustellen und neben Plünderungen und anderen Unregelmäßigkeiten vor allem die durch die NS-Propaganda angekündigte Werwolf-Tätigkeit ${ }^{22}$ zu unterbinden, wurden auch in den Westzonen übliche Maßnahmen wie Sperrstunde, Einschränkung der Mobilität und Postüberwachung erlassen. ${ }^{23}$ Auch die ersten Festnahmen dienten nicht der Überprüfung der sowieso weitgehend paralysierten Verwaltungen und Betriebe, sondern der Ausschaltung potentieller Gefahren für die Besatzungsmacht. Dazu nutzten die Sowjets vorwiegend zwei Instrumente: Internierung und Militärgerichtsbarkeit.

Nach den Berichten Betroffener gingen die Besatzungstruppen dabei unkoordiniert, planlos und willkürlich vor. Der bei Fricke zitierte Bericht eines Ende September 1945 Internierten, der im Verhör danach befragt wurde, "wer hauptamtlich bei der Partei gewesen sei, wo sich die Ortsgruppenleiter und Zellenleiter befänden und ähnliches mehr“, ${ }^{24}$ zeugt davon, daß sie zum Teil fünf Monate nach der Besetzung noch keinen Überblick über die Lage hatten. Die Internierungen - zuerst in provisorischen Haftanstalten, dann in sukzessive eingerichteten Sammellagern für zivile politische und kriminelle Häftlinge sowie für Kriegsgefangene ${ }^{25}$ - waren auch ein Mittel zur präventiven Herrschaftssicherung und Disziplinierung der Bevölkerung. ${ }^{26}$

Eine in den ersten Wochen seltene Alternative zur Internierung für Gefangene der Besatzungsmacht war die Verurteilung durch Militärtribunale;27 für Mecklenburg-Vorpommern nennt Fricke Militärgerichte in Schwerin, Rostock, Greifswald und Güstrow.28 Urteile solcher Militärgerichte wurden teilweise aus ,pädagogischen' Gründen zur Abschreckung bekanntgemacht; beispielsweise wurde der Bevölkerung im weitverbreiteten Befehl Nr. 3 des Militärkommandanten von Schönberg vom 8. Oktober 1945

${ }^{21}$ Doernberg, Hilfe, S. $97 f$.

22 Einige unbestimmte Hinweise auf Werwolf-Aktivitäten in Neubrandenburg und Malchin in: Jahnke, Ende, S. 87, 89. Nach Fricke, Politik, S. 114f., hat es „eine organisierte Werwolf-Tätigkeit im eigentlichen Wortsinne [...] im sowjetischen Besatzungsgebiet augenscheinlich nicht gegeben“; ihre „Fiktion" sei auch von der Roten Armee bald aufgegeben worden, „da selbst die sowjetischen Ermittlungsbehörden ihre Unsinnigkeit erkennen mußten“.

${ }^{23}$ Siehe beispielsweise MLHA, RdK Schönberg/Grevesmühlen 28, Bl. 1.

24 Fricke, Politik, S. 59.

25 Klonovsky/von Flocken, Lager, S. 26ff.; Fricke, Politik, S. 15.

${ }^{26}$ Zur präventiven Ausschaltung und Isolierung potentiell und tatsächlich oppositioneller Bevölkerungsgruppen zitiert Fricke, Politik, S. 69f., den Tscheka-Begriff der ,sozialen Prophylaxe'; siehe auch Klonovsky/von Flocken, Lager, S. 22-25.

27 Finn, Häftlinge, S. 26ff.; Finn, Kriegsverbrecherprozesse; Fricke, Politik, S. 55, 64, 128.

${ }^{28} \mathrm{Zu}$ den Gründen für ihre rechtliche Zuständigkeit siehe Fricke, Politik, S. $101 \mathrm{ff}$. 
das Militärtribunal-Urteil Nr. 34 mitgeteilt,, ${ }^{29}$ durch das der 1892 geborene ehemalige NS-Bürgermeister des Dorfes G., Friedrich L., wegen des versteckten Besitzes von zwei Jagdgewehren, einer Pistole und 400 Schuß Munition zum Tode verurteilt wurde: „Das Urteil ist vollstreckt." Anschließend forderte der Kommandant die Deutschen erneut zur Ablieferung aller Waffen auf. Trotz des Hinweises, daß der Verurteilte staatlicher Funktionsträger und Mitglied der NSDAP gewesen war, wurde er ausschließlich wegen des Waffenbesitzes verurteilt. Ein weiterer Grund für drastische Militärtribunal-Urteile waren Verstöße gegen landwirtschaftliche Ablieferungsvorschriften und andere ökonomische Vorgaben, ${ }^{30}$ die aufgrund der Notsituation als politische Straftaten geahndet wurden. ${ }^{31}$

Verhaftungen wurden unsystematisch durchgeführt. Es mangelte an genauen Instruktionen der kämpfenden Truppen für die Maßnahmen während der ersten Besatzungszeit, deren Verhalten hing daher stark von den Entscheidungen der jeweiligen Kommandanten ab. Der Landrat von Güstrow berichtete am 28. Mai 1945 von der selbst innerhalb seines Landkreises unterschiedlichen Verhaftungspraxis: „In Laage sind 45 Personen verhaftet, die im Sammeltransport nach Grimmen überführt wurden. Bis auf 5 Personen sind die Verhafteten inzwischen wieder zurückgekehrt. In Krakow sind bisher keine Verhaftungen erfolgt. In Schwaan und Bützow wurden einige wenige Verhaftungen durch die Rote Armee vorgenommen. Auf dem platten Land wußte man über Verhaftungen im allgemeinen kaum etwas zu berichten." ${ }^{32}$ Nicht zufällig beurteilte er die

${ }^{29}$ Zwecks öffentlicher Bekanntgabe wurde der Befehl sogar gedruckt (MLHA, RdK Schönberg/ Grevesmühlen 28, Bl. 10); nach Berichten der mecklenburgischen Landesverwaltung hielten ehemalige NSDAP-Mitglieder noch 1946 Waffen versteckt (MLHA, MinPräs 1673); siehe auch Fricke, Politik, S. 115.

${ }^{30}$ Der SMAM-Befehl Nr. 6 vom 20. 8. 1945 verkündete das in öffentlicher Sitzung gefällte Urteil eines sowjetischen Kriegstribunals gegen Hans C. im Kreis Parchim, der wegen falscher Pflichtablieferungen und der Verheimlichung von 23 Hektar Aussaatfläche angeklagt worden war: „Erschießen sowie Beschlagnahme des gesamten Vermögens"; zur Begründung wurde auf das „Strafgesetzbuch der RSFSR“ verwiesen (MLHA, MdI 197, Bl. 299). Auch dieses Urteil wurde propagandistisch ausgewertet: Der für Zivilangelegenheiten verantwortliche Verwaltungschef der SMAM, Skossyrew, ordnete auf der Konferenz der Oberbürgermeister und Landräte am 20./21. 8. 1945 an, „dieses Urteil der gesamten Bevölkerung bekannt zu geben und den Kampf zu führen gegen alle Saboteure, die im Interesse der Faschisten arbeiten " (MLHA, MdI 245, Bl. 75); einen Monat später wurde es im Mitteilungsblatt Güstrow, $\mathrm{Nr}$. 5 (1945), S. 1, abgedruckt.

${ }^{31}$ Sowjets und KPD begannen früh, bei Wirtschaftsvergehen politische Motive zu unterstellen; bereits am 22. 8. 1945 erließ die SMAD den Befehl Nr. 30 über die „Sabotage bei der Ernteeinbringung und Verheimlichung von Saatflächen und Vieh bei der Erfassung“ (MLHA, MinPräs 1458a). Fast jede politische oder gesellschaftliche Abweichung konnte als ,Sabotage" verurteilt werden, so daß schon 1945 die Verbreitung von, Gerüchten' darunter fiel.

${ }^{32}$ MLHA, MdI 2078. Einen Eindruck von der Bereitschaft einiger sowjetischer Kommandanten, schnell zu Verhaftungen und Internierungen zu greifen und dabei Deutsche zu Hilfe zu ziehen, vermittelt das Protokoll einer Aussprache der KPD-Landesleitung am 5. 9. 1945 mit drei Kommunisten aus Schönberg. Gegenstand war der Verstoß gegen die Weisung der KPD-Leitung, beim Beginn der Bodenreform keine Gutsbesitzer zu verhaften, weil der Kreiskommandant eine entgegengesetzte Order gegeben hatte: „Gen. Puchmüller: Der Hauptschuldige an der ganzen Geschichte ist der Kommandant. Unser Fehler war, daß wir dem Kreiskommandant nicht sagten, wir haben eine solche Anweisung noch nicht bekommen, wir können nicht so weit gehen" (MLHA, LL KPD I/2, Bl. 114-117). 
Zusammenarbeit mit den Kommandanten von Bützow, Krakow und Schwaan als sehr gut, mit dem von Laage dagegen als schlecht.

Angaben über die soziale und politische Herkunft der Internierten lassen vermuten, daß die lokal durchgeführten Registrierungsmaßnahmen und die damit verbundene Auflösung der NS-Organisationen, Wehrmachtsverbände und der Polizei zu umfangreichen Festnahmen führten: ${ }^{33}$ NS-Funktionsträger, sonstige politisch Belastete, Bürgermeister, Beamte, Polizei etc. bildeten „zusammen mit den während der Kampfhandlungen auch unter der Zivilbevölkerung gemachten Gefangenen [...] das, erste Kontingent von Häftlingen “. ${ }^{34}$ Aufgrund der mangelhaften Systematik, der lokalen Differenzen und vor allem der durch die Flüchtlingszüge sehr einfachen Möglichkeiten, zu flüchten oder sich zu verstecken, war dies nur ein bescheidener Anfang der Entnazifizierung. Viele Honoratioren und Funktionsträger aus Staat und Partei waren vor der Roten Armee in den Westen geflohen, und die in den Flüchtlingstrecks mitziehenden NS-Belasteten waren nur schwer ausfindig zu machen. ${ }^{35}$ Zwar sind Urteile von Militärtribunalen wegen des Besitzes von Waffen oder wirtschaftlicher Unregelmäßigkeiten veröffentlicht worden, aber entsprechende Hinweise auf Verfahren gegen hohe Nazis, Militärs oder Funktionsträger sind nicht zu finden. Fricke erklärt dies damit, daß Angehörige der Wehrmacht, SS-Verfügungstruppen und Polizei als „Häftlinge mit Kombattantenstatus für gewöhnlich als Kriegsgefangene in die Sowjetunion deportiert und erst hier verurteilt worden sind, sofern sie nicht überhaupt auf sowjetischem Territorium in Gefangenschaft geraten waren." ${ }^{36}$ Die Entnazifizierung war damit eigentlich beendet, weil alle Nazis entweder interniert, als Kriegsgefangene ins Ausland verbracht, geflohen oder unerkannt waren ${ }^{37}$ oder aber als so wenig belastet galten, daß vorläufig nicht gegen sie vorgegangen wurde.

${ }^{33}$ Siehe beispielhaft die oben zitierte Direktive der ersten Belorussischen Front vom 1. 3. 1945 und die im Befehl des Rostocker Stadtkommandanten vom 5. 5. 1945 aufgezählte Liste inkriminierter Organisationen. Nach einem Erlebnisbericht setzten sich die politischen Häftlinge nin der ersten Zeit nach der Kapitulation [...] in erster Linie aus Angehörigen der ehemaligen NSDAP oder ihrer Gliederungen zusammen"; seit Anfang 1946 habe die NSDAP-Zugehörigkeit als Belastungsmoment an Bedeutung verloren (Fricke, Politik, S. 70).

${ }^{34}$ Fricke, Politik, S. 14f.

${ }^{35}$ Nach Jahnke "liefen bis in die Vormittagsstunden des 1. Mai [...] vor allem vom Rostocker Hafen Schiffe aus, die Wehrmachts- und SS-Angehörige, führende Nazis und Verwundete nach Schleswig-Holstein brachten" (Jahnke, Ende, S. 86; siehe auch Meinicke, Entnazifizierung [Diss], S. 213f., Anmerkung 107; Fenske, Verwaltung, S. 166). Die Mitarbeiter der Staatspolizeistelle Schwerin flohen in der Nacht zum 1. 5. 1945 mit ihren Familienangehörigen nach Kiel; auch die Stettiner Gestapo wurde per Schiff nach Schleswig-Holstein gebracht. Zahlreiche schwer belastete Nazis wie der Kommandant des KZ Auschwitz, Rudolf Höß, zogen auf dem Weg nach Schleswig-Holstein durch Mecklenburg und Vorpommern (Paul, Parole).

${ }^{36}$ Fricke, Politik, S. 129. Dies entsprach der alliierten Abmachung, Kriegsverbrecher zur Verurteilung in die Länder ihrer Taten auszuliefern (Steinbach, Vergangenheitsbewältigung, S. 412).

${ }^{37}$ "Die Zahl der ,Landfremden ' ist um ein mehrfaches größer als die der Alteingesessenen. Unter dieser Schicht halten sich bestimmt noch Faschistenführer auf“ (Bericht der Landesverwaltung Mecklenburg vom 21.7. 1945, MLHA, MdI 345; siehe dazu Kapitel I.2, S. 111-116). 


\section{Entstebung lokaler Verwaltungsorgane}

Die Abrechnung mit NS-Belasteten war zunächst eine Angelegenheit der Sieger. Der spätere Landespolizeichef Gustav Hase stellte noch im August 1945 gegenüber Oberbürgermeistern und Landräten fest: „Politische Polizei aufzuziehen, ist verboten von der Roten Armee. Verfolgung von politischen Verbrechern erfolgt durch die Rote Armee selbst. “38 Erst nachdem neue Funktionsträger eingesetzt waren und die Verwaltungen wieder regulär zu arbeiten begannen, wurde auf Bürgermeisterkonferenzen und ähnlichen Zusammenkünften die Entlassung von NSDAP-Mitgliedern und die Beschlagnahme von Eigentum thematisiert. Die neuen lokalen Vertrauensleute und Ausführungsorgane der Kommandanturen waren größtenteils von den kurz vor Kriegsende unmittelbar aus Moskau nach Pommern eingeflogenen Mitgliedern der Initiativgruppe Sobottka eingesetzt worden oder selbst Rückkehrer aus sowjetischem Exil oder Kriegsgefangenschaft.

KPD-Instrukteure der Initiativgruppe Sobottka. Bei der Auswahl der Deutschen, die verantwortlich an Neuaufbau und Entnazifizierung mitarbeiten konnten, spielten die Instrukteure um Gustav Sobottka sowie die beiden anderen Initiativgruppen in der SBZ eine zentrale Rolle, wodurch auch eine gewisse Einheitlichkeit der ersten Aktivitäten in der gesamten SBZ gesichert wurde. Die Vorbereitungen, Anweisungen und Direktiven kamen aus Moskau und standen im Zeichen einer breiten Volksfrontpolitik, um auch nichtkommunistische Kräfte in den Neuaufbau zu integrieren. ${ }^{39}$ Von vorrangiger Bedeutung waren zunächst die noch im Exil formulierten „Richtlinien der Parteiführung der KPD für die Arbeit der deutschen Antifaschisten in dem von der Roten Armee besetzten deutschen Gebiet“ vom 5. April 1945.40 Die in der Einleitung aufgezählten „Hauptaufgaben“ lassen die Priorität der Sicherheitsfrage erkennen: „Herstellung der Ordnung, Schaffung der Bedingungen des täglichen Lebens der Bevölkerung, Unterstützung der Roten Armee bei der Liquidierung der nazistischen Terror- und Provokationsnester und Organisierung des Kampfes für die politisch-moralische Ausrottung des Nazismus, Militarismus“. Der Zugriff auf einzelne Nazis und die Ahndung einzelner Straftaten wurden der Sicherheitsfrage und der allgemeinen gesellschaftlichen Funktionstüchtigkeit nachgeordnet. ${ }^{41}$

${ }^{38}$ MLHA, MdI 30, Bl. 156. Hilfestellungen für die Kommandanturen waren allerdings seit Beginn der Besatzung unumgänglich; siehe beispielhaft den Bericht des Stadtpolizeileiters von Grimmen (MLHA, LBdVP, 274, Bl. 2). Das Personal der Polizei wurde in der SBZ sofort vollständig ausgetauscht; viele der neuen Polizisten waren alte Kommunisten und Sozialdemokraten, darunter auch zahlreiche ehemalige KZ-Häftlinge (Bessel, Police, S. 294f.; VpLA NL Warnke, V/6/24/2, Bl. 101-104; SAPMO-BA, SGY 30, 1016, Bl. 195f.).

39 Wie das Sekretariat des ZK der KPD am 28. 7. 1945 betonte, lockerte die Volksfrontstrategie keineswegs die Ein- und Unterordnung der Instrukteure in die Parteihierarchic: „Die für die Arbeit der Partei notwendigen Instrukteure sind Instrukteure des Sekretariats. Sie erhalten ihre Aufträge vom Gesamtsekretariat und für spezielle Aufträge von den einzelnen Sekretären bzw. Abteilungsleitern" (SAPMO-BA, RY 1/I2/5, 49, Bl. 27).

${ }^{40}$ Erler/Laude/Wilke, Hitler, S. 380-386.

${ }^{41}$ Auch Welsh, Wandel, S. 43, stellt für Sachsen und Thüringen fest, daß die „große politische Säuberung $[\ldots]$ aufgeschoben" war. 
Die KPD hielt am 5. April 1945 für die Tätigkeit der Mitglieder der Initiativgruppen fest, daß sie „bestimmten Bezirks- und Kreisstädten zur Arbeit zugeteilt" würden, wovon einige „Funktionen in der Stadt für längere Zeit“ übernehmen sollten, „während andere beauftragt werden, in den kleineren Städten und Gemeinden [...] bei der Schaffung der Gemeindeverwaltungen zu helfen bzw. zu kontrollieren“..42 Beispielhaft für ihre rege Tätigkeit ist ein Auszug aus dem „Bericht über durchgeführte Versammlungen vom 14. Mai bis 4. Juni $1945^{\text {“43 }}$ des Instrukteurs Kahne, in dem er Rechenschaft über drei gewöhnliche Tage ablegte: „22.V. Besprechung mit dem Bürgermeister der Stadt Parchim, mit dem Landrat des Kreises Parchim und mit dessen Stellvertretern in der Frage der Neuorganisierung des Magistrats und des Landratsamtes. Rücksprache mit der Bevölkerung, die wegen Brot und Milch vor den Läden stand. Versammlung mit den früheren Mitgliedern der KPD. 23.V. Versammlung mit der Lehrerschaft. Von 34 Lehrern waren nur 5 Nicht-Mitglieder der NSDAP. Nachmittags Versammlung ca. 15000 Teilnehmer, anschließend Tanz im Saale. 24.V. Rücksprache mit dem Bürgermeister und Kommandanten in Sachen Auflösung der, Wirtschaftsabteilung der Wehrmachtskommandantur beim Magistrat der Stadt Parchim“ und Auflösung dieser Abteilung. Nachmittags Ankunft in Lübz. 6 Uhr abends Versammlung. Ca. 2500 Teilnehmer. " Daß die Instrukteure in dem vorgegebenen Rahmen weitgehend freie Hand hatten, berichtete der in Rostock tätige Arbeiterschriftsteller Willi Bredel an Sobottka, den Leiter seiner Initiativgruppe: „Wie du ja selber weißt, bin ich in meiner hiesigen Arbeit ganz auf mich gestellt, denn ich höre auch leider von dir nichts, bekomme keine Richtlinien und Anweisungen, ich muß mich halt alleine nach der Presse und dem Rundfunk orientieren. [...] Ich habe auch an Walter [Ulbricht] in Berlin geschrieben, aber auch von ihm keine Antwort erhalten. Ich habe kleine Beiträge der ,Deutschen Volkszeitung' geschickt, die zum Teil auch erschienen sind, aber nie auf meine Briefe eine Antwort erhalten." ${ }^{44}$

Diese Selbständigkeit hielt sich allerdings in den klar vorgegebenen Grenzen, die schon im Moskauer Exil vorgezeichnet waren und kontrolliert wurden. ${ }^{45}$ Während Bredel seine Berichte an Sobottka sandte, ${ }^{46}$ mußte dieser wiederum gegenüber dem Leiter der zentralen Initiativgruppe in Berlin, Walter Ulbricht, Rechenschaft ablegen. ${ }^{47} \mathrm{Ul}$ bricht selbst stand in regelmäßigem Austausch mit dem vormaligen Generalsekretär der 1943 aufgelösten Komintern, Georgi Dimitroff, in Moskau, den er beispielsweise um die Entsendung weiterer Exilkommunisten nach Deutschland bat, ihn darüber informierte,

42 Erler/Laude/Wilke, Hitler, S. 386.

${ }^{43}$ MLHA, LL KPD I/1, Bl. 41-45.

44 MLHA, LL KPD I/22, Bl. $6 \mathrm{ff}$.

${ }^{45}$ Die Grenzen der Kontroll- und Sanktionsmöglichkeiten zeigt der ausführliche Bericht der KPDLandesleitung vom 6.9. 1945 an das ZK in Berlin, in dem über den Instrukteur Keller berichtet wird, der Ende Mai 1945 aus Moskau kam, nach Greifswald geschickt wurde, von dort aber keine Berichte sandte, sich zum Professor ernennen ließ, nicht zu dem mit allen Instrukteuren verabredeten Treffen mit der Parteileitung zurückkehrte, Ende Juli 1945 eine Tätigkeit in Schwerin ablehnte, zu der zentralen Parteikonferenz am 5. 8. 1945 nicht erschien und auch andere Verpflichtungen nur ungenügend erfüllte (MLHA, LL KPD I/1a, Bl. 262-265).

${ }_{46}$ Zahlreiche weitere Instrukteursberichte aus dem Norden der SBZ in: MLHA, LL KPD I/1; MLHA, LL KPD I/1a; SAPMO-BA, RY 1/I3/15, 34.

${ }^{47}$ Siehe MLHA, LL KPD I/1a, Bl. 243f.; SAPMO-BA, RY 1/I3/15, 35, Bl. 1-21; SAPMO-BA, RY $1 / \mathrm{I} 3 / 15,32$, Bl. $1 \mathrm{ff}$. 
daß „wir die örtlichen Komitees ,Freies Deutschland“ liquidieren“, in einem Telegrammbericht urteilte, daß es „mit der Bildung der Verwaltungsorgane gelingt [...], einen breiten Zusammenschluß der antifaschistisch-demokratischen Kräfte herbeizuführen“, und sich deshalb positiv darüber äußerte, daß „die roten Fahrzeuge mit Hammer und Sichel [...] allmählich aus dem Stadtbild" verschwänden. ${ }^{48}$ Die Leiter der Initiativgruppen, Akkermann, Sobottka und Ulbricht, flogen bereits in den ersten Wochen nach Moskau zu Besprechungen mit dem KPD-Vorsitzenden Wilhelm Pieck, Dimitroff und Stalin. ${ }^{49}$ Parallel zu der hierarchischen Kontrolle innerhalb der internationalen kommunistischen Bewegung ${ }^{50}$ gab es eine Informationsstruktur zwischen deutschen Stellen und sowjetischen Kommandanturen, in die die deutschen Funktionsträger auf allen politischen Ebenen (Gemeinde, Stadt, Kreis, Land, Zone) eingebunden waren.

Das Verhältnis zwischen Initiativgruppen und Roter Armee ist aufgrund der dürftigen Quellenlage nur schwer nachzuzeichnen. Die KPD-Richtlinien vom 5. April 1945 legten die enge Zusammenarbeit durch Mittelsleute fest: Der „führenden Gruppe der Genossen“ werde „ein Oberst der Roten Armee für die Mitarbeit und Verbindung beigegeben“, während den drei Frontstäben der Roten Armee „je eine Arbeitsgruppe von drei Genossen beigegeben [wird], die als Instrukteure bei der Organisierung der Stadtverwaltungen helfen“. Dieselben Richtlinien forderten wiederholt, „die Bevölkerung zu überzeugen, daß die Durchführung der Befehle und Maßnahmen der Militärverwaltung in ihrem eigenen Interesse liegt" ${ }^{51} \mathrm{Die}$ enge organisatorische und politische Anbindung an die Armee ist offensichtlich; trotzdem finden sich in den Berichten der Instrukteure und der bald eingesetzten deutschen Funktionäre wiederholt Hinweise auf unterschiedliche Formen der Zusammenarbeit mit den örtlichen Kommandanten.52 Daß das Verhältnis auch den aus Moskau eingeflogenen Funktionsträgern nicht vollständig klar war, zeigt eine Besprechung Anfang Juli mit dem Instrukteur für Neubrandenburg, der nicht nur Mitglied der Initiativgruppe Sobottka, sondern vorher schon Lehrer in einer AntifaSchule in der UdSSR gewesen war: „Gen. Switalla wird von Gen. Sobottka nochmals darauf aufmerksam gemacht, daß der Kommandant die Anweisung von Marschall Schukow hat, die Parteiinstrukteure zu unterstützen. “53

${ }^{48}$ SAPMO-BA, NY 4182 (NL Ulbricht), 851, Bl. 91, $94 f$.

${ }^{49}$ Badstübner/Loth, Pieck, S. 50 ff.

50 Ulbricht berichtete beispielsweise ausführlich am 6.5.1945 dem späteren Geheimdienstchef in der SBZ, Generaloberst Iwan Alexandrowitsch Serow, über sein erstes Zusammentreffen mit dem späteren CDU-Vorsitzenden Andreas Hermes (SAPMO-BA, NY 4182 [NL Ulbricht], 851, Bl. 85-89).

${ }^{51}$ Erler/Laude/Wilke, Hitler, S. 386, $381 \mathrm{ff}$.

52 Siehe in diesem Sinne Landrat Beltz am 28. 5. 1945 an den Oberbürgermeister von Stadt und Kreis Güstrow: „Bericht über die Lage im Kreisgebiet Güstrow“ (MLHA, MdI 2078) und seine "Zusammenstellung der Berichte für die Zeit vom 16.-22. Juni 1945“ (MLHA, MdI 2078). Ähnlich die Klage eines Instrukteurs aus Plau vom 12. 7.1945 über den „unmöglichen Zustand“, daß die Kommandantur zwei alte NSDAP-Mitglieder als Richter und Rechtsanwalt zugelassen habe (SAPMO-BA, RY 1/I3/15, 34, Bl. 22). Ein weiteres Beispiel für die ungeklärte Machtstruktur, die in den folgenden Jahren immer wieder zu Kompetenzproblemen zwischen deutschen und sowjetischen Stellen unterschiedlicher Rangordnung führte, ist der bereits zitierte Konflikt im Kreis Schönberg (MLHA, LL KPD I/2, Bl. 114-117).

53 MLHA, LL KPD I/18, Bl. 1; Broszat/Weber, SBZ-Handbuch, S. 1040. 
Die Differenzen zwischen sowjetischen Militärs und deutschen Zivilisten bezogen sich allerdings meistens auf die praktische Arbeit und waren durch einen theoretisch begründeten Konsens überformt. Sowohl die sowjetischen Militärs als auch die deutschen Zivilisten handelten ausschließlich im Rahmen der aus Moskau vorgegebenen politischen Zielsetzungen. Politische Überzeugung, Loyalität und Lebensweg der deutschen Kommunisten waren nicht national, sondern auf ihre international ausgerichtete Partei bezogen. Der Hinweis auf einer Besprechung Ende Juli 1945, daß Gehälter „momentan nicht bezahlt" werden, sondern es „im Ermessen des Genossen Sobottka [liegt], wer welche Entschädigung bekommt", ${ }^{54}$ zeigt sowohl die hohe Motivation der eingesetzten kommunistischen Kader als auch die autoritäre und hierarchische Arbeitsstruktur. Dies rührte nicht erst aus der Ausnahmesituation im zerstörten Heimatland her, sondern war bereits in der Sowjetunion im Alltag des Exils erlernt: Durch die ,Säuberungen' der dreißiger Jahre und die außerordentliche Willkür und Undurchsichtigkeit der Exil-KPD und des sowjetischen Herrschaftsapparates war jahrelang ihre Bereitschaft erprobt worden, persönliche Anliegen hinter die der Partei zurückzustellen. Einen Eindruck dieser mit dem politischen Engagement verbundenen privaten Opferbereitschaft vermittelt ein Brief Sobottkas an Ulbricht vom 14. August 1945: „Du mußt entschuldigen, wenn ich Dich in einer persönlichen Angelegenheit belästige. [...] Wie Du weißt, ist er [Kurt Bürger] verhältnismäßig plötzlich aus dem Lager abberufen worden und von drüben nach hierher geschickt. Seine Frau und Tochter blieben dort im Lager“; seitdem habe „sich niemand mehr um die Frau gekümmert, so daß sie kaum Bescheid weiß, wo ihr Mann geblieben ist. " 55

Neue Parteien und Funktionsträger. Das primäre Ziel der Instrukteure bestand in der Sammlung und Auswahl politischer Kräfte für die neu aufzubauenden staatlichen Verwaltungsstrukturen und die offiziell noch nicht zugelassene Kommunistische Partei sowie in der politischen Agitation der Bevölkerung. Daher suchten sie zuerst überlebende, noch bekannte antifaschistische Politiker und hielten zahlreiche öffentliche Versammlungen und Aussprachen ab, zu denen sie in größeren Städten meistens bestimmte Berufs- und Bevölkerungsgruppen einluden.56 Anders als in den Westzonen waren dabei nicht Kirchenmänner und bekannte bürgerliche und sozialdemokratische Politiker der Weimarer Republik die ersten Ansprechpartner der sowjetischen Kommandanten und

${ }^{54}$ MLHA, LL KPD I/2, Bl. 1f.

${ }^{55} \mathrm{Daß}$ dieses Engagement nicht die Abkehr von traditionellen Lebensweisen bedeutete, verdeutlicht der Brief ebenfalls: „doch liegen die Dinge beim Gen. Bürger und mir so, daß wir hier die Hauptarbeit verrichten müssen und daß man dann jemand haben muß, der sich auch um einen sorgt und auch die häuslichen Arbeiten verrichtet, damit man wenigstens mal eine Stunde häuslicher Ruhe findet und sich erholen kann; was nicht möglich ist, wenn man spät nach Hause kommt, sich dann noch etwas zu essen zubereiten muß und morgens dasselbe ist und Dienstboten oder Anwartefrauen können wir leider nicht beschäftigen. Es ist dringend notwendig, daß man auch Drüben darauf hinweist, daß man unsere Frauen so schnell wie möglich schickt, es liegt im Interesse der Arbeit“ (MLHA, LL KPD I/1a, Bl. 248). Zur Frage der Rückkehr der Ehefrauen siehe auch SAPMO-BA, RY 1/I2/5, 43b, 524, 540f.

${ }^{56}$ SAPMO-BA, SGY 26/VG125, 1, Bl. 47f.; MLHA, LL KPD I/1a, Bl. 243f.; MLHA, LL KPD I/ 5, Bl. 8-14; MLHA, LL KPD I/1, Bl. 41-45. 
kommunistischen Instrukteure, sondern vor allem alte Kommunisten. ${ }^{57}$ Beispielhaft für die häufig ungewisse Suche nach neuen Funktionsträgern ist der Bericht über das erste Zusammentreffen von Bredel mit Warnke in Güstrow. ${ }^{58} \mathrm{Daß}$ die alten Kommunisten quantitativ kein bedeutsames Potential stellten, zeigt das Protokoll der ersten Mitgliederversammlung der KPD-Ortsgruppe Güstrow am 19. Juni 1945: „28 Genossen und 9 Genossinnen, die sich während der Naziherrschaft als Kommunisten bewährt haben, nahmen an der Versammlung teil. " ${ }^{59}$ Bereits vor 1933 war die KPD in Mecklenburg und Vorpommern nur schwach verankert gewesen; sie zählte im November 1932 in beiden mecklenburgischen Ländern 2800 Genossen und in Gesamtpommern etwa 7500 eingeschriebene Mitglieder. ${ }^{60}$ Wie ein Bericht der Landesverwaltung festhielt, hatten sich Verfolgung und Krieg verschärfend ausgewirkt: „Durch das faschistische Regime haben wir die besten antifaschistischen Kräfte verloren (Alfred Schulze, Willi Schröder, Walter Griesbach, Frieda Schulz, Anna Beutin, Erdreich Bernitt und viele andere mehr). Der Krieg hat weitere Opfer gefordert." 61

Im ganzen waren der KPD-Landesleitung Anfang Juli etwa 900 alte Kommunisten in Mecklenburg-Vorpommern bekannt, von denen zahlreiche zu den Überlebenden des Todesmarsches aus dem KZ Sachsenhausen gehörten, der bei Crivitz in der Nähe von Schwerin geendet hatte. ${ }^{62}$ Auf ihre Hilfe konnte die Landespartei sofort zurückgreifen, obwohl ihnen Mecklenburg-Vorpommern bis dahin mehrheitlich unbekannt war. Mecklenburg und Vorpommern zählten insgesamt acht kreisfreie Städte, zwanzig Landkreise, 78 kreisangehörige Städte und 2322 Landgemeinden. ${ }^{63}$ Nur in einer Minderheit der Städte und Gemeinden standen politisch geschulte und erfahrene Personen aus Mecklenburg-Vorpommern zur Verfügung, ${ }^{64}$ so daß häufig in der Sowjetunion ausgebildete Emigranten oder ehemalige Kriegsgefangene eingesetzt wurden, die sich zur Mitar-

${ }^{57}$ In seinen Erinnerungen berichtet der Schweriner Sozialdemokrat Xaver Karl von der Verkehrung der Situation nach dem Abzug der Angelsachsen: Seitdem hatten nicht mehr die Sozialdemokraten, sondern die Kommunisten einen privilegierten Zugang zur Besatzungsmacht (SAPMO-BA, SGY 30, 1290, 14).

${ }^{58}$ Mühlstädt, Warnke, S. 148f.

59 MLHA, LL KPD I/13. Vor dem Hintergrund der aus Moskau vorgegebenen Volksfrontstrategie ist die scharfe Polemik der bislang isolierten Kommunisten gegen die SPD bemerkenswert: „Die Kämpfe 1918-1933 haben gezeigt, daß die SPD Steigbügelhalter der Reaktion war." Beispielhaft für die mangelhafte Erfahrung der Kommunisten in der politischen Arbeit ist Bredels Bericht vom 16. 7. 1945 über eine Versammlung, auf der sie ein schlechtes Bild gegenüber den "sozialdemokratischen Routiniers" abgaben (MLHA, LL KPD I/22, Bl. 6ff.).

${ }^{60}$ Kornow, Arbeiterklasse, S. 15; Jahnke, Forschungen, S. 483; Lamprecht, Partei, S. 200f.; Antifaschistischer Widerstandskampf, S. 17f.; diese Angaben basieren auf Nachkriegserhebungen, so daß sie nicht sehr genau sind (Voßke, Kampf, S. 32).

${ }^{61}$ MLHA, MdI 345. Schon 1942 hatte die KPD-Führung in der Sowjetunion eine „sehr ernste" Kadersituation infolge der Verluste im ,Dritten Reich' festgestellt (Erler/Laude/Wilke, Hitler, S. 36).

${ }^{62}$ SAPMO-BA, RY 1/13/15, 37, Bl. 77ff.

${ }^{63}$ Kornow, Arbeiterklasse, S. 38, 69; siehe Statistisches Landesamt, Gemeindeverzeichnis.

${ }^{64}$ Der Personalmangel prägte den gesamten Neuanfang in Mecklenburg-Vorpommern seit 1945. Selbst für die wichtigsten Posten in der Landesverwaltung gab es keine große Auswahl; siehe Kapitel 1.1, S. 51-61. Während die Verwaltung schnell wuchs und ihre Funktionstüchtigkeit bewies, wurde noch jahrelang über den mangelhaften Organisationsgrad der mecklenburgischen KPD/ SED geklagt. 
beit im NKFD bereit erklärt hatten. ${ }^{65}$ Ihr Pathos, ihren Glauben an die eigene Mission, die Arbeitsbereitschaft sowie die Schnelligkeit, mit der Entscheidungen getroffen und Veränderungen realisiert wurden, verdeutlicht der Bericht des Bürgermeisters von Bützow auf einer Besprechung im Landratsamt Güstrow Ende Mai: „Es läuft alles. Ich habe keine Schwierigkeiten. Ich genieße durch den Kommandanten jeden Schutz. Wir haben die Bevölkerung in einer Versammlung über alles aufgeklärt. Wir werden jeden unterstützen, der uns stützt, wir werden aber jeden vernichten, der gegen uns ist. [...] Bezüglich der Lage auf dem Lande klappt es in 41 Gemeinden, in 12 Gemeinden nicht. Diese hole ich mir aber noch ran. [...] U. und B. werde ich wahrscheinlich raussetzen. Ich gebe jedem eine Bewährungsfrist. Wir haben nur zu arbeiten und das Vertrauen der Roten Armee zu gewinnen, sonst können wir quittieren. [...] Ich habe den Auftrag zum Aufbau übernommen und in 3-4 Wochen läuft Bützow glänzend. Mehr als 3000 Flüchtlinge habe ich bereits abtransportiert. [...] Was in den 10 Tagen, wo ich nicht anwesend war, geschehen ist, bereinige ich. Die Gemeinden sind sämtlich besetzt." ${ }^{66}$ Die neuen Funktionsträger forcierten überall einen Aufbau der Verwaltung von Kreisen, Städten und Gemeinden nach den Richtlinien vom 5. April 1945. Gleichzeitig begann mit ihrer Auswahl und Etablierung die Sammlung politisch kooperationswilliger Menschen, die auch den Aufbau der kommunistischen Partei mittragen konnten, deren offizielle Zulassung erst durch den SMAD-Befehl Nr. 2 vom 10. Juni 1945 möglich wurde. Mehrere äuBere Faktoren erleichterten den Aufbau der KPD: Erstens hatte sie bereits seit Anfang Mai durch die von der Exilleitung beauftragte Initiativgruppe eine autorisierte Leitung; ${ }^{67}$ zweitens war sie nach Ansicht vieler sowjetischer Militärs und deutscher Remigranten nicht neu zu gründen, sondern hatte - entsprechend einer „schmunzelnd[en]“ Formulierung des Kommandanten in Stettin - nur mit der Parteiarbeit „aus der Illegalität heraus[zu]treten "; 68 drittens hatten die kommunistischen Spitzenpolitiker immer einen Informationsvorsprung, den sie organisatorisch zu nutzen wußten: Zwei Tage vor dem

${ }^{65}$ In der SBZ gab es 1945110 Antifa-Schulen mit vierwöchigen Lehrgängen, etwa 50 Gebietsschulen mit dreimonatigen Lehrgängen und drei zentrale Antifa-Schulen mit sechsmonatigen Lehrgängen (Welsh, Wandel, S. 42; siehe auch Foitzik, Sowjetische Militäradministration, S. 35f.; Groehler, Opfergruppen, S. 21f.; Erler/Laude/Wilke, Hitler, S. 63-68, 107-115). Noch 1948 wurden Kriegsgefangene in der Sowjetunion politisch geschult, um in der SBZ als SED-Kader eingesetzt zu werden (MLHA, LL SED IV/2/5/156, Bl. 12). Die Lehrpläne, politischen Resolutionen etc. aus verschiedenen Lagern deutscher Kriegsgefangener in der Sowjetunion zeigen, daß in den sowjetischen Antifa-Schulen der gleiche politische, moralische und ästhetische Stil gepflegt wurde wie in der KPD/SED (SAPMO-BA, DY 30/IV 2/11, 245). Wiederholt nutzten Kriegsgefangene die Schulen auch nur dazu, ihre Rückkehr in die Heimat zu beschleunigen und dann in die Westzonen zu fliehen (MLHA, LL SED IV/2/5/164, Bl. 2).

${ }^{66}$ MLHA, MdI 30, Bl. 106.

${ }^{67}$ Gustav Sobottka, Kurt Bürger und Aenne Kundermann bildeten nach einem Gespräch mit Pieck in Moskau und einer Arbeitstagung von Mitgliedern der Initiativgruppen in Rüdersdorf bei Berlin die provisorische Landesleitung der KPD-Mecklenburg (Geschichte der Landesparteiorganisation, S. 86ff.). Keiderling, Gruppe, S. 42ff., weist allerdings darauf hin, daß die Initiativgruppen vor der offiziellen KPD-Gründung am 11.6.1945 nicht KPD-Organe, sondern Hilfsorgane der Roten Armee waren. Am 28. 7. 1945 wies das Sekretariat des ZK der KPD darauf hin, daß die Instrukteure der Partei unterstünden (siehe oben Anmerkung 39).

${ }^{68}$ Erinnerungsbericht des vorläufigen Bürgermeisters von Stettin, Erich Wiesner (SAPMO-BA, SGY 30, 1016, Bl. 180; die Übergabe Stettins an Polen oder der Verbleib bei der SBZ blieb 1945 unklar; siehe Stettin). Auf der Bürgermeisterkonferenz am 29. 5. 1945 in Güstrow wurde die Bil- 
SMAD-Befehl Nr. 2 zur Zulassung von Parteien vom 10. Juni $1945^{69}$ hatte Ulbricht bereits einen „Etat für die Bezirke“ mit hauptamtlichen Parteiarbeitern für MecklenburgVorpommern erstellt; $; 0$ selbst im entfernten Vorpommern wurden schon am 10. Juni 1945 die ersten KPD-Registrierungen beantragt, ${ }^{71}$ und in weniger als einer Woche legte die provisorische Landesleitung „Richtlinien über die Anerkennung der alten Mitgliedschaft und für Neuaufnahmen " in die KPD vor. ${ }^{72}$ Außerdem wurde die KPD durch ihre Nähe zur Besatzungsmacht auch hinsichtlich weiterer Ressourcen (Autos, Druckerei, Zeitung etc.) gegenüber anderen politischen Kräften bevorzugt. ${ }^{73}$

Auch für die SPD hatten Mecklenburg und Vorpommern niemals Hochburgen dargestellt, aber immerhin zählte sie vor der Machtübernahme der Nazis einige tausend Mitglieder mehr als die KPD: Im November 1932 gab es in Mecklenburg mehr als 35000 eingeschriebene Sozialdemokraten und in Pommern zum Jahresende 193115 704.74 Ihre stark schwankenden Wahlergebnisse lagen stets deutlich über denen der KPD. Im siebten Ordentlichen Landtag Mecklenburg-Schwerins gewann die NSDAP 1932 mit 49 Prozent der Stimmen die absolute Mehrheit der Sitze und stellte fortan die Regierung. Zuvor hatte es immer wechselnde Koalitionen unter verschiedenen Ministerpräsidenten gegeben, an denen seit 1920 immer wieder SPD, DDP, DNVP und die DVP beteiligt waren. ${ }^{75}$ Dichotome Politikmuster und das politische Denken in Freund-FeindKategorien verhinderten die Bereitschaft zur Konsensbildung. Die gesamte Landespolitik in dem bis 1918 feudal verfaßten Mecklenburg-Schwerin war durch die Differenzen und Brüche zwischen den politischen Lagern und Parteien geprägt. ${ }^{76}$ Trotz einzelner ge- $^{-}$ meinsamer Initiativen, die aber „zu keinem Zeitpunkt wesentlich für ihr prinzipielles Verhältnis zueinander" waren, blieben beide Arbeiterparteien stets verfeindet. Die SPD

dung der KPD noch nicht erlaubt, wohl aber die eines antifaschistischen Aktivs, ,in dem sich alle die Menschen sammeln, die gegen den Faschismus sind" (MLHA, MdI 30, Bl. 91). Dies entsprach der Politik der Initiativgruppen, bevor sie aus Moskau die Weisung zur Gründung von Parteien erhielten (Keiderling, Gruppe, S. 87-99).

${ }^{69} \mathrm{Um}$ ein antifaschistisch-demokratisches Deutschland, S. $54 \mathrm{f}$.

${ }^{70} \mathrm{Er}$ sah zwei Sekretäre, acht Instrukteure, drei politische und vier technische Mitarbeiter für Mecklenburg vor; dieser Umfang entspricht in etwa dem der anderen Länder. Da damit zu rechnen sei, "daß in den ersten drei Monaten keine Einnahmen vorhanden sind ", wurde die Finanzierung der Bezirksleitung erst ab dem 1. 1. 1946, die der Unterbezirke seit dem 1.9. 1945 durch Mitgliederbeiträge projektiert (SAPMO-BA, NY 4182 [NL Ulbricht], 851, Bl. 50).

71 Geschichte der Landesparteiorganisation, S. 87f.; Seemann, Vereinigung.

72 Darin wurde festgehalten, daß alle Menschen, „die keiner faschistischen Organisation angehörten (mit Ausnahme der DAF), sich nicht faschistisch betätigten und sich entschlossen haben, auf der Basis des Aktionsprogramms der KPD für ein demokratisches freies Deutschland zu kämpfen", in die KPD aufzunehmen seien. Ehemalige Mitglieder der KPD und des Kommunistischen Jugendverbands (KJV), „welche zeitweilig einer faschistischen Organisation angehörten (mit Ausnahme der DAF), können nur durch die Landesleitung wieder aufgenommen werden" (SAPMO-BA, RY 1/I3/15, 37, Bl. 51f.).

${ }^{73}$ Siehe dazu die vorbereitenden Anweisungen in der KPD-Verordnung vom 4. 5. 1945; zu Mecklenburg-Vorpommern siehe: MLHA, LL KPD 1/1a; MLHA, LL KPD I/2.

${ }^{74}$ Kornow, Arbeiterklasse, S. 15; Voßke, Kampf, S. 32; Lamprecht, Kampf. Nach Matull, Arbeiterbewegung, S. 282, konnte die SPD ihre Mitgliederzahlen von 1925 bis 1929 in Pommern von 6930 auf 14834 mehr als verdoppeln.

75 Schwabe, Krone, S. 185-188.

${ }^{76}$ Koch, Politik, S. $312 f$. 
legte auch auf Landesebene eine "prinzipiell antikommunistische Einstellung“ an den Tag, ${ }^{77}$ wodurch sie die Zusammenarbeit mit den Kommunisten verweigerte, und auch die Landes-KPD legte mehr Wert auf Abgrenzung als auf Kooperation. ${ }^{78}$

Ebenso wie den Arbeiterparteien mangelte es auch dem städtischen Bürgertum und den Großgrundbesitzern an politischer Einheit. Schon mit dem Kapp-Putsch 1920 begann „die liberale Mitte des Bürgertums zu zerfallen “ ${ }^{79}$ Die Monarchisten waren in diesem Freistaat, in dem erst 1918 die alten Stände aufgehoben worden waren, unter anderem aufgrund ihrer ungebrochenen regionalen Wirtschaftsmacht noch so stark und die Differenzen zwischen DNVP, DVP und DDP so groß, daß der Rostocker Chemiefabrikant und Vater des späteren CDU-Wirtschaftsministers, Friedrich Carl Witte, schon Anfang der zwanziger Jahre erklärte, daß seine Partei, die DDP, „Schulter an Schulter mit den Mehrheitssozialisten [steht], gegen die Deutschnationale Volkspartei, die weder deutsch noch national, noch eine Volkspartei ist" ${ }^{80}$ Die politischen Brüche schwächten die parlamentarische Demokratie und führten im Juni 1932 zu einer alleinigen NSDAPRegierung in Mecklenburg-Schwerin, nachdem diese Partei bereits im Frühjahr 1932 Koalitionspartner der DNVP in Mecklenburg-Strelitz geworden war. ${ }^{81}$

Landtagswahlen in Mecklenburg-Schwerin 1919 bis 1932 in Prozent: ${ }^{82}$

$\begin{array}{lrrrrrrrr} & 1919 & 1920 & 1921 & 1924 & 1926 & 1927 & 1929 & 1932 \\ \text { KPD } & - & 0,4 & 4,6 & 13,6 & 6,6 & 5,1 & 5,2 & 7,4 \\ \text { USPD } & - & 7,7 & 0,8 & 0,8 & - & - & - & - \\ \text { SPD } & 47,9 & 39,9 & 41,7 & 22,8 & 39,9 & 40,7 & 38,3 & 30,0 \\ \text { DDP } & 27,3 & 6,9 & 4,3 & 3,6 & 3,0 & 2,9 & 2,8 & - \\ \text { DVP } & 4,3 & 15,4 & 17,5 & 7,3 & 8,4 & 7,9 & - & - \\ \text { DNVP } & 13,1 & 22,1 & 22,2 & 28,9 & 22,6 & 22,0 & - & 9,1 \\ \text { NSDAP } & - & - & - & - & 1,7 & 1,8 & 4,1 & 49,0 \\ \text { Sonstige } & 7,4 & 7,6 & 8,9 & 23,0^{83} & 17,8 & 19,6 & 49,6^{84} & 4,5\end{array}$

1945 waren die meisten Unterschiede zwischen den demokratischen Positionen in Deutschland stark abgeschwächt. Die Niederlage von 1933, die auch auf die Uneinigkeit der Parteien zurückgeführt werden mußte, und die gemeinsamen Verfolgungserfahrungen schufen die Bereitschaft zu einem breiten politischen Bündnis. In der SPD gab es zahlreiche Befürworter eines Zusammengehens mit den Kommunisten; die KPD bekundete die Bereitschaft, von ihren alten Revolutions- und Sozialismuskonzepten Abschied zu nehmen; bis weit in bürgerliche Kreise war Kapitalismuskritik salonfähig, Verstaatli-

\footnotetext{
77 Schwabe, Krone, S. 57, 64-69.

${ }^{78}$ Koch, Demokratie, S. $21 \mathrm{f}$.

79 Koch, Demokratie, S. $22 \mathrm{f}$.

${ }^{80}$ Zitiert nach: Koch, Politik, S. $312 \mathrm{f}$.

${ }^{81}$ Jahnke, NSDAP; Urbschat, Aufstieg; Urbschat, Bildung; Urbschat, Kampf; Koch, Verfolgung, S. 331; Kornow, Arbeiterklasse, S. 16; Koch, Politik, S. 314f. Am 30. 1.1933 zählte die NSDAP 16366 Mitglieder in Mecklenburg-Schwerin (Urbschat, Aufstieg, S. 326).

${ }^{82}$ Mit den Zahlen für den Landtag in Mecklenburg-Strelitz und den Preußischen Provinziallandtag Pommern in: Falter/Lindenberger/Schumann, Wahlen, S. 98f., 102; Schwabe, Krone, S. 180-184.

${ }^{83}$ Darunter $19,3 \%$ für die "Deutschvölkische Freiheitsbewegung".

${ }^{84}$ Darunter 44,6\% für die "Einheitsliste Nationaler Mecklenburger“ (DNVP, DVP, WP, Deutschvölkische Freiheitsbewegung, Landvolkpartei).
} 
chungen wurden befürwortet, ${ }^{85}$ und selbst zwischen Liberalen und Kommunisten fanden sich Gemeinsamkeiten, wenn sie sich auch auf allgemeine rhetorische Formeln wie die des Antifaschismus oder auf politische Randbereiche wie die Kirchen- und Schulpolitik beschränkten.

Entsprechend konnten alle vier Parteien, die die sowjetische Besatzungsmacht zuließ, mit ihrer Gründung auf das Konzept der einheitlichen Zusammenarbeit im Blocksystem verpflichtet werden. Die CDU gründete sich am 5. Juli 1945 unter dem Vorsitz von Reinhold Lobedanz, ${ }^{86}$ der wie die meisten der zwanzig Gründungsmitglieder in Schwerin ehemaliges Mitglied der DDP war; diese Partei war bis 1929 wiederholt Koalitionspartnerin der SPD gewesen, da das Zentrum im protestantisch geprägten Mecklenburg und Vorpommern fast gar nicht existiert hatte. ${ }^{87}$ Ende 1945 betrug ihre Mitgliederzahl 10528 in 87 registrierten Ortsgruppen. Damit war sie in zahlreichen Städten und Gemeinden nicht präsent, was durch die seit Mitte Dezember 1945 erschienene Zeitung Der Demokrat streckenweise ausgeglichen wurde. ${ }^{88}$ Noch kleiner war die LDPD, deren Landesverband in Schwerin erst am 4. Januar 1946 entstand, als sie in Mecklenburg-Vorpommern etwa 2000 Mitglieder hatte; der erste Vorsitzende war bis 1947 Ernst Harzmann. ${ }^{89}$

Wie sich auch bei der späteren Besetzung der Landesverwaltung zeigte, ${ }^{90}$ war die gezielte Suche nach sympathisierenden politischen Kräften und nach neuen Funktionsträgern breit angelegt und reichte weit über die Gruppe der alten Kommunisten und anderer bis 1933 politisch Organisierter hinaus. ${ }^{91}$ Dennoch gab es eine Priorität der Arbeiterparteien, deren detaillierte und schon verhältnismäßig früh einsetzende Mitgliederstatistiken zeigen, daß sie viel mehr Mitglieder als die beiden bürgerlichen Parteien gewinnen

${ }^{85}$ Thränhardt, Geschichte, S. 18; Kocka, 1945, S. 147.

${ }^{86}$ Reinhold Lobedanz (1880-1955); Jurist; 1907 Amtsassessor in verschiedenen Städten Mecklenburgs; 1912 Vorsitzender des Versicherungsamtes Wismar; 1914-1920 Regierungsrat und Leiter des Versicherungsamtes Schwerin; 1915-1920 Vorstandsmitglied und Geschäftsführer des Landesausschusses für Kriegsbeschädigte, der Flüchtlingsfürsorge und des Landesvereins zur Bekämpfung der Tuberkulose; seit 1920 Ministerialrat unter anderem im Innenministerium; DDPMitglied; seit 1945 1. Landesvorsitzender der CDU und 3. Vorsitzender der Zentralleitung Berlin; 20. 11. 1945 Ernennung zum Ministerialdirektor und Leiter der Präsidialabteilung; 1946 stellvertretender Präsident der Beratenden Landesversammlung; 1946-1952 MdL; MdV; 1949-1955 Präsident der Länderkammer der DDR; Vizepräsident der Gesellschaft für Deutsch-Sowjetische Freundschaft; siehe Koch, Lobedanz.

${ }^{87}$ Ob Lobedanz tatsächlich Landesvorsitzender der DDP-Mecklenburg gewesen ist, wie in der DDR-Literatur wiederholt behauptet (Geschichte der Landesparteiorganisation, S. 100), ist zu bezweifeln, da die Broschüre zum Mecklenburg-Schwerinschen Landtag von 1929 nicht ihn, sondern Richard Möller als Vorsitzenden des Landesvorstands nennt (Bureau des MecklenburgSchwerinschen Landtages, Landtag, S. 28). Möller wurde 1945 Kurator der Universität Rostock, dann aber schon bald in das Internierungslager Neubrandenburg-Fünfeichen gebracht, wo er im Dezember 1945 starb.

88 Suckut, Christlich-Demokratische; Brebach/Koch, Bewährung; Koch, Fortschritt; ACDP, 07/ $011,1306$.

${ }^{89}$ Dähn, LDP; Papke, Liberal-Demokratische. In Schwerin hatte die LDP bis Ende 1945 noch keine fünfzig Mitglieder (ADL, LDP 10408); noch im August 1947 zählte sie nicht mehr als insgesamt 6856 Mitglieder (ADL, LDP 15875).

${ }_{90}$ Siehe Kapitel 1.1, S. 51-61.

${ }^{91}$ Gesellschaftlich engagierte Personen wurden nicht nur als Oberbürgermeister und Landräte oder in Arbeitsämtern und für ähnliche Verwaltungsposten gesucht: Der Schweriner Oberbürgermei- 
konnten. Nachdem die KPD bereits aus der Initiativgruppe Sobottka entstanden war, gründete sich der Bezirks- beziehungsweise Landesverband der SPD im Juli 1945 unter dem Vorsitz von Carl Moltmann, ${ }^{92}$ einem alten mecklenburgischen Parlamentarier, der im ,Dritten Reich“ wiederholt verhaftet worden war und 1946 mit Kurt Bürger ${ }^{93}$ zum gleichberechtigten Landesvorsitzenden der SED wurde. Vor allem die beiden Arbeiterparteien verzeichneten einen großen Zulauf:94 Zählte die KPD noch Anfang Juli nur etwa 900 Mitglieder, die sämtlich alte Genossen waren, vervielfachte sich ihr Bestand sehr schnell: Ende Juli waren es bereits 3 193, Ende August 7975 , Ende September 16 225, zum Jahresende 31 975, und Mitte März, kurz vor der Vereinigung zur SED, zählte die KPD-Mecklenburg-Vorpommern bereits sechzigmal so viele Mitglieder wie am 30. Juni 1945: 56 944. Obwohl sich der Abstand stetig verkleinerte, hatte die KPD damit immer weniger Mitglieder als die SPD, von der keine Zahlenangaben der ersten Wochen und Monate vorliegen. 95 Anfang September zählte sie 16 023, Anfang November 25 409, zum Jahresende 40 288, Ende Januar 194649245 und Ende Februar 63765 Mitglieder. Die KPD vergrößerte ihren Mitgliederbestand vom 31. August 1945 zum 28. Februar 1946 um das 6,7fache, die SPD im selben Zeitraum um das Vierfache.

Diese großen Zuwachsraten zeigen den Ehrgeiz der Parteien bei der Werbung neuer Mitglieder. Neben der Motivation, zuverlässiges und kontrollierbares Personal zu rekrutieren, bestand das Interesse der Rückkehrer aus dem sowjetischen Exil auch darin, ein Gegengewicht gegen die häufig linksradikalen Altkommunisten zu schaffen, die aufgrund ihrer Verfolgung und ihres Widerstands während des ,Dritten Reichs' eine große moralische Autorität hatten und sich nur ungern der Volksfront-Linie der eingeflogenen

ster Wiesner erinnerte sich beispielsweise, „bereits Anfang Oktober 1945 [...] in Schwerin auf Großkundgebungen rund 4000 Haus- und Straßenobleute" versammelt und zu ehrenamtlichen Tätigkeiten in Verwaltungs-und Wohlfahrtsbereichen verpflichtet zu haben (SAPMO-BA, SGY 30, 1016, Bl. 198). Siehe zu den Vertrauens- und Obleuten auch die KPD-Richtlinie vom 5. 4. 1945 Erler/Laude/Wilke, Hitler, S. 383 und Keiderling, Gruppe, S. 50 f.

92 Carl Moltmann (1884-1960); Arbeitersohn aus Brüz bei Goldberg; gelernter Tischler; seit 1902 Gewerkschaft und SPD; 1919-1933 MdL und Fraktionsvorsitzender; Direktor des Arbeitsamtes Schwerin; 1932 Reichstagsabgeordneter; seit 1933 in der ,freien 'Wirtschaft tätig; 1944 verhaftet; 1945/46 Leiter des Landesarbeitsamtes und der Landesabteilung Arbeit und Sozialfürsorge; 1945 SPD- und seit 1946 paritätischer SED-Landesvorsitzender; 1946-1952 MdL und Landtagspräsident; 1948-1950 MdVR/MdV; bis 1960 Mitglied des ZK der SED.

${ }^{93}$ Kurt Bürger (1894-1951, eigentlich Karl Ganz); Schlosser aus Baden; 1912 Gewerkschaft und SPD; 1919 Mitbegründer der Bayerischen KPD; nach der Münchener Räterepublik vier Jahre Zuchthaus; bis 1933 Funktionär der KPD und des Roten Frontkämpferbundes; Parteijournalist; Mitarbeiter im ZK der KPD; wiederholte Haftstrafen; 1933 Emigration in die Sowjetunion; Funktionär im Apparat der Komintern und der Roten Gewerkschaftsinternationale; Politkommissar im spanischen Bürgerkrieg; 1938 Rückkehr nach Moskau; Journalist und Sprachlehrer; 1941-1945 Lehrer in Antifa-Schulen; Gründungsmitglied des NKFD; Mitglied der Initiativgruppe Sobottka; ab 1946 paritätischer SED-Landesvorsitzender; 1946-1952 MdL und Fraktionsvorsitzender; 1948-1951 MdVR/MdV; 1951 Ministerpräsident von Mecklenburg.

${ }^{94}$ Statistiken in: SAPMO-BA, RY 1/I3/15, 37, Bl. 39f.; SAPMO-BA, DY 30/IV 2/5, 4972, Bl. 1018b, Bl. 32.

${ }^{5}$ SPD-Statistiken in: MLHA, LV SPD Mecklenburg II/1, Bl. 62; MLHA, LV SPD Mecklenburg II $/ 2$, Bl. $305 f$. 
Parteileitung unterordneten. ${ }^{96}$ In den ersten Wochen und Monaten verzichtete die KPD bei neuen Funktionsträgern häufig auf die Parteimitgliedschaft als Loyalitätskriterium, so daß die Politisierung umgekehrt verlief und viele Personen erst nach der Übernahme eines Amtes der SPD oder KPD beitraten. Entsprechend berichtete die KPD-Ortsgruppe Warnemünde am 6. August 1945: „Die Leitung der Stadtverwaltung liegt fast ausschließlich in kommunistischen Händen [...]. Allerdings sind diese Posten nicht etwa von der KPD besetzt worden, sondern in den meisten Fällen sind die betreffenden Leiter erst zur KPD gestoßen, nachdem sie bereits längere Zeit [das heißt seit höchstens drei Monaten] im Amt waren. "97 Entscheidende Posten blieben allerdings den bereits bekannten und politisch zuverlässigen Personen vorbehalten. Vizepräsident Grünberg verlangte beispielsweise in seinen „Richtlinien über den Aufbau von Kultur- und Volksbildungsämtern in Stadt- und Kreisverwaltungen" vom 10. Juli 1945, daß zur Leitung jeder städtischen Kulturabteilung „der beste, fähigste, ergebenste Antifaschist des betr. Ortes oder Kreises" auszuwählen sei.98

Die vielfältigen und unterschiedlichen Vorgänge zeigen trotz aller lokalen Eigenheiten eindeutige, politisch reflektierte Weisungen;99 so zum Beispiel die noch häufig in der Geschichte der SBZ wiederholte Entscheidung, einflußreiche Personen in die zweite Reihe der offiziellen Hierarchien zurückzunehmen und weniger starke Politiker nach vorne zu stellen: „In den Städten werden auf Verlangen der Ortskommandanten die bisherigen von der Roten Armee mitgebrachten ersten Bürgermeister zu stellvertretenden Bürgermeistern gemacht, und die bisherigen stellvertretenden Bürgermeister treten an die erste Stelle, so in Bützow, Krakow und Laage. " ${ }^{100}$ Mit einer ähnlichen Argumentation wurde

${ }_{96}$ Neben Instruktionen, Belehrungen und Ermahnungen der alten Kader diente auch die forcierte Neuaufnahme politisch bislang Unorganisierter dazu, die KPD auf den in Moskau festgelegten Kurs zu bringen, da die alten Genossen dadurch bald nur noch eine kleine Minderheit bildeten. Von den 16225 Mitgliedern Ende September waren nur 2200 schon vor 1933 in der KPD gewesen: die eine Hälfte in Mecklenburg und Vorpommern, die andere Hälfte waren Zugezogene. In den Berichten der Instrukteure tauchen allerdings nur wenige Hinweise auf Linksabweichungen im Norden der SBZ auf (SAPMO-BA, RY 1/13/15, 34, Bl. 19, 23, 32, 41-85; SAPMO-BA, RY 1 / I3/15, 37, Bl. 79). Eine Mitteilung des Stellvertreters des Obersten Chefs der SMAD, Serow, vom 7. 8. 1946 über oppositionelle Gruppen aus der alten KPD in der SED bezieht sich ausschließlich auf Berlin (Badstübner/Loth, Pieck, S. 77ff.; Keiderling, Gruppe, S. 75ff.; Schwarzenbach, Kaderpolitik, S. 67). Obwohl das Problem schnell gelöst war, gab es immer wieder vereinzelte Konflikte der Altkommunisten mit der offiziellen Parteilinie (z. B. MLHA, LL SED IV $/ 2 / 3 / 77, \mathrm{Bl}$. 40-76).

97 MLHA, LL KPD I/22, Bl.51f. Auf der KPD-Unterbezirkskonferenz in Güstrow am 15. 7. 1945 formulierte der spätere Landrat von Güstrow, Bernhard Quandr, die reduzierten politischen Anforderungen: Nicht alle Bürgermeister müßten Kommunisten sein, „dazu sei die Partei auch noch zu schwach und zu klein. Gefordert müsse aber werden, daß jeder Bürgermeister Antifaschist sei“" (MLHA, LL KPD I/13).

98 MLHA, LL KPD I/8.

99 Die zentralen Absprachen und Anweisungen waren aber keine festen Gesetze, sondern steckten nur den allgemeinen Rahmen ab, denn die lokale Zusammenarbeit zwischen der Besatzungsmacht und den Deutschen ihres Vertrauens blieb uneinheitlich; beispielsweise wurden die Bürgermeister in Warin „von einem Major der russischen Polizei eingesetzt“, was der KPD-Richtlinie vom 5. 4. 1945 entsprach, während der Güstrower Stadtkommandant die Besetzung der Bürgermeisterstellen an die leitenden deutschen Funktionäre delegierte (MLHA, MdI 2078).

100 Beltz am 28. 5. 1945 an den Oberbürgermeister von Stadt und Kreis Güstrow: „Bericht über die Lage im Kreisgebiet Güstrow" (MLHA, MdI 2078). 
auf einer Bürgermeisterkonferenz am 14. Juni 1945 die Kritik an unseriösen Bürgermeistern zurückgewiesen: „Klagen über diese Bürgermeister müssen wir einstweilen zurückstellen. Wir müssen erst mit diesen Leuten weiterarbeiten. Die Russen wünschen Einheimische und keine ortsfremden Leute, die nicht der Partei (NSDAP) angehört haben. "101 Durch diese Strategie wurde die Eigenständigkeit und Autonomie der deutschen Funktionsträger betont, ohne daß Kommunisten und Sowjets an gesellschaftlichem Einfluß verloren. Obwohl die Abhängigkeit der deutschen Funktionsträger von der Besatzungsmacht offensichtlich war - die neuen Polizisten trugen beispielsweise rote Armbinden mit deutscher und russischer Schrift und Reisegenehmigungen und andere Ausweise von Funktionsträgern waren nur mit sowjetischem Stempel gültig -, zielte die sowjetische Politik wiederholt darauf ab, die Akzeptanz der Bevölkerung für die Besatzungspolitik und den intendierten gesellschaftlichen Wandel dadurch zu erhöhen, daß repräsentative Posten in die Hände Deutscher gelegt wurden. Diese Strategie war bereits in der Emigration festgelegt worden und erwies sich nach einem Bericht des Instrukteurs Herbert Hentschke vom 6. Juni 1945 auch als notwendig: „Die gemachten Erfahrungen [bestätigen] voll und ganz die Richtigkeit der diesbezüglichen Moskauer Direktiven [...], die empfahlen, alles zu vermeiden, was uns in den Augen der Selbstverwaltung und der Bevölkerung als, Agenten Moskaus' [...] erscheinen ließe. Davon hängt der wirkliche Erfolg unserer Arbeit in der gegenwärtigen Periode und auch in der Zukunft ab. "102

Angesichts der bereits in den ersten Wochen erhobenen Klagen über unfähige, undisziplinierte und korrupte Deutsche berichtete ein Beteiligter auf der Bürgermeisterkonferenz am 14. Juni 1945 über ihre schnelle Auswahl: „Die Bürgermeister, die wir eingesetzt haben, sind aus der Entwicklung entstanden. Wir freuten uns, wenn am 4., 5. und 6. Mai mutige Leute zu uns kamen und berichteten. Selbstverständlich sind hierbei Mißgriffe entstanden. "103 Diese Unklarheit war auch einige Wochen nach dem Einmarsch noch nicht behoben. Selbst auf Kreisebene fehlte es an einem entsprechenden Überblick.

101 MLHA, MdI 30, Bl. 135.

102 SAPMO-BA, RY 1/I3/15, 34, Bl. 31-36; Erler/Laude/Wilke, Hitler, S. 381ff. Dimitroff kritisierte am 25. 5. 1945 in einem Gespräch mit Pieck, die Rote Armee „als Befreier des dtsch. Volkes [zu] bezeichnen“, da dies „nicht als aufrichtig verstanden“ würde, denn die „Mehrheit wäre froh, wenn Hitler gesiegt" hätte (Keiderling, Gruppe, S. 383).

${ }^{103}$ MLHA, MdI 30, Bl. 135. Nicht nur die Übergriffe der Siegerarmee, sondern auch die vieler deutscher Funktionsträger müssen beträchtlich gewesen sein. Im Oktober 1945 stellte Höcker z. B. diverse Strafanträge gegen Landräte, die Unregelmäßigkeiten mit Lebensmittelkarten zuließen oder selbst dafür verantwortlich waren (MLHA, MinPräs 1051). Höcker informierte am 4. 2. 1947 den Landtag davon, daß die SMAM einen Gesetzentwurf des Landtags vom 25. 11. 1946 „zur Befriedigung des Rechtslebens wegen nach Beendigung der Kampfhandlungen im Jahre 1945 vorgenommener Maßnahmen“ abgelehnt habe, der die Verfolgung aller zwischen dem 30. 4. 1945 und 1. 9. 1946 [sic] begangenen strafrechtlichen Delikte beenden und bereits erfolgte Urteile aufheben sollte, wenn der Täter „das Wohl der Allgemeinheit im antifaschistischen, demokratischen Sinne wollte“ und „die Tat in Ausübung öffentlicher Gewalt begangen ist und der Täter weder sich noch einem anderen [...] einen nach Lage der Sache nicht gerechtfertigten Vermögensvorteil verschaffen wollte“. Ausdrücklich sollten unrechtmäßige Beschlagnahmungen dieser Zeit , durch diese Verordnung legalisiert“ und der Verkauf solcherart enteigneter Gegenstände „rechtswirksam“ werden (MLHA, MinPräs 77; Akten und Verhandlungen, Bd. 2 [Drucksachen], S. 35). 
Oberbürgermeister Warnke kannte Ende Mai 1945 noch nicht alle Bürgermeister des erweiterten Kreises Güstrow ${ }^{104}$ und forderte daher deren Lebensläufe und Personalfragebogen an, obwohl sie bereits einzelnen Gemeinden vorstanden und an der Konferenz teilnahmen, auf der er diese Bürgermeister und weitere leitende Funktionsträger des Kreises in eine zentralistische Struktur einband. ${ }^{105}$ Wie in ganz Deutschland lag dies an den kriegsbedingten Kommunikationsschwierigkeiten durch die Reisebeschränkungen, die zerstörte Infrastruktur, die Behandlung als besiegte Bevölkerung und durch umfangreiche Umzüge und Adressenänderungen infolge der Flüchtlingsströme und Zerstörungen. Verstärkt wurden diese Schwierigkeiten in Mecklenburg-Vorpommern durch die geringe Anzahl demokratischer Politiker aus der Zeit der Weimarer Republik und vor allem durch die weite Ausdehnung des dünn besiedelten und weitgehend agrarisch geprägten Landes. Dennoch mußte die Einsetzung ungemein schnell erfolgen: Am 29. Mai 1945 verlangte der Stadtkommandant von Güstrow, 106 in allen Städten und Gemeinden innerhalb einer Woche Bürgermeister zu benennen. Bis dahin gab es im Kreis Güstrow (ohne Neukloster, Brüel und Sternberg) bereits 121 Bürgermeister, in 82 Ortschaften noch nicht. ${ }^{107}$ Die aus der Sowjetunion zurückgekehrten Instrukteure und die in den letzten zwölf Jahren ohne ihre vormaligen Kontakte und Kommunikationsnetze lebenden Altgenossen waren vielfach auf erste Eindrücke, unzuverlässige Informationen und Menschen mit Eigeninitiative angewiesen. ${ }^{108}$ Die Attraktivität der Posten bestand nicht nur im Sozialprestige, sondern auch in den Karrierechancen und in der Nähe zu den

104 Der erweiterte Kreis Güstrow umfaßte „das bisherige alte Gebiet des Landkreises Güstrow, dem inzwischen vom Kreis Wismar die Bezirke Neukloster, Warin, Brüel und Sternberg und vom Kreis Schwerin der Bezirk Crivitz zugeteilt sind “ (Landrat von Güstrow am 24. 6. 1945 an Marschall Schukow, MLHA, MdI 210b).

${ }_{105}$ MLHA, MdI 30, Bl. 128ff.

${ }^{106}$ MLHA, MdI 30, Bl. 94.

107 MLHA, MdI 30, Bl. 91RSf. Ob diese Angaben Warnkes korrekt sind, ist fragwürdig, da er selbst am zweiten Tag der gleichen Tagung andere Zahlen nannte: „Wir haben rund 250 Gemeinden, in rund 50 Gemeinden noch keine Bürgermeister" (MLHA, MdI 30, Bl. 102; nach Kornow, Arbeiterklasse, S. 40, gab es im erweiterten Kreis Güstrow fast 400 Gemeinden). Auf der gleichen Tagung hieß es, daß von den 19 Bürgermeisterstellen in Brüel zwölf bereits besetzt seien und die restlichen sieben bald besetzt würden (MLHA, MdI 30, Bl. 102). Die Veränderungen und Unklarheiten zeigt eine "Liste der neu eingesetzten Bürgermeister" vom 15. 5. 1945, auf der noch keine Stellvertreter aufgeführt sind und einige Personen z. T. schon wieder durchgestrichen und neu eingetragen wurden (MLHA, RdK Güstrow 113, Bl. 25-30; nach Kornow, Arbeiterklasse, S. 51, waren Ende 1945 nur noch 39,5\% der im Mai 1945 bestallten Bürgermeister der kreisangehörigen Städte im Amt).

108 Einen beispielhaften Bericht über die unkonventionelle Art, wie Posten erobert (und Parteimitglieder gewonnen) wurden, enthält die "Vorgeschichte zu der Neugründung der SPD in Gadebusch": Nach dem Einmarsch der US-amerikanischen Truppen wurde der Kommunist - und spätere Leiter des Landesumsiedleramtes - Karl Brincker Bürgermeister. „Nachdem bekannt wurde, daß am 1. Juli das restliche Mecklenburg von der roten Armee besetzt werden sollte, wurden alle Mitglieder und Freunde des Antifa-Kampfbundes am Abend des 30. Juni zum Rathaus gerufen [...]. An diesem Abend wurden von Bürgermeister Karl Brincker und seiner Sekretärin Mitgliedskarten der Kommunistischen Partei an alle Kampfbundmitglieder verteilt. Einige wenige Genossen hatten den Mut, die Annahme abzulehnen. Später wurde in einer Kampfbundsitzung der gesamte Kampfbund vom Gen. Brincker als Kommunistische Partei erklärt“ (MLHA, LV SPD II/3, Bl. 1f.). 
neuen Herrschern in Zeiten des Hungers. ${ }^{109}$ Daß dabei mancher Mißgriff geschah, ist selbstverständlich: In Dierhagen im Kreis Rostock wurde der Bürgermeister beim Einmarsch der Roten Armee durch einen alten Sozialdemokraten ersetzt, der diesen Posten bereits vor 1933 innegehabt hatte, aber noch vor der Machtübernahme der NSDAP „wegen einer Amtsunterschlagung von 6-7 000 RM mit Zuchthaus bestraft" 110 worden war.

Das Problem blieb noch lange bestehen; Sobottka forderte auf der „Konferenz verantwortlicher Parteiarbeiter am 5. August 1945" in Verwaltungen und Industriebetrieben „eine gründliche Reinigung von Elementen, die hineingekommen sind, aber nicht hineingehören“, da die Kommandanten „nicht am Kopf erkennen [konnten], ob es sich um einen ehrlichen Mann handelt oder um einen, der Theater spielt"."11 Noch nach der Vereinigung zur SED beschäftigten diese Fehlgriffe die Landesleitung, da sie sich im Wahlkampf als belastend erwiesen. ${ }^{112}$

Daß zahlreiche der neuen Funktionsträger eine undurchschaubare Vergangenheit hatten, war den Instrukteuren zwar bewußt, deswegen aber nicht einfacher zu handhaben, weil es nicht immer möglich war, die politischen und biographischen Angaben der Betreffenden zu überprüfen. Der Hauptgrund dafür war die umfangreiche Bevölkerungsfluktuation. Während viele Flüchtlinge und Vertriebene in die Städte zogen, waren zahlreiche ihrer Bewohner auf das Land evakuiert worden. Die meisten kamen aus dem Osten, andere waren aus den bombardierten Städten im Westen evakuiert. Dadurch blieben ehemalige Parteizugehörigkeiten oder Vergehen wie Denunziationen vielfach unerkannt. Entsprechendes äußerte Bredel am 22. Juni 1945 gegenüber Bürger: „Einen schlechten Eindruck habe ich von der neugegründeten Ortsgruppe in Warnemünde. Etwa zwanzig Genossen waren bei der Besprechung anwesend, eine Besprechung, die von kleinlichem Stunk und Zank erfüllt war. Die meisten Genossen sind keine Warnemünder und man kann überhaupt nicht feststellen, ob sie überhaupt früher Mitglieder der Partei waren. Einer großen Anzahl traue ich nicht über den Weg. Ich werde gerade diese Ortsgruppe besonders im Auge behalten. "113

${ }^{109}$ Höcker, Warnke, Möller und Quandt aus Güstrow sind dafür beispielhaft. Ein unauffälligeres Beispiel für die Chancen des sozialen Aufstiegs bietet der Steuerinspektor W., der am 22. 7. 1945 bei der KPD in Schwerin anzeigte, daß in der Schweriner Reichsfinanzverwaltung 66-70\% der Dienstkräfte ehemalige Pgs seien. Die Beschwerde wurde sofort überprüft und bereits am folgenden Tag Sobottka gemeldet, daß sich dort fast hundert Beamte und Angestellte seit Kriegsende "mehr oder weniger mit sich selber" beschäfrigten, $z$. B. indem "während der Dienststunden Skat gespielt" werde. Zur Veränderung der Situation wurde vorgeschlagen, den politisch unbelasteten Steuerinspektor, der zudem KPD-Anwärter war, nals aktive Persönlichkeit möglichst umgehend mit der kommissarischen Leitung " zu beauftragen (MLHA, LL KPD I/28, Bl. 107; unkommentierte Hervorhebungen in Zitaten entsprechen stets dem Original).

110 MLHA, LL KPD I/4, Bl. 116. Auch Bredel berichtete Mitte Juli aus Rostock, daß „viele unserer Genossen leider oftmals rein selbstsüchtigen Zielen nachjagen. So mußten wir einen bereits aus der Partei rausschmeißen und einen anderen sogar verhaften lassen " (MLHA, LL KPD I/22, Bl. 6ff.). Ähnlich äußerte sich ein Kommunist auf einer KPD-Versammlung in Malchin am 12. 7. 1945: "Wenn man Fehler gemacht hat, dann soll man ehrlich sein und vor die Leute hintreten und sagen, ich habe einen Fehler gemacht. Es sind unter uns welche, die haben sich in einer Form bereichert, daß Gerüchte in der Stadt umlaufen und es heißt, das ist dasselbe, was die Faschisten gemacht haben, auch das moralische Leben als solches" (SAPMO-BA, RY 1/I3/15, 36, Bl. 77).

111 MLHA, LL KPD I/3, Bl. 36.

112 MLHA, LL SED IV/2/1/10, S. 109f.; MLHA, LL SED IV/2/3/77, S. 96.

113 MLHA, LL KPD I/22, Bl. $1 \mathrm{ff}$. 
Flüchtlingsland Mecklenburg-Vorpommern. Durch den Zuzug von Flüchtlingen und Umsiedlern aus den ehemals ostdeutschen Gebieten verdoppelte sich in der Nachkriegszeit die mecklenburgische Bevölkerung nahezu. Die Gegenwart der Migranten prägte alle Bereiche des gesellschaftlichen Lebens, da sie nicht nur Lebensmittel und Wohnraum beanspruchten, sondern allein aufgrund ihrer Quantität das Sozialgefüge Mecklenburg-Vorpommerns grundlegend veränderten. ${ }^{114}$ Durch die Kriegs-, Vernichtungsund Bevölkerungspolitik des deutschen Faschismus hatten Bevölkerungsbewegungen in Europa bereits seit Anfang der vierziger Jahre ein bis dahin unbekanntes Ausmaß erreicht, unter dem vor allem die Menschen in den besetzten osteuropäischen Staaten gelitten hatten. Zudem waren seit 1943 mehrere Millionen Stadtbewohner wegen des Bombenkriegs innerhalb Deutschlands in ländliche Regionen evakuiert worden, die nach Kriegsende langsam in ihre Heimatstädte zurückkehrten. ${ }^{115}$ Eine Aufstellung der Zentralverwaltung für Umsiedler in Berlin zählte für Mitte November 1945 unter den 1404380 Ortsfremden in Mecklenburg und Vorpommern 248803 Westevakuierte, deren Anzahl im Laufe der folgenden Monate abnahm. ${ }^{116}$ Außerdem vermehrte die Repatriierung der mehrere Millionen ausländischen Verschleppten und Zwangsarbeiter, die durch das Kriegsende befreit waren, die Züge der Entwurzelten und Heimatsuchenden. Ebenso wie in den anderen Ländern Deutschlands wurde auch in Mecklenburg-Vorpommern vielfach über die DPs (Displaced Persons) und ihre gewalttätigen Übergriffe geklagt, obwohl ihre Kriminalitätsrate nicht höher gewesen zu sein scheint als die der deutschen Bevölkerung. ${ }^{17}$ Auf der Bürgermeisterkonferenz Ende Mai 1945 in Güstrow reagierte Warnke resolut: „Vor allem muß versucht werden, die Ausländer abzuschieben. Meldet uns, sagte mir der Kommandant, wo ein Haufen Ausländer versteckt liegt. " 118 In der SBZ konnte dieses Problem schneller gelöst werden als im Westen Deutschlands, da die Westeuropäer in die britische und US-amerikanische Zone und die Osteuropäer in ihre Länder geschickt wurden. Bereits am 24. Juni 1945 teilte der Landrat von Güstrow mit: „Die polnischen Wanderarbeiter [sic] sind in der Hauptsache abtransportiert." 119 Diese beschleunigte und häufig gegen den Willen der Betroffenen

${ }^{114}$ Allgemeine Informationen zu den politisch-administrativen, sozialen und lebensweltlichen Schwierigkeiten bieten Just, Lösung; Meinicke, Flüchtlinge; Meinicke, Integration; von Plato, Stern; Schwartz, Flüchtling; Schwartz, Zusammenbruch; Wille/Hoffmann/Meinicke, Flüchtlinge.

${ }^{115}$ Nach einer NS-Erhebung wurden bis Ende 1944 fast 9 Millionen Personen evakuiert (Kleßmann, Staatsgründung, S. 40).

116 BAP, DO1/10, 14, Bl. 27; weitere Zahlenangaben im Anhang.

117 Jacobmeyer, Zwangsarbeiter, S. 47ff.

118 MLHA, MdI 30, Bl. 87R. Landrat Beltz forderte den beschleunigten Abtransport der Polen und Italiener, denn "die englischen, amerikanischen, französischen und holländischen Kriegsgefangenen und Zivilarbeiter verhalten sich einwandfrei" (MLHA, MdI 2078).

119 MLHA, MdI 210b. Dabei muß es sich um eine große Gruppe gehandelt haben, denn im Herbst 1944 stellten Kriegsgefangene und andere Zwangsarbeiter $80 \%$ der Beschäftigten auf den Gütern Mecklenburgs (Bauerkämper, Bodenreform, S. 126). Zur Rückführung sowjetischer und anderer ausländischer Bürger in ihre Heimat siehe auch die Befehle vom 18. und 22. 10.1945 des sowjetischen „Bevollmächtigten für Repatrïerungsangelegenheiten des Landes MecklenburgVorpommern", Major 'Tschetwerikow (MLHA, MfV 39, Bl. 36f.). 
durchgeführte Rückführung verhinderte, daß die Anwesenheit der DPs zu einem ähnlichen gesellschaftlichen und politischen Problem wurde wie in Westdeutschland. 120

Für die weitere Entwicklung des Landes waren aber nicht die Evakuierten und DPs, sondern die aus den ostdeutschen Gebieten Geflohenen und Zwangsumgesiedelten prägend, deren Behandlung auf eine rasche Integration zielte. ${ }^{121}$ Obwohl führende Sozialisten vor den Kreis- und Landtagswahlen im Herbst 1946 die langfristige Gültigkeit der Grenzziehung zwischen Polen und der SBZ in Frage stellen konnten ${ }^{122}$ und damit den noch lange virulenten Rückkehrwünschen und -phantasien zusätzliche Nahrung gaben, richtete sich die konkrete Politik in zentralen Bereichen wie Bildung, Soziales, Wohnungsbau oder Arbeitsmarkt auf eine langfristige Eingliederung. Für Mecklenburg-Vorpommern ist dabei an erster Stelle die Bodenreform zu nennen, durch die die Hälfte des im ganzen Land agrarisch nutzbaren Bodens enteignet und zu 78,6 $(75,9)$ Prozent wieder verteilt wurde. Über 35 Prozent der 92510 (114 519) Nutznießer waren Flüchtlinge: 32621 (38 892). ${ }^{123} \mathrm{Da}$ sie zu denjenigen gehörten, die die größeren, durchschnittlich 9-10 Hektar großen Parzellen erhielten, sicherte ihnen die Bodenreform vorerst einen Ort, der ihnen Möglichkeiten gab, zu leben, zu arbeiten und sich zu ernähren. Ähnlich wie in der Verwaltung, wo zahlreiche Flüchtlinge dank ihrer wenig aufmerksamen Entnazifizierung vermutet werden müssen, ${ }^{124}$ verschuf sich die aktivste politische Partei damit eine große Popularität, weil zahlreiche Umsiedler ihren persönlichen Neuanfang mit dem gesellschaftlichen Umbruch und Neubeginn gleichsetzten. ${ }^{125}$

Die Unterbringung und Integration gestaltete sich schwierig, da die Quantität der Umsiedler ungeahnte Ausmaße hatte und die Ausgangsbedingungen durch die Kriegsfolgen extrem verschlechtert waren. Die Bevölkerung war in Mecklenburg und in den

120 Jacobmeyer, Zwangsarbeiter, S. 153-244.

121 Die Versuche zu einer schnellen gesellschaftlichen Integration gingen einher mit der bis 1989 in der SBZ/DDR durchgehaltenen Tabuisierung der Migrationserfahrungen. Dabei ist mit Kleßmann, Staatsgründung, S. 40, zwischen „Flucht, Zwangsausweisung und Umsiedlung “ zu unterscheiden; weil Zeitpunkt, Veranlassung und Umstände der Migration hier nicht von Interesse sind, werden die Begriffe ,Flüchtling' und ,Umsiedler' synonym gebraucht. In der SBZ gab es dagegen schon früh eine sprachliche Vereinheitlichung: Der Begriff ,Flüchtling' wurde bereits in der ersten Verordnung der Zentralverwaltung für deutsche Umsiedler vom 2. 10. 1945 untersagt und dafür die Bezeichnung, Umsiedler' eingeführt (Schneider, Zentralverwaltung); die gleiche Anweisung gab auch die entsprechende Abteilung in Mecklenburg-Vorpommern in ihrem ersten Schreiben am 16.10. 1945 (BAP, DO1/10, 8, Bl. 79f.). Den politischen Nutzen dieser Sprachregelung erläuterte das Landesumsiedleramt am 27.3. 1946: „In dem Wort Flüchtlinge liegt der Begriff Flucht beschlossen und im Begriff Flucht wieder die Annahme von etwas Feindlichem, das zu dieser Flucht Veranlassung gab. Die Streitkräfte der Besatzungsarmeen, und für unseren Sektor die Rote Armee, sind aber nicht als Vertreter böser Mächte, sondern als Befreier des deutschen Volkes von nazistischer Schreckensherrschaft nach Deutschland gekommen" (MLHA, RdK Güstrow 27, Bl. 16). Dieser Sprachregelung entsprach die Praxis seit Anfang der fünfziger Jahre, die ,Umsiedler' durch den Begriff ,Neubürger' zu erfassen, bis sie vollkommen aus der offiziellen statistischen Wahrnehmung in der DDR verschwanden (Schneider, Zentralverwaltung, S. 242).

122 Dokumente der Sozialistischen Einheitspartei Deutschlands, Bd. 1, S. $92 \mathrm{f}$.

${ }^{123}$ Die ersten Zahlen beziehen sich auf den 15. 11. 1946, die in Klammern gesetzten auf den 1. 1. 1950 (Murken, Transformation, S. 77, 79).

124 Siehe Kapitel I.2, S. 111-116; Meinicke, Flüchtlinge, S. 78.

125 Die Bodenreformstatistiken zeigen, daß diese von Jochen-Christoph Kaiser (Marburg) auf dem Leipziger Historikertag 1994 hervorgehobene Klientelbildung nur in Verbindung mit den wei- 
Vorpommerschen Städten und Kreisen von 1925 bis Ende 1945 kontinuierlich von 1241384 (Juni 1925) auf 1407292 (Mai 1939) gewachsen; diese Entwicklung riß auch im Krieg nicht ab, sondern steigerte sich bis zum Januar 1944 (Vorpommern) beziehungsweise Februar 1945 (Mecklenburg) auf 1677 542. In der zweiten Hälfte des Jahres 1945 war ein quantitativer Sprung zu verzeichnen, der die bisherige Tendenz weit überragte: Anfang September wurden bereits 1924573 und am 31. Dezember 1945 schon 2199781 Personen in Mecklenburg-Vorpommern gezählt; davon waren 729813 beziehungsweise 1033703 Flüchtlinge, die erst seit wenigen Wochen und Monaten im Lande waren. ${ }^{126}$ Vor jeder Überlegung zu ihrer wirtschaftlichen und kulturellen Integration mußte ihre Ernährung und Unterbringung gesichert werden. ${ }^{127}$

Dabei zeigten die Verwaltungen anfangs nur wenig Bereitschaft zu Hilfe und Kooperation. Die Flüchtlingstrecks zogen in großen Gruppen durch die SBZ und hatten Schwierigkeiten, Aufnahme mit halbwegs gesicherten Lebensbedingungen zu finden, weil sie von einem Land ins nächste und von einem Kreis in den benachbarten geschickt wurden. ${ }^{128} \mathrm{Um}$ solche (Gruppen-)Egoismen zu verhindern, die weder die individuellen Schicksale noch die politischen und sozialen Probleme einer Lösung näherbrachten, suchte die Landesverwaltung, einheitlichen Regelungen näherzukommen. ${ }^{129}$ Wie in Berlin und anderen Ländern der SBZ lagen auch in Schwerin vorerst keine realistischen

teren Integrationsleistungen wirkte. Angesichts von einer Million Flüchtlingen ist die Zahl der 32621 (38 892) Begünstigten nicht überragend, so daß ähnliche Prozesse in anderen Bereichen quantifiziert werden müssen: Wie viele Umsiedler waren Nutznießer der Verpachtung und des Verkaufs von enteigneten Handwerks- und Handelsbetrieben, wie viele kamen in der Verwaltung unter, wie viele wurden selbst politische Funktionsträger etc.?

${ }^{126}$ MLHA, MdI 349; siehe Anhang, S. 356. Die statistischen Angaben über die Gesamtbevölkerung und den Anteil der Ortsfremden variieren und widersprechen sich teilweise. Trotz der Differenzen belegen alle, daß Mecklenburg-Vorpommern im Laufe der ersten Nachkriegsjahre eine überdurchschnittlich große Anzahl von Umsiedlern aufgenommen hat. Eine Aufstellung des Statistischen Landesamts bestätigt die Zahlen vom 31.12. 1945 (MLHA, MdI 139, Bl. 72); ebendort auch die Zahlen für den 30.11. 1945: 223837 Einwohner, 1040638 Flüchtlinge (MLHA, MdI 139, Bl. 69). Zum 2. 9. 1945 nannte das Statistische Landesamt am 19.9. 1945 2068207 Einwohner, davon 800152 Flüchtlinge (MLHA, MdI 345). Für den 31. 3. 1946 ermittelte das Statistische Landesamt eine Gesamtbevölkerung von 2075304 Menschen, wovon 906134 Flüchtlinge (43,66\%) waren; am 31. 10. 1946 waren es schon 1024 615, d. h. 47,46\% von insgesamt 2158564 Einwohnern (MLHA, MinPräs 661, Bl. 175, 79). Eine Aufstellung vom 10. 11.1945 nennt sogar 1404380 Fremde in Mecklenburg-Vorpommern bei einer Gesamtbevölkerung von 2507271 (56\%); davon seien 248803 (17,7\%) Westevakuierte und 1155577 $(82,3 \%)$ aus den Ostgebieten (BAP, DO1/10, 14, Bl. 27).

${ }^{127}$ Daß die insgesamt 69 Flüchtlingslager im Land eine Aufnahmekapazität für nur 126050 Personen hatten (BAP, DO1/10, 14, Bl. 27), macht die organisatorischen Schwierigkeiten dieses Migrationsschubs deutlich.

${ }_{128}$ Siehe zur Not und zum organisatorischen Chaos der Umsiedler in der SBZ: Meinicke, Flüchtlinge, S. 30f. Die Ziel- und Perspektivlosigkeit wurde durch den forcierten Rücktransport sowjetischer Soldaten und DPs und durch die Schließung der Zonengrenzen verstärkt (MLHA, MdI 30, Bl. 129; MLHA, MdI 210b).

${ }^{129}$ MLHA, MdI 245, Bl. 32. Zur zonalen Vereinheitlichung der Behandlung der Flüchtlinge und zur Gründung der Zentralverwaltung für Umsiedler siehe Meinicke, Flüchtlinge, S. 35-38; Schneider, Zentralverwaltung, und vor allem Schwartz, Zusammenbruch. 
Zahlen vor, ${ }^{130}$ aber dennoch beschäftigte sich die Landesverwaltung früh mit der Einquartierung und Verpflegung der Fremden, deren bevorzugte Unterbringung die SMAD in agrarischen statt in städtischen und industrialisierten Regionen angeordnet hatte, wodurch Mecklenburg-Vorpommern stärker belastet wurde als alle anderen Länder der SBZ. ${ }^{131}$

Kein anderer Faktor veränderte die Gesellschaft dieser traditionellen Auswanderungsregionen in diesem Jahrhundert so einschneidend wie die demographischen Umwälzungen infolge des Kriegsendes, die dem Land eine zu beinahe 50 Prozent ortsfremde Bevölkerung brachten. Zahlreiche Studien haben die tiefgreifenden gesellschaftlichen Folgen dieser Migrationsbewegung für Regionen und Städte gezeigt, die weit weniger Migranten aufnehmen und integrieren mußten. Die umfangreiche Bevölkerungsfluktuation betraf auch die Verwaltungs- und Entnazifizierungspolitik: Schon früh wurden Klagen über korrupte, unfähige und anders belastete neue politische Funktionsträger laut, deren Vergangenheit unkontrollierbar sei. Den politisch Verantwortlichen war das Ausmaß des Problems ebenso bekannt wie die später auftretenden Schwierigkeiten bei der Entnazifizierung der Flüchtlinge; ${ }^{132}$ in beiden Fällen wichen sie einer expliziten Auseinandersetzung aber aus und suchten die Lösung in der individuellen Ausbildung weitgehender politischer Loyalität gegenüber Besatzungsmacht, Landesverwaltung und $\mathrm{KPD} / \mathrm{SED}$ und einer repressiv durchgesetzten Disziplin aller Funktionsträger.

Ergebenheit und Zentralisierung. Entsprechend der politischen Zielsetzung der Kommunisten waren die Bereitschaft zur Zusammenarbeit mit den neuen Machthabern und die soziale Herkunft wichtigere Kriterien zur Auswahl der neuen Funktionsträger als die fachliche Kompetenz: „Treckerfahrer Wilhelm D. als Bürgermeister eingesetzt." ${ }^{133}$ Entsprechend den Erfahrungen der jungen Sowjetunion, deren wirtschaftlicher Aufbau und militärische Verteidigung maßgeblich durch übermäßige individuelle Anstrengungen, Improvisationen und das Versprechen auf ein besseres Leben in einer ,Neuen Zeit ${ }^{\star}$ ermöglicht worden waren, sollten auch in der SBZ fachliche Defizite durch besonderen Eifer kompensiert werden: „Wir brauchen Leute, die Mut und Rückgrat haben, wenn es auch keine Fachleute sind. Leute, die einen neuen Geist haben, dann geht alles. Die Post und Eisenbahn haben einen neuen Geist bekommen und das hat der Nichtfachmann getan. Er muß Mut haben und darf keine Angst zeigen vor Spezialisten. Nicht bange sein!

130 Ende Juli 1945 wurde beispielsweise noch mit 3000000 Flüchtlingen für Mecklenburg-Vorpommern gerechnet, wovon 100000 in den sieben kreisfreien Städten und alle anderen in den Landkreisen untergebracht werden sollten (MLHA, MfW 294, Bl. 119f.). Ähnliche Zahlen und ein ähnliches Aufnahmevolumen der Agrargebiete legte auch der mit führenden Landespolitikern besetzte „Ausschuß für Flüchtlingsfragen“ am 3. 8. 1945 seinen Planungen zugrunde (MLHA, MdI 345); siehe dazu auch Meinicke, Flüchtlinge, S. 33.

131 Meinicke, Flüchtlinge, S. 31. Kein anderes Land in allen vier Besatzungszonen nahm in bezug auf die Gesamtbevölkerung so viele Flüchtlinge auf wie Mecklenburg-Vorpommern (Kleßmann, Staatsgründung, S. 356).

${ }^{132}$ Siehe Kapitel I.2, S. 111-116.

${ }^{133}$ Aktenvermerk Warnkes vom 13.5. 1945 nach einer Rundfahrt über Tarnow nach Bützow (MLHA, MdI 2078). 
Wenn Fehler gemacht werden, werden sie auch wieder ausgemerzt, das ist nun mal so!"134

In den ersten Wochen der Besatzung und des Neuaufbaus wurde häufig an die Eigeninitiative, das selbständige Engagement der neuen Funktionsträger appelliert: „Ich betone aber immer wieder, daß die Selbsthilfe eine gute ist.“ Mut, Offenheit, Experimente, Spontaneität und Selbsthilfe waren in der Situation des Chaos nicht nur genehmigt, sondern notwendig: „Wo sich die Leute selber geholfen haben, sind sie schneller vorwärtsgekommen. Selbsthilfe ist immer gut. " ${ }^{135}$ Entsprechend sollten die Bürgermeister die lokale Verwaltung „nicht schematisch aufbauen, sondern sich danach richten, wie ihre örtlichen Verhältnisse sind". ${ }^{136}$ Diese Einladung zur Improvisation war unabdingbar: Ein „Tätigkeitsbericht der Abteilung Handel und Versorgung in Bützow“ schildert die Ernährungslage nach Kriegsende so, als seien Verbesserungen nicht ohne spontane, halblegale und couragierte Aktionen der Verwaltungsmitarbeiter möglich gewesen: „Es war einfach ein trauriges Bild. Überall Zerstörung und brutale Vernichtung. [...] Die Läden waren ausgeraubt. Kein Geschäft intakt. Fett wurde gar nicht erzeugt, weil sich kein Bauer mit Milch zur Molkerei wagen konnte. [...] Das Vieh [...] mußten wir auf heimlichen und unheimlichen Wegen heranschaffen. Es war nicht leicht, ein Stück Vieh durch die Postenketten und den umherstrolchenden Banditen heranzuschaffen. [...] Sehr oft wurden die Molkereien ausgeraubt, und die anliefernden Bauern verprügelt und die Pferde gestohlen." 137

Trotz der Verweise auf die lokale Eigenständigkeit wurde seitens des Oberbürgermeisters, der Instrukteure oder der Kommandantur ein Plan für den Aufbau der lokalen Verwaltung vorgegeben, der eine Vereinheitlichung des Finanzwesens, der Gerichtsverfassung, der Kulturabteilungen, der Quartierämter und weiterer mit klar bestimmten Aufgaben ausgestatteter Sekretariate in allen Gemeinden des erweiterten Landkreises Güstrow vorsah. ${ }^{138}$ Dieser Plan zeigte an, wie Warnkes Hinweise auf die lokale Eigenständigkeit verstanden werden sollten: Die neuen und vielfach unerfahrenen Funktionsträger hatten die Freiheit, dem von der führenden Partei und der Besatzungsmacht vorgeschlagenen Weg zu folgen. „Wir können nicht warten, bis wir eine Landesregierung oder eine Reichsregierung haben, wir haben einen Landrat und wir haben Bürgermeister [...]. Wir haben einen Organisationsplan vervielfältigen lassen. Dieser Plan ist genau mit

${ }_{134}$ Warnke am 29. 5. 1945 über den Aufbau der Zivilverwaltung (MLHA, MdI 30, Bl. 89).

${ }_{135}$ Warnke am 29. 5. 1945 (MLHA, MdI 30, Bl. 87).

136 MLHA, MdI 30, Bl. 101.

${ }^{137}$ MLHA, MdI 210a. Der Bericht vom 19. 7. 1946 verschweigt, daß ein erheblicher Teil der Übergriffe von sowjetischen Soldaten verübt wurde. Siehe den „Reisebericht über die Besichtigung der Industrie" in den östlichen Kreisen des Landes von Karl-Heinz Kaltenborn und Rasehorn vom 11. 8. 1945, in dem sie die katastrophale Ernährungslage vor allem auf die sowjetischen Demontagen und die chaotischen gesellschaftlichen Zustände zurückführen (MLHA, MfW 294, Bl. 110-114).

${ }^{138}$ Diese Vereinheitlichung entsprach der bereits Anfang Juli 1945 organisatorisch und personell stark ausdifferenzierten Kreisverwaltung, die eine analoge Umsetzung in den Gemeinden und kreisangehörigen Städten erforderte; siehe den undatierten Organisationsplan, der unter anderem die Namen von drei der vier zukünftigen (Vize-)Präsidenten Mecklenburg-Vorpommerns und die weiterer später einflußreicher Landespolitiker enthält: Oberbürgermeister Warnke; stellvertretender Oberbürgermeister Höcker und Möller, verantwortlich für Landwirtschaft (MLHA, MdI 197, Bl. 377f.). 
dem Kommandanten durchgesprochen und anerkannt worden. "139 Die Anpassung an die vorgegebene Struktur wurde nicht mit Zwang durchgesetzt, sondern als administrative Notwendigkeit dargestellt. ${ }^{140}$ So wie die Herrschaft von Warnke und den anderen führenden Kommunisten auf der Zusammenarbeit mit der Besatzungsmacht und ihrer Anerkennung in der KPD-Führung beruhte, waren die lokalen Funktionsträger durch die Kommandanturen und vor allem durch Warnkes Unterstützung legitimiert. Die Gefolgschaft zu verweigern, hätte das Amt gekostet. Tatsächlich hielten sich die lokalen Funktionsträger auch an diese Anweisungen: „Als ich s. Z. das Amt in Sternberg übernahm, standen wir vor einem Nichts. Alles war verbrannt, und wir mußten ganz von vorn anfangen mit allem. Wir haben es dann so gemacht, wie es von der Oberbürgermeisterei hier bekanntgegeben wurde. " ${ }^{141}$

Entsprechend den zitierten Unregelmäßigkeiten und der angestrebten administrativen Vereinheitlichung wurden wiederholt Appelle an die Disziplin erlassen, die sich gegen Übergriffe und Anmaßungen der Funktionsträger ${ }^{142}$ richteten: „Die Bürgermeister müssen als führende Leute in den Gemeinden durch ihr Benehmen und das Zusammenarbeiten mit der Kommandantur die gesamte Bevölkerung beeinflussen, damit für alle ein gutes Zusammenarbeiten möglich ist. Erforderlich ist ein freies Benehmen gegenüber der Roten Armee. Unsere deutsche Polizei grüßt jeden russischen Offizier, das ist kein Unterbeugen, keine Kriecherei, es ist nur zu unserem Vorteil, wenn wir es tun. " ${ }^{143}$ Durch Zentralisierung und Disziplinierung stärkte Warnke gleichzeitig die eigene Herrschaft, weil die selbständige Anmaßung von Rechten auf lokaler Ebene die Autorität der übergeordneten Hierarchieebene in Frage stellte. Dieses Problem beschäftigte die neue politische Führung noch länger: In den folgenden Jahren wurden wiederholt Aufrufe zur Disziplin und zur genauen Beachtung politischer Vorschriften erlassen, die sich sowohl gegen illegale Maßnahmen (besonders bei Beschlagnahmungen, Zwangseinweisungen in Wohnungen, Bußgeldern und Festnahmen) als auch gegen mangelhafte Disziplin gegenüber übergeordneten Behörden richteten. ${ }^{144}$

Die Landräte, Bürgermeister, Gemeindevorsteher und anderen Träger der neuen Verwaltungsstrukturen standen in den ersten Tagen und Wochen nach dem Einmarsch vor einer Vielzahl von Aufgaben. Während der größte Teil dieser Herausforderungen eine

139 MLHA, MdI 30, Bl. 88.

${ }^{140} \mathrm{Im}$ selben Atemzug kündigte Warnke eine ,Belohnung' an, wenn das entscheidende Kriterium erfüllt werde: „Die Rote Armee will ein Deutschland ohne Faschismus zurücklassen, dann kehrt sie zurück. Der Verwaltungsapparat muß natürlich durchgearbeitet, durchgeknetet werden“" (MLHA, MdI 30, Bl. 88).

141 Bürgermeister von Sternberg am 29./30. 5. 1945 (MLHA, MdI 2078).

142 Siehe oben Anmerkung 103.

143 Warnke am 14.6. 1945 (MLHA, MdI 30, Bl. 149).

${ }^{144}$ Das Protokoll der Unterbezirkskonferenz der KPD am 15. 7. 1945 verzeichnet Hinweise an die leitenden Funktionäre für ihre persönliche Lebensführung: „Sie hätten zu beweisen, daß sie keine Bonzen sind, da wir sonst die Sympathien der Massen verlieren würden. Es sei notwendig, stets eine enge Verbindung zu den Massen zu halten" (MLHA, LL KPD I/13). Auch die zahlreichen Verordnungen, die Ende August 1945 klare Linien für Sequestrierungen formulierten (van Melis: Denazification, Anmerkung 41), intendierten die Eindämmung lokaler Auswüchse und mit dieser Disziplinierung auch eine Verpflichtung der neuen Funktionsträger auf einen parteikonformen Lebensstil, da private Bescheidenheit als entscheidender Schutz gegen den Mißbrauch der individuellen Machtfülle angesehen wurde (Schwarzenbach, Kaderpolitik, S. 50). 
funktionierende Verwaltungsstruktur voraussetzte, waren einige Probleme in kurzer Zeit zu lösen: Tierkadaver begraben, Straßensperren räumen, kaputte Autos bergen, Hygienemaßnahmen gegen die drohende Seuchengefahr erlassen, zerstörte Häuser wieder herrichten, ${ }^{145}$ Arbeitskräfte rekrutieren etc. ${ }^{146}$

Die Funktionstüchtigkeit der neuen Verwaltung diente der Besserung der Lebenssituation der deutschen Bevölkerung und gleichzeitig der Besatzungsmacht. Die drängenden und häufig wiederholten Hinweise auf die Einbringung der Ernte ${ }^{147}$ waren ein Reflex darauf, daß auf vielen der verlassenen Güter nicht mehr gearbeitet wurde. Zufrieden stellte Landrat Beltz am 28. Mai 1945 fest, „daß im Gegensatz zu dem Bild, das das platte Land noch vor etwa 8 Tagen bot, jetzt fast überall im Kreisgebiet auf den Feldern gearbeitet wird“. ${ }^{148}$ Die Nahrungsmittelversorgung wurde unter anderem durch neue Lebensmittelkarten und durch die Beschlagnahmung aller in Geschäften und Lagern vorhandenen Lebensmittel sichergestellt. ${ }^{149}$ Die Anweisung, daß jedem Bauern „bis zum 15. Juli [...] die Norm bekannt sein [muß], damit gleichzeitig eine Bilanz des zu erwartenden Ernteertrages festgestellt wird" 150 , bezeugt ebenso wie der erste Satz in einer Ansprache von Landrat Beltz auf der Bürgermeisterkonferenz Ende Mai 1945 die Eile, mit der man das Nahrungsmittelproblem anging: „An der Spitze aller unserer Betrachtungen und unserer Arbeit muß die Erwägung stehen, daß jeder Quadratmeter deutschen Bodens bepflanzt werden muß. Wir haben bestimmt für den Winter eine Hungersnot zu erwarten. "151 Mecklenburg und Vorpommern waren Agrargebiete, aus deren Erträgen traditionell auch andere Gebiete Deutschlands ernährt worden waren. Obwohl das Land nur kurzfristig Ort direkter militärischer Auseinandersetzungen geworden war, hatte die Produktivität der Landwirtschaft stark unter dem mehrjährigen Krieg und seinen Folgen gelitten. Durch Krieg und ,Drittes Reich' hatten zahlreiche Menschen und vor allem viele der volkswirtschaftlich produktivsten, nämlich der, wehrfähigen' Männer, ihr Leben verloren oder befanden sich noch in Kriegsgefangenschaft. Seit 1939 waren sie durch Zwangsarbeiter aus unterworfenen Ländern ersetzt worden, die aber seit

145 Entsprechend dem nachlassenden Widerstand gegen den Einmarsch der sowjetischen Truppen nahmen auch die Zerstörungen von Wohnraum in Mecklenburg-Vorpommern gegen Westen immer stärker ab (MLHA, MfW 294, Bl. 93f.; MLHA, LL KPD I/8). Die Landesbauabteilung hielt in einer Liste vom 12. 9. 1945 über den Baustoffbedarf fest, daß 14200 Gebäude in 26 Städten und 3800 Gebäude in den Landgemeinden zerstört seien. Dies entspreche einer Zahl von 60000 Wohnungen, von denen 75\% total zerstört seien (MLHA, MfW 294, Bl. 95). Abweichende Angaben enthält ein Vortrag auf der Konferenz der Oberbürgermeister und Landräte am 13.6. 1946 über "Wohnungswesen und Wohnungswirtschaft in Mecklenburg-Vorpommern": 1939 habe es in Mecklenburg und Vorpommern 390000 Wohnungen gegeben, von denen noch 274400 vorhanden seien; 115600 Wohnungen seien unbewohnbar, davon 58900 völlig zerstört und 56700 schwer und mittelschwer beschädigt; 13600 Wohnungen seien bislang wiederhergestellt worden (MLHA, LL SED IV/2/6/235, Bl. 162; siehe auch Voßke, Kampf, S. 23, 26).

146 Zahlreiche Beispiele für diese und andere Einzelfragen sind im Protokoll der Bürgermeisterkonferenz im Kreis Güstrow vom 14.6. 1945 nachzulesen (MLHA, MdI 30, Bl.135-149a).

${ }^{147}$ Beispielsweise sollten Personalwechsel während der Erntekampagne vermieden werden (MLHA, MdI 10, Bl. 1f.).

148 MLHA, MdI 2078.

149 MLHA, MdI 2078 passim.

${ }^{150}$ Tagung der Landräte und Bürgermeister am 1. 7. 1945 in Neubrandenburg (MLHA, MdI 244, Bl. 8).

151 MLHA, Mdl 30, Bl. $116 f$. 
Mai 1945 als Arbeitskräfte ausfielen. Außerdem fehlten zahlreiche landwirtschaftliche Maschinen sowie Nutz- und Zugtiere, die - teilweise in den letzten Kriegstagen - zum Einsatz an der Front abgeliefert werden mußten. Nicht für den Krieg requiriertes Vieh wurde dann vielfach im Mai 1945 zum Opfer von Kriegshandlungen oder entwendet: von westwärts fliehenden Menschen, von abziehenden DPs, von sowjetischen Beuteabteilungen oder von regulären Truppen. Weiterhin waren die Bauern im ,Dritten Reich aufgrund der forcierten Rüstungsproduktion mit zunehmend weniger Dünge- und anderen Betriebsmitteln beliefert worden, wodurch sich die Ertragsqualität langfristig verschlechtert hatte. ${ }^{152}$ Die letzte große Schädigung für die Landwirtschaft waren die Füchtlingszüge, deren Trecks und Lagerplätze die teilweise noch verminten Wälder, Wiesen und Äcker in Mitleidenschaft zogen. ${ }^{153}$

In den ersten Tagen nach Kriegsende wurde auf zahlreichen Feldern nicht gearbeitet: Viele Eigentümer waren aufgrund von Krieg oder Flucht abwesend, soziale Netze und nachbarschaftliche Organisationen waren vielfach zusammengebrochen, und die allgemeine Unsicherheit und Angst vor Übergriffen von Soldaten oder DPs hielt viele Menschen, vor allem Frauen, von der Arbeit auf den Feldern ab. ${ }^{154}$ Erst langsam wurde die Arbeit wieder aufgenommen, verlassene Felder und Höfe wurden unter Treuhand gestellt und kollektiv bearbeitet. Damit folgte man den ständigen Ermahnungen der Kommandanturen und KPD-Instrukteure, die die Priorität der landwirtschaftlichen Produktivität hervorhoben. Dies diente nicht nur dem Wohlergehen der Deutschen, sondern ebenso der Ernährung der sowjetischen Truppen. Der Bürgermeister von Sternberg berichtete beispielsweise: „Bezüglich der Ernährungsfrage sieht es sehr schlecht aus, weil in Sternberg 3000 Russen sind, die dort neu ausgebildet werden. Die Leute werden in Lagern aufgefangen und müssen selbstverständlich aus Sternberg versorgt werden. " 155 Auch andere Bereiche dienten sowohl dem Neuaufbau als auch der Besatzungsmacht: Die Arbeitsämter organisierten nicht nur den Arbeitskräftebedarf für Aufräumarbeiten und deutsche Betriebe, sondern versuchten auch, die Besatzungsmacht von spontanen Zwangsverpflichtungen abzuhalten, inderm sie ihr eine ausreichende Anzahl von Arbeitskräften zur Verfügung stellten; der Einsatz gegen die katastrophalen medizinischen und hygienischen Zustände schützte Sieger und Besiegte gleichermaßen; auch die Wiederherstellung der Infrastruktur (Straßennetz, Bahn, Telefon, Post, Brücken, Wasserund Elektrizitätsversorgung) half beiden Seiten, weil die Sowjets beispielsweise intakte Eisenbahnnetze zum Abtransport ihrer Truppen und direkte Kommunikationswege zur Kontrolle der eigenen Dienststellen auf dem Land benötigten. Auch unauffälligere Bereiche erleichterten der Roten Armee ihre Rolle als Besatzungsmacht, weil sie das Leben normalisierten und damit die allgemeine Zufriedenheit, Ruhe und Ordnung stärkten.

${ }^{152}$ Murken, Transformation, S. 25-28; Weisz, Versuch; Badstübner, Geschichte, S. 79ff.; Rasper, Rolle, S. 1-30; Schäwel, Vorbereitung, S. 30-82.

153 Ähnlich sah es in der Fischerei aus: Zum Beispiel waren Fischer vor Stralsund noch lange nach Kriegsende von Seeminen gefährdet.

${ }^{154}$ Beispielhaft ist die Reaktion auf den Besuch eines KPD-Instrukteurs zwischen Mitte Mai und Anfang Juni 1945: „Als unser Auto zur Vorbereitung der Versammlung in das Dorf Werder ankam, sind die Mädchen und jungen Frauen aus den Häusern geflüchtet und haben sich in die nahen Roggenfelder versteckt" (MLHA, LL KPD I/1, Bl, 44).

${ }^{155}$ MLHA, MdI 2078; Foitzik, Sowjetische Militäradministration, S. 16. 
Daher engagierten sich die Kommandanturen schon früh dafür, daß die neuen Verwaltungen öffentliche Aufgaben wie die politische Organisation der Jugend, die Wiederherstellung funktionierender Steuer- und Finanzsysteme, die Eröffnung von Kinos, Theatern, Bibliotheken und anderer Kultureinrichtungen sowie die Tätigkeit der Forstämter zur Verhinderung planloser Abholzungen in Angriff nahmen.

Neben der Verwaltung bedurfte es auch der Etablierung oder Reorganisation weiterer staatlicher Institutionen; eine besondere Rolle spielte dabei die Justiz. Unabhängig vom später systematisch vorgenommenen Umbau des Justizwesens in der SBZ, das sich zu einem großen Teil auf ganz neues Personal ohne juristische Vorbildung stützte, ${ }^{156}$ wurde in den ersten Wochen der Besatzung vor allem auf politisch unbelastete Juristen und auf Laienkräfte zurückgegriffen. Ein von Warnke vorgelegter „Vorschlag über ein vorläufiges Gerichtswesen“ vom 22. Mai 1945 sah für den Kreis Güstrow ein Kreisgericht und fünf Amtsgerichte vor, deren Präsidenten, Richter, Laienrichter und Staatsanwälte vom Oberbürgermeister im Einvernehmen mit der Kommandantur für ein Jahr zu bestellen waren und jederzeit absetzbar blieben. Da auch die Zulassung der Rechtsanwälte vom "Oberbürgermeister im Einvernehmen mit dem Kommandanten" ausgesprochen wurde, lief der gesamte Justizbereich „in der Spitze beim Oberbürgermeister zusammen“. 157

Die Justiz und die Verwaltung des erweiterten Kreises unterstanden damit Warnke. Als Vertrauensmann der Besatzungsmacht und der Initiativgruppe Sobottka zentralisierte er somit den Aufbau der politischen Institutionen in Güstrow. Schon früh wurde damit die Gewaltentrennung zwischen Exekutive, Legislative und Judikative verworfen: Der ehemalige Dachdecker und KPD-Parlamentarier leitete die Verwaltung, die angesichts der fehlenden lokalen Regierung als Exekutive wirkte. Gleichzeitig stand er der Justiz vor, deren Unabhängigkeit durch Warnkes Einstellungs- und Entlassungskompetenzen aufgehoben war. Eine legislative Instanz fehlte, weil keine Gesetze formuliert wurden; eine ähnliche Funktion erfüllten nur die Kommandantur und die KPD-Leitung im Kreis, deren volles Vertrauen Warnke aber ganz offensichtlich genoß.

Nicht in allen anderen Kreisen und Städten griff die administrative und politische Zentralisierung so weitgehend, schnell und reibungslos wie im erweiterten Kreis Güstrow, da nicht überall ähnlich günstige Umstände herrschten: ${ }^{158}$ Erstens war das Kreisgebiet durch die Grenze zwischen den angelsächsischen und den sowjetischen Truppen erweitert worden, so daß die Integration der westlichen Gebiete der Kreise Wismar und

${ }^{156}$ Hinweise zur Entnazifizierung der Justiz und zu den Volksrichtern in: Kapitel III.3.

${ }_{157}$ MLHA, MdI 30, Bl. 83, 90RS. So wie die Kreisverwaltungen nach der Gründung der Landesverwaltung in deren Struktur eingepaßt wurden, bemühte sich die Landesverwaltung seit $\mathrm{Au}-$ gust auch um eine landesweite Zentralisierung des häufig wenig professionell aufgebauten neuen Justizwesens (siehe z. B. MLHA, MinPräs 1309, Bl. 37).

158 Dennoch sicherten sich die Kommunisten mit Hilfe der Kommandanturen bald überall die Vormachtstellung gegenüber ihren einzigen ernsthaften Konkurrenten, den Sozialdemokraten. In der Stadt Rostock gab es aufgrund der traditionell kräftigen Sozialdemokratie noch bis 1947/48 starke Auseinandersetzungen zwischen Kommunisten und Sozialdemokraten. Typischer war die Entwicklung in der Stadt Stralsund, in der der Stralsunder Sozialdemokrat Otto Kortüm im Mai 1945 zum Oberbürgermeister eingesetzt wurde, aber schon bald den jungen Remigranten Emil Frost als einflußreichen Stellvertreter zur Seite gestellt bekam (Stadtarchiv Stralsund, Arbeitssammlung Strukturpläne; Stadtarchiv Stralsund, Rep 50-12; Eggert, Ende, S. 51ff.). 
Schwerin eine vorläufige Neuordnung des Kreises Güstrow notwendig machte. Zweitens standen in Güstrow mit Höcker und Warnke alte Landespolitiker zur Verfügung, die auf einen umfangreichen politischen Erfahrungsschatz und genaue Kenntnisse ihres Landes und Kreisgebietes zurückgreifen konnten. ${ }^{159}$ Entscheidend war aber wohl drittens die Gegenwart von Sobottka und anderen verantwortlichen Mitgliedern seiner Initiativgruppe; sie befanden sich zwar bis zur Übernahme Schwerins durch die Rote Armee zuerst in Stettin und dann in Waren, ${ }^{160} \mathrm{im}$ Zuge der Vorbereitungen der Landesverwaltung hatten sie aber wiederholt Kontakte zu den späteren (Vize-)Präsidenten in Güstrow. Dadurch konnte die Initiativgruppe in Güstrow direkteren Einfluß nehmen als durch die reisenden Instrukteure. Daß dieser Einfluß Wirkung zeigte und daß die politischen Aktivitäten im Kreis Güstrow während des Frühsommers 1945 den Vorstellungen von Besatzungsmacht und KPD-Leitung entsprachen, zeigt die Auswahl von drei Güstrower Politikern in die vierköpfige Spitze der Anfang Juli 1945 installierten Landesverwaltung. Daß Warnke seit Juli 1945 in der Landesverwaltung die gleichen politischen Schwerpunkte und die gleiche administrative Zentralisierung wie im Kreis Güstrow durchsetzte, unterstreicht diese Beobachtung ebenso wie das umfangreiche Vertrauen der Besatzungmacht in ihn, wodurch er für mehrere Jahre zum Zentrum der politischen Herrschaft in Mecklenburg-Vorpommern wurde.

\section{Ausdifferenzierung des Herrschaftssystems - Die Etablierung der Landesverwaltung}

Besatzungsmacht und kommunistische Politiker hatten sich in den ersten Wochen nach Kriegsende vorwiegend auf die zonale Politik und auf die Etablierung und Kontrolle der lokalen Verwaltungsapparate konzentriert. Das Beispiel Güstrow zeigt die frühen und erfolgreichen Bemühungen um eine straffe, auf Kommunisten ausgerichtete Zentralisierung von Politik, Administration und Justiz und die Auswahl von Mitarbeitern, deren Loyalität oberstes Einstellungskriterium war. Schon Anfang Juli 1945 wurde dieses Herrschaftssystem dadurch ausdifferenziert, daß die Besatzungsmacht $z$ wischen Kreisen und Zone eine zusätzliche, für die nächsten Jahre entscheidende politische und administrative Ebene einrichtete: Wenige Tage nach der Übernahme der bis Ende Juni 1945 britisch und US-amerikanisch besetzten Gebiete Westmecklenburgs und Thüringens durch die Rote Armee installierte die SMAD in der SBZ fünf Provinzial- und Landesverwaltungen und parallel dazu sowjetische Kommandanturen. Nach der Etablierung dieser regierungsähnlichen Landesverwaltung in Schwerin mußte sie ähnliche Aufgaben bewältigen, wie sie im vorhergehenden Kapitel für den Kreis Güstrow nachgezeichnet wurden: die Klärung der eigenen Strukturen und Kompetenzabgrenzungen, die politische Kontrolle und den Umbau der Administration und die Auswahl politisch loyaler Verwaltungsmitarbeiter. Wiederum konnten sich dabei zwei Tendenzen gegenseitig verstärken: die etatistische Tradition der Arbeiterbewegung, zunehmend mehr gesellschaftliche Bereiche in die Verantwortung eines möglichst zentralen Staatsapparates zu über-

${ }^{159}$ Zahlreiche Oberbürgermeister und Landräte kamen aus der Migration oder als NKFD-Mitglieder aus der Kriegsgefangenschaft zurück, so daß sie diese Voraussetzungen nicht mirbrachten.

${ }^{160}$ Geschichte der Landesparteiorganisation, S. 74, 86f. 
geben, und die ausufernden sozialen und politischen Probleme der, Zusammenbruchgesellschaft ${ }^{`}$ (Kleßmann), ${ }^{161}$ die nach einer überregionalen Koordination riefen.

Anstoß und Rahmen für den Übergang der bloß lokal organisierten zur landesweiten Politik gab die Gründung der Landesverwaltung Anfang Juli 1945 nach dem Abzug der Briten aus Westmecklenburg 162 in Schwerin. Sie stand unter der Hegemonie der Kommunisten; Sozialdemokraten und bürgerlichen Politikern wurden ebenfalls verantwortliche Posten der Landesverwaltung übertragen, um den Parteienproporz zu wahren und weil zudem nicht ausreichend befähigte Linke zur Verfügung gestanden hätten. Die Auswahl der neuen Politiker, die die wichtigsten landespolitischen Protagonisten der folgenden Untersuchung sind, erfolgte vor allem durch den Leiter der aus Moskau eingeflogenen Initiativgruppe, Sobottka. Etwa zeitgleich mit der Installierung der Landesverwaltung ${ }^{163}$ bildeten KPD, SPD und CDU - der Landesverband der LDPD wurde erst im Januar 1946 gegründet - den Parteienblock auf Landesebene, dem es allerdings

${ }^{161}$ Kleßmann, Staatsgründung; zuerst bei Dröll, Zusammenbruchskrise, S. 164-174.

162 Westmecklenburg wurde einschließlich Wismars, Schwerins und Ludwigslusts Anfang Mai 1945 von US-amerikanischen und vor allem britischen Truppen besetzt und in einer von sowjetischer und britischer Seite sorgfältig vorbereiteten Aktion ,in einem Geist freundlicher Kooperation “ an die Rote Armee übergeben, die nach einem britischen Bericht den Wert der ${ }_{n}$ gegenseitigen Bekanntschaft und Freundschaft zwischen Kommandeuren" zeige (PRO-WO 171, 4368). Die Übergabe wurde der Schweriner Bevölkerung am 30.6. 1945 mitgeteilt und war bereits am 1. 7. 1945 um 15 Uhr vollständig abgeschlossen. Die Akten der britischen Einheiten enthalten nicht viel mehr als ihre Kriegstagebücher, in denen stichpunktartig über Einmarsch, vereinzelten Widerstand, Dankgottesdienste in den besetzten Orten, DPs, Versorgungsangelegenheiten etc. berichtet wird. Lang- und mittelfristige Planungen mit deutschen Funktionsträgern auf lokaler oder regionaler Ebene scheint es nicht gegeben zu haben, da den militärischen Einheiten ihr Rückzug aus dem Gebiet bereits Mitte Juni 1945 mitgeteilt worden war. Unterlagen zur Entnazifizierung liegen fast keine vor (PRO-FO 1060, 3822; PRO-WO 171, 4195; PRO-WO 171, 4196; PRO-WO 171, 4198; PRO-WO 171, 4199; PRO-WO 171, 4200; PRO-WO 171, 4201; PRO-WO 171, 4203; PRO-WO 171, 4204; PRO-WO 171, 4205; PRO-WO 171, 4369; PROWO 171, 7944; PRO-WO 171, 8092; Archiv der Stadt Schwerin, R1-43). Damit bestätigt die Aktenlage die von seiten der DDR-Historiographie wiederholt vorgetragenen Anschuldigungen, die Briten hätten in den westlichen Teilen der späteren SBZ fast keine Entnazifizierung durchgeführt (z. B. Stadtarchiv Schwerin, Befreier; Kornow, Arbeiterklasse, S. 53-58; Schöneburg, Anfängen, S. 35f.). Das anklagende Pathos dieser Schriften wird durch einen Blick auf die Entnazifizierungspolitik in der gesamten britischen Zone gebrochen, die im Frühjahr und Sommer 1945 "nur langsam an Umfang und Tiefe zu[nahm]“ (Vollnhals, Entnazifizierung, S. 24f.; Turner, Denazification, S. 246ff.). Ein umfangreicher Bericht über den Stadt- und Landkreis Schwerin vom 10.6. 1945 verzeichnete immerhin neben einer Liste der weiterhin tätigen Staatsdiener, daß der Oberbürgermeister von Schwerin, Richard Crull, bereits verhaftet war, die Verhaftung von Gauleiter Friedrich Hildebrandt „, in einer anderen Gegend“ durchgeführt und der Aufenthaltsort des NSDAP-Kreisleiters Röpcke unbekannt sei (PRO-WO 171, 7986). Neben dem generell zurückhaltenden Beginn der Entnazifizierung in der britischen Zone sahen sich die Westalliierten auch nicht zur Eile getrieben, weil sie von ihrem bevorstehenden Abzug wußten (siehe auch Beck, Entstehung, S. 201; Büchner/Freundlich, Situation; Jürgensen, Gebietsaustausch).

${ }^{163}$ Der SMAD-Befehl Nr. 110 vom 22. 10. 1945 räumte den Landesverwaltungen das Recht zum Erlaß von Gesetzen ein und stattete die bereits erlassenen Verordnungen rückwirkend mit Gesetzeskraft aus (Befehle des Obersten Chefs, S. 19f.). 
anders als auf zonaler Ebene nicht gelang, sich entscheidend in die Landespolitik einzuschalten. ${ }^{164}$

Der mecklenburgische Staatsminister während des Besatzungswechsels hieß Hans Jeß. Nach seiner Entlassung aus kurzfristigem automatic arrest hatten die Briten den seit 1919 ohne Unterbrechungen in städtischen und staatlichen Diensten Schwerins und Mecklenburgs tätigen Verwaltungsfachmann zum Leiter der Reste der Landesregierung ernannt. ${ }^{165}$ Nach den Anfangsschwierigkeiten seiner Regierungstätigkeit - die Verhaftung hatte ihn überrascht, weil seine Anwartschaft für das Amt des Staatsministers schon vor Kriegsende so weit abgesprochen war, daß Friedrich Stratmann das Amt nur mit der Versicherung der Briten annahm, es sofort nach Jeß' Entlassung aus der Haft zu seinen Gunsten zurückgeben zu können ${ }^{166}$ - schien er eine Kontinuität im Amt über den Besatzungswechsel angenommen zu haben. In den ersten Tagen nach der Übernahme Schwerins durch die Rote Armee suchte er seine Tätigkeit fortzusetzen und nahm noch strukturelle Veränderungen in der Landesregierung vor. Auch nach dem Rückzug der Briten versuchte Jeß an der alten Landesregierung festzuhalten. Noch am 4. Juli 1945 teilte er die Bestellung des Leiters der Abteilung Justizverwaltung und eines Sachbearbeiters

164 SAPMO-BA, RY 1/13/15, 38, Bl. 1f.; siche den Gründungsaufruf in: Volkszeitung (13. 7. 1945). Der Zentrale Blockausschuß in Berlin konnte sich durch die anfängliche Schwäche der Zentralverwaltungen einen nicht unbedeutenden politischen Einfluß sichern; mindestens durch Voten und verhinderte Entscheidungen (wie im Fall der Bodenreform) konnten einzelne Vorhaben der $\mathrm{KPD} / \mathrm{SED}$ verhindert oder verändert werden. Die Stärke der KPD/SED verdankte sich daher in Mecklenburg-Vorpommern nicht nur der Unterstützung durch die Besatzungsmacht, sondern auch dem mangelnden Widerspruch von CDU und LDPD. Beide Parteien hatten Landesvorsitzende, die vor und während des Faschismus leitende Posten in der mecklenburgischen Administration innegehabt hatten: Lobedanz und Suhrbier waren zwar keine NSDAP-Mitglieder gewesen, blieben aber aufgrund des im Zuge der Entnazifizierung zunehmend breiter gefaßten Belastungsspektrums immer vom ,Faschismus'-Vorwurf bedroht. Dies schwächte sie nicht nur bei ihren administrativen Tätigkeiten in der Präsidial- bzw. Finanzabteilung, sondern verhinderte in beiden Landesparteien auch die Stärkung oppositioneller Gruppen.

165 Staatshandbuch 1938, S. 7, 12, 149; Staatshandbuch 1939, S. 7; Broszat/Weber, SBZ-Handbuch, S. 940. Jeß mischte auch in Schweriner Lokalangelegenheiten aktiv mit. Karl berichtet in seinen Erinnerungen, daß sich bürgerliche Kreise in der Umbruchphase um Ministerialdirektor Jeß gruppiert und für die friedliche Übergabe der Stadt votiert hätten. Bei einem Gespräch zwischen Jeß und Karl beanspruchten beide den Oberbürgermeisterposten für ihre Partei: Karl habe sich kompromißbereit gezeigt, als Jeß den früheren Stadtrat von Wismar, Maus, als Kandidaten vorschlug (SAPMO-BA, SGY 30, 1290, Bl. 11ff.).

166 In einer Darstellung der Schweriner LDPD-Geschichte vom Landesverband Mecklenburg vom Juli 1948 heißt es, Jeß sei einverständlich von Moltmann und Stratmann als Regierungsleiter ausgesucht und auf ihren Vorschlag von den US-Amerikanern und Briten eingesetzt worden. „Leider änderte sich das Bild während der Nacht. Dr. Jeß, der während der Nazizeit bereits im Ministerium des Inneren, also im Bereiche des Himmlerschen Polizeiwesens gearbeitet hatte, wurde am nächsten Morgen vom Secret Service in Haft genommen. Oberst Wilson [...] beabsichtig[t]e, Stratmann um 10.00 Uhr den Regierungsbeamten als Prime-Minister vorzustellen. Stratmann erklärte sich für die Dauer der Haft von Dr. Jeß zu dieser Tätigkeit bereit. [...] Etwa 5 Wochen dauerte die Regierungszeit von Dr. Stratmann. Während der gleichen Zeit leitete Moltmann das Sozialministerium und die Arbeitsämter. Da wurde Dr. Jeß aus der Haft freigelassen. Dr. Stratmann gab sein Amt an die englische Regierung zurück und der englische Kommandant setzte Dr. Jeß als Prime-Minister ein. Seine Tätigkeit dauerte jedoch nur wenige Tage, da rückte die englische Truppe nach dem Westen ab“ (ADL, LDP 10408). 
mit ${ }^{167}$, und am 2. Juli 1945 bestimmte er rückwirkend für den 1. Juni 1945 die Integration der bislang vom Reichsjustizminister, vom Oberlandesgerichtspräsidenten und vom Schweriner Generalstaatsanwalt wahrgenommenen Aufgaben in eine der Landesregierung eingegliederte Justizverwaltung. ${ }^{168}$ Dieses Schreiben war von einer alliierten Zensur- oder Kontrollinstanz abgezeichnet, die Datumsangabe („2.“) aber nachträglich handschriftlich eingesetzt worden. Anscheinend besaß Jeß von der britischen Besatzungsmacht beglaubigte Schreiben auf Vorrat und nutzte sie, um seine Regierungstätigkeit fortzusetzen. Der Besatzungswechsel schien für ihn keinen Bruch darzustellen, mindestens keinen gravierenden. Anders als viele Zeitgenossen, die lieber auf der Flucht als unter sowjetischer Besatzung lebten, fürchtete Jeß weder um sein eigenes Leben obwohl er auf einer Verhaftungsliste der Westalliierten gestanden hatte - noch um seine politische Stellung. Er verstand sich als unpolitischer Beamter, der - wie viele Bürgermeister, Landräte etc. - seine Aufgabe fortführen wollte. Ähnlich wie in Thüringen, wo der ehemalige Buchenwald-Häftling und Sozialdemokrat Hermann L. Brill zwei Wochen nach Abzug der US-Amerikaner auf Anordnung der sowjetischen Besatzungsmacht durch Rudolf Paul ersetzt wurde, ${ }^{169}$ konnte sich aber auch Jeß nicht durchsetzen: Sowjets und Initiativgruppe Sobottka wünschten keine modifizierte alte Landesregierung, sondern setzten durch sowjetischen Befehl die schon in Güstrow vorbereitete völlig neue Verwaltungsspitze ein.

Nachdem die provisorische KPD-Landesleitung aus Sobottka, Aenne Kundermann und Bürger seit Juni 1945 aus Stettin nach Waren umgezogen war und sich damit Schwerin näherte, wo sie sich nach der Besetzung der Stadt durch die Sowjets niederließ,170 wurden Vorbereitungen getroffen, um die wichtigsten politischen Posten der einzurichtenden Landesverwaltung vor allem mit Personen aus Güstrow (Warnke, Möller, Hökker) zu besetzen und einige vorwiegend verwaltungstechnische Aufgaben Schwerinern wie Moltmann, Lobedanz, Jeß und Max Suhrbier ${ }^{171}$ zuzuteilen. Warnke hatte sich als handfester, politisch erfahrener, linientreuer und außerordentlich kooperationsbereiter Kommunist erwiesen. In den umfangreichen Unterlagen aus der Zeit vor seinem Umzug nach Schwerin finden sich keine Hinweise auf Eigensinnigkeiten, Abweichungen oder Kritik gegenüber den aus Moskau instruierten Genossen. Neben diesen Eigenschaften und seiner führenden Rolle in der Mecklenburg-Schweriner KPD der Weimarer Republik qualifizierte ihn auch das Team, mit dem er in Güstrow zusammengearbeitet hatte. Er konnte bereits auf eine mehrwöchige Kooperation mit seinem Stellvertreter in Gü-

167 MLHA, MdI bis 1945 8, Bl. 187.

168 MLHA, MinPräs 1255, Bl. 51.

169 Welsh, Thüringen, S. 174; Overesch, Machtergreifung, S. 95ff.; Staritz, Gründung, S. $46 f$.

170 Geschichte der Landesparteiorganisation, S. 74, 86f.; Voßke, Initiativgruppe.

${ }^{171}$ Max Suhrbier (1902-1971); Jurist; 1928-1933 Assessor beim Landgericht Rostock und im Staatsministerium Schwerin; Mai 1933 Berufung zum Regierungsrat; 1934 Referent im mecklenburgischen Finanzministerium; Juli 1936 Oberregierungsrat; Juli 1945 Ministerialrat; 1946 Mitbegründer LDPD Mecklenburg-Vorpommern; 1947 LDPD-Zentralvorstand; MdL; $1945 / 46$ Mitarbeiter im Finanzministerium; 1949-1952 Landesfinanzminister; Mitglied der Länderkammer; MdV; 1959-1961 stellvertretender DDR-Finanzminister; 1960-1967 LDPD-Vorsitzender; 1960-1965 stellvertretender Vorsitzender des DDR-Ministerrats. 
strow, Höcker, zurückblicken. ${ }^{172}$ Die Zusammensetzung im neuen Landespräsidium war ein zentrales Kriterium zur Auswahl des Sozialdemokraten Höcker und des Christdemokraten Möller: Sie hatten bereits mit Warnke zusammengearbeitet und sich ohne Widerspruch der Hegemonie von Besatzungsmacht und Kommunisten untergeordnet. Diese Bereitschaft zur Subalternität war wichtig, da die Besatzungsmacht in allen fünf neuen Ländern und Provinzen nichtkommunistische Präsidenten ernannte. Threm Volksfrontkonzept entsprechend beanspruchten die Kommunisten nicht die ersten Stellen, sondern überließen sie Sozialdemokraten und Bürgerlichen. Teil dieser, Großzügigkeit' war allerdings, daß die zweitwichtigsten Ämter stets an politisch erfahrene und einflußreiche Kommunisten vergeben wurden. Die mit dieser Strategie verbundenen Hoffnungen erfüllten sich in Mecklenburg-Vorpommern vollkommen, da sich Höcker als höchst konfliktscheuer und anpassungsbereiter Landespräsident erwies und damit nur nominell der Chef seines bisherigen Vorgesetzten wurde. ${ }^{173}$

Oberbürgermeister Warnke gab in der Dezernentenbesprechung in Güstrow am 30. Juni 1945 bekannt, daß Höcker, er selbst und andere vom stellvertretenden Chef der SMAD, Wassili Dawidowitsch Sokolowski, beauftragt worden seien, „für das Gebiet des früheren Freistaates Mecklenburg einschließlich Strelitz und den westlichen Teil Pommerns eine Landesregierung zu bilden“..17 Bereits am 27. Juni 1945 hatten sich Warnke, Höcker, Möller und Grünberg mit Sobottka über Mitarbeiter für die Arbeit in der Landesverwaltung verständigt. ${ }^{175}$ Die Spitze der Landesverwaltung setzte sich aus vier Männern zusammen, deren politischer Einfluß keineswegs mit der offiziellen Ämterhierarchie übereinstimmte. Während Warnke sich schnell zum mächtigsten Mann in der Landesverwaltung entwickelte und mit ständiger Rückendeckung der SMAM arbeitete, zeugen sowohl die umfangreichen und thematisch weit gestreuten Unterlagen des Präsidialamtes als auch einzelne, im folgenden beschriebene politische Vorgänge davon, daß Höcker sich mit fast allen landespolitisch relevanten und auch vielen irrelevanten Fragen beschäftigte, ohne daß dabei ein dezidierter persönlicher Standpunkt sichtbar wird. Grünberg besaß durch seine einwandfreie kommunistische Biographie - ihm war im Exil die sowjetische Staatsbürgerschaft verliehen worden - zuerst einen beträchtlichen Einfluß, von dem sein umfangreiches Aufgabenfeld zeugt: Kultur, Justiz, Gesundheitswesen und Volksbildung, obwohl er nach eigener Auskunft „eine deutsche Universität [...] noch nicht von innen gesehen “ hatte. ${ }^{176} \mathrm{Nach}$ wiederholter Kritik von seiten

172 Nach Darstellung der von Warnke selbst autorisierten Biographie mußte Höcker durch den Kommandanten und durch Warnke fast gezwungen werden, nicht in die KPD einzutreten, sondern die SPD zu gründen, damit - so die damals häufige und auch ihm gegenüber geäußerte Begründung - die SPD keine Partei des antikommunistischen Flügels der Sozialdemokratie werde (Mühlstädt, Warnke, S. 154f.; VpLA NL Warnke, V/6/24/6).

173 Warnke brachte nicht nur seinen Stellvertreter, sondern auch seinen persönlichen Sekretär mit in die Landesverwaltung: Der Sozialdemokrat Saul war seit Mai 1945 Warnkes Sekretär in Güstrow (Mühlstädt, Warnke, S. 146f.) und später in Schwerin; außerdem leitete Saul die FDGBGruppe in der Landesverwaltung.

${ }^{174}$ MLHA, MdI 2078. Vom 30. 6. 1945 liegt ein nicht signierter Vorschlag an die SMAD zur Gründung der Landesverwaltung mit Strukturplan vor (MLHA, MdI 10, Bl. 18f.).

${ }^{175}$ MLHA, MdI 10, Bl. 7f. Siehe die Bestätigung der Landesverwaltung durch die SMAD vom 4. 7. 1945 in: Um ein antifaschistisch-demokratisches Deutschland, S. 82f.; Ernennungsurkunden in: MLHA, MinPräs 1658, Bl. $5 \mathrm{ff}$.

${ }^{176}$ Grünberg, Mitglied, S. 627. 
der SMAM an seiner nicht politisch, sondern organisatorisch unzulänglichen Arbeit verlor er zunehmend an Einfluß. Möller taucht in den Akten der Landesverwaltung nur marginal auf. Als ausgewiesener Agrarfachmann übernahm er das für MecklenburgVorpommern bedeutende Landwirtschaftsressort und war als, Quoten-Bürgerlicher für den öffentlich behaupteten Proporz notwendig. Von seiner weitgehenden politischen Bedeutungslosigkeit zeugt nicht nur sein geringer Einfluß auf den alles überragenden Vorgang in der Landwirtschaft der SBZ, die Bodenreform, sondern auch die rücksichtslose Art, mit der er Anfang 1948 zum Rücktritt gedrängt wurde. ${ }^{177}$ Neben dem Präsidenten und seinen drei Stellvertretern traten Anfang Juli auch andere Personen an exponierter Stelle in den Dienst der Landesverwaltung. ${ }^{178}$ Ende Juni wurden dem Obersten Chef der SMAD, Schukow, noch sieben Ministerialdirektoren als Mitglieder einer Landesregierung Mecklenburg-Pommern vorgeschlagen, ${ }^{179}$ die Höcker am 8. Juli 1945 zum Teil berief: Er schickte Jonny Löhr, Mitglied der Initiativgruppe Sobottka, durch das Land und ließ die Aufforderung überbringen, „ihr Amt schnellstens [zu] übernehmen". 180

Ähnlich wie in den Kreisen, Städten und Gemeinden war die Suche nach geeigneten Personen wegen des dünnen Personalangebots in Mecklenburg-Vorpommern auch auf Landesebene nicht leichtgefallen. In der Besprechung am 27. Juni 1945 berieten die zukünftigen (Vize-)Präsidenten mit Sobottka über mögliche Amtsträger in der Landesverwaltung. Neben den Anwesenden wurden weitere 15 Namen aufgelistet, die ein Bild von den personalpolitischen Schwierigkeiten auf Landesebene geben. Nicht mehr als fünf Personen kamen aus der Arbeiterbewegung, zwei verwiesen explizit auf die Differenzen zwischen Kommunisten und Sozialdemokraten, und nur zwei schienen zur vorbehaltlosen Zusammenarbeit mit der KPD bereit zu sein. Beispielhaft war der Wunsch des späteren Bürgermeisters von Rostock, Albert Schulz, „daß die Kommunisten evtl. durch Vermittlung des Genossen Sobottka eine Verbindung mit dem Zentralausschuß der SPD in Berlin vermitteln. Er wünscht, daß er persönlich mit den führenden Männern in Berlin eine Aussprache führen kann, ehe er sich mit Begeisterung in die Arbeit stürzen will." Ebenso äußerte sich Martin Müller, dem der Aufbau der Gewerkschaftsarbeit zugetraut wurde; der alte sozialdemokratische Beamte Johann Oldach wurde als weniger abgeneigt gegenüber einer von den Kommunisten geführten Volksfrontpolitik beschrieben, „braucht aber eine politische Führung“. ${ }^{181}$ Nur zwei uneingeschränkt KPDfreundliche Sozialdemokraten, Wilhelm Hörning und Kufahl (ehemals Rote Hilfe), konnten aufgeführt werden. Der spätere Präsident des Landesrechnungshofes in Bonn, Franz Ballerstaedt, stammte zwar aus einer sozialdemokratischen Familie, wurde selbst aber nicht als Sozialdemokrat genannt. Aus dem bürgerlichen Spektrum schlug die zu-

\footnotetext{
177 MLHA, MinPräs 19/1; MLHA, MinPräs 644, Bl. 80-83, 101.

${ }^{178}$ Siehe zu einzelnen Personen und ihren biographischen Angaben die Fragebögen, Lebensläufe und Personallisten in: MLHA, MdI 747.

${ }^{179}$ Heinrich Heydemann (Finanzministerium), Erich Schlesinger (Innenministerium), Otto Prieff (Sozial- und Wohlfahrtsministerium), Willi Kahmann (Landwirtschaftsministerium), Ernst Goldenbaum (Wirtschaftsministerium), Richard Möller (Kulturministerium), Franz Ballerstaedt (Justizministerium), in: MLHA, LL KPD I/8.

180 MLHA, MinPräs 1255, Bl. 44-48.

${ }^{181}$ MLHA, MdI 10, Bl. 7f.
} 
künftige landespolitische Spitze insgesamt neun Personen vor, die politische Erfahrungen und einen antifaschistischen Leumund nachweisen konnten: Hasse, Heinrich Heydemann, Jakobs, Hans Lachmund, Richard Möller, Prange, Erich Schlesinger und den kurzzeitigen Staatsminister Jeß; das Protokoll vermerkt, daß über Lobedanz noch Erkundigungen einzuziehen seien. Eine Anlage nannte drei weitere Personen: Otto Prieff und die Remigranten Willi Kahmann und Jonny Löhr. ${ }^{182}$ Diese Auswahl war keineswegs üppig. Daß wichtige Posten bürgerlichen Politikern anvertraut werden sollten, war damit nicht nur parteistrategisches Gebot der Volksfrontpolitik, sondern ebenso ein Reflex auf den Personalmangel.

Das Protokoll dieser Besprechung enthält kritischere Äußerungen gegen Sozialdemokraten wie Schulz als gegen die lange Liste Bürgerlicher wie Jeß und Möller, deren antikommunistischer Grundeinstellung man ebenso gewiß sein konnte wie ihres stets entgegengesetzten ,Klassenstandpunktes‘. Wie die spätere Entwicklung zeigte, schätzten die führenden Kommunisten die Probleme des breiten politischen Bündnisses richtig ein: Während diejenigen bürgerlichen Politiker, die so früh zur Mitarbeit mit Sowjets und deutschen Kommunisten bereit waren, über lange Zeit ihre weitreichende politische und moralische ,Flexibilität bewiesen (Suhrbier, Lobedanz) oder ohne größeres Aufsehen flohen oder abgeschoben werden konnten und ins einfache Muster der ,Klassenfeinde“ einzuordnen waren (Jeß, LDPD-Landtagsfraktionsführer Paul Friedrich Scheffler, Wirtschaftsminister Siegfried Witte), blieben die ausgewiesen antifaschistischen Sozialdemokraten eine größère Gefahr für die Verfügungsgewalt und den Handlungsspielraum der KPD. Schon früh stieß man sich auf kommunistischer Seite an ihrem Eigensinn, schon früh betonte man bei ihnen - nicht bei den Bürgerlichen - die Notwendigkeit der "politische[n] Schulung".

Nicht alle der von Sobottkas Statistik erfaßten 900 Altkommunisten in MecklenburgVorpommern konnten in den Dienst der Landesverwaltung treten, da viele Aufgaben in den lokalen Verwaltungen, in Betrieben, in Schulen und nicht zuletzt im Parteiapparat übernahmen. Dabei waren sie immer wieder vor neue, ihnen unbekannte Verantwortungsbereiche gestellt. Während sich eine große Anzahl in ihren Stellungen zurechtfand und sich im Laufe der Jahre eine Annäherung zwischen persönlicher Qualifikation und dem durchschnittlichen Anforderungsstandard ergab, mußten viele schon früh aufgrund mangelhafter Tauglichkeit von verantwortlichen Posten ferngehalten werden. Die Karriere von Jonny Löhr ist dafür beispielhaft: Er war seit den zwanziger Jahren KPD-Mitglied, zeitweise Mitarbeiter der Komintern und hatte bis zu seiner Emigration in der Sowjetunion 1940 mehrere Jahre wegen prosowjetischer Aktivitäten in rumänischer Haft verbracht. Als Remigrant mit lupenreiner kommunistischer Biographie war er in den ersten Wochen und Monaten immer wieder Teilnehmer bei Gesprächen und Konferenzen der (Vize-)Präsidenten, der Kommandanten und der KPD-Spitze. Bereits Ende August 1945 formulierte Sobottka jedoch deutliche Kritik an seiner zu wenig rigorosen Politik, ${ }^{183}$ und im Laufe der folgenden Monate verlor er im Zuge der Erweiterung der Landesverwaltung nicht durch formelle Degradierung, sondern durch einen Karrierestopp

182 MLHA, MdI 10, Bl. $10 f$.

${ }^{183}$ Bericht Sobottkas vom 1. 9. 1945 über die "Versammlung der Parteigruppe Landesverwaltung“ am 31. 8. 1945 (MLHA, LL KPD I/8). 
immer mehr landespolitischen Einfluß.184 Auch darin glichen sich die Probleme auf Kreis- und Landesebene: Die KPD-Gruppe in Krakow beklagte Ende Juli 1945 den „Mangel an politischen Leitern [...], die ihrer heutigen Aufgabe gewachsen sind“. Es fehlte nicht die Bereitschaft zum Engagement, sondern die Qualifikation: Es gebe „einige gute, ehrliche Proleten, die aber geistig nicht so sehr geschult sind, daß sie die Partei in einer Stadt der heutigen Zeit entsprechend führen können“. ${ }^{185}$

Partiell konnte das Problem von außen gelindert werden. Bereits Sobottkas Statistik zählte etwa achtzig überlebende Kommunisten des Todesmarsches in Crivitz. Darüber hinaus erhielt Mecklenburg-Vorpommern wiederholt personelle Unterstützung durch das Zentralkomitee in Berlin. Anfang August 1945 gab es eine „Kommandierung“ von zwölf Kommunisten „im Auftrage des Zentralkomitees der Kommunistischen Partei Deutschlands nach Schwerin zur Arbeit im Gebiete der Landesverwaltung Mecklenburg. Die 12 Genossen werden geleitet zum Mitglied des ZK der KPD, dem Reichstagsabgeordneten Sobottka, in Schwerin. " 186 Ähnliche Hilfe erhielt Mecklenburg-Vorpommern auch aus den abgetretenen ostdeutschen Gebieten, woher nicht nur Flüchtlinge mit unüberprüfbaren biographischen Angaben kamen, sondern auf Veranlassung des Zentralkomitees auch geschlossene Gruppen ausgewiesener Kommunisten mit ihren Familien. ${ }^{187}$

Obwohl die Personaldecke dünn war, fanden sich Landesverwaltung und KPD-Führung schnell mit den neuen Aufgaben zurecht und etablierten schon kurze Zeit nach ihrer Einsetzung einen klassischen Arbeits- und Lebensstil führender Politiker: Bereits am 3. September 1945 verfügte Höcker "auf Anordnung des Chefs der Militärischen Administration“ die „Unterbringung der leitenden Beamten und ihre Verpflegung in der Sebastian-Bach-Straße“, einem der schönsten Straßenzüge in der Schweriner Innen-

${ }^{184}$ Ebenso wie seine Ehefrau Frieda Löhr wechselte er 1948 zur NDPD, blieb bis 1950 in Mecklenburg, wurde danach Botschafter in Rumänien, MdV und Präsident der Industrie- und Handelskammer (IHK) der DDR.

${ }^{185}$ MLHA, LL KPD I/13.

${ }^{186}$ MLHA, LL KPD I/1, Bl. 203. Siehe auch den Brief der Kader-Abteilung der Landesleitung der KPD vom 21. 9. 1945 an das ZK mit einer Liste von 71 männlichen Antifaschülern und kurzen Angaben über ihre Berufe und Qualifikationen (MLHA, LL KPD I/4, Bl. 17).

${ }_{187}$ Nach Mecklenburg kamen 16 Antifatransporte mit etwa 4000 Personen aus der Tschechoslowakei, von denen nach dem Umzug eines Teils von ihnen nach Thüringen und Sachsen etwa 3000 im Land blieben. Das ZK der KPD informierte Sobottka am 27. 7.1945 von einer Gruppe oberschlesischer Kommunisten mit Familien: „Einige davon sind sehr brauchbare Genossen, die man im Parteiapparat, für Verwaltungsarbeit oder sonst wo einsetzen kann" (MLHA, LL KPD I/1, Bl. 182). Dennoch hatten sie in den neuen Städten und Gemeinden ähnliche Integrationsschwierigkeiten wie die anderen Flüchtlinge (LL KPD I/5, Bl. 186, 211, 239f., 243, 329-335). Noch am 7. 5. 1947 gab die Personalabteilung des SED-Landesvorstands den Kreisleitungen Verfahrensregeln über die bevorzugte Rückkehr von Mitgliedern der Arbeiterparteien und ihrer Söhne aus der Kriegsgefangenschaft (MLHA, LL SED IV/2/5/164, Bl. 103). Der SED-Landesvorstand berichtete dem Zentralsekretariat am 28. 3. 1947, „daß ein hoher Prozentsatz der umgesiedelten Genossen in Partei und öffentlichem Leben" als Bezirkssekretäre, Schöffen, SEDStadtteilkassierer, Gesangslehrer, Bürgermeister, Polizisten, Volksrichter, Neubauern, bei der Volkssolidarität oder in Genossenschaften aktiv seien. Damit sei „der Zweck der geschlossenen Umsiedlung“ erfüllt: die Stärkung des mecklenburgischen „Funktionärskörpers“ und die Hilfe bei der Gründung neuer Existenzen (MLHA, LL SED IV/2/5/155, Bl. 57f.). 
stadt. ${ }^{188}$ Ähnliches zeigte sich auch bei der regionalen KPD-Elite, von deren großzügiger Unterstützung Namenslisten der führenden hauptamtlichen Parteikader von Anfang August 1945 zeugen, auf denen neben den Gehältern nicht nur die Kantinenverpflegung, sondern auch noch die Versorgung mit zusätzlichen Lebensmitteln präzise und hierarchisch abgestuft festgelegt war. ${ }^{189}$ Außerdem beantragte Warnke am 26. Oktober 1945 bei der SMAM, „für folgende Männer der Zentralverwaltung Pistolen mit einem Waffenschein auszuhändigen: " Höcker, Warnke, Grünberg, Möller, Löhr, Saul, Landespolizeichef Hase und seinen Stellvertreter Janzen: „Die 3 Letztgenannten stehen an verantwortlicher Stelle in der Verwaltung. Sie sind alle 3 Mitglieder der Kommunistischen Partei und als Antifaschisten bekannt. Saul hat das Vorzimmer des Vizepräsidenten Warnke inne." 190

Mitte Juli 1945 begann die Arbeit der Landesverwaltung. Zuerst mußten Strukturen geschaffen und Arbeitsgebiete zugeteilt und voneinander abgegrenzt werden. Über die Gliederung der Landesverwaltung in acht Abteilungen ${ }^{191}$ hatte Höcker die Fachabteilungen bereits am 10. Juli 1945 informiert und lud zu einer Besprechung darüber am 17. Juli 1945 ein. ${ }^{192}$ Zahlreiche Details zeigen zwar, wie stark in den ersten Wochen improvisiert werden mußte, ${ }^{193}$ aber die Landesverwaltung war Mitte Juli 1945 installiert und konnte nach der Selbstorganisation ihre eigentliche Arbeit beginnen. Sie zielte auf eine Zentralisierung der fast ausschließlich lokal koordinierten Verwaltungs- und Kommunikationsstrukturen. Dabei folgte sie einerseits dem Gebot der Stunde, weil bestimmte gesellschaftliche Aufgaben erst durch die landesweite Koordination gelöst wer-

${ }^{188}$ SAPMO-BA, NY 4103 (NL Grünberg), 1, Bl. 26. Seiner 25jährigen Tochter Edith Höcker übertrug er die Verwaltung und Geschäftsführung der Unterbringung und Verpflegung (SAPMOBA, NY 4090 [NL Grotewohl], 303, Bl. 20). Nach einem Bericht des Schweriner Oberbürgermeisters waren die Beschlagnahmungen aufgrund eines mündlichen Befehls der Roten Armee ergangen; eine antifaschistische Begründung - z. B. die NS-Belastung der Eigentümer oder ihre Beteiligung an Kriegsverbrechen - nannte er nicht (MLHA, MinPräs 278). Zum gleichen Vorgang in Berlin siehe Keiderling, Gruppe, S. 60f., der auf die politischen Vorteile der gemeinsamen Wohnbezirke zur ,Sonderbehandlung' bei möglicher Dissidenz hinweist. Warnke und Höcker wohnten anfangs sogar im gleichen Haus und gingen ,jeden Morgen gemeinsam zu Fuß zu unserer Wirkungsstätte [...]. Dabei wurde die Arbeit [...] besprochen " (Warnke, zit. nach: Mühlstädt, Warnke, S. 178).

${ }^{189}$ MLHA, LL KPD I/1; Gniffke, Jahre, S. 58ff. Siehe auch SAPMO-BA, RY 1/I2/5, 49, Bl. 24ff.; Leonhard, Spurensuche, S. 155, 158.

190 MLHA, MdI 60, Bl. 324.

${ }^{191}$ Präsidialamt, Innere Verwaltung, Wohlfahrt und Sozialpolitik, Finanzen (für den Bereich der Landesbauverwaltung mit dem Zusatz ,[Landesbauverwaltung] $]^{\circ}$ ), Landwirtschaft und Forsten, Wirtschaft, Volksbildung und Justiz (MLHA, MdI bis 1945 8, Bl. 190).

192 MLHA, MdI 343. Der entsprechende Strukturplan in: MLHA, MinPräs 1255, Bl. $25 f$.

${ }^{193}$ Mitte Juli 1945 war die Frage der Gehälter für die Spitzen der Landesverwaltung noch ungeklärt (MLHA, 343); kurzfristig richtete die Landesverwaltung ein Amt des Bevollmächtigten des Präsidenten in Greifswald ein und löste es wieder auf (MLHA, MdI bis 1945 8, Bl. 196, 198; MLHA, MdI bis 1945 84, Bl. 64-68; MLHA, MinPräs 1255, Bl. 63f.; Kornow, Arbeiterklasse, S. 67f.); bei Höckers Einweisung in die Aufgaben der Landesverwaltung mußte General Skossyrew am 8. 7. 1945 mitteilen, daß die „entsprechenden Ausweise“ noch nicht fertig seien (MLHA, MinPräs 1309, Bl. 2); Sobottka übte noch am 31. 8. 1945 KPD-intern grundlegende Kritik an zu großer Handlungsspielräumen einzelner Entscheidungsträger und einer unzureichenden Mitarbeit der Parteigruppe in der Landesverwaltung (MLHA, LL KPD I/8). 
den konnten, und andererseits ihrem eigenen Interesse an einer politischen und administrativen Zentralisierung.

Die Einrichtung der Landesverwaltung war ein entscheidender Schritt zur Ausdifferenzierung der politischen Herrschaft. Sie erweiterte nicht nur die bis dahin auf die zonale und lokale Ebene beschränkten politischen Strukturen der SBZ, sondern integrierte auch zahlreiche Bürgerliche und Sozialdemokraten, die bis dahin keine großen Sympathien für KPD und Besatzungsmacht gezeigt hatten, nunmehr aber an der von der Siegermacht installierten Herrschaft partizipierten. Der Aufruf, mit dem sich die Landesverwaltung der Bevölkerung des Landes vorstellte, zeigt ihr Bewußtsein für die dürftige Legitimität: Sie seien von der SMAD eingesetzte „Männer, die auf eine langjährige politische und wirtschaftliche Tätigkeit zurückblicken" könnten. „Wir können Euch keine Versprechungen machen“, und als einziger Weg „für ein neues, besseres und schöneres Deutschland [...], in dem unsere Kinder und Nachkommen glücklicher leben können als wir“, wurde „Arbeiten“ vorgeschlagen, „Arbeiten mit der ganzen Kraft““. ${ }^{194} \mathrm{Da}$ sie ihre Herrschaft weder durch konkrete Hinweise auf ihre Leistungen in der Vergangenheit noch durch ein überzeugendes Zukunftsprogramm legitimieren konnten, mußten sie nun praktische Nachweise ihrer Legitimität erbringen; die lagen allgemein in einer Verbesserung der Lebensverhältnisse, im besonderen aber in einer Effizienzsteigerung der ihr unterstellten Verwaltungsapparate.

\section{„Selbstverwaltung muß zentral gelenkt werden"}

Nach der Berufung der neuen Landespolitiker in ihre Ämter und den ersten Entscheidungen über die Arbeitsverteilung und Organisationsstruktur innerhalb der Landesverwaltung mußten die bis dahin ausschließlich lokal entstandenen und agierenden Verwaltungsbereiche auf die Zentrale in Schwerin ausgerichtet und ihr untergeordnet werden. Im ersten Aktenvermerk Höckers über ein Gespräch mit Skossyrew vom 8. Juli 1945 hielt er neben Einzelaufgaben der Landesverwaltung auch deren Grundausrichtung fest: „Damit ein normales Leben wieder eintritt, ist es notwendig, einen straffen, starken Apparat einzurichten." ${ }^{195}$ Dieser Prozeß war vor allem durch zwei Faktoren bestimmt: Ähnlich wie Oberbürgermeister Warnke in Güstrow konnte auch die Landesverwaltung ihre Funktion erst durch eine praktisch durchsetzbare Weisungskompetenz erfüllen und ihre Existenz legitimieren. Außerdem war das Ausmaß der gesellschaftlichen Probleme so groß, daß ihre Regelung landesweit vereinheitlichte Strukturen notwendig machte. Städte und Landkreise waren beispielsweise mit den Flüchtlingen, dem Aufbau der neuen Polizei- und Justizapparate und der Reaktivierung eines funktionstüchtigen Steuer- und Finanzsystems überfordert. Das Ziel der Zentralisierung wurde auch dadurch unterstrichen, daß - unter anderem in Anlehnung an die Aufbauerfahrung der Sowjetunion und aufgrund der Organisationsgeschichte der KPD - gesellschaftliche Probleme nicht subsidiär, sondern in den größtmöglichen Einheiten erörtert und gelöst werden sollten.

Angesichts des Fehlens eines nationalen Handlungsrahmens bildeten die Länder und Provinzen die größten politischen Einheiten, da die SBZ vor allem aus deutschlandpoli-

194 MLHA, MdI 10, Bl. 12.

${ }^{195}$ MLHA, MinPräs 1309, Bl. 2. 
tischen Gründen erst im Laufe der Besatzungszeit eine einheitliche Verwaltung erhielt. ${ }^{196}$ Die selbständige und nur von der Besatzungsmacht abhängige Herrschaft der Landesverwaltung währte länger als die der Landräte und Oberbürgermeister, da sie in zahlreichen Politikfeldern nicht von den Berliner Zentralverwaltungen oder den Zentralen der politischen Parteien abhängig war. Im Falle der Entnazifizierung kann der Übergang in die Verantwortung der Berliner Stellen mit dem SMAD-Befehl Nr. 201 auf den Spätsommer 1947 datiert werden. ${ }^{197}$ Bis dahin blieb die von der Besatzungsmacht angeleitete und kontrollierte Landesverwaltung bzw. Landesregierung mit ihrem seit 1945 aufgebauten neuen administrativen Apparat die entscheidende Trägerin der Entnazifizierung.

Auf Landesebene wurden gleichwohl nicht alle Bereiche gleichzeitig auf die Schweriner Zentrale ausgerichtet. Dies hing nicht allein vom politischen Willen, sondern auch von den sozioökonomischen Notwendigkeiten und Möglichkeiten ab. Angesichts der umfangreichen Aufgaben wurde unterschieden, in welchen Bereichen die Zentralisierung sofort durchzusetzen und in welchen sie aufzuschieben war: In manchen Gebieten (beispielsweise die Behandlung der Flüchtlingszüge, der Polizeiaufbau, das Kredit- und Bankenwesen und vor allem die Personalbesetzung, Stringenz und politische Zuverlässigkeit der landesweiten Verwaltungsstruktur) war der Schweriner Landesverwaltung besonders daran gelegen; andere Sektoren, die für weniger wichtig oder im lokalen Rahmen ausreichend lösbar erachtet wurden (zum Beispiel die Entnazifizierung im Gesundheitssektor und die Sequestrierungen ${ }^{198}$ ), waren vom Zentralisierungseifer vorerst ausgenommen.

Entscheidend für die Durchsetzung der landesweiten Vereinheitlichung des Verwaltungsaufbaus und der politischen Richtlinienkompetenz der Landesverwaltung war eine zweitägige Konferenz der Oberbürgermeister und Landräte aus ganz MecklenburgVorpommern am 20./21. August 1945 in Schwerin, zu der auch verschiedene kommunale Abteilungsleiter eingeladen waren. Ausführlich und zum Teil kontrovers wurde über die Organisation der kreisfreien Städte und Kreise und das Verhältnis zwischen Landräten und Oberbürgermeistern diskutiert. ${ }^{199}$ Dabei hatte die Landesverwaltung die Unterstützung der SMAM, deren Vertreter auch anwesend waren. Drei Tage zuvor hatte ihr Chef, Generaloberst Fedjuninski, vom Präsidialkollegium „mehr Verantwortungs-

${ }^{196}$ Eine zu frühe Stärkung der Berliner Zentralverwaltungen hätte angesichts ihrer Einflußlosigkeit in den Westzonen noch früher die Wiederherstellung eines einheitlichen Deutschlands verhindert (Welsh/Zank, Zentralverwaltungen, S. 204f.).

${ }^{197}$ Siehe Kapitel III.2. Der sukzessive Verlust politischen Handlungsspielraums der Länder bis zu ihrer Auflösung 1952 bedarf thematisch und regional beschränkter Einzeluntersuchungen wie beispielsweise Schwartz, Zusammenbruch, S. 59-75.

198 Während z. B. Wertsachen und Gelder abgeliefert werden mußten, bemühten sich weder SMAM noch Landesverwaltung in den ersten Wochen nach ihrer Gründung darum, beschlagnahmte Betriebe selbst zu verwalten. Bis zur Vereinheitlichung der Sequestrierungen und bis zur Bodenreform im Herbst 1945 war nur entscheidend, daß die Betriebe produzierten, nicht aber, wem sie unterstanden (SMAM-Befehl Nr. 3 vom 24. 7. 1945 [MLHA, MinPräs 1462, Bl. 8f.] und SMADBefehl Nr. 11 vom 25. 7. 1945 [MLHA, MinPräs 1458, Bl. 18]; Um ein antifaschistisch-demokratisches Deutschland, S. 189-192, 194ff.; Amtsblatt, Nr. 1 [1946], S. 4f.).

199 MLHA, MdI 30, Bl. 150-159; MLHA, MdI 245. 
bewußtsein und mehr Initiative“ der Landesverwaltung gegenüber den Oberbürgermeistern und Landräten verlangt, denn diese hätten ihre Weisungen nicht von den lokalen Kommandanturen, sondern von der Landesverwaltung zu erhalten. ${ }^{200}$ Zahlreiche lokale Funktionsträger hatten sich in den ersten Besatzungsmonaten gemeinsam mit den Kommandanturen so gut eingerichtet, daß sie die neue Landesverwaltung nur als Beschneidung eigener Kompetenzen erfuhren. Die mangelhafte Autorität seiner Landesverwaltung und die damit verbundenen Ordnungsprobleme führte der Präsident unter anderem darauf zurück, daß sich Lokalpolitiker „hinter dem örtlichen Kommandanten verstecken [...] und die Kommandantur selbst [...] zum Teil diese Bestrebungen" unterstützte. Dagegen suchte der SMAM-Chef die Zentralisierungstendenzen und die Autorität Höckers zu stärken: „Er erwartet, daß der Landespräsident ihn in Kenntnis setzt, wenn ihm in Ausübung dieser Autorität von irgend einer Seite Schwierigkeiten bereitet werden. “201 Dies entsprach der auch im weiteren verfolgten Tendenz, direkte Interventionen nachgeordneter sowjetischer Stellen in Aufgabengebiete zu untersagen, die an deutsche Instanzen übertragen waren. ${ }^{202}$ Ausdrücklich versicherte Fedjuninski, die Landräte und Oberbürgermeister am 20. August 1945 und seine Kommandanten bei einem späteren Treffen darauf hinzuweisen.

Auf dieser Konferenz war die wichtigste Zielgruppe für die landesweite Zentralisierung der Verwaltung versammelt: Oberbürgermeister, Landräte und einige Leiter lokaler Fachressorts. ${ }^{203}$ Dabei ist ein Unterschied zwischen Kreis- und Landespolitik hervorzuheben: Während sich Warnke nur wenig für den Aufbau und das Geschick der Landes-KPD/SED interessierte und sich auch nicht im Landesparteienblock hervortat, wurden die Oberbürgermeister und Landräte entscheidende Akteure in der lokalen Verwaltungs- und Parteienlandschaft, so daß sie auf der gleichen Tagung instruiert wurden, in Kreisen, Städten und Gemeinden Parteien-Blockausschüsse zu bilden und ihren Vorsitz zu übernehmen. ${ }^{204}$ Landesverwaltung und SMAM ging es um die Einbindung der Parteien in Politik und Gesellschaft: „Die Blockausschüsse sind mitverantwortlich für das, was getan wird. "205 Damit vergrößerte sich der politische Handlungsspielraum der Parteien allerdings nicht bedeutend, weil die Vorsitzenden der auf Einstimmigkeit angewiesenen Blockausschlüsse gleichzeitig unter die wachsende Aufsicht Schwerins gestellt

200 MLHA, MinPräs 1309, B1. 35-38.

201 Ebenda.

202 Nach dem SMAD-Befehl Nr. 201 vom August 1947 überließ die SMAM beispielsweise die Kontrolle und Anweisung der Entnazifizierung in Mecklenburg-Vorpommern weitgehend den deutschen Stellen in Berlin.

203 Warnke hatte auch die Leiter der Finanz-, Wirtschafts-, Landwirtschafts- sowie der Kultur- und Volksbildungsabteilungen zur Tagung eingeladen (MLHA, MdI 245, Bl. 22).

204 Nach einem Bericht der Landesverwaltung vom 21. 7. 1945 gab es unter den zwanzig Landräten und acht Oberbürgermeistern in Mecklenburg-Vorpommern acht Kommunisten, sieben Sozialdemokraten, drei Demokraten und zehn Parteilose (MLHA, MdI 345). Dies änderte sich jedoch schnell, so daß Kornow, Arbeiterklasse, S. 87, zum Jahreswechsel in diesem Personenkreis nur noch einen CDU-Vertreter und sonst nur Mitglieder der Arbeiterparteien ausmachte:

$\begin{array}{lccccc} & \text { Gesamt } & \text { KPD } & \text { SPD } & \text { CDU } & \text { parteilos } \\ \text { Oberbürgermeister } & 8 & 3 & 4 & 1 & 0 \\ \text { Landräte } & 20 & 13 & 7 & 0 & 0 \\ \text { Bürgermeister } & 76 & 58 & 14 & 2 & 2\end{array}$

205 Warnke, in: MLHA, MdI 245, Bl. 37. 
wurden. Vielmehr ist festzustellen, daß die Ausweitung des Blocksystems auf lokaler Ebene die demokratische Legitimation der Verwaltung stärkte und in den folgenden ereignisreichen Monaten die Mobilisierung von Bevölkerung und Politikern für Sequestrierungen und Bodenreform unterstützte. $\mathrm{Da}$ die von oben angeordneten gesellschaftlichen Umgestaltungen der nächsten Monate und Jahre nicht ohne die aktive Beteiligung lokaler Instanzen denkbar waren, ist die Bedeutung dieser Konferenz für die Landespolitik kaum zu überschätzen. Die Verantwortlichen legten die organisatorische Grundlage für eine enge Verzahnung von Landes- und Kreispolitik: Oberbürgermeister und Landräte wurden auf die Abteilung Innere Verwaltung ausgerichtet und die ihnen unterstehenden lokalen Parteiorganisationen in die aus Berlin und Schwerin angestoßene Politik eingebunden.

Durch diese enge Verquickung zwischen Parteien und Verwaltung übernahmen Parteistellen viele Aufgaben, die eindeutig im Bereich der Verwaltung lagen. Das Mitglied des Zentralkomitees der KPD, Franz Dahlem, informierte beispielsweise am 5. August 1945 eine KPD-Parteiarbeiterkonferenz über die Beschlüsse der Potsdamer Konferenz, über Gewerkschafts-, Enteignungs- und Entnazifizierungsfragen, noch bevor die Landesverwaltung davon erfuhr. Aufgrund des dürftigen parteipolitischen und administrativen Organisationsgrades im agrarisch geprägten Mecklenburg-Vorpommern bedurfte es dieser engen Kooperation, um die Gesellschaft verändern und formen zu können. Der designierte Landrat von Güstrow, Quandt, forderte diesen Dualismus auf einer lokalen KPD-Konferenz am 8. August 1945 sogar ausdrücklich: „Die Dörfer und Güter [sind] mit einem Netz von Vertrauensleuten zu überziehen, um somit in wenigen Tagen ein Fundament zu schaffen und eine Organisation, die den oberen Verwaltungsorganen und der Regierung für ihre kommenden Entschlüsse zur Seite stehen wird, damit sie ihre Beschlüsse in die Tat umsetzen kann. Die Schaffung eines starken Landarbeiter-Verbandes ist somit eine vordringliche Aufgabe. Solange wir auf dem Lande keine Organisation haben, fehlt uns die Verbindung mit den Massen, und alle Beschlüsse unserer oberen Verwaltungsorgane hängen in der Luft. Deswegen lautet die Parole der Partei für die nächste Zeit: Das Gesicht dem Dorfe zu! " 206 Deutlich wurde dies auf der Tagung der Oberbürgermeister und Landräte, als wiederholt die Verordnungen angekündigt wurden, die die Landesverwaltung keine zwei Wochen später zur Vereinheitlichung der Sequestrierungen und der Entnazifizierung erließ. ${ }^{207}$ Für deren Realisierung, die zusammen mit der Bodenreform eine umfassende Veränderung der mecklenburgischen Gesellschaft bewirkten, war die Mitarbeit der Oberbürgermeister und Landräte so notwendig, daß sie ähnlich der Ämterfülle Warnkes auf Landesebene - neben ihren Verwaltungsämtern und dem Blockvorsitz auch zu Vorsitzenden der Bodenreform- und Sequestrierungskommissionen wurden. Bevor die Landesverwaltung für alle drei Prozesse fast zeitgleich Verordnungen erließ, war diese Konferenz die letzte eindringliche Instruktion an ihre wichtigsten Verbindungsmänner in den einzelnen Kreisen, Städten und Gemeinden.

${ }^{206}$ MLHA, MdI 197, Bl. 340. Ein ähnlicher organisatorischer Aufbau wurde auf der Sitzung des Parteienblocks in Schwerin am 17. 8. 1945 beschlossen: „Die Parteien des antifaschistisch demokratischen Blocks sind sich prinzipiell einig, eine Art Vertrauensmännerorganisation über die ganze Stadt auszubauen" (MLHA, LL KPD I/8).

${ }^{207}$ Siehe Kapitel I.2, S. 93-111. 
Der spätere Innenminister begrenzte auf dieser Konferenz die Eigenständigkeit und den Einfluß der Parteien in der Landespolitik ausdrücklich durch konzeptionelle Überlegungen zu Fragen von Demokratie, Mitbestimmung und Staatsaufbau. Ausdrücklich schloß er ein Anknüpfen an die Weimarer Republik aus, formulierte die ablehnende Haltung der KPD gegenüber einer pluralistischen Gesellschaft und parlamentarischen Demokratie und reaktivierte die kommunistische und antifaschistische Tradition, Politik primär in polaren Kategorien wahrzunehmen. Trotz des Mehrparteiensystems und der offiziell verkündeten Volksfrontstrategie gab es bei seiner Beurteilung politischer Subjekte nur die Wahl zwischen den von der Besatzungsmacht zugelassenen antifaschistischen Parteien und Faschisten. Warnke formulierte zwar moderater als mit der holzschnittartigen und im Exil korrigierten Sozialfaschismusthese, aber dennoch blieb die Dichotomie bestehen, deren unerbittliche Grenzlinie er als Kommunist meinte ziehen zu können: „Sollen wir zu den Mitteln kommen wie vor 1933, daß jeder Mann und jede Frau wählen darf, den sie wählen wollen? Sollen wir allen Faschisten erlauben, mitzubestimmen bei den Wahlen, das Recht zu haben, Versammlungen abzuhalten? In diesem Sinne nie, das können wir nicht erlauben. Wer hat denn nur das Recht, an der Selbstbestimmung in der Verwaltung teilzunehmen? Das Recht hat der ganze antifaschistische Block. Diese Kreise haben nur das Recht, mitzubestimmen an der Selbstverwaltung. Diese Kräfte haben schon sehr bald von Marschall Schukow die Erlaubnis bekommen, antifaschistische Parteien zu bilden, freie Gewerkschaften zu bilden." 208 Ein undatierter Text mit handschriftlichen Korrekturen Warnkes über den „vorläufige[n] Verwaltungsaufbau in Mecklenburg-Vorpommern" begann mit einer programmatischen Aussage, die seinen wiederholten Aufrufen als Oberbürgermeister in Güstrow zur Eigeninitiative glich: „Ziel des Wiederaufbaues einer Verwaltung ist eine weitgehende Dezentralisierung und auf breitester demokratischer Grundlage ruhende lokale Selbstverwaltung. Der totale Zusammenbruch macht es notwendig, diesen Aufbau schrittweise durchzuführen. “209 Die Stärkung der bereits selbständig funktionierenden lokalen Selbstverwaltungen klang demokratisch, motivierte die einzelnen Oberbürgermeister und Landräte und fand Unterstützung bei den Parteien; allerdings wurde sie nirgends realisiert. Nicht nur Warnke, auch Höcker äußerte sich in seiner Ansprache am 20. August 1945 ausdrücklich zur Zentralisierung der Herrschaft und zur Disziplinierung der lokalen Funktionsträger und propagierte, „daß draußen im Lande überall nunmehr Sicherheit, Ruhe, Ordnung und Gesetzmäßigkeit“" wiederherzustellen sei. Dies verstand er eindeutig zentralistisch, denn er wandte sich gleichzeitig gegen eine zu große lokale Autonomie von Oberbürgermeistern und Landräten, die „glauben, sie können alleine Gesetze machen. Sie, meine Herren, müssen für sich in Anspruch nehmen, daß Ihre Autorität den unteren Behörden gegenüber gewahrt bleibt, und Sie müssen dafür eintreten, daß die Autorität der Landesverwaltung nicht untergraben, sondern gestärkt wird. Nur die Landesverwaltung ist im Benehmen und mit Genehmigung der Militärischen Administration berechtigt, Verordnungen zu erlassen, die die unteren Verwaltungsbehörden durchzuführen haben." 210

${ }^{208}$ MLHA, MdI 245, Bl. $36 f$.

${ }^{209}$ MLHA, MdI 10, Bl. 14-18.

${ }^{210}$ MLHA, MdI 245, Bl. 29. 
Diese Zentralisierung war verbindlich und fand die Zustimmung der lokalen Funktionsträger unter anderem aufgrund ihrer Überforderung in der unmittelbaren Nachkriegszeit. Während es auf lokaler Ebene keine Schwierigkeiten bereitete, Trümmer zu entsorgen oder im eigenen Kreis erzeugte Güter zu verteilen, waren der Wiederaufbau des Justizwesens, die Einstellung und Ausbildung neuer Verwaltungsfachkräfte und Lehrer, die Ausarbeitung neuer Lehrpläne, die Bewältigung des Flüchtlingselends, eine gleichmäßige medizinische Grundversorgung oder die Versorgung mit Gütern aus überregionalen Fabrikationsstätten vielfach nicht ohne die Unterstützung fachkundiger Kräfte aus Schwerin oder eine landesweite Koordination möglich. Gleichzeitig wurde die Zustimmung aber auch eingefordert. Wer auf der von oben vorgegebenen Linie nicht mitzumachen bereit war, wurde unter Druck gesetzt, und gegen Verfechter abweichender Ansichten wurden scharfe Sanktionen angekündigt. Eine Auseinandersetzung zwischen Warnke und dem Landrat von Barth zeigt, daß es dabei keineswegs um politische Glaubensfragen oder ökonomische essentials gehen mußte: „Vizepräsident Warnke: Das Landratsamt muß nach Stralsund. Landrat und Oberbürgermeister sollen sich darauf einrichten, daß der Umzug kommt. Landrat Barth: Dann lege ich meinen Posten nieder. Vizepräsident Warnke: Ablehnung ist Fahnenflucht." 211 Warnkes Vergleich aus dem militärischen Leben und das Fehlen jeglicher inhaltlicher Begründung sprechen für seinen in der jahrelangen Parteipraxis des Demokratischen Zentralismus verinnerlichten autoritären Stil. Die Entscheidung einer hierarchisch übergeordneten Stelle mußte angenommen und umgesetzt werden. Diskussionen wurden nur vorher geduldet - wenn sie erwünscht waren. Diese hierarchische Struktur galt zwischen Landräten, Gemeindevorstehern und Bezirksbürgermeistern, die Warnke zu weisungsabhängigen Bevollmächtigten des Landrats erklärte, ${ }^{212}$ ebenso wie in den einzelnen Ressorts. Diese mußten sich nicht nur parallel zur Struktur der Landesverwaltung reorganisieren, sondern zudem ihre inhaltliche Arbeit den auf der Tagung erteilten Anweisungen anpassen, „damit auch Sie im Sinne der Richtlinien arbeiten können und mit den Aufgaben konform gehen und Ihre Aufgabengebiete erfaßt werden, wie wir sie in der Landesverwaltung haben“.213

Diese autoritär-zentralistische Praxis war durch eine umfassende, auf den Begriff der Selbstverwaltung bezogene Rhetorik gebrochen. Die Spannung zwischen der in den Zeiten des Chaos notwendigen Eigeninitiative und Freiheit der Funktionsträger und dem Kontroll- und Weisungsanspruch der Landesverwaltung ließ sich ebensowenig leugnen wie die Bewährung vieler der größtenteils zuvor unerfahrenen lokalen Funktionsträger in den ersten Wochen nach dem Zusammenbruch: „Wir wollen keinen Verwaltungsaufbau nach Führerprinzip [...]. Ein solches Prinzip in der Verwaltung mußte sich Hitler

211 MLHA, MdI 30, Bl. 154f. Nach einem Bericht des Stralsunder Kreispersonalamtes vom 12. 3. 1946 an die KPD-Kreisleitung zog das Landratsamt Ende Februar 1946 von Barth nach Stralsund um (MLHA, LL SED IV/4/1138, Bl. 198f.).

${ }^{212}$ MLHA, MdI 30, Bl. 155. Die Landräte wurden - so eine Formulierung auf der Konferenztagesordnung - „die staatliche Mittelinstanz“, die auch die Reichsbehörden aufsog (MLHA, MdI 210b). Siehe entsprechend Ministerialdirektor Heydemann am 17.7. 1945 über die Auflösung der Reichsbauämter Schwerin und Greifswald und die Integration ihrer Aufgaben in die lokalen staatlichen Hochbauverwaltungen (MLHA, MdI bis 1945 8, Bl. 195).

${ }^{213}$ MLHA, MdI 245, Bl. 37. 
schaffen [...]. Unser neues Deutschland soll seinen Verwaltungsapparat aufbauen nach der Grundlage der Selbstverwaltung, und die Selbstverwaltung ist auch notwendig, um diese schwere Zeit, die wir infolge des Hitlerregimes zu spüren haben, zu überwinden. [...] Aber diese Selbstverwaltung muß zentral gelenkt werden." 214 Dabei wendete Warnke den Begriff der "Selbstverwaltung“ dahin, daß der Oberbürgermeister oder Landrat nicht „Herrscher" oder „alleinige[r] Herr“ sein dürfe, sondern „aus dem Volk hinaus [getragen werde], er muß enge Verbindung haben mit dem Volke“.215 Dies richtete sich zur Disziplinierung der neuen Kommunalpolitiker gerade gegen deren Autonomie: Während sich die von der Besatzungsmacht gestützte Landesverwaltung als Trägerin des umfassenden gesellschaftlichen Wissens, der übergreifenden und gültigen Entscheidungen präsentieren konnte, legte Warnke den Verantwortungsträgern in Städten und Gemeinden Bescheidenheit und Volkstümlichkeit ans Herz. Seine Rede von einer "gesunden Mischung zwischen kommunaler Selbstverwaltung und zentraler Lenkung“ setzte eine durchsetzungsfähige Definitionsmacht voraus: Seine biologistischen Kategorien ,gesund ' und ,krank` suggerierten die Möglichkeit einer objektiven, präzisen und verbindlichen Entscheidung; diese machte der 1945 in der SBZ hegemoniale Zeitgeist sicherlich nicht im Individuum, sondern im übergeordneten Parteikollektiv aus. Wer solche Entscheidungen fällen durfte, war angesichts der nicht sachbezogen, sondern mit rhetorischen Floskeln geführten Auseinandersetzung ausschließlich eine Frage der Herrschaft. Deutlicher war diese nicht in Ideologie zu kleiden. ${ }^{216}$

Innerhalb weniger Wochen war die Herrschaft der Landesverwaltung so weit etabliert, daß sie sich einen eigenen Verwaltungsapparat aufbauen konnte. Diesen gewann sie durch die Anbindung der lokalen Funktionsträger, die bis dahin selbst mit umfangreichen Herrschaftskompetenzen ausgestattet gewesen waren und über eigene administrative Apparate verfügt hatten. ${ }^{217}$ So wie die ebenfalls erst Anfang Juli 1945 gegründete SMAM ihre Position gegenüber den lokalen Kommandanturen durchsetzen mußte, ${ }^{218}$ so entwickelte sich die Landesverwaltung zu einem konstitutiven Teil des von der Besatzungsmacht eingesetzten Herrschaftssystems. Die Oberbürgermeister, Landräte und weiteren politischen Größen auf lokaler Ebene verloren ihre weitreichenden Kompetenzen und wurden zu ausführenden Instanzen für die Landesverwaltung, die mit Hilfe ihrer Loyalität fortan die Gesellschaft Mecklenburg-Vorpommerns umgestaltete.

${ }^{214}$ MLHA, MdI 245, Bl. 32.

215 Ebenda.

${ }^{216}$ Eine ähnliche Funktion hatte die Rede von der gesellschaftlichen ,Normalisierung'; siehe Kapitel II.

217 Wie zum Beweis dieser Selbständigkeit betonte Warnke die zunehmenden Kompetenzen der Landesverwaltung gegenüber der Besatzungsmacht: Die Landräte würden nun nicht mehr vom Kommandanten, sondern vom Präsidenten auf Vorschlag des Parteienblocks und im Einvernehmen mit dem Kommandanten ernannt. Dies sei „für unsere Arbeit ein ungeheueres [...] Vertrauen [...]. Wir haben die Verantwortung für das Volk, nicht irgendeine Besatzungstruppe“ (MLHA, MdI 245, Bl. 36).

218 Das Chaos innerhalb der Besatzungsmacht war so groß, daß im August 1945 ein eigener SMADBefehl zur „Herstellung der Ordnung auf dem Gebiete der Verwaltung und der Arbeit der Militärkommandanturen" erlassen wurde, weil "Anarchie in der Arbeit der Militär-Kommandanturen der sowjetischen Zone Deutschlands" herrsche, wodurch „die Ausführung der Grundaufgaben um[ge]stoßen“ werde (BAP, DX1, SMAD-Befehl Nr. 33/45, 22. 8. 1945). 
Nachdem Oberbürgermeister, Landräte und ihre Ressortleiter auf die Linie der Landesverwaltung gebracht waren, richtete Warnke den Auf- und Umbau der Verwaltung auf zwei weitere Ziele: Er suchte erstens einen personellen Neuanfang durchzusetzen, und strebte zweitens eine qualitative Veränderung verwaltungstechnischen Handelns an: „Nicht nur die Köpfe beseitigen und andere Männer einsetzen, sondern von Grund auf das Neue schaffen." 219 Obwohl weder Warnke noch andere Verantwortliche die neuen Vorhaben inhaltlich bestimmten, bereiteten sie damit einen weiteren entscheidenden Schritt zur Sicherung ihrer Herrschaft vor. Entsprechend Max Webers These von der Unentrinnbarkeit einer funktionierenden Verwaltung, deren Selbstlauf auch nicht durch eine neue Leitung zu verändern sei, ${ }^{220}$ ging es um einen rigorosen Neuanfang: „Voraussetzung ist natürlich, wenn wir das Neue schaffen wollen, daß der alte Verwaltungsapparat zerschlagen wird. “221 Der Neuanfang sollte so tiefgreifend sein, daß selbst die Kompetenz erfahrener Fachleute mißachtet und politisch verdächtigt wurde: „Wenn auch nach Entfernung dieser Leute Spezialkräfte fehlen werden, so müssen wir es mit gesunden Menschen aus dem Volke versuchen, die nicht belastet sind, sondern frei von dem ,Wissen", was alles in den Akten niedergelegt sein muß.“222 Dazu boten sich die Maßnahmen der Entnazifizierung an, die es ermöglichten, die weitgehend nach den Vorstellungen der neuen Herrscher durchgeführten strukturellen Veränderungen des Verwaltungsapparates auch personalpolitisch abzusichern. ${ }^{223}$

\section{Entnazifizierung und Verwaltungsbruch}

$\mathrm{Zu}$ Beginn der Besatzung nahmen Deutsche fast ausschließlich an lokalen Maßnahmen zur Entnazifizierung teil, bis die Landesverwaltung ihren eigenen Zugriff im August 1945 langsam systematisierte. Schon früh erstritten sich die Kommunisten dabei eine monopolartige Zuständigkeit für die Personalpolitik. Seitdem leiteten sie die Entnazifizierung, die Entlassungen und die Neueinstellungen vor allem unter dem Aspekt der Umgestaltung des Verwaltungsapparates und des gesellschaftlichen Neuaufbaus unter kommunistischer Hegemonie.

\footnotetext{
${ }^{219}$ MLHA, MdI 245, Bl. 33.

220 Weber, Wirtschaft, S. 569ff., 682, 687, 834-837.

${ }^{221}$ MLHA, MdI 245, Bl. $32 \mathrm{f}$.

222 Ebenda.

223 Einen formellen Abschluß dieser landesweiten Zentralisierung setzte Warnke am 13.9. 1945 durch zwei Schreiben an alle Fachabteilungen, Kreise, Parteien etc. über den genauen Verwaltungsaufbau (MLHA, MdI bis 1945 84, Bl. 64f., 66ff.). Bis zum 25. 9. 1945 war ihm zu melden, wie mögliche Kompetenzüberschneidungen zwischen kreisfreien Städten und Kreisverwaltungen gelöst seien. Daß diese Strukturvorgaben von den lokalen Verwaltungen realisiert wurden, zeigt der Brief des stellvertretenden Landrats des Kreises Güstrow, Holthus, vom 27. 9. 1945 an die Bürgermeister über den Aufbau der Landkreisverwaltung (MLHA, RdK Güstrow, 113, Bl. 3).
} 


\section{Spontan und lokal: Erste Abrechnungen}

Niethammers Einschätzung für Bayern, daß sich „die Entnazifizierungspraxis unmittelbar nach dem Umbruch [... nur grob abschätzen" läßt, ${ }^{224}$ trifft auch für die SBZ zu. Außer den häufig allzu eindeutigen Aussagen aus den SED-Erinnerungsseminaren ${ }^{225}$ gibt es nur einzelne, unzusammenhängende Überlieferungen. Das entspricht dem zeitgenössischen Vorgehen: keine zentralen Weisungen, keine einheitlichen Kriterien. ${ }^{226}$ Ähnlich wie in Bayern war das Besatzungsmilitär auch im Nordosten Deutschlands ,angesichts des ungeheuren Durcheinanders am einzelnen Ort bei Kriegsende zunächst an einer gewissen Stabilisierung der Lage [...] interessiert“",227 wodurch Verbrechen eher zufällig geahndet und Verwaltungen und Betriebe nur nebenbei überprüft wurden.

Gegen NSDAP-Mitglieder. Ein KPD-Instrukteur berichtete im Juli 1945 aus Plau im Kreis Parchim, daß außer den Ämtern des Bürgermeisters, seines Stellvertreters und des Polizeikommandanten, die von zwei Kommunisten und einem Sozialdemokraten besetzt seien, "sämtliche Stadträte, Inspektoren und sonstige Angestellte durchweg Mitglieder der NSDAP in Amt und Würden [waren], d. h. daß praktisch die Stadt von den alten Nationalsozialisten regiert" werde. Die Kommunisten hätten die alten Nazis nicht entlassen, da sie sonst überfordert gewesen wären. Erst er selbst habe alle Pgs durch Sozialdemokraten und Bürgerliche ersetzt.228 Ähnlich erging es Instrukteur Kahne Ende Mai im nordbrandenburgischen Lychen: „Ein zwanglos geführtes Gespräch mit der Bürgerin Frau Gertrud K., Lychen Bahnhofstrasse X, hatte folgendes Resultat. Frau K. teilte mit, daß eine gewisse Frau Hella O., früher als eifrige Büroarbeiterin bei der SS beschäftigt, heute schon einen Unterschlupf als Büroarbeiterin in der Polizei der Stadt Lychen gefunden hat, was von der Bevölkerung mit Befremden zur Kenntnis genommen wird. Ich habe noch kurz vor der Abfahrt von der Stadt Lychen hierüber einen schriftlichen Bericht gemacht und diesen in Abwesenheit des Bürgermeisters dem Leiter der landwirtschaftlichen Abteilung zur Weiterleitung an den Bürgermeister übergeben." ${ }^{229}$

${ }^{224}$ Niethammer, Mitläuferfabrik, S. 147. Diese "Phase der Improvisation“ umfaßt bei ihm nicht mehr als drei der insgesamt 666 Textseiten (S. 147ff.).

${ }^{225}$ Die ehemaligen SED-Archive enthalten umfangreiche Erinnerungsberichte, deren Inhalte und Entstehung eigene Untersuchungen über die SED-gelenkte Traditionsbildung der DDR wert sind; sie wurden teilweise veröffentlicht (Vereint; Unbeugsame).

226 Da die Vorgänge selbst auf lokaler und regionaler Ebene undurchsichtig blieben, waren sie hinsichtlich der ehemaligen Reichs- und Landesbehörden, für die es keine verantwortliche Leitung und darum keinen Zugriff gab, noch schwieriger; siehe MLHA, LL KPD I/28, Bl. 107.

${ }^{227}$ Niethammer, Mitläuferfabrik, S. 148. Dies galt auch für die deutschen NS-Gegner: Schon bei den Versuchen der kampflosen Übergabe der Städte ging es stärker darum, Zerstörungen zu vermeiden, als politisch oder strafrechtlich belastete Personen aufzugreifen. Karl berichtet beispielsweise von der Übergabe Schwerins, daß die Anweisung des NS-Gauleiters Hildebrandt, Gas-, Elektrizitäts- und Wasserwerke beim Einmarsch der Alliierten zu zerstören, durch Absprachen zwischen antifaschistischen Arbeitern und Maschinisten nicht realisiert worden sei (SAPMO-BA, SGY 30, 1290, Bl. 10; zum Erfolg solcher Absprachen siehe den britischen Lagebericht aus Schwerin, in: PRO-WO 171, 7986). Im Vergleich zu solchen Hinweisen finden sich nur wenige auf Festnahmen führender Staats- oder NS-Größen.

${ }_{228}$ SAPMO-BA, RY 1/I3/15, 34, Bl. 24.

${ }^{229}$ MLHA, LL KPD I/1, Bl. 43. Die Instrukteure orientierten sich bei ihren Einsätzen nicht an den späteren Grenzen der fünf Länder und Provinzen. 
Die Quantifizierung der Entlassungen im Mai und Juni 1945 ist ähnlich schwierig wie die der Internierungen durch die Sowjets: Flucht, Vertreibungen, Internierungen, Kriegsgefangenschaft, Berufswechsel, Schwarzmarkttätigkeiten etc. machten die Lage undurchsichtig. In seinen regelmäßigen Arbeitsberichten nannte der Güstrower Landrat Beltz konkrete Zahlen: am 28. Mai $1945^{230}$ „etwa 85 Entlassungen“; der Bericht zur zweiten Juniwoche: „Landratsamt. Zahl der vor Besetzung beschäftigten Personen 173. Entlassen am 16. Mai 87 Personen, am 1. Juni 4 Abteilungsleiter und 2 Stenotypistinnen, am 18. Juni weitere 19 Personen, sämtlich wegen politischer Unzuverlässigkeit. Neueingestellt wurden 19 Personen, davon 5 als Dolmetscher. Die Bereinigung der Dienststellen von Angehörigen der NSDAP muß und wird mit größter Beschleunigung fortgesetzt, insbesondere beim Arbeitsamt, Kreisgericht. In der Verwaltung des Oberbürgermeisters befinden sich keine früheren Mitglieder der NSDAP. Die Schöffen des Amtsund Kreisgerichtes gehörten sämtlich der NSDAP nicht an. Die Orts-und Landeskrankenkassen werden ebenfalls durchgekämmt. [...] Volksbildung: Nazifrei. “231 Und in der Zusammenstellung der Berichte vom 16. bis 22. Juni 1945: „Landratsamt: Personal einschl. Gesundheitsamt ursprünglich 173 Personen. Jetzt auf 91 vermindert; davon 75 Landratsamt, Gesundheitsamt 16. Vor der Bereinigung des Personals 60\% Mitglieder der NSDAP, heute nur noch 6 Beamte und Angestellte sowie 1 Lehrling $=6 \%$. Gesundheitsamt im April von 8 Beamten und Angestellten 6 Mitglieder der NSDAP, heute nur noch eine Schwester. “232

Wie später auf Landesebene wurde auch im erweiterten Kreis Güstrow zuerst von oben nach unten ,gesäubert ${ }^{c}$. Während sich in der Verwaltung des Oberbürgermeisters bereits keine NSDAP-Mitglieder mehr befanden, stellte der Bürgermeister von Neukloster bei Crivitz zur gleichen Zeit fest: „Es ist noch alles beim alten. Wir sind gestern zusammen gewesen und haben die Anweisung erhalten, es so zu machen wie in Güstrow. In Güstrow würden wir alles Nähere erfahren." ${ }^{233}$ Fast sechs Wochen nach dem Einzug war beim Verwaltungspersonal „noch alles beim alten“, hatte sich außer dem Wechsel des Bürgermeisters nicht viel getan. Der Bürgermeister verspürte zwar ein Unbehagen, ein Problembewußtsein, ihm war aber nicht klar, was und wie geändert werden mußte.

Dabei spielten die umfangreiche Fluchtbewegung Richtung Westen und das allgemeine Chaos eine wichtige Rolle. Das schwer NS-belastete Personal war größtenteils geflohen, um sich der Verantwortung am Ort der eigenen Tätigkeit zu entziehen. Die Flucht vom Heimatort bot zunächst die größte Sicherheit vor dem Zugriff der Besatzungsmacht und vor Anklagen durch Mitbewohner. Dem entsprechen die vielen Erinnerungsberichte über umfangreiche Fluchtaktivitäten lokaler und regionaler NS-Größen in den letzten Tagen vor dem Einmarsch alliierter, vor allem sowjetischer Truppen. ${ }^{234}$ Der Kommandant von Güstrow setzte den Einzug der sowjetischen Truppen in die Stadt sogar damit gleich, „daß die Faschisten aus der Stadt verjagt sind“. ${ }^{235}$ Die

230 MLHA, MdI 2078.

231 MLHA, MdI $210 \mathrm{~b}$.

232 MLHA, MdI 2078.

${ }^{233}$ Der Bürgermeister aus Neukloster auf der Bürgermeisterkonferenz am 14.6. 1945 (MLHA, MdI 30, Bl. 137).

${ }^{234}$ Nach Kornow, Arbeiterklasse, S. 149, fand die Rote Armee in Mecklenburg und Vorpommern keine einzige funktionstüchtige Kreisverwaltung vor; „alle Landräte und Oberbürgermeister 
Flucht und Abwesenheit der exponiertesten Nazis nahm der Entnazifizierung ihre Dringlichkeit und relativierte die Belastung der Überprüfbaren.

Die Unsicherheit des Bürgermeisters von Neukloster zeigt, daß es noch keine plausiblen und selbstverständlichen Kriterien für NS-bedingte Entlassungen gab. Wer für untragbar gehalten wurde, stand im Belieben der lokalen Verantwortlichen. 236 In Güstrow konnten selbst die führenden deutschen Verantwortlichen noch nicht die angekündigten klaren Anweisungen geben. Eher verlegen stellte der Landrat Beltz die bisherige Entlassungspraxis dar: „Wir müssen dazu übergehen, aus unserer Verwaltung die Angehörigen der NSDAP hinauszubringen. Wie weit und in welchem Umfange kann ich Ihnen im Augenblick verbindlich noch nicht sagen. Alle Abteilungsleiter sind hoffentlich schon heraus. Stadtverwaltung, Eisenbahn und Post, alles muß gereinigt werden. Das muß alles einem zuverlässigen Menschen übertragen werden. Wir gehen jetzt dazu über, diejenigen Mitglieder der NSDAP, die bis zum Jahre 1937 Mitglied geworden sind, zu entlassen." 237

Die ersten Systematisierungen der Entnazifizierung stellten häufig die Frage nach dem NSDAP-Eintrittsdatum und nach der jetzigen Position: Früh eingetretene NSDAPler und gegenwärtige Verantwortungsträger, die Parteimitglieder gewesen waren, mußten ihre Stellungen räumen. Damit wurde die Parteimitgliedschaft schon früh zum entscheidenden Belastungskriterium. ${ }^{238}$ Beltz wies auf den Rigorismus hin, mit dem die Sowjets an diesem Kriterium festhielten, da sie weder den frühzeitigen Austritt oder Ausschluß aus der NSDAP noch Hinweise auf den beruflich bedingten NSDAPEintritt als Entlastungskriterien anerkannten. ${ }^{239}$

Allerdings wurde dies nicht starr gehandhabt; so wiegelte Warnke auf derselben Konferenz ab: „Wir können keine Mitgliedslisten der NSDAP zur Hand nehmen, daraus die Namen ablesen und einfach sagen: alle heraus, weil ihr Mitglied der Partei wart - nein,

und die Mehrheit der Bürgermeister der kreisangehörigen Städte wie auch die ,Hoheitsträger der NSDAP und andere Spitzenfunktionäre" waren geflohen oder hatten Suizid begangen; siehe auch Anmerkung 35 in Kapitel I.1.

${ }^{235}$ MLHA, MdI 30, Bl. 95. Ähnliches vermutet auch Niethammer für Bayern: „Die Zahl der Entlassungen [...] dürfte beim allgemeinen Stillstand von Wirtschaft und Verwaltung, wegen der Flucht vieler Betroffener und der akuten Knappheit an vorgebildetem Personal gering gewesen sein" (Niethammer, Mitläuferfabrik, S. 148).

${ }^{236}$ In den ersten Wochen setzten viele Behörden, Betriebe, Schulen etc. eigene Untersuchungskommissionen ein, in denen ehemalige, alte und neue Mitarbeiter ihre Kollegen beurteilten. Anscheinend fanden viele NSDAP-Mitglieder, die sich diesen spontanen Ausschüssen stellten und nicht geflohen waren, Gnade; bei der Überprüfung der städtischen Lehrer in Greifswald am 14.6. 1945 wurde dem Oberbürgermeister z. B. vorgeschlagen, 17 Lehrer fristlos und ohne Gehalt zu entlassen, 17 weitere Lehrer für ein Jahr als Beamte auf Widerruf im Dienst zu belassen und 55 Lehrer, die auch in der NSDAP gewesen waren, ohne Sanktionen weiterzubeschäftigen (Stadtarchiv Greifswald, Rep 6 Ia-116); siehe auch die Protokolle solcher Ausschüsse in Schulen des Kreises Neustrelitz (MLHA, RdK Neustrelitz 281, Bl. 28-32).

237 MLHA, MdI 30, Bl. 137.

${ }^{238}$ Daß dieses Kriterium Schwierigkeiten bereitete, hatte Beltz schon Ende Mai geäußert: In Laage verlange der Kommandant „die Entlassung des mir seit langen Jahren bekannten Stadtinspekteurs H., der meines Wissens erst 1939 Mitglied der NSDAP wurde. Ich weiß aus persönlicher Kenntnis, daß $\mathrm{H}$. sich innerlich niemals zum Nationalsozialismus bekannt hat. Beide Bürgermeister in Laage verlangen, daß er im Amt bleibt. Diese Frage müßte in der Besprechung mit den Kommandanten am 29. Mai geklärt werden" (MLHA, MdI 2078). 
so geht das nicht. Heraus müssen möglichst alle faschistischen Kräfte aus der Verwaltung. Wir können nicht sämtliche Ärzte hinauswerfen, wir müssen anders vorgehen. Von Fall zu Fall ist zu überprüfen, wie die einzelne Person eingestellt war. Leute, die bis 1937 in die Partei getreten sind, dürfen nicht mehr in der Verwaltung beschäftigt werden. Man kann vielleicht einmal Ausnahmen machen, wir gebrauchen jetzt zum Beispiel das gesamte sanitäre Personal. Was sollte werden, wenn jetzt alle entlassen würden?" 240

Ausschaltung politischer Gegner. Da Warnke in unmittelbarer Nähe zu Sobottka und damit zum engsten Machtzirkel stand, war seine Position sicherlich nicht gegen generelle Anweisungen der Sowjets gerichtet. Der Unterschied zwischen dem zukünftigen Innenminister und Beltz spiegelt eher Differenzen zwischen verschiedenen Truppenteilen der Sowjets wider: Während einzelne Kommandanten sich besonders rigoros zeigten, legten andere mehr Wert auf den Neuaufbau. Entsprechend dieser Gruppe war auch Warnke flexibler und pragmatischer orientiert. Ihm ging es primär um den Neuaufbau, womit er allerdings schon früh die Ausschaltung politischer Gegner verband. Zum Abschluß der Konferenz Ende Mai 1945 formulierte er sein dichotomes Weltbild, das er der Entnazifizierungspolitik zugrunde legte; es liest sich wie eine Zusammenfassung der Entnazifizierungsgeschichte in der SBZ: "Wir werden nicht nur jeden Faschisten, den wir kennen, offen bekämpfen, sondern auch die Unbekannten, die durch Verbreitung von Gerüchten Verwirrung in die Bevölkerung bringen. Wer falsche Gerüchte verbreitet, ist ein Volksfeind und wird so behandelt." 241 Zur Bestimmung der Faschisten wandte er ein stärker politisches Kriterium als Beltz an. Während der Landrat bei der Benennung des eher formalen Kriteriums der NSDAP-Mitgliedschaft auf seine Unsicherheit hinwies, war sich Warnke seiner Definitionsmacht so sicher, daß er sogar zwischen, guten' und ,schlechten' Opfern des Faschismus zu unterscheiden wußte: „Ich fasse alle Verfemten und Verfolgten zusammen, soweit sie anständige Kerle sind. Es kommt immer auf den Kern an. Nicht jeder, der im Zuchthaus oder im Konzentrationslager war, rechnet hierzu. Die Konzentrationäre hatten Lebensmut, niemals wurden sie zaghaft, immer haben sie

${ }^{239}$ "Die Russen legen einen sehr engen Maßstab an. Es nützt nichts, wenn vorgebracht wird, ich bin aus der Partei heraus geworfen, ich bin seit 1937 nicht mehr darin. Die Russen erklären hierzu, der Mann hat sich zum Faschismus bekannt, hat nachher Pech gehabt, das ist seine eigene Sache. [...] Hat er nachher 3-4 Jahre im KZ gesessen oder hat er Zuchthaus gehabt, so sind das Gründe, die auch in den Augen der Russen einen anderen Maßstab zulassen. Ein anderer Fall: Vorgebracht wurde von einem Angehörigen der NSDAP, daß er 1937 der Partei beitreten mußte, weil er bei einer öffentlichen Behörde war. Er hätte sonst seinen Posten verloren, wenn er es nicht getan hätte. Es wurde ihm darauf von dem zuständigen russischen Personaloffizier entgegnet: Also hast Du Dich freiwillig zum Faschismus bekannt. 1937 hättest Du überall in der Privatwirtschaft Arbeit gefunden. Wenn Sie alles so betrachten, finden Sie den richtigen Maßstab" (MLHA, MdI 30, Bl. 137).

${ }^{240}$ MLHA, MdI 30, Bl. 148. Bei dieser Argumentation tritt bereits deutlich zutage, daß Warnke der Neuanfang wichtiger war als die Abrechnung; zur Begründung seiner rigorosen Entnazifizierungsverordnung Ende August drehte er das Argument genau um und erklärte Einzelprüfungen für zu aufwendig, weshalb alle Pgs zur Entlassung bestimmt wurden; siehe Kapitel I.2, S. 96-102 und zur Entnazifizierung der Mediziner Kapitel I.2, S. $117 \mathrm{f}$.

${ }^{241}$ MLHA, MdI 30, Bl. 128ff. Siehe ebenfalls Warnke: „Auch Versammlungen müssen gehalten werden, Aufklärung geht über alles, was geschehen soll. Das Volk hungert danach. Vor allem aber, bekämpft die Gerüchte. Kampf gegen den Faschismus!" (MLHA, MdI 30, BI. 91RS). 
durchgehalten, weil sie ein Ziel hatten: Morgen steht Deutschland, dafür will ich kämpfen. Dieser Geist muß unserer Jugend beigegeben werden. Auch ich habe einmal in einem Konzentrationslager gesessen, aber dennoch bin ich frei von jedem persönlichen $\mathrm{Ha} ß$ und Rachegefühlen und das ist auch bei den anderen so, bei meinen Freunden. Doch hart sind wir, wenn es um die gesamte Sache geht. Dieser Geist muß kommen! [...] Das wichtigste ist, daß die Wirtschaft in Gang kommt. “242

Das Kriterium war eindeutig. Warnke betonte gesellschaftliche Veränderungen und damit nicht die individuelle, sondern eine strukturelle Entnazifizierung: den Aufbau einer besseren gesellschaftlichen Ordnung, an die die ,guten' $\mathrm{KZ}-\mathrm{Häftlinge,} \mathrm{die} \mathrm{,guten}$ Opfer des Faschismus immer geglaubt hatten. Alle, die sich daran orientierten, waren ,anständig', das heißt, sie verhielten sich gemäß der für allgemeingültig erklärten Normen. Verschiedene Bevölkerungsgruppen legten der eigenen Bestimmung von NS-Belastung diese Kategorie des ,Anstands‘ zugrunde; sie ist eine der besonders auffälligen, weil beinahe beliebig nutzbaren Leerformeln, mit denen versucht wurde, die Stoßrichtung der Entnazifizierung zu bestimmen. ${ }^{243}$ Angesichts der wenig eindeutigen Verhältnisse im ,Dritten Reich' und auch in den Konzentrationslagern ${ }^{244}$ zeigt diese schlichte Trennung, daß Warnke nicht auf die Analyse oder ein Verstehen des Verhaltens einzelner in den vergangenen zwölf Jahren abzielte. Ihm ging es vielmehr um die Durchsetzung politischer Interessen, wozu er der gesamten Geschichte vor und seit 1945 das polare antifaschistische Weltbild der KPD überstülpte. Die gesellschaftlich anerkannte Definitionsmacht über gut und böse, anständig und unanständig bot beste Chancen zur Ausrichtung der Entnazifizierung gegen die eigenen Gegner, indem deren Ideologie und Praxis in Kontinuität zum Nazismus gesetzt wurde. Wer sich nicht daran hielt, war nicht mehr Antifaschist, sondern „Schnüffler und Petzer“.245

Am Ende seiner ausführlichen Ansprache auf der Konferenz aller Bürgermeister und Gemeindevorsteher des erweiterten Kreises Güstrow versicherte Warnke dem Kommandanten, „daß alle Männer, wie sie hier sitzen, den ernsten Willen gezeigt haben, daß wir alle faschistischen Kräfte niederkämpfen und uns durchbeißen und durchkämpfen wollen, um ein neues und freies Deutschland aufzubauen “. ${ }^{246} \mathrm{Da}$ in diesem Zusammen-

242 MLHA, MdI 30, BI. 91RS. Warnke unterscheidet hier zwischen den Opfern des Faschismus anhand von politischen Kategorien. In diesem Zusammenhang ging es nicht um das Problem der Betrüger, die an Sozialleistungen für die Opfer des Faschismus (OdF) zu gelangen suchten. Nach einem Telefongespräch mit Warnke vermerkte Oberkirchenrat Arnold Märker dazu am 9. 8. 1945, daß die OdF-Ausschüsse dazu dienten, „die wirklichen Opfer des Faschismus festzustellen, zu rehabilitieren und in das Erwerbsleben wieder einzugliedern“. Es gelte, "die wirklichen Opfer vor solchen Schwindelexistenzen zu schützen" (Landeskirchliches Archiv, Bestand Oberkirchenrat, II 1/O, 1, Nr. 2).

${ }^{243}$ Siehe die unterschiedlichen Interpretationen in den verschiedenen gesellschaftlichen Großgruppen und Regionen: Niethammer, Mitläuferfabrik, S. 611, verortet Anstand z. B. im Kontext der Entnazifizierung in Bayern zwischen „Legalität, berufliche[m] Pflichtbewußtsein, private[r] Gutwilligkeit, politische[r] Passivität ${ }^{\text {" }}$. Eine Differenzierung der verbreiteten (Anti-)NS-Bestimmungen könnten weitere Entnazifizierungsstudien bringen, die sich nicht auf geographische Einheiten, sondern auf Bevölkerungsgruppen und Organisationen (Gewerkschaften, Parteien, Künstler etc.) beziehen; siehe z. B. Bergmann, Erbe; Vollnhals, Kirche.

${ }^{244}$ Niethammer, Antifaschismus.

${ }^{245}$ Warnke, in: MLHA, MdI 30, Bl. 91.

${ }^{246}$ MLHA, MdI 30, Bl. 105. 
hang nicht über Entnazifizierung oder Sequestrierungen gesprochen wurde, war der Ausdruck „alle faschistischen Kräfte niederkämpfen“ ein Synonym für den Aufbau eines friedlichen Deutschlands und die Herrschaft der, anständigen' Antifaschisten. Damit relativierte sich die Notwendigkeit, gegen konkrete Nazis und einzelne NS-Verantwortliche vorzugehen, denn sie waren nunmehr politisch unter Kontrolle. ${ }^{247}$ Dementsprechend wurde bereits früh mit Vehemenz gegen Wirtschaftsvergehen, ,Gerüchtemacher" und sonstige ,Saboteure“ vorgegangen, während Blockwarte, BDM-Führerinnen und Propagandachefs nur selten konkret benannt wurden. ${ }^{248}$ Die Entnazifizierung richtete sich in den ersten Tagen eher zufällig gegen diese Personen, wenn sie in Folge des unterschiedlich großen politischen Eifers der jeweiligen neuen Vorgesetzten, Mitarbeiter, Treuhänder oder Bürgermeister in ihren Betrieben oder Verwaltungseinheiten nicht mehr haltbar waren; die Initiative gegen diese Nazis vor Ort ging also nicht von Oberbürgermeistern oder Landesverwaltung aus, sondern von der Basis.

Rituale statt Erinnerung: Opfer und Täter außerbalb des Blickfelds. Dem Schweigen über die konkreten Täter entsprach das Schweigen über die konkreten Opfer. Symptomatisch ist ein Bericht aus Güstrow vom 12. August 1945 über die Bergung eines Unfallwagens. Im Kofferraum des Wagens waren zufällig Dokumente aus einem $\mathrm{KZ}$ gefunden worden, die den Tod von fast 2000 Menschen benannten: Erhängen, Erschießen etc. Der Bericht erläuterte nicht nur die KZ-Greuel, sondern auch das Erschrecken der Finder über diese Dokumente. Trotzdem endete der Text nicht mit einer Klage über die konkret benennbaren Opfer oder mit der Denunziation der bekannten Täter, sondern mit einem politischen Appell: „Das Volk hat alle Ursache, Abrechnung mit dieser Verbrecherclique zu halten und alle Kraft darein zu setzen, daß niemals eine derartige Zeit wiederkommt. Das geschieht am besten, wenn man dieser faschistischen Gesellschaft den Boden unter den Füßen wegzieht, indem man die Schwerindustrie liquidiert und die Enteignung der Großgrundbesitzer vornimmt. Damit treffen wir den Faschismus an seinen Wurzeln."249 Obwohl der Arzt erwähnt wurde, der die falschen Sterbescheine unterschrieben hatte, und der Bericht über den „Massenmord mit Maschinengewehr“ die Täter beinahe un-

${ }^{247}$ Es sind auch einige Beispiele einer alternativen Wahrnehmung des Faschismus zu verzeichnen: In Stralsund beschlossen beispielsweise Ende Juni 26 Antifaschisten aus unterschiedlichen politischen Gruppierungen, „öffentliche Anklage gegen diejenigen Faschisten“ zu erheben, „die als Mörder in den Konzentrationslagern wirkten [...], die Verbrechen gegen unsere Volksgenossen begingen, insbesondere [...] die sich abscheulicher Brutalitäten bei der Judenverfolgung zuschulden kommen ließen “. Der Stil des öffentlich ausgehängten Aufrufs unterscheidet sich deutlich von den meisten zeitgenössischen Stellungnahmen in der SBZ: Der explizite Verweis auf die Judenverfolgung und die unterlassene Benennung der Opfer aus den Reihen der Arbeiterbewegung sind Zeichen des starken Einflusses nichtkommunistischer Kräfte in diesem Ausschuß. Dem entsprach der Versuch, schon im Sommer 1945 ein selbständiges und mit Deutschen besetztes Gericht in Stralsund zu konstituieren, um NS- und Kriegsverbrechen zu verfolgen (SAPMO-BA, DY 55/VG125, 1, Bl. 45f.; Stadtarchiv Stralsund, Rep 50-12, Bl. 15f., 20).

${ }^{248}$ Beispielhaft waren die von einem Militärtribunal ausgesprochenen Todesurteile wegen Waffenbesitzes oder landwirtschaftlicher Fehlablieferung; siehe Kapitel I.1, S. 24-27.

${ }^{249}$ MLHA, LL KPD I/13. 
mittelbar vor Augen führte, wurde eine politische und nicht eine auf die konkreten Subjekte bezogene Abrechnung gefordert. Sowohl Opfer als auch Täter verschwinden. ${ }^{250}$

Wenn dennoch erinnert wurde, geschah dies eher in ritualisierten Formen der politischen Akklamation. ${ }^{251}$ Es ging nicht um selbstkritische Fragen zur Niederlage der Antifaschisten von 1933, nur selten um die konkreten, in den einzelnen Orten keineswegs namenlosen Opfer und noch weniger um mögliche Schattenseiten oder mit der Verfolgung verbundene Zweifel dieser Menschen. Die Erläuterung des sowjetischen Kommandanten von Güstrow zum Thälmann-Bild im Saal der Bürgermeisterkonferenz zeigt den Charakter der statt dessen gepflegten plakativen Erinnerung: „Ich frage die Bürgermeister, ob sie schon daran gedacht haben, warum Gen[osse] Thälmann hier hängt. Thälmann hat sein Volk und Deutschland über alles geliebt und ist für das Volk gestorben. Er hat bei Stalin gelernt und war sein bester Freund." 252 Vergleichbar der beschränkten Wahrnehmung der KZs durch Warnke, die nicht einmal allen politischen Gefangenen gerecht wurde, wird auch hier schon früh versucht, die Toten vor allem anderen zur Legitimation der neuen politischen Situation zu benutzen. ${ }^{253}$ Weder das Leiden selbst noch dịe durch jahrelange Verfolgung und Haft hervorgerufenen eigenen Deformationen wurden öffentliches Thema. ${ }^{254}$ Es mußte vorangehen. Der Blick zurück diente nur der Stärkung im Engagement, nicht der Irritation.

Das öffentliche Desinteresse an den bekannten und politisch geschätzten Opfern von Juden, Jüdinnen, Homosexuellen, Roma, Zeugen Jehovas etc. ganz zu schweigen beruhte darauf, daß es beim Neuaufbau um das Projekt dieser Verstorbenen, um die Erfüllung ihres Vermächtnisses, gehen sollte: der Neuaufbau als konkrete, praktische Erinnerungsarbeit. Der beschränkte und unpersönliche Umgang mit dem aktiven Antifaschismus bot die Möglichkeit, den kritischen Impuls dieser widerständigen Praxis abzubiegen und damit den Einfluß der Remigranten in der ,demokratisch-zentralistisch organisierten Partei abzusichern, obwohl ihnen die ,natürliche` Autorität einiger Subalterner, die im ,Dritten Reich' gelitten hatten, fehlte. Die Pflege und Erinnerung der Opfer des Faschismus wurde, losgelöst von der konkreten Politik und Herrschaftsausübung, im Rahmen von VVN-und OdF-Organisationen praktiziert. ${ }^{255}$ Der politische Antifa-

${ }^{250}$ Ebenda. Ähnlich klang die Aufforderung des Stadtkommandanten von Güstrow an die Bürgermeister nach einem Hinweis auf ihre Schwierigkeiten während des ,Dritten Reiches': „Doch jetzt haben sie Mut und Kraft, ein neues Leben anzufangen, um das alte und grausame zu vergessen" (MLHA, MdI 30, Bl. 96).

${ }^{251}$ Siehe Kapitel II.3, S. 183-187, über die Kampagne zum Kriegsverbrecherprozeß in Nürnberg.

252 MLHA, MdI 30, B1. 96. Auch die wiederholten Darstellungen und Publikationen über seine Frau Rosa Thälmann und ihre Tochter Irma Thälmann, die im Außenlager Neubrandenburg des KZ Ravensbrück befreit wurde, zeigen immer nur politisch überzeugte Klassenkämpferinnen (Geschichte der Landesparteiorganisation, S. 59, 65f.).

253 Daß dies kein Einzelfall war, zeigen die systematischen Reflexionen in der KPD/SED-Führung über den Umgang mit den ehemaligen Pgs, die sich seit 1945 zur KPD/SED oder einer der anderen neuen Parteien wandten; siehe Kapitel II.3.

${ }^{254}$ Daß die inzwischen öffentlich diskutierte unfreiwillige Beteiligung der „roten Kapos“ an diesen Leiden in der SBZ/DDR nicht thematisiert wurde, ist beinahe eine Selbstverständlichkeit, obwohl sie zumindest einigen Kreisen in der Partei bekannt war (Niethammer, Antifaschismus).

${ }^{255}$ Die früh eingerichteten Organisationen der Opfer des Nazismus setzten historische Kommissionen zur Erforschung von Widerstand und Leiden im ,Dritten Reich' ein, deren Tätigkeit öffentlich unterstützt und während der ganzen Geschichte der DDR fortgesetzt wurde. Im erwei- 
schismus erging sich dagegen in öffentlichen Proklamationen und einer vielfach autoritär durchgesetzten Politik, die durch diese Trennung nicht von alten Kommunisten - von denen sich sowieso einige mit der ihres Erachtens zu gemäßigten KPD-Politik unzufrieden zeigten ${ }^{256}$ - unterbrochen, infrage gestellt oder gar verhindert werden konnte.

Allerdings war die Behandlung der Schuldfrage keineswegs gradlinig. Beispielhaft sind die Ausführungen des Instrukteurs Herbert Hentschke auf einer KPD-Parteiversammlung in Malchin am 12. Juli 1945.257 Er klärte seine neuen Genossen auf, daß das oberste politische Ziel die „Ausmerzung aller jener Kräfte [...], die uns in diesen Krieg und dieses Elend gebracht haben“, sei: „der Nazismus, der preußische Militarismus und der deutsche Imperialismus. “ Diese Aufgabe sei „zu einer Volksaufgabe geworden, an der jede Klasse, jede Schicht und jeder anständige Deutsche" Interesse habe und die daher gemeinsam mit den anderen Parteien durchzuführen sei. Nach diesen eher allgemeinen (bündnis)politischen Ausführungen lokalisierte er die Schuld nicht nur bei „Nazihäuptlinge[n] und Schwerreichen“, sondern auch "sehr tief in fast jedem Deutschen“. Daran schloß er eine Analyse des Herrenmenschentums, des Militarismus und anderer bis zum Zusammenbruch anerkannter Ideologeme im Spiegel von Krieg und ,Drittem Reich' an. ${ }^{258}$ Ähnlich äußerte sich Dahlem auf der KPD-Konferenz in Schwerin am 5. August 1945, wo er auch die eigene KZ-Haft nicht verschwieg: „In Deutschland hat man gewußt, was in den Konzentrationslagern los ist, daß dort hunderttausende Menschen vernichtet werden." 259

Die Frage nach Schuld und Verantwortung wurde entsprechend der Beobachtung Dahlems aber schon im August so gestellt, „daß sie einem zum Halse heraushängt “.260 Indem die KPD, später sogar die ganze DDR, sich die moralische Autorität des Antifa-

terten Kreis Güstrow wurde bereits auf der Bürgermeistersitzung am 14.6. 1945 festgehalten, daß „Ermittlungen anzustellen [sind] über Menschen, die als politische Verbrecher durch das Nazi-System verfolgt sind. Fragebogen hierüber sind ausgegeben und der Gefangenen-Sammelstelle zuzustellen" (MLHA, MdI 30, Bl. 138). Auch einige der bei Niethammer, Antifaschismus, zusammengestellten Dokumente stammen von solchen frühen Untersuchungen über die Verfolgung im ,Dritten Reich', bei denen allerdings nach den weniger heroischen Seiten des Lebens im Konzentrationslager gefragt wurde. Gleichzeitig ist nicht zu vernachlässigen, daß viele Opfer des Faschismus und ihre Angehörigen in der SBZ/DDR großzügige soziale Unterstützung erhielten, obwohl nicht einmal dies der Politisienıng durch die SED entging (Foitzik, Vereinigung; Groehler, Opfergruppen; Groehler, Integration).

${ }_{256}$ Groehler, Opfergruppen, S. 20ff.; Keiderling, Gruppe, S. 34, 97; Schwarzenbach, Kaderpolitik, S. 67.

257 SAPMO-BA, RY 1/13/15, 36, Bl. $70 \mathrm{ff}$.

${ }^{258}$ Die Schulungsmaterialien der KPD zur Analyse des Nazismus gingen neben der Ökonomie auch durchaus differenziert auf Fragen wie Rassismus, Nationalismus, Militarismus und Gehorsamstraditionen ein (siehe SAPMO-BA, RY 1/12/2, 27).

${ }^{259}$ MLHA, LL KPD I/3, Bl. 23.

260 MLHA, LL KPD I/3, Bl. 29. Die Schuldfrage war so wichtig, daß auf der KPD-Sekretariatssitzung am 12. 7. 1945 beschlossen wurde, daß ${ }_{n}$ dem von der KPD den 3 anderen Parteien übermittelten Entwurf" über die Bildung des Parteienblocks nach dem ersten Satz noch die Ergänzung eingefügt werden solle: „Die Kriegsschuld Hitlerdeutschlands ist offenkundig“ (SAPMOBA, RY 1/I2/5, 49, Bl. 14). Siehe den Aufruf vom 14. 7.1945 mit einer ähnlichen Eingangsformulierung in: Suckut, Blockpolitik, S. 64f. Ähnliche Beobachtungen wie die Dahlems über den Unmut, den die Fragen nach Schuld und Verantwortung sowie das Auftreten ehemaliger KZler hervorriefen, finden sich schon bei Kogon, SS-Staat, S. $410 \mathrm{ff}$. 
schismus aneignete, konnten gesellschaftliche Verantwortung und Schuld im Laufe der folgenden Monate anders angesprochen werden, weil die Bevölkerung auf die kritischen Ansprachen der Reisekader unwillig reagierte: „In der Frage der Anerkennung der Mitschuld des deutschen Volkes am Krieg und den Kriegsverbrechen der Hitlerbande bestehen in der großen Mehrheit Unklarheit und direkter Widerstand. Die meisten argumentieren so, daß sie mit der Hitlerbande nicht einverstanden waren, aber nichts machen konnten, da der Terror der Hitlerbande zu stark war. Meistens erklärt man, daß man über die Verbrechen und deren Umfang nichts wußte. Man argumentiert, diese Verbrechen könnten nur von der SS und der Gestapo vollbracht worden sein. Besonders die Frauen sind überzeugt, daß ihre Männer, so etwas nicht machen würden'."261

Dadurch, daß die Frage der NS-Belastung schon bald zur ausschließlich politischen und ökonomischen Systemfrage reduziert wurde, konnte sich die politisch loyale Bevölkerung der SBZ/DDR durch einen Willensakt strukturell auf die Seite der Sieger stellen. Schon in der Blocksitzung am 13./14. Juli 1945 visierte Pieck in seinen privaten Schriften genau diese Richtung an und reflektierte sie im Rahmen der politischen Situation: „Nicht Schuld betonen - auch was von Mitschuld - Volk will das nicht hören [...] Schuld der Nazikreise, nicht Schuld des ganzen Volkes [doppelt unterstrichen] (Mitschuld) [...] Schuld, daß 1918 nicht Konsequenzen." 262 Politisch umgesetzt wurde diese Position in den folgenden Jahren erst, als die meisten ehemaligen NSDAP-Mitglieder bereits entlassen oder mit anderen Sanktionen belegt waren. Dennoch zeigte sich schon früh eine $\mathrm{Hal}-$ tung, die mögliche kritische Impulse aus der konkreten Erinnerung und den Erfahrungen der vergangenen zwölf Jahre durch den fortschrittsgläubigen Blick in die Zukunft abgebogen hatte. Angesichts dieses Umgangs mit den Toten, der wahrscheinlich durchaus im Sinne vieler, vor allem kommunistischer Opfer des Faschismus war, wurde es später auch moralisch und politisch möglich, die konkreten Täter zu decken, mindestens nicht aufzustöbern, sofern sie umgelernt, sich bewährt, sich angepaßt hatten. ${ }^{263}$

\section{Entnazifizierung und Personalpolitik auf Landesebene}

Vor der Rehabilitierung und gesellschaftlichen Reintegration der anpassungsbereiten Pgs ging es aber um die Abrechnung mit dem Faschismus und die von den Alliierten vorgeschriebene Entnazifizierung. Keine politische Gruppierung in der Sowjetischen Besatzungszone lehnte sie ab, so daß nicht ihre generelle Durchführung unklar war, sondern nur der Rahmen, in dem sie stattfinden sollte. Diesen gab die Landesverwaltung in Absprache mit der Besatzungsmacht vor. Er hatte vor allem zwei Seiten: Die weniger bedeutsame bildete das individuelle Verhalten einzelner im ,Dritten Reich“ und beschränkte sich zwischen August und November 1945 auf nur wenige Personen, weil keine Individualüberprüfungen, sondern pauschale Entlassungen durchgeführt wurden. Wichtiger war dagegen das zukunftsorientierte politische und administrative Interesse im (Vize-)Präsidialkollegium, das die ersten Entnazifizierungsaktivitäten der Landesverwaltung der allgemeinen Personalpolitik unterordnete. Dabei bildeten nicht die Ent-

\footnotetext{
${ }^{261}$ „Bericht über unsere Tätigkeit in Greifswald und Rügen in der Zeit vom 15.5. bis 1. 6. 1945“ von Grünberg und Switalla (SAPMO-BA, RY 1/13/15, 34, Bl. 4f.).

262 SAPMO-BA, NY 4036 (NL Pieck), 715, Bl. $72 \mathrm{f}$.

${ }^{263}$ Siehe dazu ausführlich Kapitel II.3.
} 
lassungen selbst den Schwerpunkt, sondern die Frage, wer sie vornehmen und bestimmen dürfe. Erst nachdem diese Auseinandersetzung entschieden war, setzte eine breite Entnazifizierungswelle ein, die dem alten Verwaltungsapparat zahlreiche Entlassungen und noch mehr neues Personal brachte.

Es geht im folgenden also um zwei miteinander verschränkte Prozesse: die Entnazifizierung der staatlichen Verwaltungsdienststellen in Mecklenburg-Vorpommern und die Zuweisung der damit verbundenen personalpolitischen Kompetenzen. Hauptprotagonist ist wiederum der erste Vizepräsident Warnke; dieses Mal tritt er nicht gegen nachgeordnete Funktionsträger auf, zu deren Instruktion er aufgrund seiner Verantwortung für den Verwaltungsaufbau beauftragt war, sondern gegen den einzigen ihm formal übergeordneten mecklenburgischen Landespolitiker: seinen Stellvertreter aus Güstrower Zeiten, Präsident Höcker. Dabei wurde in Mecklenburg-Vorpommern das erste Mal die Tragfähigkeit des in allen Ländern der SBZ realisierten Konzepts getestet, den ersten Posten der Landes- beziehungsweise Provinzialverwaltung mit einem schwachen sozialdemokratischen oder bürgerlichen Politiker zu besetzen und die Kommunisten aus der zweiten Reihe als Vizepräsidenten agieren zu lassen. ${ }^{264}$

\section{Kontinuität und Entlassungen}

Die Personalpolitik war bestimmt durch das Interesse an Funktionalität und politischer Loyalität des Verwaltungsapparates. Es ging um die Entlassung von NS-belastetem Personal und um die Errichtung einer funktionierenden Landes- und Präsidialverwaltung, mit der die umfangreichen politischen Vorhaben durchsetzbar wurden. Das Schwergewicht lag zuerst auf der Besetzung der leitenden Posten der Ministerialbürokratie. Dabei wurden sowohl alte Sozialdemokraten, Kommunisten, Remigranten, Mitglieder des NKFD und andere NS-Gegner als auch Mitglieder der Landesverwaltung eingesetzt, die sich schon im ,Dritten Reich", in der Weimarer Republik und zum Teil im Dienst für den Großherzog bewährt hatten. Das gegenwärtige Parteibuch war keineswegs einziges ausschlaggebendes Kriterium. ${ }^{265}$

Die Entnazifizierung war notwendig, weil die Landesverwaltung mitsamt ihrem Personal nicht neu gegründet wurde, sondern in Kontinuität zu der bisherigen mecklenburgischen Landesregierung stand und deren alte Dienstkräfte teilweise übernahm. In der Bestätigung der Landes- beziehungsweise Provinzialverwaltungen in Mecklenburg, Sachsen und Brandenburg durch Schukow vom 4. Juli $1945^{266}$ wurde ganz selbstverständlich auf das Land „Mecklenburg“ Bezug genommen. Wie Präsident Höcker am 24. Juli 1945 gegenüber der SMAM betonte, war die Kontinuität ausdrücklich gewünscht, denn ihm war „im Hauptquartier des Herrn Marschalls Schukow gesagt worden [...], daß Mecklenburg im Gegensatz zu der Provinz Brandenburg eine Landesverwaltung bekommen solle, weil es früher ein selbständiges Land gewesen sei“ ${ }^{\alpha 267}$ Obwohl

${ }^{264}$ Daß der Erfolg dieser Strategie nicht selbstverständlich war, zeigt der Fall des Landespräsidenten Paul in Thüringen (Braun, Regierungsangelegenheiten; John, Ära; Staritz, Gründung, S. 46f.; Welsh, Thüringen, S. 179).

${ }^{265}$ Siehe Kapitel I.1, S. 38.

$266 \mathrm{Um}$ ein antifaschistisch-demokratisches Deutschland, S. 82f.

${ }^{267}$ MLHA, MinPräs 1255, Bl. 35f. Die Kontinuität wurde dadurch unterstrichen, daß der vorpommersche Teil zuerst nicht im Landesnamen Erwähnung finden sollte; dies gründete auch darin, 
Mecklenburg-Vorpommern ein Zusammenschluß bis dahin unterschiedlicher administrativer und politischer Einheiten war, war der Rückgriff auf das 1934 durch die Zusammenlegung der beiden ehemaligen Großherzogtümer Mecklenburg-Strelitz und Mecklenburg-Schwerin geschaffene Land Mecklenburg offensichtlich. Das vorpommersche Verwaltungszentrum Stettin hatte durch die Übergabe der Stadt an Polen seine Funktion verloren und wurde auch durch die kurzfristige Tätigkeit eines eigenen Beauftragten des Präsidenten für Vorpommern in Greifswald nicht einmal ansatzweise ersetzt. ${ }^{268}$

Die bedingungslose Kapitulation, die Machtübernahme der Alliierten und die territoriale Neuordnung wurden nicht dazu genutzt, wenigstens formal eine vollständig neue Verwaltung zu schaffen, obwohl dies von einzelnen Personen und Verwaltungsabteilungen angenommen wurde. Die Justizabteilung erklärte beispielsweise die Entlassungsverordnung der Abteilung Innere Verwaltung vom 30. August 1945 für überflüssig, da aus dem SMAD-Befehl Nr. 2 vom 10. Juni 1945 hervorgehe, „daß mit dem 5. Juni 1945 die Übernahme der höchsten Autorität auf dem ganzen Territorium Deutschlands durch die Siegerstaaten erfolgt" sei, wodurch „die frühere Reichsregierung und die ihr nachgeordneten Behörden beseitigt worden“ seien. Daraus folgerte die Justizverwaltung, daß „mithin [...] auch die bei den Behörden tätig gewesenen Beamten, Angestellten und Arbeiter entlassen worden“ seien und eine "nochmalige Entlassung dieser Personen durch die Landesverwaltung [...] weder notwendig noch zulässig “ sei. ${ }^{269}$ Diese Ansicht fand keine Mehrheit, so daß durch die Entscheidung über zahlreiche Einzelfälle eine Mischung zwischen Kontinuität und dem weitreichenden politischen Neuordnungswillen austariert werden mußte und die alten Verwaltungsapparate vorerst übernommen waren. ${ }^{270}$ Die Pensionsfrage machte die Kontinuität besonders deutlich: Angesichts der gesellschaftlichen Umbrüche und der damit verbundenen Unübersichtlichkeit und Not war bedeutend, ob und wie staatliche Pensions- und Versorgungsansprüche weitergezahlt würden. Die Verordnung der Landesverwaltung, mit der sie Anfang Juli 1945 vor

die Verbindung zu den nunmehr polnischen Gebieten Pommerns zu schwächen. Am 8. 7. 1945 legte Skossyrew fest, daß „die Sowjetunion erlaubt, ein Land Mecklenburg zu bilden“, dessen Landesverwaltung "sich zunächst Landesverwaltung Mecklenburg-Vorpommern, dann aber nur Mecklenburg“ nenne (MLHA, MinPräs 1309, Bl. 2). Anfang März 1947 veranlaßte SMAMChef Nikolai Iwanowitsch Trufanow, daß,Vorpommern' aus dem Namen des Landes und seiner Verwaltung gestrichen wurde (Höckers Unterschrift vom 1.3.1947 und Trufanows handschriftliche Bestätigung, in: MLHA, MinPräs 1258, Bl. 18f.; siehe auch: Akten und Verhandlungen, Bd. 1 [1. Wahlperiode], Sp. 351ff.). Am gleichen Tag informierte Höcker alle Dienststellen und wies dabei auf die Veranlassung durch Trufanow hin (MLHA, MinPräs 94, Bl. 125). Daher wird in der vorliegenden Arbeit für den Zeitraum seit März 1947 nicht mehr, Mecklenburg-Vorpommern', sondern ,Mecklenburg' geschrieben.

268 Neben dem 1934 geschaffenen Mecklenburg und den vorpommerschen Landkreisen Anklam, Demmin, Franzburg-Barth, Greifswald, Grimmen, Randow, Rügen, Ueckermünde und Usedom-Wollin sowie den vorpommerschen Stadtkreisen Greifswald und Stralsund gehörten auch Teile der ehemaligen preußischen Provinzen Hannover und Schleswig-Holstein zu Mecklenburg-Vorpommern (Kornow, Arbeiterklasse, S. 139; Stettin; Brunner, Verwaltung, S. 1225f.; Fait, Föderalismus, S. 8; Fait, Mecklenburg, S. 103; Fenske, Verwaltung, S. 167-170; Schreckenbach, Bezirksverwaltungen, S. 75f.).

${ }^{269}$ Schreiben vom 5. 9. 1945, handschriftlich korrigiert auf 11. 9. 1945 (MLHA, MinPräs HA Justiz 79). Entsprechend handelte die Justizverwaltung auch: Die rigorose Entlassungsanordnung vom 24. 11.1945 (siehe Kapitel I.2, S. 108 ff.) beantwortete sie noch am selben Tag mit der kurzen Mitteilung, daß diese Anweisung für sie unnötig sei, weil „in der Justiz [...] alle Angehörigen der 
die Bevölkerung trat, ${ }^{271}$ erklärte zwar „alle öffentlichen Rechte und Ansprüche auf Zahlung von Ruhegehältern, Pensionen und Renten“ für aufgehoben; als Begründung wurde aber nicht der Neuanfang angeführt, sondern nur die „gegenwärtige Finanzlage“, wodurch die eigene Verantwortung für die Pensionsansprüche der ehemaligen Staatsangestellten indirekt bestätigt und die Kontinuität unterstrichen wurde. ${ }^{272}$

Die Kontinuität war notwendig, weil die Landesverwaltung mit ihren vier (Vize-)Präsidenten bereits nach kurzer Zeit mit einer außerordentlich ausdifferenzierten Struktur arbeitete, die eine entsprechende Anzahl ausgebildeter Fachkräfte erforderte, um in einem solchen administrativen Rahmen zu agieren: Ende Juli 1945 zählte sie bereits acht Abteilungen mit insgesamt 79 Unterabteilungen; 273 ähnlich differenziert war der Personalbestand von Warnkes Innerer Verwaltung. ${ }^{274}$

Behörden mit der Übernahme der Regierungsgewalt durch die Siegerstaaten ohne weiteres als aus ihren Ämtern entlassen angesehen worden [seien]. Die neu eingestellten Kräfte sind sämtlich nicht ehemalige Mitglieder der NSDAP“ (MLHA, MinPräs HA Justiz 79).

270 Meinickes Feststellung, daß in Brandenburg und Mecklenburg „die Antifaschisten davon aus[gingen], daß der alte Staatsapparat zerschlagen war und an seiner Stelle völlig neue staatliche Organe zu treten hätten“, womit ,jeder Anspruch aktiver Nazis auf Weiterbeschäftigung erloschen" sei, trifft für das nördliche Land nicht zu (Meinicke, Entnazifizierung, S. 971; Meinicke, Entnazifizierung [Diss], S. 11); es stimmt auch nicht, daß der Aufruf des ZK der KPD vom 11. 6. 1945 bereits „die Forderung Lenins nach der restlosen Zerschlagung des alten Staatsapparates“ formuliert habe (Meinicke, Entnazifizierung [Diss], S. XIIf.), da im Aufruf die lokalen ebenso wie die Landes- und Provinzialverwaltungen ausdrücklich anerkannt werden (siehe Punkt 4, 6, 7, in: Erler/Laude/Wilke, Hitler, S. 390-397). Die Kontinuität wurde auch in einem Rundschreiben der Finanzabteilung vom 29. 8. 1945 über Löhne, Gehälter und Trennungsentschädigungen bestätigt: Die vor dem Zusammenbruch gezahlten Löhne und Gehälter seien an alle noch Beschäftigten weiterzuzahlen und „die hiernach für den Monat Juli 1945 noch zu leistenden Nachzahlungen [...] umgebend zu veranlassen" (MLHA, MdI 613). Auch in der Verordnung vom 30. 8. 1945, mit der die Entnazifizierung landesweit vereinheitlicht und forciert wurde, gibt es keinen entsprechenden Hinweis (MLHA, MinPräs 1167; siehe Kapitel I.2, S. 96ff.). Die ähnliche Entnazifizierungsverordnung der sächsischen Landesverwaltung vom 17.8.1945 benennt Bruch und Neuanfang dagegen explizit, wodurch alle Beschäftigungs- und Pensionsansprüche entfielen (Welsh, Wandel, S. 177f.; Fenske, Bürokratie, S. 56).

${ }^{271}$ MLHA, MdI 10, Bl. 13.

${ }^{272}$ Dies fand seinen Niederschlag auch in der weiteren Landespolitik. Die (Vize-)Präsidenten und Ministerialdirektoren erkannten die Versorgungsansprüche der „in den Ruhestand versetzten Beamten und ihre[r] Hinterbliebenen " auch noch am 18. 7.1945 ausdrücklich an und schlossen nur „die aus politischen Gründen bereits beurlaubt[en] oder entlassen[en]“ aus (MLHA, Min. $f$. Soz., 107). Der SMAM-BefehI Nr. 3 vom 24. 7.1945 untersagte zur „höchstmögliche[n] Verringerung des Verwaltungsapparates" jede Gehaltserhöhung und die Auszahlung von Pensionen und anderen Unterstützungen (MLHA, MinPräs 1462, Bl. 8f.). Dem Befehl wurde aber nur unzureichend nachgekommen, so daß Höcker einen Monat später alle Oberbürgermeister und Landräte darauf hinwies, daß alle Pensions- und Unterstützungszahlungen bis zur Neuregelung der Pensionsordnung einzustellen seien; Ausnahmen wurden nur für mittellose Arbeitsunfähige gemacht, die kein Mitglied in der NSDAP oder einer ihrer Gliederungen gewesen waren (MLHA, MinPräs 1024). Die begrenzte Wirkung des SMAM-Befehls und vor allem seine haushaltspolitische Begründung zeugen davon, daß auch die Sowjets von der Kontinuität der Verwaltungsapparate ausgingen.

${ }^{273}$ MLHA, MinPräs 1255, Bl. 25f.; siehe Anmerkung 191 in Kapitel 1.1. Diese acht Abteilungen hatten bereits 302 Dienstkräfte (siehe statistischen Anhang).

${ }^{274}$ MLHA, MdI 343. 


\section{Frühe Entnazifizierung}

Weil durch diese bewußt gewählte und angesichts der sozialen und politischen Aufgaben beinahe unumgängliche personelle Kontinuität nicht alle Dienstkräfte neu eingestellt, sondern viele kollektiv übernommen wurden, war die Überprüfung und Entlassung der NS-Belasteten zwingend. 275 Die Beschreibung des Amtsantritts des Kommunisten Erich Wiesner als Oberbürgermeister von Schwerin zeigt, wie stark die Entnazifizierung mit alten Ressentiments gegen die Verwaltung und ihr überwiegend konservatives Personal vermischt war. Wiesner, der seit 1914 SPD- und seit 1919 KPD-Mitglied war, betonte in seinen Erinnerungen beispielhaft, daß die Entnazifizierung auch zur Abrechnung mit dem von Kommunisten stets als repressiv und herrschaftsstabilisierend erfahrenen Staatsapparat genutzt wurde. „Hier in Schwerin aber war der Verwaltungsapparat völlig intakt, aber was für Menschen wirkten hier! Schon bei einem flüchtigen Rundgang waren mir so etliche Herren mit Schmissen im Gesicht und feisten SS-Visagen, die ich allzugut kennengelernt hatte, aufgefallen. Was sollte ich mit dieser Gesellschaft in einer neuen demokratischen Verwaltung wohl anfangen, so fragte ich mich immer wieder? Rausschmeißen! Das war meine Antwort [...]. Am anderen Morgen begann mein Dienst als Oberbürgermeister damit, daß mir sämtliche Mitarbeiter und Angestellte vorgestellt wurden. [...] Da gab es eine Anzahl ,Beamté, die stammten noch aus der Zeit Wilhelm des II. Nach ihnen brauchte ich nicht lange zu suchen. An ihrem stockkonservativen Gesichtsausdruck waren sie sofort herauszufinden. In all den Jahren der Weimarer Republik hatten sie sich gut gehalten und waren allmählich weiter nach oben geklettert. Schon vor der Machtübernahme durch die Nazis hatten die meisten rechtzeitig ihr Parteibuch gewechselt und nun, wo es auch mit den Nazis zu Ende war, standen sie vor einem leibhaftigen Bolschewisten. Schön ist es nicht, aber auch mit dem wird es irgendwie weitergehen, so las ich in den Gesichtern. “276 Angesichts der bis in den „Gesichtsausdruck“ wahrgenommenen kulturellen und biographischen Differenzen war nicht nur die Entlassung NS-Belasteter, sondern eine generelle Neuorientierung der Administration intendiert. Allerdings wurden weder Kritik noch Neuanfang konkretisiert: Die Kritik richtete sich generell gegen die vom Kaiserreich bis zum ,Dritten Reich“ gepflegte Rechtslastigkeit der Verwaltung, nicht aber gegen ihre Strukturen und Arbeitsweise. Die Gehorsams- und Untertanenmentalität verhöhnte Wiesner zwar angesichts der veränderten Machtverhältnisse, forderte sie in den folgenden Jahren und Monaten aber von den Untergebenen ebenso wie alle seine Parteigenossen. Die wiederholt vorgetragene Kritik am ,Bürokratismus' wurzelte sowohl darin, daß der Neuaufbau zwischen Trümmern und Chaos nur unzureichend vom Schreibtisch aus organisiert werden konnte, als auch im politischen Stil und der Vergangenheit der KPD: in der Klandestinität und konfrontativen politischen Strategie entwickelter Aktionismus und den aufgrund ihrer politischen Marginalisierung in der Weimarer Republik verhinderten Erfahrungen in alltäglicher und administrativer Sacharbeit innerhalb des Staatsapparates. Diese unspezifische ,Bürokratismus'-Kritik hatte zur Folge, daß das alte Verwaltungspersonal seit Septem-

275 Eine Liste der Abwesenheitsgründe der 39 abwesenden der insgesamt 135 „Gefolgschaftsmitglieder" der Abteilung Innere Verwaltung vom Juli 1945 verdeutlicht, daß selbst Soldaten (23), Beurlaubte (6) und sogar Inhaftierte (5) noch zum Personalbestand der Verwaltung gezählt wurden (MLHA, MdI 343).

${ }^{276}$ SAPMO-BA, SGY 30, 1016, Bl. $195 f$. 
ber 1945 rigorosen Überprüfungs- und Entlassungswellen und einer systematischen Unterordnung unter den Herrschaftsanspruch der KPD/SED ausgesetzt war, wodurch der alte und trotz Krieg und Kapitulation noch funktionstüchtige Herrschaftsapparat weitgehend neubesetzt und umgebaut wurde.

Bei der Entnazifizierung kam es zunächst auf die Personen in den zentralen Ämtern, also den Schweriner Zentralbehörden an. Dies entsprach der Priorität auf lokaler Ebene, wo den Nazis zuerst aus den Verwaltungen der Oberbürgermeister und Landräte gekündigt worden war: „Soweit wir Überblick haben, sind in den großen Städten alle Faschisten [...] aus dem Staats- und städtischen Apparat entlassen. “277 Der „bevollmächtigte Vertreter der Landesverwaltung über die Landkreise Anklam, Ückermünde und Randow" berichtete am 2. August 1945, daß der neue Landrat in Ückermünde „als erste seiner Maßnahmen das Landratsamt von allen faschistischen Elementen gesäubert“ habe, ${ }^{278}$ wodurch „die Basis des Landratsamtes [...] schwach und einseitig“ geworden sei, weil den Verwaltungen trotz der Übernahme der alten Strukturen nicht ausreichend politisch und fachlich qualifizierte Arbeitskräfte zur Verfügung standen. Dies lag an der hohen Anzahl von NS-Mitgliedern. Im Schweriner Landratsamt waren am 21. Juli 1945 41 der 117 Beschäftigten (35 Prozent) als NSDAP-Mitglieder erkannt, in der Stadtverwaltung Schwerin sogar fast die Hälfte, 302 von 621 (48,6 Prozent). ${ }^{279}$

Auch auf Landesebene wurde "mit den wichtigsten Positionen und Dienststellen“ begonnen, um „dann den Kreis der Betroffenen systematisch zu erweitern“.280 Die Landesverwaltung suchte die Reichs- und Landesbehörden sowie die lokalen Verwaltungen zu entnazifizieren, die sie aus der Zeit des, Dritten Reiches' und der britischen Besatzung übernommen hatte. Ein undatiertes Mitarbeiterverzeichnis der Landesverwaltung ${ }^{281}$ aus den ersten Tagen nach der Installierung der Landesverwaltung nennt Zahlen über ehemalige und gegenwärtige Parteizugehörigkeiten in den einzelnen Abteilungen: Unter den 314 Dienstkräften gab es noch 113 ehemalige NSDAP-Mitglieder und nur 17 Mitglieder der neuen Parteien, die allerdings sämtlich auf leitenden Posten standen. Die geringe Anzahl von Sozialdemokraten (7), Kommunisten (5) und „Demokraten“ (5) belegt die bereits erwähnte Personalknappheit der alten Parteien, die selbst auf der Ebene der späteren Ministerien nur etwa fünf Prozent des Personals stellen konnten. ${ }^{282}$ In Höckers Hauptabteilung gab es neben dem Präsidenten kein weiteres Mitglied einer Arbeiterpartei, statt dessen aber noch neun ehemalige NSDAPler. Mehrere Wochen später, am 20./21. August 1945, nannte Warnke endgültige Zahlen über die Entlassungen in der Zentralen Landesverwaltung seit dem Abzug der Briten:283 Unter den 371 übernommenen Personen waren 239 Mitglieder der NSDAP, fünf Sozialdemokraten und keine Kommunisten gewesen. Inzwischen seien insgesamt 204 neue Dienstkräfte angestellt,

277 Der erste KPD-Bezirkssekretär aus Pommern, Kollwitz, am 15. 8. 1945 an die KPD-Landesleitung (MLHA, LL KPD I/1a, Bl. 250).

${ }^{278}$ MLHA, LL KPD I/8. Ähnliches berichtete der Landrat des Kreises Güstrow auf der Konferenz der Oberbürgermeister und Landräte am 20./21. 8. 1945 (MLHA, MdI 210b).

279 Bericht der Landesverwaltung vom 21. 7. 1945 (MLHA, MdI 345).

${ }^{280}$ Meinicke, Entnazifizierung (Diss), S. 20. Die Entnazifizierung in konzentrischen Kreisen war auch von den Sowjets intendiert: Die SMAM verlangte z. B. am 17. 8. 1945, „daß die Zentralverwaltung" in drei Tagen „restlos bereinigt ist“ (MLHA, MinPräs 1309, Bl. 35-38). 
von denen kein einziger NSDAP-Mitglied gewesen sei: „68 neue Kräfte aus dem Volk [...], die an der Spitze stehen. 136 sind noch übernommene Beamte". 284

Mitarbeiterverzeichnis der Landesverwaltung Anfang Juli 1945:285

Insgesamt

Hauptverwaltung

Innere Verwaltung

Kultur und Volksbildung

Finanzen, einschl. Bauverwaltung

Landwirtschaft und Forsten

Wirtschaft

Justiz

$\begin{array}{crc}\text { Beschäftigte insgesamt } & \text { Pgs } & \text { Neue Parteimitglieder } \\ 314 & 113 & 17 \\ 42 & 9 & 3 \\ 68 & 21 & 5 \\ 29 & 21 & 4 \\ 98 & 45 & 1 \\ 41 & 16 & 3 \\ 35 & 8 & 1 \\ 1 & 0 & 0\end{array}$

Diese statistischen Angaben enthalten mehrere Unsicherheitsfaktoren. Immer wieder ist zuerst auf die mangelhafte Kontrolle der biographischen Angaben der zahlreichen Ortsfremden hinzuweisen. Eine statistische Beschreibung der Entnazifizierung in den Zentralverwaltungen in Schwerin wird zudem durch die mehrwöchige britische Besatzung der Landeshauptstadt verhindert, weil die ersten Personalwechsel bereits in dieser Zeit stattfanden und die zitierten Statistiken sich nicht auf die Zeit des Faschismus, sondern des Besatzungswechsels beziehen. ${ }^{286}$ Weiterhin erschwert sind alle Angaben durch die tiefgreifenden Veränderungen in den staatlichen Verwaltungsapparaten im ,Dritten Reich': Die NSDAP begrenzte die Kompetenz und Ausstattung der traditionellen Verwaltungsapparate systematisch durch die Errichtung zahlreicher Sonderverwaltungen, und außerdem veränderte sich ihr Personalbestand seit 1939 durch den Kriegsdienst zahlreicher Mitarbeiter. ${ }^{287}$ Außerdem wurden die Entlassungen, Verhaftungen und In-

${ }^{281}$ MLHA, MdI 343; siehe die folgende Statistik.

282 Siehe Kapitel I.1, S. 51-61.

${ }^{283}$ MLHA, MdI 245, Bl. 33f. Dieselben Zahlen auch im Bericht der Landesverwaltung vom 21. 7. 1945 (MLHA, MdI 345). Dort wird angegeben, daß von den 239 Pgs 145 bereits vor 1937 NSDAP-Mitglieder gewesen waren.

${ }^{284}$ Die Landesverwaltung umfaßte am 3. 8. 1945 incl. Fahrer, Putzfrauen etc. etwa 270 Personen (MLHA, MdI 343). In der Personalliste der Präsidialabteilung vom 3. 8. 1945 waren von 23 ausgewiesenen Stellen drei mit N.N. angegeben, niemand war in der NSDAP, aber nur 14 waren seit 1945 beschäftigt; ein Kraftfahrer und zwei Amtsgehilfen waren seit 1920, der Referent Max Suhrbier seit 1932 in ihren Stellungen (MLHA, MinPräs 947, Bl. 11). Die Personalliste der Hausverwaltung vom 4. 8. 1945 zählt von dreißig Stellen (ein Hilfsreferent, sonst Hausmeister, Telefonisten, Elektriker, Wächter, Heizer etc.) zehn als noch unbesetzt auf; auch dort hatte niemand der NSDAP angehört, 13 waren jedoch schon vor 1945 in ihren Stellungen gewesen (MLHA, MinPräs 947, Bl. 12f.). Diese Liste zeugt von der Personalknappheit selbst für weniger spezialisierte Stellen.

${ }^{285}$ MLHA, MdI 343.

${ }^{286}$ Die Bevölkerung wurde erst kurzfristig über den bevorstehenden Besatzungswechsel informiert, wodurch die beteiligten Alliierten umfangreiche Flüchtlingsbewegungen verhinderten (Jürgensen, Gebietsaustausch, S. 126; PRO-WO 171, 4368). Einzelnen Deutschen, besonders wenn sie an hervorgehobener Stelle mit den Alliierten kooperiert hatten, machten die Briten und US-Amerikaner aber Angebote, gemeinsam mit ihnen in den Westen zu gehen; beispielhaft ist das entsprechende Angebot der US-Amerikaner an Hermann Brill (Overesch, Machtergreifung, S. 97; Welsh, Universität, S. 342f.). 
ternierungen der ersten Wochen und Monate statistisch nur unzureichend erfaßt, weil sie häufig spontan und bloß lokal koordiniert durchgeführt wurden und weil die wenigsten lokalen Verantwortungsträger an quantitativen Erhebungen interessiert oder dazu fähig waren. Damit gibt es keinen festen Zeitpunkt für einen Vergleich. Ferner zeigen sich in zahlreichen Statistiken Widersprüche und ungenügende Angaben über ihre Kriterien, weil viele Dienstkräfte trotz des großen administrativen Eifers, der sich in Verordnungen, Berichten, Statistiken und Planungen materialisierte, ungenügend geschult waren. Anscheinend förderte ihre mangelhafte Qualifikation nicht die Bereitschaft, eigene Schwierigkeiten oder sachliche Mängel offenzulegen; statt dessen suchten viele Mitarbeiter dadurch Sicherheit über den Erfolg des eigenen Weges und die Effektivität ihrer Untergebenen zu gewinnen, daß das eigene Handeln immer häufiger in zunehmend umfassenderen und undurchschaubareren monatlichen und wöchentlichen Erfolgsgeschichten und Zahlenkolonnen dokumentiert sein sollte. Darüber hinaus blieb die Informationsbasis häufig bruchstückhaft, weil die Funktionsträger trotz der häufigen Mahnungen aus Schwerin und Berlin anderen Aufgaben als der Berichterstattung Priorität gaben. ${ }^{288}$

Diese Schwierigkeiten weisen auf generelle Probleme einer realistischen Quantifizierung der Entnazifizierung. Die bisherigen Versuche zur Bestimmung der Gesamtzahl der in der SBZ und ihren Ländern Betroffenen enthalten große Unsicherheitsfaktoren und gehen auf politisch motivierte Angaben zurück. ${ }^{289}$ Neben den genannten Unsicherheitsfaktoren ist weiterhin zu beachten, daß die Entnazifizierung in der SBZ im Rahmen größerer Veränderungen betrieben wurde: Auch die Bodenreform und die Sequestrierungen tangierten berufliche Existenzen; und für die Entnazifizierung des öffentlichen Dienstes zeichnete das Personalamt verantwortlich, für das sie im entscheidenden Jahr 1945 nur eine von verschiedenen Aufgaben darstellte, ohne daß die Grenze zwischen der Entnazifizierung und sonstigen Gründen für oder gegen Einstellungen und Entlassungen jeweils exakt zu ziehen war. Hinzu kommt, daß die befristeten Wiedereinstellungen, erneuten Entlassungen, wiederholt negativ beschiedenen Einstellungsgesuche und die unklaren Stellenpläne mitsamt den plan- und außerplanmäßig angestellten Dienstkräften eine seriöse Quantifizierung auf Landes- oder sogar Zonenebene unmöglich machen.

Die zitierten Angaben über die ersten Wochen und Monate entsprechen nur ungenau den seit dem 1. August 1945 monatlich aufgestellten Statistiken des Landespersonalamtes über Anzahl und Parteiangehörigkeit der Dienstkräfte der Landesverwaltung sowie über Entlassungen und noch im Amt befindliche ehemalige NSDAPler. ${ }^{290}$ Danach gab es am 31. Juli 1945 insgesamt 304 Beschäftigte bei den acht Fachabteilungen und im Laufe des Juli 1945227 Entlassungen, wovon 217 wegen der Zugehörigkeit zur NSDAP ausge-

287 Thamer, Verführung, S. 351-383.

${ }^{288}$ Schon früh wurde über die durch das Berichtswesen verursachte Zeitverschwendung und Nutzlosigkeit geklagt. Beispielhaft ist der Schluß eines Berichtes vom November 1945 an den Landrat von Parchim: „Bemerken möchten wir noch, daß die Abteilung Handel und Versorgung Lübz mit der Einreichung von Meldungen aller Art ausreichend beschäftigt ist" (MLHA KPD I/20, Bl. 123f.).

${ }^{289}$ Diesen Hinweis enthält bereits Meinicke, Entnazifizierung (Diss), S. 54f.; siehe auch Badstübner, Geschichte, S. 332ff. Dennoch wird wiederholt die Gesamtzahl von 520000 Entlassenen an- 
sprochen wurden; 39 NSDAPler blieben weiterhin bedienstet. Für den 1. September 1945 wurden insgesamt 341 Beschäftigte festgestellt, von denen noch 37 NSDAPler waren, weil im August nur zwei Personen wegen NSDAP-Mitgliedschaft entlassen worden waren. Im September wurden drei NSDAPler entlassen, während die Anzahl der Bediensteten auf 385 stieg. Da keine NSDAPler eingestellt wurden, sank die Zahl zum 1. Oktober 1945 auf 34. Aufgrund der landesweit vereinheitlichten und forcierten Entnazifizierung sank die Zahl der Pgs in den Fachabteilungen bis Ende November auf zwei, während die Beschäftigtenzahl kontinuierlich anstieg. ${ }^{291}$

Obwohl noch weitere Entlassungen anstanden, wurden schon diese ersten als so umfangreich empfunden, daß sich die Klagen in der Verwaltung häuften, die Aufgaben nicht ohne die Entlassenen erfüllen zu können. ${ }^{292}$ Die Justizabteilung beklagte sich beispielsweise über den „Stillstand“, da Ersatzkräfte „bei den schwierigen Verkehrsverhältnissen [...] von außerhalb nur mit großem Zeitverlust herbeigeholt werden “ könnten und neue Kräfte eine Einarbeitungszeit beanspruchten. ${ }^{293}$ In der Landesbauverwaltung hatte die Entnazifizierung bis Ende Juli nur noch fünf der insgesamt 28 Planstellen besetzt gelassen: ein Ministerialamtmann und vier weibliche Angestellte, deren Dienstbezeichnungen und Qualifikationen nicht genannt wurden, mit denen aber "selbstverständlich der Geschäftsbetrieb nicht aufrecht zu erhalten" war. ${ }^{294}$ Dabei kündigte sich

geführt, die das Neue Deutschland am 21.4. 1948 unmittelbar nach der Auflösung der letzten Entnazifizierungskommissionen veröffentlichte. Nach Zank, Wirtschaft, S. 51f., entließen einige Länder laut Statistik sogar mehr Verwaltungsmitarbeiter, als dort zuvor beschäftigt gewesen waren.

290 Siehe den statistischen Anhang; diese Erhebungen wurden für die Kreise und Städte erst im November 1945 begonnen.

291 Siehe Kapitel I.2, S. 102-111.

292 Es gab auch andere Gründe für Entlassungen als die Entnazifizierung, obwohl sie in der Landesverwaltung quantitativ nicht stark zu Buche schlugen. Beispielsweise verlangte die SMAM wiederholt die Konsolidierung des Haushalts (MLHA, MinPräs 1309, Bl. 5f., 8-11, 20), worauf Höcker wiederholt hinwies, als er von nachgeordneten Behörden forderte, Personalkosten einzusparen; siehe z. B. SMAM-Befehl Nr. 3 vom 24. 7. 1945 (MLHA, MinPräs 1462, Bl. 8f.), eine ähnliche SMAM-Anweisung vom 28.7. 1945 (MLHA, MinPräs 1309, Bl. 20), SMAM-Befehl Nr. 44 vom 3. 11. 1945 (MLHA, MinPräs 1462, Bl. 79f.), Ballerstaedt am 5.10. 1945 an alle Oberbürgermeister, Landräte und Bürgermeister (MLHA, MdI 345) oder Höckers Hinweise bei der Berufung Suhrbiers am 26. 11. 1945 als "persönlichen Referenten in allen das Finanzund Haushaltswesen der Landesverwaltung betreffenden Fragen" (MLHA, MdI bis 1945 20).

293 Justizabteilung am 26. 7. 1945 an Jeß (MLHA, MinPräs HA Justiz 79).

${ }^{294}$ MLHA, MinPräs 1255, Bl. 38ff. Erst seit 1947 gab es innerhalb der Verwaltung verstärkte Anstrengungen, Frauen durch gezielte Qualifizierungsmaßnahmen zur Übernahme von Leitungspositionen fortzubilden (MLHA, MdI 645; MLHA, MdI 656; MLHA, MdI 731; MLHA, MdI 734), obwohl auch zahlreiche der nachrückenden Männer für diese Arbeiten nicht qualifiziert waren. Seit 1945 gab es in der Verwaltung Frauenausschüsse, die allerdings nicht den Abteilungen für Innere Verwaltung, sondern den Kultur- und Volksbildungsabteilungen zugeordnet waren. Dies verdeutlicht bereits ihren geringen Einfluß, den der verantwortliche Vizepräsident Grünberg Ende 1946 gegenüber Oberbürgermeistern und Landräten beklagte: „Der Prozentsatz der in der Verwaltung [...] tätigen Frauen ist ein Gradmesser für den Stand der Demokratisierung des öffentlichen Lebens. [...] Es ist nicht nur das Recht der Frauen, im öffentlichen Leben mitwirken zu dürfen, sondern auch die Pflicht jedes Beamten, den Frauen diese Mitarbeit zu ermöglichen und zu erleichtern“" (MLHA, MinPräs 750). 
bereits die Frage der Spezialisten an, die die ganze Geschichte der Entnazifizierung prägte und immer zwischen politischem Rigorismus und Sachzwängen pendelte. ${ }^{295}$

Die mit den Entlassungen einhergehenden Neueinstellungen begründeten die im folgenden dargestellten Auseinandersetzungen im Präsidialkollegium über die Richtlinienkompetenz in Personalfragen. Entnazifizierung und Personalpolitik waren nicht primär vergangenheitsbezogene Beurteilungen alter Dienstkräfte, sondern der Schlüssel zur Ausrichtung des stark anwachsenden Verwaltungsapparates auf neue Aufgaben. Daher formulierte Warnke klare Anforderungen an die nicht entlassenen Verwaltungsfachkräfte: Sie müßten sich "restlos einfügen in den neuen Geist und in die neue Arbeit " und eine „Bewährungsprobe“ bestehen, um zu sehen, „ob sie nicht nur nicht Mitglieder der NSDAP waren, sondern ob sie auch Antifaschisten sind“". ${ }^{296}$

Daher waren die neu eingerichteten Personalämter zentraler Bestandteil des gesellschaftlichen Eingriffs- und Ordnungsvermögens und die Besetzung ihrer Leitungsposten mit erprobten Kommunisten schon im Exil in der KPD-Verordnung vom 5. April 1945 gefordert worden. ${ }^{297}$ Warnke unterstrich dies bei der Erläuterung des allgemeinen Verwaltungsaufbaus gegenüber Oberbürgermeistern und Landräten und wiederholte dabei die Stereotype über veraltetes und neues Verwaltungshandeln: „Ich nenne dabei das Personalamt als 1. Unterabteilung. Das Personalamt [...] ist nicht einfach eine Stelle, wie es früher war, daß dort die Akten aufgebaut werden, je länger der Beamte da ist, je länger also dicker wird der Stapel Akten und jedes Schreiben, jedes Urlaubsgesuch muß diesen Weg gehen. "298 Vielmehr lenke es die Besetzung aller Stellen in der Verwaltung, wache über die politische Ausrichtung und den Umgang mit politisch Belasteten und kontrolliere den weiteren Berufsweg der im Rahmen der Entnazifizierung bereits Sanktionierten, damit diese nicht an anderer Stelle erneut in den staatlichen Dienst kämen; indirekt formulierte er damit bereits die Unterordnung der gesamten administrativen Arbeit unter den Herrschaftsanspruch der KPD, die den entscheidenden Unterschied zwischen dem traditionellen, von Max Weber beschriebenen, und dem , volksdemokratischen' Typus von Bürokratie ausmachte. Wie weitreichend die damit verbundene Herrschaft sein sollte, zeigte Warnke, als er die Personalämter mit den Arbeitsämtern verglich: „Heute ist das Arbeitsamt die Stelle, wo das ganze Volk registriert ist. Das Arbeitsamt lenkt das ganze arbeitende Volk in der Stadt dahin, wo es gebraucht wird. Wenn wir uns die neuen Aufgaben der Arbeitsämter vorstellen, dann ist das Arbeitsamt für das ganze Volk die zentralste Personalstelle, die überhaupt da ist. "299 Die Zielsetzung war klar: politische Kontrolle und gesellschaftliche Lenkung. Arbeits- und Personalämter boten die Möglichkeit, daß „die Arbeitskräfte [...] nach dort und dort hin geworfen werden“, und näherten sich damit auch der Möglichkeit, jede einzelne berufliche Karriere und jede personelle Veränderung in Betrieben und im öffentlichen Dienst zu kontrollieren, zu ermöglichen oder zu verhindern. ${ }^{300}$

\footnotetext{
${ }^{295}$ Siehe Kapitel I.2, S. 102-111.

${ }_{296}$ MLHA, MdI 245, Bl. $33 \mathrm{f}$.

297 Erler/Laude/Wilke, Hitler, S. 383.

298 MLHA, MdI 245, Bl. 37.

299 Warnke in: MLHA, MdI 245, B1. 39.

300 MLHA, MdI 245, Bl. 39. Zur Umsetzung dieses Bürokratiemodells in Mecklenburg-Vorpommern siehe Kapitel II.1; zur zentralen Rolle, die das Personalamt dabei spielte, siehe Kapitel II.2.
} 
Politische Belastung konnte unterschiedlich sanktioniert werden. Die Abrechnung und Ahndung von NS-Belastung geschah in allen vier Besatzungszonen neben Verhaftungen fast ausschließlich durch Vermögensentzug und Verpflichtungen zum Arbeitseinsatz oder durch Berufsverbote; wiederholt tauchen auch weitere Alternativen auf, wie die Beschränkung des privaten Radio-Gebrauchs, ${ }^{301}$ verstärkte Einquartierungen und Wohnungstausch mit Opfern des Faschismus und Flüchtlingen, ${ }^{302}$ finanzielle Sonderabgaben und politisch erzwungene ,freiwillige' Sach- und Geldspenden; ${ }^{303}$ teilweise wurde auch gefordert, ehemalige NSDAP-Mitglieder gegen Kriegsgefangene auszutauschen. ${ }^{304}$ Die häufigste und selbstverständlichste Form aber waren Eingriffe ins Berufsleben. Damit wurden die Arbeits- und Personalämter zu zentralen Stellen beim Umbau der ostdeutschen Nachkriegsgesellschaft. Während die Arbeitsämter die Besetzung von Leitungsposten in der Wirtschaft mit belasteten Personen zu verhindern hatten, kontrollierten die Personalämter die Einstellungen und Entlassungen im Staatsdienst. Dies war der Beginn einer jahrelangen engen Kooperation zwischen den Arbeitsämtern und den für die Entnazifizierung verantwortlichen und vom Landespersonalamt angeleiteten lokalen Funktionsträgern. Zur besseren Überwachung hatte der Leiter des Landespersonalamtes bei der Abteilung Innere Verwaltung, Paul Lau, bereits Ende August 1945 alle nachgeordneten Dienststellen aufgefordert, die im Zuge der Entnazifizierung Entlassenen den örtlich zuständigen Arbeitsämtern zu melden, ${ }^{305}$ die gemäß dieser gesellschaftspolitischen Rolle, die weit über ihre traditionellen Aufgaben hinausging, von Warnke „in den neuen Verwaltungsapparat eingereiht “ wurden, um Landräten und Bürgermeistern aktive Einflußmöglichkeiten zu gewähren. ${ }^{306}$ Dies stärkte den Trend zur

Die Formulierung Warnkes erinnert an eine ähnliche von Lenin aus den ersten Jahren der Sowjetunion: Es sei das Ziel, Kader „von einem Ende des Landes an das andere zu werfen“ (zitiert nach: Balla, Bürokratische, S. 118). Dies zeigt, daß das Parteikaderprinzip nicht nur auf das Verwaltungspersonal, sondern sogar auf die gesamte arbeitende Bevölkerung übertragen wurde; die Arbeitsämter besaßen das Arbeitsvermittlungsmonopol seit dem 21. 9.1945 (Amtsblatt, Nr. 1 [1946], Bl. 13f.).

301 Siehe den nicht numerierten SMAM-Befehl vom 10. 10. 1945 (MLHA, MfW 587, Bl. 444).

302 Siehe z. B. MLHA, LL KPD I/5, Bl. 211.

${ }^{303}$ „Zu der vorgesehenen freiwilligen Spinnstoffabgabe werden in 1. Linie die ehemaligen Pgs der NSDAP mit herangezogen (AS, SS und NSKK)!“ (Beschluß des Parteienblocks vom 1. 9.1945 in Tessin; MLHA, LL KPD I/22, Bl. 84). Nach einem Bericht vom Februar 1946 an die KPDLandesleitung wurde überall die Forderung laut, daß den Nazis „zum mindestens die Leibwäsche abgenommen und den Flüchtlingen zur Verfügung gestellt" werde (MLHA, LL KPD I/22, Bl. 289). Der Leiter der Finanzabteilung, Gottfried Winckler, kritisierte die Sonderabgaben von Nazis am 27.2. 1946 nim Einvernehmen mit der Abteilung Innere Verwaltung " (MLHA, MinPräs 1446a); ähnlich äußerte sich der Präsident der Deutschen Zentralfinanzverwaltung in der SBZ Anfang Dezember 1946 in einem Runderlaß mit einem Verweis auf einen Brief der SMAD vom 10. 4. 1946 (MLHA, MinPräs 3, Bl. 172f.). Daß der KPD-Landesvorsitzende Bürger die Kreissekretäre demgegenüber auf einer Parteisitzung am 15.12. 1945 ausdrücklich zur Annahme von Pg-Spenden aufforderte (SAPMO-BA, RY 1/I3/15, 36, Bl. 150), zeigt die Distanz der Landesparteiorganisation der KPD vom Alltagsgeschäft der Landesverwaltung.

304 Siehe z. B. ACDP, 07/013, 1000; ACDP, 07/010, 2179, Bl. 70-76.

${ }^{305}$ Die Schreiben gingen am 27. 8. 1945 an die Fachabteilungen und am 30. 8. 1945 an die Landräte, Oberbürgermeister und Bürgermeister (MLHA, MdI 757). Dies diente neben der Verhinderung von Wiederanstellungen auch der Erfassung für den öffentlichen und unbezahlten Arbeitseinsatz als Sühneleistung.

${ }^{306}$ MLHA, MdI 245, Bl. 39. 
funktionalen Entdifferenzierung und institutionellen Fusionierung, indem die Landesabteilung Innere Verwaltung und die ihr nachgeordneten Oberbürgermeister und Landräte sich arbeitsmarktpolitische Eingriffskompetenzen aneigneten, die bis dahin den selbständig organisierten Arbeitsämtern auf Orts- und Landesebene zugestanden hatten. Die Folge war ein Einflußverlust des von Carl Moltmann (SPD) geleiteten Landesarbeitsamts und der vom zweiten Vizepräsidenten Möller (CDU) geleiteten Abteilung Arbeit und Sozialfürsorge zugunsten der Abteilung Innere Verwaltung. Nicht das einzige Mal dienten damit Entnazifizierung und politische Kontrolle dazu, den Kompetenzbereich von Warnkes Abteilung und der auf sie ausgerichteten Kreise und kreisfreien Städte zu erweitern.

Eine ähnliche, aber weiterreichende Entwicklung spielte sich im Landespräsidium ab, dessen Mitglieder sich in den ersten Wochen ihrer Tätigkeit weniger um die konkrete Entnazifizierung ihrer Abteilungen als um den eigenen Einfluß auf die Bestimmung der allgemeinen Entlassungs- und Einstellungsmodi kümmerten. Die Entnazifizierungs-, Entlassungs- und Einstellungskompetenz wurde zur ersten großen Auseinandersetzung an der Spitze der neuen landespolitischen Elite, deren Ausgang für den weiteren Rahmen der , antifaschistisch-demokratischen Umwälzung' bestimmend war. Die Gestaltung der Personalpolitik erlaubte es, die Auswahl des neuen Personals und die Schulung und politische Ausrichtung der neuen ebenso wie der alten, nicht entlassenen Dienstkräfte zu bestimmen. Auf diese Mitarbeiter der staatlichen Verwaltungen waren Landespräsidium, Besatzungsmacht und KPD bei der Durchführung der weiteren Politik angewiesen: Die mit administrativen und politischen Mitteln realisierten Veränderungen des Sozialgefüges der SBZ und DDR basierten auf der Loyalität und Mitarbeit des Verwaltungspersonals, das in den ersten Monaten nach der Kapitulation erneuert und ausgewählt wurde.

Konflikte um die Personalpolitik - Zentralisierung durch die Abteilung Innere Verwaltung

Bereits am 12. Juli 1945, eine Woche nach der Errichtung der Landesverwaltung, forderte die Präsidialabteilung von den Fachabteilungen alle Personalakten, ${ }^{307}$ um die Personalpolitik zu zentralisieren. Verantwortlich dafür war Hans Jeß, der seit dem Besatzungswechsel in Schwerin als versierter Verwaltungsfachmann und enger Berater Hökkers die Präsidialabteilung leitete. Eine weitere Woche später weitete er diese Befugnis auch auf die nachgeordneten Dienststellen aus: „Durch die inzwischen festgestellte Geschäftsverteilung “ ${ }^{308}$ sei „die Bearbeitung der Personalsachen der Präsidialabteilung zugewiesen worden" und jede Entlassung von Beamten und Angestellten von ihm selbst auszusprechen: „Ich bitte deshalb, die [...] Dienstkräfte nicht unmittelbar dort zu entlassen, sondern mir nur Ihr Einverständnis mit den von mir gemachten Vorschlägen mitzuteilen. Die Entlassung werde ich alsdann aussprechen.“ 309 Die Zentrale der Landes-

307 MLHA, MdI 759.

${ }^{308}$ Am 17. 7. 1945 wurde die Aufgabenverteilung innerhalb der Landesverwaltung entschieden (MLHA, MdI 343).

309 MLHA, MdI 751, Bl. 191. Die Fachabteilungen informierte Höcker am 19.7. 1945 (MLHA, MinPräs 947, Bl. 3) über die Veränderung des Einstellungs- und Entlassungsverfahrens durch die Festlegung der Geschäftsverteilung in der Landesverwaltung vom 17. 7. 1945 (MLHA, MinPräs 1255, Bl. 25f.). 
verwaltung zog die alleinige Entscheidungsgewalt über den Personalbestand an sich: Über Einstellungen und Entlassungen im staatlichen Dienst sollte allein in der Präsidialabteilung entschieden werden. Daß sie tatsächlich entsprechend verfuhr und die Anzahl und Namen der zu Entlassenden bestimmte, zeigt eine Anweisung Höckers vom 13. Juli 1945 an Warnke, ${ }^{310}$ neben den $z$ wanzig schon entlassenen Beamten seiner Abteilung fünf weitere „in den Ruhestand zu versetzen“, wobei sich die Partizipation der Abteilung auf eine einwöchige Berufungsfrist beschränkte.

Allerdings beabsichtigte das Präsidialamt keineswegs, sich in jede einzelne Entlassung und Einstellung einzumischen. Der zitierten Entlassungsliste an Warnkes Abteilung fügte Höcker abschließend die Bitte hinzu, Warnke möge „von sich aus eine Überprüfung des weiblichen Personals der Ihnen unterstehenden Dienststellen" vornehmen. Die Initiative für diese Entlassungen wurde der nachgeordneten Stelle anvertraut, obwohl dasselbe Schreiben festlegte, daß dies jenseits ihres Kompetenzbereichs lag: Frauen besetzten keine führenden Positionen, und die neue Landesregierung unterstellte ihnen anscheinend eine generelle politische Harmlosigkeit, so daß ihre Entnazifizierung als nebensächliches und daher delegierbares politisches Anliegen bewertet wurde. ${ }^{311}$

Schon am 19. Juli 1945 meldete Jeß den ersten Erfolg, der den von Meinicke genannten hierarchischen Entnazifizierungsablauf bestätigt: Die „Entfernung der aus politischen Gründen nicht tragbaren Dienstkräfte aus der Zentralverwaltung [ist] im wesentlichen durchgeführt" ${ }^{312}$ Nunmehr sei "die gleiche Maßnahme" bei allen nachgeordneten und bei den früheren Reichsverwaltungen „so schnell wie möglich in Angriff“" zu nehmen. Die Dienststellen ersuchte er innerhalb weniger Tage „mit möglichster Beschleunigung "um die Entlassung der Belasteten und um Aufstellungen aller bereits Entlassenen, aller aufgrund dieses Schreibens Entlassenen und aller verbleibenden Dienstkräfte. ${ }^{313}$ Die über Entlassung oder Weiterbeschäftigung entscheidenden Kriterien wurden nicht weiter erläutert. Nichts weist darauf hin, daß jeder einzelne Fall in der Präsidialabteilung entschieden wurde; die meisten Dokumente lassen ebenso wie der oben zitierte Briefwechsel der Landesbauverwaltung ${ }^{314}$ vielmehr vermuten, daß vor allem NSDAP-Mitglieder betroffen waren: Dieses Kriterium scheint so selbstverständlich gewesen zu sein, daß es weder schriftlich festgehalten noch erörtert wurde.

${ }^{310}$ MLHA, MdI 751, Bl. 192.

311 Warnke teilte am 20.7.1945 auf der Rückseite des Papiers den Vollzug der Entlassungen mit und schlug zwei Frauen zur Entlassung vor, da sie schon seit Februar bzw. März 1932 NSDAP-Mitglieder waren (MLHA, MdI 751, Bl. 192R).

312 MLHA, MdI 751, Bl. 193. So wie es sich noch einige Male wiederholen würde, war diese Erfolgsmeldung voreilig gewesen, da die Überprüfung des Personals und der Versuch, einen personalpolitischen Überblick zu gewinnen, sich erheblich schwieriger gestalteten als erwartet.

${ }^{313}$ Damit begann die noch häufig angeforderte Erstellung von entnazifizierungsbezogenen Personenlisten, die vor allem Dienststellenleitern und Mitarbeitern die Kontroll- und Zugriffsmöglichkeit der Schweriner Zentralverwaltung demonstrierte. Mit der Erstellung solcher Listen waren sämtliche Behörden beschäftigt; siehe z. B. die Anweisung der Landeswohlfahrtsabteilung vom 20. 7. 1945 an die Versorgungsämter in Rostock und Schwerin (MLHA, MdI 751, B1. 189f.). $\mathrm{Da}$ es sich dabei nicht nur um eine Informationserhebung, sondern auch um ein mit Disziplinierung verbundenes Ritual handelte, zeigen vor allem die von jedem Mitarbeiter handschriftlich zu unterzeichnenden Listen, die seit dem Sommer 1946 angefordert wurden, obwohl die Entnazifizierung bereits für beendet erklärt worden war; siehe Kapitel III.

${ }^{314}$ MLHA, MinPräs 1255, Bl. 38ff. 
Nach den KPD-Richtlinien vom 5. April 1945 sollte die Personalpolitik in den Händen eines bewährten Genossen liegen. ${ }^{315} \mathrm{Daß}$ nicht Warnke, sondern der Präsidialabteilung bei der ersten Geschäftsverteilung der Landesverwaltung am 17. Juli 1945 das Aufgabengebiet „Personalien der Landesverwaltung“ zugeordnet wurde, ${ }^{316}$ zeigt, daß nicht jede Anweisung der Partei tatsächlich realisiert wurde. Höcker schien zu Beginn seiner präsidialen Tätigkeit ein eigenständiges Gewicht beim administrativen Neuaufbau zu suchen und Warnkes Übermacht einzugrenzen, der sich die meisten zentralen Ressorts (wie Polizei, Enteignungsrecht, Wahlen, landrätliche Verwaltung) gesichert hatte. Während Warnke für den Verwaltungsaufbau in den Kreisen und Städten verantwortlich zeichnete, unterstand Höcker der Aufbau der Zentralverwaltungen in Schwerin, die auch entscheidenden Einfluß auf die parallel aufgebauten Fachressorts in den Kreisen und Städten hatten. Dies suchte Warnke bald rückgängig zu machen.

Höckers aktiv gestaltete Personalpolitik zeigt, daß auch er Interesse an ihr hatte: Am 19. und 20. Juli $1945^{317}$ informierte die Präsidialabteilung alle Fachabteilungen von ihrer Kompetenz bei Entlassungen und Einstellungen, und wenig später nutzte Höcker eine Anfrage der SMAM dazu, sich in der gleichen Angelegenheit per Fernspruch an alle Landräte und Bürgermeister zu wenden. ${ }^{318}$ Die Verschiebung der gesamten personalpolitischen Zuständigkeit Anfang August an Warnke zeigt, daß es eine Auseinandersetzung zwischen dem Präsidenten und seinem ersten Vizepräsidenten gab. Warnke bemühte sich, den vollständigen Einfluß auf die umfangreichen personellen Wechsel zu gewinnen. Der Konflikt wurde zum Monatswechsel gegen die im präsidialen Kollegium am 17. Juli 1945 festgelegte Ressortverteilung zugunsten von Warnke entschieden. Obwohl Höcker die Geschäftsverteilung anläßlich von Kompetenzauseinandersetzungen anderer Ressorts noch am 30. Juli $1945^{319}$ für „endgültig festgestellt und im Anschluß daran allen Fachabteilungen als verbindlich mitgeteilt" hatte, wodurch „eine abermalige Änderung der Geschäftsverteilung [...] nicht vertretbar" sei, teilte er selbst zwei Tage später eine gravierende Veränderung mit: „Das Personalreferat wird mit dem heutigen Tage der Abteilung Inneres angegliedert. Die Überprüfung des Personals, die Notwendigkeit der Weiterbeschäftigung sowie die Neueinstellungen und Entlassungen werden von dem Vizepräsidenten Warnke durchgeführt. Anträge der Abteilungen gehen also zukünftig an die Abteilung Inneres. Die Einstellung und Entlassung selbst behalte ich mir in jedem Falle vor, d. h., daß Entlassungsschreiben und Einstellungsurkunden durch den Vizepräsidenten Warnke verantwortlich zu zeichnen und mir zur Unterschrift vorzulegen sind. “ 320

${ }^{315}$ Erler/Laude/Wilke, Hitler, S. 383.

316 MLHA, MinPräs 1255, Bl. 25f.

317 MLHA, MinPräs 947, Bl. 3; MLHA, MdI 751, Bl. 191.

${ }^{318}$ MLHA, MdI 733; MLHA, MinPräs 1309, Bl. 16. Auch am 24. 7. 1945 betonte er gegenüber den Fachabteilungen, daß nur er persönlich Beamte ernennen und in den Ruhestand versetzen könne; daß nicht entsprechend verfahren wurde, zeigt die Forderung vom gleichen Tag, seine Zustimmung „bei der Bestellung leitender Beamter nachgeordneter Behörden [...] vor ihrer Ernennung" einzuholen (MdI bis 1945 20).

${ }^{319}$ MLHA, MinPräs $1255, \mathrm{Bl}$. 28. In den ersten Wochen der Landesverwaltung traten wiederholt Schwierigkeiten bei der Koordination und bei Absprachen zwischen einzelnen Behörden auf; siehe beispielhaft aus Bereichen wie Kultur, Finanzen, Wirtschaft, Bauabteilung, Stiftungssachen: MLHA, MinPräs 1255, Bl. 27-40. 
Wann, wo und von wem diese Entscheidung gefällt wurde, ist archivalisch nicht rekonstruierbar; da es sich dabei um einen eindeutigen Verstoß gegen vorherige präsidiale Absprachen handelt, ist eine Intervention der Kommandantur zu vermuten. ${ }^{321}$ Das entspricht der grundsätzlichen Bevorzugung der Kommunisten durch die Besatzungsmacht, die sich nicht nur auf die Parteiorganisation, sondern auch auf zahlreiche Einzelentscheidungen bezog; die von Overesch dargestellten Umstände über die Absetzung Brills am 10./11. Juli 1945, bei denen die Besatzungsmacht erst nach der Intervention von führenden deutschen kommunistischen Remigranten aktiv wurde, läßt auch hier konspirative Entscheidungswege vermuten. ${ }^{322}$ Warnke war der bevorzugte Partner der Sowjets in Mecklenburg-Vorpommern. In der deutsch-sowjetischen Doppelstruktur im Lande verantwortete und beherrschte er den Aufbau und die Funktionstüchtigkeit des neuen deutschen Verwaltungsstabes, der im Laufe der Jahre mit seiner zunehmenden Ausrichtung auf die SED auch immer mehr diejenigen Kompetenzen übernahm, die bei Kriegsende auf die sowjetischen Kommandanturen übergegangen waren.

Dieser Konflikt um die Personalpolitik dient nicht zur Erhellung des deutsch-sowjetischen Verhältnisses in Mecklenburg-Vorpommern. Für die innerpräsidiale Arbeitsund Kompetenzverteilung ist er dagegen von struktureller, über die Personalpolitik hinausgehender Bedeutung. In der Auseinandersetzung bewies Höcker das erste Mal seine Nachgiebigkeit, die ihn zu einem Präsidenten machte, unter dessen Namen Warnke als Vertreter der KPD weitgehend ungestört agieren konnte. ${ }^{323}$ Der Präsident entsprach der von Moltmann 1947 aufgestellten "Charakteristik", in der er nicht nur als Person vorgestellt wurde, „die repräsentieren kann, [...] ein geschickter Verhandlungsleiter [ist] und [...] gut in jeder Gesellschaft auftrete“, sondern auch als Politiker, der „sich leicht beeinflussen“ lasse, was zu „einige[n] Schwankungen" führe. ${ }^{324}$ Die in der gesamten Zone angewandte Strategie der Kommunisten, den Eindruck einer nur von ihnen bestimmten Politik durch die Besetzung hochrangiger Posten mit Sozialdemokraten und Bürgerli-

${ }^{320}$ MLHA, MinPräs 1309, Bl. 21.

${ }^{321} \mathrm{Da}$ Höcker Sozialdemokrat war, ist eine entscheidende Einflußnahme des ZK oder der Landesleitung der KPD - anders als beim Wechsel der Leitung im Personalamt Ende 1945 (siehe Kapitel II.2, S. 155ff.) - auszuschließen. Die deutschen Quellen geben diesbezüglich keine weitere Auskunft.

322 Overesch, Machtergreifung, S. 98-101.

${ }^{323}$ Höckers Rolle als einflußloser Präsident bedarf weiterer Untersuchungen anhand anderer Politikfelder. Die Handakten Höckers geben diesbezüglich keine konkrete Auskunft, und leider ist kein privater Nachlaß vorhanden; siehe weitere Konflikte in Kapitel II.2, S. 155-167.

324 Beispielsweise habe er sich erst dann klar für die Bodenreform entschieden, als sie schon „in vollem Schwung war". Bei der SED-Gründung habe er "nicht aus Gegnerschaft der Einheit" geschwankt, sondern „weil er sich leicht von ehemaligen Freunden (Jesse, A. Schulz) beeinflussen ließ“; „erst durch den Schwung“ sei er zum „begeisterte[n] Kämpfer der SED“ geworden. Als langjähriger SPD-Linker sei er durch seine effektive politische Arbeit in der Weimarer Republik „etwas von seiner Verbindung zur Arbeiterschaft abgekommen“, wohingegen „die Bürgerlichen [...] seine ,Geschicklichkeit" " geachtet und gelobt hätten. Wie zum Ausgleich dieses negativen Bildes hatte Höckers alter Parteifreund „aber keinen Zweifel“ an seiner Ehrlichkeit und versicherte, daß er sich inzwischen "keineswegs mehr an seine ehemaligen Freunde in der SPD" halte (SAPMO-BA, NY 4090 [NL Grotewohl], 303, Bl. 17f.). Ähnlich berichtete Warnke auf der KPD-Konferenz Anfang Januar 1946 in Berlin über Höckers Rolle bei der Bodenreform: „Selbst den Präsidenten [haben wir] hineingejagt, damit er von der Bewegung mitgerissen wurde. Er mußte einige Aufteilungen mit durchführen" (SAPMO-BA, RY 1/12/2, 17, Bl. 44). 
chen abzuschwächen und dennoch nicht an Handlungsspielraum zu verlieren, bewährte sich hier.

Die auf lokaler Ebene gleichermaßen praktizierte Politik der KPD, die nominell ersten Posten mit schwachen nichtkommunistischen Personen zu besetzen, war der allgemeine Hintergrund der Auseinandersetzung. In diesem Kontext bildeten die zentrale Stellung und der große Einfluß von Hans Jeß in der Präsidialabteilung ein unübersehbares Problem. Er arbeitete seit 1919 kontinuierlich in der öffentlichen Verwaltung in Mecklenburg, war während der britischen Besatzung Regierungschef gewesen, wurde daraufhin enger Mitarbeiter Höckers und war seit 1948 Polizeipräsident in Frankfurt a.M. und ab 1952 Leiter des Bundeskriminalamtes. ${ }^{325}$ Seinem großen verwaltungstechnischen Können entsprach anscheinend die ähnlich ausgebildete Fähigkeit, sich in wechselnden politischen Systemen zurechtzufinden. Er konnte von der neuen Landesverwaltung bruchlos übernommen werden, da er niemals Mitglied der NSDAP gewesen war. Ähnlich wie anderen leitenden und subalternen Dienstkräften der Landesverwaltung wurde ihm die Möglichkeit gegeben, sich innerhalb der kommunistisch dominierten Verwaltung einzugliedern und dieser damit ihr Funktionieren zu sichern. Allerdings beschränkte er seine Aktivität nicht auf ein unauffälliges Maß wie andere leitende Verwaltungsmitarbeiter wie Suhrbier und Lobedanz, die später führende politische Posten in Mecklenburg und in der DDR einnehmen konnten. Als rechte Hand Höckers engagierte sich Jeß vielmehr vehement und zielbewußt; dabei schätzte er das Ausmaß der Hegemonie von Besatzungsmacht und KPD, die geringe Bedeutung der Präsidialabteilung und seinen eigenen Einfluß falsch ein.

Seine Arbeit für Höcker und sein großes Engagement in der Personalpolitik gefährdeten die Strategie, alle ersten Ämter der fünf Provinzial- und Landesverwaltungen in der SBZ durch ihre Besetzung mit schwachen Personen weitgehend einflußlos zu halten. Daß es Jeß sogar um mehr als die Personalkompetenz ging, nämlich um einen leitenden Einfluß der Präsidialabteilung auf die gesamte Landespolitik, zeigt sein Schreiben vom 12. Juli 1945 an die Fachabteilungen, mit dem er den Zugang zur Besatzungsmacht in der Präsidialabteilung zu monopolisieren suchte: „Die für den Verkehr mit den russischen Dienststellen erforderlichen Dolmetscher und Übersetzer sollen nicht von jeder Fachabteilung für ihren Geschäftsbereich, sondern einheitlich von der Präsidialabteilung eingestellt werden. Ich habe bereits verschiedene Kräfte für diesen Zweck in Aussicht genommen. " ${ }^{326}$ Sein mit verwaltungstechnischem Sachverstand gepaarter Ehrgeiz war im Dienste des Sozialdemokraten Höcker nicht genehm. Ende Juli, wenige Tage bevor Warnke die Zentralisierung sämtlicher Personalangelegenheiten in seinen Händen durchsetzen konnte, wurde Jeß von seinem Posten entfernt. Höcker selbst schlug der SMAM den „energische[n] und tüchtige[n] Verwaltungsbeamte[n]“ am 24. Juli 1945 als Reichsbahnpräsidenten von Schwerin vor, obwohl er „durch sein evtl. Fortgehen einen Beamten verlieren [werde], der mir und dem Lande bestimmt gute Dienste hätte leisten können". 327

${ }^{325}$ Staatshandbuch 1938, S. 7, 12, 149; Staatshandbuch 1939, S. 7; Broszat/Weber, SBZ-Handbuch, S. 940.

326 MLHA, MdI bis 194520.

${ }^{327}$ MLHA, MdI 758. Höckers Bedauern läßt ihn bei dieser Entscheidung nicht als initiative Kraft erscheinen; die Rolle von KPD und Besatzungsmacht ist aber wiederum nirgends archivalisch 
Trotz der Verfügung, daß die entscheidende Unterschrift unter Einstellungs- und Entlassungsschreiben ihm noch vorbehalten sei, war der Machtverlust Höckers unabweisbar: Warnkes Abteilung hatte für alle Personalentscheidungen die Informationen vorzubereiten und konnte sich dadurch nicht nur ein umfangreiches Wissen über Personalia erwerben, sondern gewann gleichzeitig die Möglichkeit, Höckers Entscheidungen durch gezielte Informationen oder deren Vorenthaltung mitzubestimmen. ${ }^{328}$ Höcker wußte um die Brisanz dieser Verfügung, so daß er in ihr gleichzeitig einen intensiveren und verbindlicheren Informationsaustausch zwischen ihm und seinen Stellvertretern anmahnte: „Da ich als Präsident [...] für alle Maßnahmen der Landesverwaltung verantwortlich bin und die Militärische Administration von mir Auskünfte aus allen Abteilungen verlangt, muß ich erwarten, daß ich auch über alle wichtigen Angelegenheiten informiert werde bzw. daß meine Zustimmung eingeholt wird!“329 Diese Minimalanforderung an Transparenz und Kommunikation klagte Höcker in den folgenden Jahren immer wieder ein: ${ }^{330}$ ein Zeichen seiner Schwäche im eigenen Verwaltungsapparat und in seiner Führungsgruppe. Daß die erste dieser Aufforderungen im Kontext der Aneignung der personalpolitischen Kompetenzen durch Warnke steht, zeigt den Präzedenzcharakter der Auseinandersetzung für die weitere Zusammenarbeit zwischen dem Präsidenten und seinem ersten Stellvertreter. Schon zwei Wochen nach der Veränderung des Einstellungs- und Entlassungsverfahrens suchte die Präsidialabteilung die konkrete Einflußnahme Höckers auf die Besetzung leitender Stellen formal abzusichern. In einem Schreiben vom 16. August 1945 wurden die Fachabteilungen instruiert, ${ }^{331}$ daß Höcker

nachweisbar. Nachdem sich Jeß so energisch für Personalangelegenheiten eingesetzt hatte, brachte ihn die Versetzung an die richtige Stelle: Höcker begründete seinen Vorschlag gegenüber der SMAM damit, daß der bisherige Präsident der Reichsbahndirektion „in Bezug auf die Bereinigung der Verwaltung bisher nichts unternommen" habe. Das "Antifaschistische Eisenbahnerkomitee Rostock und Schwerin" hatte ihm am 15.7.1945 mitgeteilt, daß "fast die gesamte Direktion aus ehemaligen Parteigenossen“ bestehe (MLHA, MdI 758).

${ }^{328}$ Am 3. 8. 1945 teilte Höcker allen Fachabteilungen den Übergang der personalpolitischen Kompetenzen an die Abteilung Innere Verwaltung mit. Darin hieß es, daß die Abteilungen alle Vorlagen in Personalsachen an Warnkes Haus zu schicken hätten, von dem ihm die Ernennungs- und Entlassungsurkunden nur noch vorgelegt würden. Damit verlor er fast jede Möglichkeit, sich personalpolitisch differenzierter als durch Zustimmung oder Veto zu artikulieren (MLHA, MinPräs 947, Bl. 14). Am 21. 8. 1945 legte Warnke in einer Verordnung fest, wie die Einstellungs- und Entlassungskompetenzen zwischen Höcker und seiner Abteilung verteilt und welche organisatorischen Schritte bei allen Personalveränderungen einzuhalten waren. Der Abteilung Innere Verwaltung waren für jede Einstellung sämtliche Personalunterlagen, eine Stellungnahme über die geplante Verwendung und Eingruppierung sowie eine fachliche und charakterliche Beurteilung einzureichen. Dieses Kontrollrecht kam einem Vetorecht gleich und reduzierte die präsidiale Befugnis zu einem bloß formalen Einstellungsakt (MLHA, MinPräs 947, Bl. 16).

${ }^{329}$ MLHA, MinPräs 1309, Bl. 21. Höckers Schreiben vom 15. 9. 1945 an Warnke wegen einer sowjetischen Anfrage über das Entnazifizierungsverfahren zeigt, wie schnell er die Kenntnis über und damit den Einfluß auf das Entnazifizierungsverfahren verloren hat (MLHA, MinPräs 1484, Bl. 98).

${ }^{330}$ Bereits vier Wochen später, am 29. 8. 1945, forderte er von den Fachabteilungen, daß ihm alle sowjetischen Befehle und alle schriftlichen Berichte aufgrund solcher Befehle vorzulegen seien, weil er "heute wiederum [habe] feststellen müssen, daß Befehle der militärischen Administration. nicht zu meiner Kenntnis gelangt sind. Ich konnte deshalb auch keine Auskunft über diesen mir unbekannten Befehl erteilen" (MLHA, MdI 345; siehe auch: MLHA, MdI 593; MLHA, MdI 651; MLHA, MdI 60, Bl. 243). 
die „Möglichkeit“ haben müsse, „die einzustellenden Personen kennenzulernen, ehe er die Urkunde über ihre Einstellung vollzieht “. Aufgrund der großen Anzahl Angestellter verzichtete Höcker auf die Vorstellung aller Einzustellenden und verpflichtete die Abteilungsleiter, nur „die zur Einstellung als Referenten in Aussicht genommenen Personen, bevor die Urkunde über ihre Einstellung dem Herrn Präsidenten zur Vollziehung vorgelegt wird, ihm zuzuführen und ihm persönlich bekannt zu machen“. Deutlicher konnte Höckers Abteilung den eigenen Machtverlust nicht formulieren. Trotz der Zusicherung seiner letztinstanzlichen Entscheidungsgewalt durch die Unterschriftsvollmacht verlor Höcker schon sechs Wochen nach der Übernahme der Präsidentschaft den Einfluß auf die Besetzung der leitenden Stellen seiner Verwaltung.

\section{Vereinbeitlichung und Abschluß der Entnazifizierung}

Nachdem die Landesverwaltung gegründet war, alle für die gesellschaftliche Umgestaltung zentralen Politikbereiche unter der Kontrolle von Warnke standen und die meisten Mitglieder der NSDAP aus den Zentralverwaltungen in Schwerin entlassen waren, begann die Landesverwaltung, die Entnazifizierung in allen staatlichen Behörden Mecklenburg-Vorpommerns zu vereinheitlichen. Inzwischen waren vom Parteienblock in Berlin und von den Alliierten Bestimmungen erlassen worden, die für die gesamte Zone beziehungsweise für ganz Deutschland Gültigkeit beanspruchten. In der SBZ blieb die konkrete Durchführung aber in der Verantwortung der Landes- und Provinzverwaltungen, in Schwerin in den Händen von Warnke. Daher wirft die Relevanz dieser länderübergreifenden Regelungsversuche ein Licht auf die Bedeutung der föderalen Spielräume in der frühen SBZ und lädt zum Vergleich zwischen den Ländern und Provinzen ein.

Gleichstellung nomineller und aktiver Parteigenossen

Ende August erließ Warnkes Abteilung Innere Verwaltung eine Entnazifizierungsverordnung, um die Überprüfungen und Entlassungen in allen Behörden im ganzen Land $z u$ vereinheitlichen und gleichzeitig zu forcieren. Zur gleichen Zeit begannen in Mecklenburg-Vorpommern auch zwei weitere Prozesse, mit denen die gesellschaftliche Umgestaltung vorangetrieben wurde: Während des Monatswechsels zum September erließ die Landesverwaltung mehrere Verordnungen, mit denen sie die Sequestrierungs- und Enteignungspolitik zu vereinheitlichen trachtete, weil sowohl die antifaschistisch als auch die sozialpolitisch begründeten Beschlagnahmungen nicht mehr ins Belieben lokaler Funktionsträger gestellt sein sollten, sondern nach landesweit verbindlichen Regeln vollzogen werden sollten. ${ }^{332}$ Außerdem riefen die im Landesblock organisierten

\footnotetext{
331 MLHA, MdI 759.

332 Verordnung vom 29. 8. 1945 über „die Inanspruchnahme von Wohnraum und Gebrauchsgegenständen durch die Gemeinden“ (MLHA, MinPräs 183); Verfügung vom 30. 8. 1945 über „die Beschlagnahme von privaten Grundstücken für die Zwecke des Landes und der Gemeinden“ (MLHA, MinPräs 183); Verordnung vom 30. 8. 1945 über „die Beschlagnahme von Gegenständen für die Rote Armee“ (MLHA, MinPräs 1289, Bl. 24); Verordnung Nr. 12a über „Politische Bereinigung der Wirtschaft" mit Ergänzungen am 15. 9. 1945 und 29. 10. 1945 (Amtsblatt, Nr. 1 [1946], S. 4f.); Verordnung vom 30. 8. 1945 über „die Beschlagnahme von Vermögen der frühe-
} 
Parteien und Massenorganisationen (SPD, KPD, CDU, Kulturbund und FDGB) am 3. September $1945^{333}$ die Bodenreform aus, durch die in wenigen Wochen fast die Hälfte der landwirtschaftlichen Nutzfläche Mecklenburg-Vorpommerns enteignet, parzelliert und verteilt wurde.

Während die Landesverwaltung zur Durchführung der Sequestrierungen und der Bodenreform auf zahlreiche Ehrenamtliche und Mitglieder der neuen Parteien unter Anleitung der Oberbürgermeister, Landräte und Bürgermeister zurückgriff, wurde die Entnazifizierung von der Abteilung Innere Verwaltung und ihrem Personalamt organisiert und durchgeführt. Damit stand für alle drei Prozesse ein weitgehend kontrolliertes Personal zur Verfügung: Die lokalen Funktionsträger unterstanden bereits der Weisungskompetenz der Abteilung Innere Verwaltung, und von den Aktivisten der in Mecklenburg-Vorpommern wenig oppositionell gesonnenen Parteien wurde auch kein Widerspruch erwartet. Außerdem waren die meisten NS-Belasteten aus den Zentralinstanzen der Landesverwaltung in Schwerin seit dem 20. August 1945 entlassen, lagen Listen der als unentbehrlich geltenden weiterhin beschäftigten Pgs vor und galten landesweit einheitliche Einstellungs - und Entlassungsregelungen. Warnke hatte durch das Personalamt und durch die Oberbürgermeister und Landräte Einfluß auf alle drei Prozesse und stand ihnen als erster Vizepräsident und als Vorsitzender der Bodenreform- sowie der Sequestrierungskommission auch formal vor. Keine Gruppe in der Landespolitik konnte dieser Ämterfülle eine vergleichbare Machtposition entgegensetzen; nicht einmal ansatzweise zeichnete sich eine offensive Eigenständigkeit und Kooperation anderer Personen in führenden Ämtern der Landesverwaltung oder Parteien ab, die Warnkes Stellung und die Ausrichtung der von ihm weitgehend bestimmten Landespolitik hätten in Frage stellen können.

Bei Sequestrierungen von Handels-, Handwerks- oder Industriebetrieben, bei Enteignungen im Rahmen der Bodenreform und bei der Entnazifizierung kam es nicht primär auf Einzelfälle und die Überprüfung einzelner Belasteter an. Obwohl die Begründung aller drei Prozesse primär antifaschistisch war, ging es vorwiegend um gesellschaftliche Veränderungen: Die Vorherrschaft des Großgrundbesitzes sollte in der Landwirtschaft gebrochen sowie enteigneter Boden an die zahlreichen Ortsfremden und Landarmen übergeben werden; die Sequestrierungen richteten sich in Mecklenburg-Vorpommern angesichts des weitgehenden Fehlens von Industrie vor allem gegen kleine und mittlere Betriebe, deren Enteignung den lokalen gesellschaftlichen Einfluß ihrer Eigentümer brach und diese häufig zum Verbleib im Westen oder zur Flucht dorthin veranlaßte. Beschränkte Kontrollmechanismen für die Bodenreform- und Sequestrierungskommissionen unterstrichen diese Tendenz ebenso wie das in den folgenden Jahren strikt durchgehaltene Prinzip, einmal enteignete landwirtschaftliche Betriebe selbst dann nicht zurückzugeben, wenn sie offensichtlich und anerkannterweise unrechtmäßig enteignet waren. ${ }^{334}$

ren NSDAP, ihrer Gliederungen und angeschlossenen Verbände“ (MLHA, MinPräs 1289, Bl. 26); Verordnung vom 31. 8. 1945 über die „Registrierung der Vermögen der aktiven Faschisten und Kriegsverbrecher" (MLHA, MinPräs 1289, Bl. 27); Verordnung vom 31. 8. 1945 „Vermögen geflohener Faschisten " (MLHA, MinPräs 19/1).

${ }^{333} \mathrm{Um}$ ein antifaschistisch-demokratisches Deutschland, S. 139-142.

334 Die Betroffenen erhielten in solchen Fällen statt dessen Ersatzflächen; die Rückgabe hätte das 
Ähnliches zeichnete sich im folgenden bei der Entnazifizierung ab. Auf seiten der Landesverwaltung gab es ein über individuelle Überprüfungen hinausgehendes Interesse. Das machen mehrere Hinweise deutlich: erstens der Rigorismus, mit dem die Verwaltungen entnazifiziert wurden; zweitens die Verhinderung der Rückkehr der unrechtmäßig Entlassenen; drittens das Tempo, mit der die Entlassungen vollzogen und dadurch neues Personal eingesetzt werden konnte; und viertens das Desinteresse an einer Entnazifizierung der Flüchtlinge, wodurch fast die Hälfte der erwachsenen mecklenburgischen Bevölkerung durch die Maschen der Entnazifizierung fallen konnte. Obwohl die Entnazifizierung in der ganzen SBZ ähnlich gestaltet wurde, zeigen diese Faktoren eine besonders schnelle und tiefgreifende Veränderung der Verwaltungen in Mecklenburg-Vorpommern. Die Priorität lag offensichtlich nicht bei der Beurteilung einzelner; es ging vielmehr um einen breiten Personalwechsel, bei dem die Bürokratie ausgetauscht werden sollte, die sich seit dem Kaiserreich als eine vermeintlich ,unpolitische ohne große Brüche gehalten und sich im ,Dritten Reich'von ihrer dienstbarsten und furchtbarsten Seite gezeigt hatte. ${ }^{335}$

$\mathrm{Da}$ eine Gesellschaft durch eine umfangreiche und wohlfunktionierende Bürokratie umfassend und unentrinnbar beherrscht werden kann, hat bereits Max Weber zu Beginn des Jahrhunderts eindringlich beschrieben. ${ }^{336}$ Die Kommunisten teilten diese Überzeugung Max Webers, nicht aber seinen damit verbundenen pessimistischen Blick. Sie schauten vielmehr ebenso hoffnungsvoll wie fortschrittsgläubig in die Zukunft. Mit Hilfe der Entnazifizierung wurde nun versucht, die Verwaltungskontinuität zu brechen, ihre herrschaftspolitische Funktion dabei aber nicht entscheidend zu beeinträchtigen. Da jede frei werdende Stelle mit neuem Personal besetzt werden konnte, begünstigte eine rigorose Entlassungspolitik den weitreichenden Umbau des Verwaltungsapparates. Entsprechend Lenins Entwurf in ,Staat und Revolution' ging es vorerst um einen Umbau, nicht um die Zerstörung der Verwaltung: „Von einer Vernichtung des Beamtentums mit einem Schlag, überall, restlos, kann keine Rede sein. Das wäre eine Utopie." Statt dessen galt es, „mit einem Schlag die alte Beamtenschaft [zu] zerbrechen und sofort mit

Vertrauen der Landempfänger in die Dauerhaftigkeit der Bodenreform und damit der Herrschaft der Besatzungsmacht und der KPD-dominierten Verwaltung geschwächt.

${ }^{335}$ Die Linke hatte seit 1933 vor allem die drastische Zunahme der staatlichen Repression und Zugriffsmöglichkeiten wahrgenommen, nicht aber die inzwischen bekannten Einflußverluste der staatlichen Bürokratie im NS-Regime. Dabei hatte das polykratische NS-Herrschaftssystem die traditionellen staatlichen Verwaltungen stark geschwächt. Vor allem in den militärisch besetzten Gebieten, aber auch schon vor 1939 und im, Altreich' waren unter der Ägide von NS-Parteiorganisationen zahlreiche Parallelverwaltungsapparate entstanden, die die Kompetenzen und Mittel der staatlichen Verwaltungen aushöhlten (siehe Broszat, Staat, S. 323ff.; Hüttenberger, Polykratie; Mommsen, Beamtentum, S. 13-123; Rebentisch, Führerstaat, besonders S. 523-531; Thamer, Verführung, S. 351-364). Ohne daß es den Akteuren in der SBZ bewußt war, vereinfachte diese Vorgeschichte den Schlag gegen die traditionelle Bürokratie erheblich.

${ }^{336}$ Das klassische Zitat dazu: „Geronnener Geist ist auch jene lebende Maschine, welche die bürokratische Organisation [...] darstellt. Im Verein mit der toten Maschine ist sie an der Arbeit, das Gehäuse jener Hörigkeit der Zukunft herzustellen, in welche vielleicht dereinst die Menschen sich, wie die Fellachen im altägyptischen Staat, ohnmächtig zu fügen gezwungen sein werden, wenn ihnen eine rein technisch gute und das heißt: eine rationale Beamten-Verwaltung und - Versorgung der letzte und einzige Wert ist, der über die Art der Leitung ihrer Angelegenheiten entscheiden soll" (Weber, Wirtschaft, S. 835). 
dem Aufbau einer neuen [zu] beginnen“. Gegen „anarchistische Träumereien“ forderte Lenin, die Revolution „mit den Menschen, wie sie gegenwärtig sind“, aufzubauen, mit „den Menschen, die ohne Unterordnung, ohne Kontrolle, ohne ,Aufseher und Buchhalter" nicht auskommen werden". ${ }^{337}$ Die neuen Herrscher nutzten die Abrechnung mit den administrativen Trägern des untergegangenen Systems, um die eigene Herrschaft in allen Behörden institutionell zu verankern: Dem von der Entlassung verschonten, vielfach noch mit beamtenrechtlichem Entlassungsschutz eingestellten Personal wurde die Abhängigkeit von der neuen Landesverwaltung demonstriert, und bei der Auswahl des neuen Personals wurde nach spezifisch politischen und sozialen Kriterien vorgegangen.

Da bei der Bereinigung der Verwaltung „nicht immer und überall eine einheitliche Linie gewahrt worden“ sei, erließ Warnke am 30. August 1945 eine ausführliche Verordnung an die Oberbürgermeister, Landräte, Fachabteilungen und anderen unterstellten Dienststellen. ${ }^{338}$ Darin zitierte er aus den „richtunggebend[en]“ Beschlüssen der Potsdamer Konferenz (17. Juli bis 2. August 1945) zur Entnazifizierung: „Alle Mitglieder der nazistischen Partei, welche mehr als nominell an ihrer Tätigkeit teilgenommen haben, und alle anderen Personen, die den alliierten Zielen feindlich gegenüberstehen, sind aus den öffentlichen und halböffentlichen Ämtern und von den verantwortlichen Posten in wichtigen Privatunternehmen zu entfernen. Diese Personen müssen durch Personen ersetzt werden, welche nach ihren politischen und moralischen Eigenschaften fähig erscheinen, an der Entwicklung wahrhaft demokratischer Einrichtungen in Deutschland mitzuwirken. “339

Die alliierte Anordnung war deutlich: Alle Aktivisten der NSDAP waren zu entlassen. Was sollte aber mit den nicht aktiven NS-Mitgliedern geschehen? Wie realisierte der KPD-Politiker Warnke die von seiner Partei seit den dreißiger Jahren im Exil ${ }^{340}$ schon anerkannte und behauptete Unterscheidung zwischen aktiven und nominellen Pgs? Obwohl die Verordnung selbst konstatierte, daß gemäß Potsdamer Abkommen nur die aktiven NSDAP-Mitglieder zu entlassen seien, bestimmte sie anderes: Die Unterscheidung zwischen nominellen und aktiven Nazis setze „eingehende Untersuchungen voraus, die in den meisten Fällen nicht von heute auf morgen getroffen werden können “. Da es aber um den „Aufbau eines wahrhaft demokratischen Deutschlands" gehe und „mit einem Verwaltungsapparat, in dem Faschisten sitzen, [...] nur das Alte, Gestrige verewigt, nicht aber Neues geschaffen werden“ könne, erfordere die Lage eine klare und schnelle Lösung: „Grundsätzlich sind deshalb unabhängig von der Frage der Betätigung zunächst alle ehemaligen Angehörigen der Nazi-Partei durch schriftlichen Bescheid zu entlassen." 341

Damit war die in Potsdam formulierte, in der KPD-Tradition verankerte und im Schreiben selbst zitierte Differenzierung innerhalb der NSDAP-Mitgliedschaft aufgehoben. Die Begründung war scheinheilig, denn die einen Tag zuvor erlassene Verordnung 12a über Beschlagnahmungen, in der der gleiche Passus zitiert war, nannte genaue

\footnotetext{
337 Lenin, Staat, S. 438.

338 MLHA, MinPräs 1167.

${ }^{339}$ Dieser Teil A, Abs. 6 des Potsdamer Abkommens ist abgedruckt in: Vollnhals, Entnazifizierung, S. 107; siehe: Amtsblatt des Kontrollrats, Nr. 1 (1946), S. 13-20.

340 Meinicke, Entnazifizierung (Diss), S. IVf.

341 MLHA, MinPräs 1167.
} 
Kriterien zur Unterscheidung der nominellen und aktiven Nazis. ${ }^{342}$ Ausnahmen wurden auch in anderen Bereichen gewährt. Beispielsweise betraf keine vergleichbare Entlassungswelle das medizinische und hygienische Fachpersonal, und auch zahlreiche Lehrer, die Mitglieder der NSDAP gewesen waren, wurden erst Anfang 1946 entlassen. Der Rigorismus richtete sich vor allem gegen den administrativen Apparat, der schnell verändert und gleichzeitig für die neuen Verhältnisse funktionstüchtig werden sollte.

Warnke gewährte den Pgs in der Verwaltung nur eine Ausnahme, die die administrative Funktionstüchtigkeit aufrechterhalten sollte: Einem Entlassenen, der „als Spezialist unbedingt erforderlich", kein aktiver Faschist gewesen und nun zur Mitarbeit am antifaschistischen Aufbau bereit sei und zudem die Gewähr böte, „bewußt und zuverlässig im demokratischen Sinne tätig zu sein“, könne die Gelegenheit gegeben werden, „ohne Wiederherstellung seines aufgelösten Beamtenverhältnisses zur Bewährung weiterverwendet zu werden“. Diese Spezialisten hätten unter „ständiger Kontrolle eines zuverlässigen Antifaschisten “ zu stehen, und ihnen dürften keine leitenden Aufgaben übertragen werden. Eine solche Verwendung Entlassener setze die Zustimmung des Präsidenten voraus, wozu der Abteilung Innere Verwaltung - die damit wiederum das Vermittlungsorgan zwischen den einzelnen Behörden und Höcker war - eine eingehende Begründung vorzulegen sei. Mit dieser Regelung für Fachkräfte wurde der Rigorismus der Verordnung teilweise aufgehoben, wobei es sich nicht um politische und soziale Gerechtigkeit gegenüber den nominellen NS-Mitgliedern handelte, sondern um die Sicherung einer gewissen Effizienz der Betriebe und Verwaltungen. 343

In der Verordnung findet sich kein Hinweis auf Möglichkeiten für die Entlassenen, in die Verwaltung zurückzukehren. Sie enthielt keine individuellen Verurteilungen, sondern war eine politisch motivierte Entlassungsmaßnahme; weil sie präventiv zu schützen vorgab, konnten sich die Betroffenen nicht über falsche Beurteilungen beschweren. Die Aufhebung der Unterscheidung zwischen nominellen und aktiven Pgs wurde politisch begründet und durchgeführt, ohne einzelne zu beurteilen. Obwohl der Hinweis auf die Notwendigkeit von "eingehende[n] Untersuchungen“ Differenzierungsbereitschaft suggerierte, enthielt der Verordnungstext keinen Hinweis auf ihre institutionalisierte Realisierung. Die Rückführung der Entlassenen in den Verwaltungsdienst war auch nicht beabsichtigt, obwohl die Verordnung Hinweise auf eine zeitliche Begrenzung enthielt („von heute auf morgen“, „zunächst... zu entlassen“): Ähnlich den Schreiben Laus vom 27. und 30. August $1945^{344}$ informierte Lobedanz am 8 . September $1945^{345}$ alle Dienststellen darüber, daß „die Namen der auf Grund der Bereinigungsaktion entlassenen und noch zur Entlassung kommenden Personen [...] jeweils dem örtlich zuständigen Arbeitsamt" mitzuteilen seien. Durch die Vermittlung in andere Stellen waren sie nicht mehr auf eine Rückführung in ihre alten Dienstverhältnisse angewiesen und fixiert.

Nicht alle fast zeitgleich erlassenen Entnazifizierungsrichtlinien der anderen Länder und Provinzen der SBZ waren so radikal: Nicht überall wurde die Entlassung aller ehe-

\footnotetext{
${ }^{342}$ Amtsblatt, Nr. 1 (1946), S. 4f. Auch als Oberbürgermeister von Güstrow hatte Warnke noch entsprechende Differenzierungen verlangt (MLHA, MdI 30, Bl. 148; siehe Anmerkung 240 in Kapitel I.2).

${ }^{343}$ Zur weiteren Behandlung dieser für unabkömmlich erklärten Pgs siehe Kapitel I.2, S. 102ff.

${ }^{344}$ MLHA, MdI 757.

${ }^{345}$ MLHA, MinPräs 1041.
} 
maligen NSDAP-Mitglieder angeordnet. Dieser Rigorismus war kein Ergebnis mangelhafter Information, da Warnke die Potsdamer Beschlüsse schon drei Tage nach dem Ende der Konferenz vorgelegen hatten. Dahlem hatte sie aus Berlin zur „Konferenz ver-

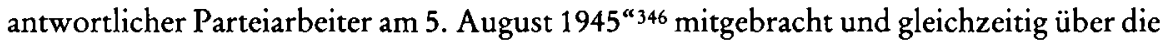
noch unveröffentlichte Entschließung der Blockparteien über die Entnazifizierung informiert, die bereits im Juli 1945 erarbeitet worden war und deren Direktivcharakter und baldige Veröffentlichung Dahlem betonte. ${ }^{347}$ In seinem langen Einführungsreferat nahm Dahlem zu Schwerpunktthemen Stellung, die im ZK der KPD bestimmt worden waren. Abgesehen von der Anordnung, möglichst schnell eine Landesorganisation der Gewerkschaft aufzubauen, deren Charakter durch die führende Rolle der Arbeiterklasse in der SBZ ,ein grundlegend anderer “ als bis 1933 werde, ${ }^{348}$ sowie Erläuterungen über die noch nicht mögliche Einheit der Arbeiterparteien, ${ }^{349}$ erteilte Dahlem keine klaren politischen Direktiven. Entnazifizierung und Sequestrierungen wurden zwar wiederholt benannt und gewürdigt, aber eine klare oder einheitliche Linie formulierte das ZKMitglied dabei nicht.

Auch die Texte von Potsdam und des Parteienblocks boten keine Grundlage für eine zonal vereinheitlichte Entnazifizierung, denn Warnkes Verordnung setzte sich ja eindeutig darüber hinweg. Ganz offensichtlich beanspruchte das Zentralkomitee der KPD in diesem Bereich keine Weisungsbefugnis gegenüber den Ländern, so daß der entschei-

${ }^{346}$ MLHA, LL KPD I/3, Bl. 21-40. Auf der KPD-Sekretariatssitzung war am 2. 8.1945 beschlossen worden, die Landesleitungen mündlich über die Potsdamer Beschlüsse, die Bestrafung der Kriegsverbrecher, die Enteignung des Großgrundbesitzes, den Gewerkschaftsaufbau und die Rolle der Gewerkschaftsmitglieder in der Wirtschaft zu instruieren (SAPMO-BA, RY 1/I2/5, $49, \mathrm{Bl} .32 \mathrm{f}$.).

${ }^{347}$ Siehe die Umstände des Entstehens und den Wortlaut dieses Parteienbeschlusses vom 30. 10. 1945 in: Meinicke, Entnazifizierung (Diss), S. 12-16; Suckut, Blockpolitik, S. 68-80, 91-94; Vollnhals, Entnazifizierung, S. 45f., 186-189.

${ }^{348}$ Ausdrücklich wurde eine gesellschaftliche Entdifferenzierung angestrebt, indem die Gewerkschaften ihrer Eigenständigkeit beraubt und zu bloßen Instrumenten für KPD/SED und des Staatsapparates werden sollten: Beispielsweise seien die Arbeiter nicht zu 8-, sondern zu 10-12Stundentagen zu motivieren: „Dem Arbeiter muß bewußt werden, daß er die führende Kraft von morgen ist" (MLHA, LL KPD I/3, Bl. 28f., 40); diese Rollenzuweisung übernahm der FDGB Mecklenburg-Vorpommern am 14. 8. 1945 (SAPMO-BA, RY 1/13/15, 42, Bl. 1f.).

${ }^{349}$ Für die Einheit der Arbeiterparteien sei es notwendig, daß sich die SPD nicht durch die Aufnahme der linken Sozialdemokraten in die KPD als rechte antikommunistische Partei konsolidiere. Außerdem müsse die KPD „erst ideologisch zusammengeschmolzen werden zu einem festen klaren Kern. Das ist eine Voraussetzung, wenn man in der Einheitsfront der Arbeiterklasse führen will.“ Darum differenzierte und hierarchisierte Dahlem verschiedene Gruppen innerhalb der KPD: Die im Land im Widerstand gewesen seien, hätten aufgrund ihrer Isolation den schlechtesten Überblick über die politische Lage; diejenigen in Lagern und KZs hätten durch deren internationale Zusammensetzung und durch illegale Lagerradios einzelne Informationen aus dem Ausland erhalten; „den besten Überblick" hätten aber die Remigranten aus der Sowjetunion; siehe auch Ulbricht am 25.6. 1945 auf der ersten KPD-Funktionärskonferenz in Berlin (Ulbricht, Geschichte, Bd. II, S. 438). Diese Hierarchie stand genau gegen eine präzise und am Einzelfall orientierte Entnazifizierung: Nicht die Kenntnis des Nazismus war wichtig, sondern die Weisungen aus Moskau. Tatsächlich wurde im folgenden auch danach verfahren, indem zuerst pauschale Entnazifizierungsverordnungen ergingen und die ,faschistische" Belastung dann seit 1946/47 zunehmend mehr an aktuellen politischen Fragen und nicht an der Zeit bis 1945 orientiert wurde (MLHA, LL KPD I/3, Bl. 24ff.). 
dende Verordnungstext nicht in Berlin, sondern von der Landesverwaltung in Schwerin entworfen wurde. Da sich die SMAM zwei Wochen lang mit der zeitgleich erlassenen Verordnung über Sequestrierungen beschäftigt hatte, ${ }^{350}$ scheinen auch bei ihr keine klaren und einheitlichen Vorgaben für Entnazifizierung und Sequestrierungen vorgelegen zu haben. ${ }^{351}$ Zensur und Genehmigungsverfahren der regionalen Besatzungsmacht ${ }^{352}$ waren anscheinend weit entscheidender als die Instruktionen vom ZK der KPD. Die Differenzen in der Behandlung der NS-Belasteten zwischen den verschiedenen Ländern der SBZ und die zu unterschiedlichen Zeitpunkten erlassenen Verordnungen bestätigen dies. ${ }^{353}$

Die Landesverwaltung bzw. -regierung verlor erst durch den SMAD-Befehl Nr. 201 vom 17. August 1947 ihre Kompetenz in Entnazifizierungsangelegenheiten, als diese zonal vereinheitlicht und in die Verantwortung der DJV und DVdI gestellt wurde. Im Unterschied zur Agrar- und Enteignungspolitik blieb die Personalpolitik vorerst Landessache: Die Bodenreform begann Anfang September 1945 nur aufgrund von Durchsetzungsschwierigkeiten im Zentralen Parteienblock als landespolitische Initiative, stand aber immer unter genauer Anleitung des ZK der KPD und der Zentralverwaltung für Landwirtschaft; ${ }^{354}$ die SMAD vereinheitlichte die Sequestrierungspolitik bereits im Ok-

350 Bereits am 14. 8. 1945 bat Warnke Höcker darum, „bei dem General nachzufragen, wie es mit der Verordnung über die Beschlagnahme des Nazivermögens" stehe, und empfahl, sie unmittelbar nach der Bewilligung zu veröffentlichen (MLHA, MdI 245, Bl. 20).

351 Die Verzögerung lag nicht an mangelhafter Funktionstüchtigkeit, denn SMAM und Landesverwaltung hatten bis zu diesem Zeitpunkt bereits zahlreiche Verordnungen und Befehle erlassen: z. B. über die Errichtung von Kreisforstämtern, den Verkauf von Pferden und die Tätigkeit von Schafscherern, über Mineraldünger, die Abgabe von Milch, Fleisch und Eiern, die „obligatorische Abgabe der landwirtschaftlichen Produkte“, die "Buchführung der unter staatlicher Aufsicht stehenden landwirtschaftlichen Betriebe", die „Erfassung und Einlagerung von Heu und Stroh" und die Behandlung der entlassenen Kriegsgefangenen (MLHA, MdI 245, Bl. 92ff., 109, 111, 114, 117, 141; MLHA, MdI 14, Bl. 86).

352 Höcker erläuterte am 7. 8. 1945 die ,nach der neuesten Vereinbarung mit der SMA[M] und dem Zensor" geltenden Bestimmungen hinsichtlich der Genehmigung von Schriftstücken: Gesetze, Verordnungen, amtliche Bekanntmachungen und für die Veröffentlichung in der Presse bestimmte Schriftstücke seien „nach wie vor zur Genehmigung bei der SMA[M] über das Dolmetscherbüro einzureichen". Auf sowjetische Initiative erlassene Rundschreiben der Fachabteilungen seien „direkt bei der zuständigen Fachabteilung der SMA[M] zur Genehmigung vorzulegen“. Interne oder rein informatorische Rundschreiben benötigten nur einen Genehmigungsvermerk des Präsidenten oder eines der Vizepräsidenten (MLHA, MdI 593).

${ }^{353}$ Siehe Errichtung, S. 93-97; Meinicke, Entnazifizierung (Diss), S. 102ff., 108-111; Vollnhals, Entnazifizierung, S. 44f.; Welsh, Wandel, S. 45-48; die SMAD mußte den gesetzten Abschlußtermin aufgrund des mangelhaften Tempos in anderen Ländern und Provinzen verlängern.

${ }^{354}$ Die zonale Einheitlichkeit zeigte sich schon im Aufruf zur Bodenreform, der in allen Ländern nach einem zentralen Entwurf formuliert wurde und daher fast gleich lautete. Laut Protokoll strich das mecklenburgische Präsidialkollegium den in der Vorlage enthaltenen Verweis auf Grundbesitz von Bistümern (Artikel II, Ziffer $5 \mathrm{~d}$ ), ${ }_{n}$ weil es in unserem Lande keine Bistümer gibt" und es „darum nach Abschreibung aussieht" (MLHA, MinPräs 239; siehe die Verordnung Nr. 19 vom 5. 9.1945 in: Amtsblatt, Nr. 1 [1946], S. 14ff.). Nicht nur der Anstoß kam aus Berlin, wo die Bodenreformverordnung am Veto des Zentralen Parteienblocks gescheitert war, auch die Durchführung oblag der ständigen Kontrolle und Beobachtung durch das ZK der KPD, deren Intensität im Rahmen der Entnazifizierung niemals erreicht wurde (Suckut, Blockpolitik, S. 88ff.; Amtblatt, Nr. 1 [1946], S. 14ff.; Bauerkämper, Antifaschismus; Bauerkämper, Bodenreform; Badstübner, Geschichte, S. 115-131; Errichtung, S. 132-153; Heitzer, DDR, S. 34-38; 
tober 1945 durch ihre Befehle Nr. 124 und 126.355 Während die Verantwortung für die weitreichenden Enteignungs- und Umverteilungspläne zonalen Institutionen übertragen wurde, blieben Verwaltungspolitik und Entnazifizierung Landesangelegenheiten: Mit Ausnahme der neuen Zentralverwaltungen in Berlin ${ }^{356}$ waren alle staatlichen Dienststellen in der SBZ auf Stadt-, Kreis- oder Landesebene angesiedelt.

Die Verordnung vom 30. August 1945 unterstreicht nicht nur die landespolitische Eigenständigkeit, sondern auch den Handlungsspielraum der eingesetzten deutschen Politiker gegenüber der Besatzungsmacht. Die Verantwortlichkeit für die Durchführung der Entnazifizierung lag nicht bei der Besatzungsmacht, die weder den Rahmen bestimmte noch die Entlassungen selbst durchführte. Den Text schrieben die deutschen Landespolitiker, und die Entlassungen sprach die Abteilung Innere Verwaltung aus. Die Bestätigung dieser Linie durch die Kommandantur war keine Routineangelegenheit: Angesichts der inhaltlichen Differenzen zu den anderen Ländern und Provinzen der SBZ weist nichts auf zonal einheitliche Vorgaben hin, und auch der mehrwöchige Genehmigungsvorgang zwischen Landesverwaltung und Landeskommandantur unterstreicht, daß die Entscheidung nicht selbstverständlich war, sondern daß es tatsächlich etwas zu überprüfen und abzuwägen gab. In einem resümierenden Brief an die SMAM über die Entnazifizierung vom November $1945^{357}$ hielt Höcker zwar fest, daß die Verordnung vom Augustende ,in Würdigung der Ausführungen“ von General Skossyrew auf der Tagung der Oberbürgermeister und Landräte am 20./21. August 1945 erlassen worden sei, aber dieser Ortshinweis deutet eher auf eine beiläufige Anordnung als auf einen Befehl hin, weil die direkte Nachbarschaft und intensive Kommunikation von SMAM und Landesverwaltung in Schwerin auch striktere Anweisungen ermöglichte. ${ }^{358}$

In den ersten Monaten nach der Kapitulation war diese Kompetenz deutscher Politiker ungewöhnlich. In den westlichen Besatzungszonen wurden im Rahmen der Entnazifizierung wiederholt größere Handlungsspielräume der deutschen Verantwortungsträger gefordert. ${ }^{359}$ Dennoch sind die Grenzen dieses Handlungsspielraums auch in Schwerin nicht zu übersehen, denn er war durch ständige Absprachen, Kontrollen und Korrekturen bestimmt. Die durch unterschiedliche Bodenreformvorstellungen ausgelöste Absetzung der beiden CDU-Vorsitzenden Walther Schreiber und Andreas Hermes im Dezember 1945 durch die SMAD zeigte schon früh, welche Folgen das Beharren auf abweichenden Positionen haben konnte. Solange die deutschen Funktionsträger aber

Kuntsche, Umgestaltung, S. 192-198; Kuntsche, Unterstützung; Moritz, Regression; Piskol/ Nehrig/Trixa, Umwälzung; Staritz, Gründung, S. 110ff.; Stöckigt, Kampf; Weber, DDR, S. 12f., 148).

${ }^{355}$ Um ein antifaschistisch-demokratisches Deutschland, S. 189-192, 194ff.

356 Die elf Deutschen Zentralverwaltungen wurden am 27.7.1945 durch SMAD-Befehl Nr. 17 in Berlin weitgehend ohne Rückgriff auf NS-belastetes Personal errichtet, so daß sie nicht entnazifiziert werden mußten (Welsh/Zank, Zentralverwaltungen).

357 MLHA, MdI 752.

${ }^{358}$ Siehe die ausführliche Einleitung in Foitzik, Inventar, S. 7-57, über die Formen der Einflußnahme der sowjetischen Kommandanturen in der SBZ.

${ }^{359}$ Fritzsch, Entnazifizierung, S. 15; Niethammer, Mitläuferfabrik, S. 321. In den ersten Monaten der Besatzung wurde diese Forderung auch in der SBZ formuliert, verstummte aber bald weitgehend; siehe z. B. den nicht unterzeichneten „Entwurf" über den wirtschaftlichen Wiederaufbau und die „Vernichtung des Nazismus" vom 21. 8.1945 im Nachlaß von Andreas Hermes (ACDP, 1/090, 017/1). 
der generellen Linie der Besatzungsmacht Folge leisteten, erhielten sie umfangreiche Spielräume in Einzelfragen. Diesen Spielraum wußte Warnke mit seiner rigorosen Variante der Entnazifizierung zu nutzen, wobei sich bei ihm allgemeinpolitische mit biographischen Momenten verbanden: Trotz der von ihm schon als Oberbürgermeister in Güstrow durchgesetzten Priorität des Neuanfangs wird auch er nach den wiederholten Gefängnis- und KZ-Aufenthalten nicht von dem Bedürfnis nach Abrechnung frei gewesen sein. ${ }^{360}$

Das Vorgehen in Mecklenburg-Vorpommern basierte vor allem darauf, daß die KPD im Land traditionell schwach war, so daß sie sich zur Sicherung der eigenen Position besonders tiefgreifender Maßnahmen bediente. Gleichzeitig bot die besondere Situation im Norden der SBZ spezifische Vorteile für eine schnelle Umwälzung: Im ganzen Land fand sich keine eigenständige politische Gruppe, die als Gegengewicht oder gar Opposition hätte auftreten können, weil die alte politische Elite sich nicht mehr im Land befand, weil es nur wenige demokratisch gesonnene und politisch aktive Bürgerliche gab und weil den Sozialdemokraten durch die geschickte Personalpolitik Sobottkas und der KPD und durch ihre Einbindung in leitende, aber weitgehend einflußlose politische Posten schon bald jede Dynamik, Initiativkraft und Eigenständigkeit fehlte. ${ }^{361}$ Dadurch konnte Warnke als Vertreter der KPD in der Landespolitik weitgehend ungehindert agieren, so daß die mecklenburgische Personalpolitik auch nicht so stark durch Klagen über die Entnazifizierung bestimmt wurde wie im Süden der SBZ. Außerdem waren die Sozialstrukturen tiefgreifender zerrüttet als in den anderen Gegenden Deutschlands, weil nirgendwo eine so große Anzahl von Flüchtlingen aufgenommen wurde, die zudem gleichzeitig als Ersatz für die Entlassenen zur Verfügung standen.

Die SMAM konnte aufgrund ihrer eigenen Informationsstruktur, die auf ihren zahlreichen Kommandanturen im Land basierte, eine weitreichende Kontrolle ausüben und überraschte die Verantwortlichen in der Landesverwaltung wiederholt mit Informatio-

${ }^{360}$ Außerdem waren ihm zahlreiche Personen der mecklenburgischen Politik, Administration und Wirtschaft seit seiner Zeit als Landtagsabgeordneter in den zwanziger und dreißiger Jahren bekannt. So wie der kritische Bezugspunkt der KPD beim Neuaufbau nicht nur das ,Dritte Reich', sondern auch die Demokratie der Weimarer Republik war, erinnerten sich viele Kommunisten nicht nur an die Zeit seit 1933, sondern auch an ihre gesellschaftliche Marginalisierung zuvor. Beispielhaft für die Distanz war die Begegnung Warnkes mit dem Rostocker Oberbürgermeister Heydemann und Regierungsrat Jeß anläßlich der Begrüßung eines sowjetischen Eisbrechers im vereisten Rostocker Hafen im Winter 1928/29 (Mühlstädt, Warnke, S. 79f.). Die Entnazifizierung bot auch eine Möglichkeit, mit dieser Vergangenheit abzurechnen.

${ }^{361}$ Die Sozialdemokraten hatten in Mecklenburg-Vorpommern größere Schwierigkeiten als in anderen Ländern der SBZ, eine eigene, einheitliche und gefestigte Position aufzubauen, weil sie von der Besatzungsmacht immer wieder behindert wurden, weil sie sich in interne Konflikte über die Zusammenarbeit mit der KPD verstrickten und weil sich ehemals führende Sozialdemokraten in Mecklenburg zum Teil schon vor der Vereinigung zur SED der KPD-Hegemonie unterordneten (Malycha, Weg, S. XXXI-XXXV, LXIV, XCff.; Geschichte der Landesparteiorganisation, S. 92-96, 131-140, 153-216; Schwabe, Zwangsvereinigung; Grebing/Kleßmann/ Schönhoven/Weber, Situation; Müller, SPD; Voßke, Kampf). Obwohl Ministerpräsident Hökker und der seit Ende 1946 amtierende Landtagspräsident Moltmann zu den erfahrenen mecklenburgischen Sozialdemokraten gehörten, blieb der sozialdemokratische Einfluß im Land vor und nach der SED-Gründung gering. Auf lokaler Ebene, vor allem in Rostock, konnten sich einige Sozialdemokraten in der Einheitspartei wenige Jahre lang deutlicher bemerkbar machen, so daß sie dort auch einem wachsenden Druck der Kommunisten ausgesetzt waren. 
nen, die ihnen selbst noch nicht vorlagen. ${ }^{362}$ Auch am 13 . September $1945^{363}$ erreichte den Präsidenten ein Schreiben des SMAM-Chefs für Zivilangelegenheiten Skossyrew. Darin lobte dieser ausdrücklich die "große Arbeit, die Sie in Bezug der Bereinigung Ihres Apparates, sowie derjenigen der Stadt-, Kreis- und Bezirksverwaltungsorgane, geleistet haben", wies aber auch auf die noch vorhandene „bedeutende Anzahl faschistischer Elemente" in Behörden und leitenden Posten privater Unternehmen hin. Über ihre unverzügliche Entlassung sei bis zum 25. September 1945 zu berichten. Weil Höcker keine Kenntnis der Entnazifizierung und des Verwaltungsumbaus hatte, leitete er das Schreiben an die Personalabteilung, die ihm drei Tage später anhand der entsprechenden Verordnungen und eines allgemeinen Berichts einen Einblick verschaffte. ${ }^{364}$ Damit unterrichtete er Skossyrew bereits am 21. September 1945,365 doch dessen Zufriedenheit schien sich in Grenzen zu halten, denn er forderte noch am gleichen Tag „die Säuberung der Verwaltung im ganzen Land" in drei Tagen. ${ }^{366}$

Nachdem Warnke allen Fachabteilungen bereits am 15. September 1945 genehmigt hatte, ${ }^{367}$ die Entlassungen in ihren nachgeordneten Dienststellen selbst auszusprechen, um die angeordneten Entlassungen innerhalb von zwei Wochen „restlos“ durchzuführen, zog der Leiter des Personalamtes, Paul Lau, nach Skossyrews Gespräch mit Höcker den Abschlußtermin auf Sonntagmittag, den 23. September 1945 vor. ${ }^{368} \mathrm{Da}$ Lau am 24. September 1945 diesbezüglich nur drei Ermahnungen verschickte, ${ }^{369}$ hatten alle anderen Kreise und kreisfreien Städte wohl zufriedenstellend reagiert. ${ }^{370}$ Damit war die Verordnung vom 30. August 1945 zur Entlassung aller nominellen und aktiven NSDAP-Mitglieder mit Ausnahme der für fachlich unabkömmlich erklärten Spezialisten durchgeführt.

Die Entnazifizierung wurde für beendet erklärt. Alle weiteren Entlassungen im Rahmen der Entnazifizierung sollten nun individuell ausgesprochen werden und sich nur noch auf bis dahin unbekannte Informationen wie Falschangaben im Personalbogen stützen. Vorerst war eine Entlassungswelle abgeschlossen, die die verwaltungstechnische Effizienz wiederum durcheinandergebracht hatte.

\section{Entlassung der Spezialisten}

Mit der Beendigung der Entlassungen in der staatlichen Verwaltung im September blieben zahlreiche NSDAPler noch auf ihren alten Posten, da sie für unabkömmlich erklärt

362 Siehe z. B. die Hinweise der SMAM vom 1. 12. 1945 an Höcker auf die Pgs im Schweriner Elektrizitäts- und Wasserwerk, nachdem dieser gerade die Entnazifizierung für beendet erklärt hatte (MLHA, MinPräs 1485, Bl. 169ff.), und den SMAM-Befehl Nr. 185 vom 9. 10.1946 gegen den Leiter der Finanzabteilung Winckler (MLHA, MinPräs 1463a, Bl. 164).

${ }^{363}$ Der Brief ist falsch mit „13. Oktober 1945“ datiert; die Richtigkeit des 13. 9.1945 ergibt sich aus dem Inhalt und dem folgenden Schreiben Höckers vom 15. 9.1945 (MLHA, MinPräs 1484, Bl. 98).

${ }^{364}$ MLHA, MinPräs 1484, Bl. 176.

${ }^{365}$ MLHA, MinPräs 1484, Bl. 177.

${ }^{366}$ Höcker am 22. 9. 1945: Niederschrift der Besprechung mit Skossyrew vom 21. 9. 1945 (MLHA, MdI 60, Bl. 329).

${ }^{367}$ MLHA, MdI 752.

${ }^{368}$ MLHA, MdI 757.

${ }^{369}$ Die Ermahnungen gingen an die Landräte von Parchim und Waren und den Oberbürgermeister von Güstrow (MLHA, MdI 757).

${ }^{370}$ Einige der entsprechenden Berichte in: MLHA, MdI 758; MLHA, MdI 752. 
worden waren. Ihre befristete Präsenz sicherte einen weicheren Übergang, denn sie stützten alte Strukturen und waren Bezugspunkte bei der Einarbeitung der Nachfolger: Nicht die persönliche NS-Belastung, sondern die administrative Effizienz bildete das entscheidende Kriterium für die befristete Weiterbeschäftigung ehemaliger Pgs.

Nach den lokalen und spontanen Überprüfungen und Entlassungen in den ersten Besatzungswochen war die Entnazifizierung durch die Verordnung vom 30. August 1945 in verbindliche Formen überführt worden. Warnke hatte eine Regel aufgestellt, die die durch zahlreiche persönliche Vorlieben oder Verbindungen geprägte Politik der ersten Wochen in eine geregelte und von Schwerin angeleitete überführen wollte. Gleichzeitig war aber auch die Tolerierung NS-belasteter Spezialisten eingeräumt worden, die ihre Tätigkeit „unter ständiger Kontrolle eines zuverlässigen Antifaschisten“ weiter ausüben durften. Daß die dafür aufgestellte Bedingung einer präsidialen Zustimmung bald aufgeweicht wurde, zeigt, wie umfangreich von dieser Möglichkeit Gebrauch gemacht wurde: Ein gegenseitiges Arrangement sicherte den Behörden ihre administrative Effizienz und den NS-Belasteten ihren Arbeitsplatz, da keine verbindlichen Kriterien für politische Tragfähigkeit und fachliche Unabkömmlichkeit formuliert waren.

Dieses Moment der gegenseitigen Angewiesenheit wurde durch die enge Beziehung betont, die zwischen den Spezialisten und ihren antifaschistischen Betreuern bestand. Diese Paare personifizierten gleichsam den Neuaufbau der Verwaltung und seine Unterordnung unter den von der KPD/SED bestimmten Primat der Politik: fachliche Qualifizierung gepaart mit dauernder politischer Kontrolle. Obwohl die Kontrolleure nicht viel von der konkreten Tätigkeit der Fachkräfte verstanden, war ihnen stets die Kompetenz zu Sanktionen gegeben, die sich nur an politischen Kriterien orientierte. Die begrenzte Gültigkeit der eigenen Rationalität der betroffenen administrativen und anderen Spezialgebiete gegenüber der politischen Hegemonialmacht konnte nicht deutlicher vor Augen geführt werden; sie waren damit gleichzeitig für alle anderen Dienstkräfte Exempel für den neuen Verwaltungsstil.

Die Möglichkeit der Weiterbeschäftigung von bestimmten Nazis entsprach der KPDRichtlinie vom 5. April 1945, die eine entsprechende Prüfung der nur gering NS-belasteten „Intellektuellen, Ingenieure, Ärzte und Lehrer“ zwecks Beschäftigung empfohlen hatte. ${ }^{371}$ Am 12. September $1945^{372}$ lockerte Warnke die Verfügung noch, indem er die Fachabteilungen ermächtigte, Entlassene in ihren nachgeordneten Dienststellen weiterzubeschäftigen und den Antrag dazu erst innerhalb eines Monats beim Personalamt vorzulegen. Bis diese liberalere Handhabung Mitte November auf Initiative der SMAD aufgehoben wurde, konnte zwei Monate mit der Regelung gearbeitet werden. Die wiederholt beklagte Vielzahl der Anträge zeigt, daß die Verantwortlichen die Hilfestellung umfangreich in Anspruch nahmen. Weil jeder Antrag für die Entlassung aufschiebende Wirkung hatte, konnten die Betroffenen bis zu einem eindeutig negativen Bescheid weiterbeschäfrigt bleiben und somit die von den Personalentlassungen behinderte Arbeit der Dienststelle vorläufig mittragen. Das war eine in allen Zonen seltene Großzügigkeit, da die Entnazifizierung als nicht strafrechtliches, sondern politisches Verfahren auf den Nachweis von Schuld verzichtete und zumeist schon den NS-Verdacht sanktionierte.

371 Erler/Laude/Wilke, Hitler, S. 383.

372 MLHA, MinPräs 752. 
Diese Großzügigkeit zeigt wiederum das Interesse an einer funktionstüchtigen Verwaltung; ihre Tradition sollte zwar gebrochen werden, wozu zahlreiche Entlassungen ausgesprochen wurden und den weiterhin Beschäftigten die Zugriffsmöglichkeit der neuen Herrscher demonstriert wurde, aber die Funktionstüchtigkeit hatte Priorität vor der Sanktionierung jedes NS-Belasteten.

Dieses Vorgehen führte zu einer Arbeitsteilung zwischen dem Personalamt und den einzelnen Dienststellen. Jede Behörde fühlte sich primär der Erfüllung der eigenen Aufgabe verpflichtet und hatte daher kein Interesse an einer Fortführung der Entnazifizierung, die den eigenen Personalbestand und damit die administrative Kontinuität und Effizienz gefährdete. Das Personalamt übernahm dagegen die Rolle, sich ständig für den personellen Bruch und die politische Loyalität einzusetzen. Ihr Vetorecht gegen jede personelle Veränderung in der gesamten Verwaltung zeigt die Priorität dieser allgemeinen politischen Richtlinien vor den Notwendigkeiten, die einzelne Behörden geltend machen wollten. In diesem Sinne vertrat das Personalamt die Position der KPD/SED gegenüber allen anderen Abteilungen in der Verwaltung ${ }^{373}$ und machte durch Warnke die ,Kompetenzkompetenz $z^{c_{374}}$ der KPD/SED geltend, die die zu schwache Landesparteiorganisation selbst durchzusetzen noch nicht in der Lage war.

Der Leiter des Personalamtes, Lau, sandte dem Leiter der Abteilung Arbeit und Sozialfürsorge, Moltmann, ${ }^{375}$ im Oktober alle zwanzig Bewährungsanträge für Mitarbeiter der Landesversicherungsanstalt und der landwirtschaftlichen Berufsgenossenschaft zurück, denn die Weiterbeschäftigung früherer Pgs sei nur eine Ausnahme, ,wenn dies im Interesse der Verwaltung unbedingt notwendig ist“. Weil solch umfangreiche Anträge schon von der Fachabteilung hätten zurückgewiesen werden müssen, bat Lau den späteren Landtagspräsidenten, „mich bei der politischen Bereinigung der Ihnen unterstellten Dienststellen zu unterstützen [...]. Wenn man die Vorschläge Ihrer Abteilung [...] zu Grunde legen würde, wäre das bedauerlichst nicht der Fall.“ Der für die Abteilung Kultur und Volksbildung zuständige Vizepräsident Grünberg wurde diesem Wunsch eher gerecht. Er sandte dem Personalamt am 13. November 1945 eine Liste mit Weiterbeschäftigungsanträgen des Rektors der Universität Greifswald, ${ }^{376}$ die er selbst schon reduziert hatte. Im Brief nannte er 32 Personen, die „m.E. nicht unbedingt notwendig, sondern durch geeignete Kräfte zu ersetzen" seien. Dabei handelte es sich um verschiedene Berufe - Näherin, Gartenarbeiter, Regierungsoberinspektor, Pfleger und Masseur, Pförtner, Küchenleiterin, Universitätsrat, Heizer etc. -, bei denen zum Teil schwer nachzuvollziehen war, wieso der Rektor sie zuerst auf die Liste der unabkömmlichen Spezialisten gesetzt hatte: ein weiteres Beispiel dafür, wie ausufernd nachgeordnete Dienststellen von der Ausnahmeregelung Gebrauch zu machen versuchten, um am bisherigen Personal festhalten zu können. Die exzessive Nutzung der Ausnahmeregelung durch die betroffenen Dienststellen beschleunigte das Ende des Übergangsprozesses.

\footnotetext{
${ }^{373}$ Die personelle Zusammensetzung des Amtes und seine konspirativ anmutende Politik dienten diesem Zweck. Die Exklusivität des Amtes zeigt sich beispielhaft in der Unzugänglichkeit seiner Arbeitsrichtlinien, und der von der KPD-Landesleitung angewiesene Austausch des Personalamtleiters Ende 1945 belegt das große Parteiinteresse; siehe Kapitel II.2.

${ }^{374}$ Siehe Lepsius, Institutionenordnung, S. $19 \mathrm{f}$.

${ }^{375}$ Lau am 10.11. 1945, 10.10. 1945 und 19. 10. 1945 (MLHA, MdI 848).

${ }^{376}$ MLHA, MdI 860.
} 
Schon vor der rigorosen Anweisung der SMAD zeichnete sich ein Ende ab: Lau teilte den Fachabteilungen am 6. November 1945 mit, ${ }^{377}$ daß „die Bearbeitung der Bewährungsanträge [...] nunmehr zum Abschluß gebracht werden" müsse und daher keine Anträge mehr angenommen werden könnten. Alle von nachgeordneten Dienststellen eingereichten Anträge seien daher ab sofort nicht mehr an das Landespersonalamt weiterzuleiten, sondern gleich mit einem Ablehnungsbescheid zurückzuschicken. Dies forderte eine Woche später auch die höchste zonale Autorität.

Am 13./14. November 1945 fand in Berlin-Karlshorst eine Konferenz des obersten Chefs der SMAD mit den Präsidenten der fünf Länder und Provinzen der SBZ statt. Nach seiner Rückkehr nach Schwerin notierte Höcker ausführlich Schukows Ausführungen, der sich unter anderem über die Schuld sämtlicher Pgs geäußert und eine Radikalisierung der Entnazifizierung gefordert hatte. Auch wenn einzelne NSDAP-Mitglieder selbst von ihrer Unschuld überzeugt wären, seien „an dem Unglück, das Hitler über die Welt, über Rußland und über Ihr eigenes Land gebracht hat, [...] alle schuld und mitschuldig, die dieser Partei als Mitglieder angehört haben. Nicht das allein; die Faschisten sind noch nicht verschwunden, sie arbeiten noch unterirdisch und es besteht die Gefahr, daß sie sich der sogen. schuldlosen und harmlosen Mitglieder der ehemaligen NSDAP bedienen, um über diese die Verwaltungsarbeit zu stören. Achten Sie auch besonders auf diejenigen, die sich heute als Kommunisten und Sozialdemokraten tarnen. Sie müssen sich vor allen Dingen gegen die Gerüchtemacherei zur Wehr setzen. Die Quellen, aus denen die Gerüchte kommen, sind uns und auch Ihnen bekannt. Sie sind nur geeignet, das Mißtrauen und die Unruhe zu verstärken. Schaffen Sie organisatorische Maßnahmen zur Bekämpfung der Gerüchtemacherei. Es ist schlimm für ein Volk, das durch diese Art der Propaganda dauernd in Unruhe gehalten wird. " 378 So wie die landesweite Systematisierung der Entnazifizierung im August 1945 in allen Ländern und Provinzen der SBZ auf eine zonal einheitliche Einflußnahme der Sowjets schließen läßt, war auch dieser Entnazifizierungsschub ein Anliegen der Besatzungsmacht. ${ }^{379}$ Deutschland war nicht

${ }^{377}$ MLHA, MinPräs HA Justiz 79. Allerdings erließ Lau am gleichen Tag auch ein Schreiben, in dem er weitere Angaben über die Weiterbeschäftigten anforderte, unter anderem, ob „der Genannte inzwischen einer der antifaschistischen Parteien beigetreten" sei (MLHA, MdI 848).

${ }^{378}$ Um ein antifaschistisch-demokratisches Deutschland, S. 203f. Nach John, Ära, S. 166, kam diese Konferenz bei der SMAD auf Initiative des thüringischen Landespräsidenten Paul zustande; siehe Foitzik, Inventar, S. 17. Tatsächlich unternahm die mecklenburgische Landesverwaltung die von Schukow geforderten organisatorischen Schritte: Warnke informierte am 12.12. 1945 über die Gründung einer Propaganda-Abteilung beim Präsidenten des Landes (MLHA, MdI bis 1945 8, Bl. 220). Sie sei „verlängerter Arm, verlängertes Ohr und verlängertes Auge des Präsidenten " und kontrolliere die Durchführung präsidialer Verordnungen, korrigiere negative Urteile in der Bevölkerung über Parteien, Landesverwaltung oder Besatzungsmacht und berichte über die Stimmung. Daß Warnke dabei nicht mit allgemeiner Zustimmung rechnete, zeigt sein Schlußabsatz, in dem er die Aufgabe der Abteilung zu legitimieren suchte und auf die weitverbreitete Trivialkomparatistik (Hübner, Diktatur, S. 22) zwischen SBZ und ,Drittem Reich“ reagierte: ${ }_{n}$ Nochmals sei in diesem Zusammenhang festgestellt, es sind keine Schnüffler, keine geheime Polizei, sondern Helfer, auch der unteren Organe. "Warnke betonte die helfende, die unterstützende Aufgabe der neuen Abteilung, wozu er in diesem Zusammenhang des sonst durchweg geschlechterneutral formulierten Verwaltungsdiskurs erwähnte, daß sich in der Abteilung „auch eine Frau befindet".

${ }^{379}$ Ohne Zugang zu den Akten der SMAD bleibt häufig nicht nur der innersowjetische Entscheidungsprozeß, sondern auch die Einflußnahme der Sowjets auf deutsche Organe unklar, da die 
ihr einziger Bezugspunkt, sondern wiederholt der Ort, an dem interalliierte Rivalitäten und Konflikte ausgetragen wurden, die nichts mit dem konkreten Politikfeld zu tun hatten. Im Herbst 1945 wurde die Entnazifizierung auch in der französischen Zone verschärft, weil die US-Amerikaner den Umgang mit NS-Belasteten im Alliierten Kontrollrat zum Thema machten: ${ }^{380}$ So wie die Wiederaufnahme der Entnazifizierung im Spätsommer 1946 eine vorbereitende Aktion auf die Moskauer Außenministerkonferenz war, war auch diese Wiederaufnahme der - zumindest in Mecklenburg-Vorpommern für beendet erklärten Entnazifizierung außenpolitischen Interessen der Besatzungsmacht zuzuschreiben. Alle Länder und Provinzen in der SBZ strengten zu diesem Zeitpunkt eine forcierte Entnazifizierung an. ${ }^{381}$ Die verantwortlichen Landespolitiker hatten zwar das Ende der Entlassungen begrüßt, mußten sich aber dem übergeordneten Interesse der Besatzungsmacht beugen, deren klare Anweisung den Deutschen keine Alternative ließ.382

Die Anweisung Schukows wurde in Mecklenburg-Vorpommern in wenigen Tagen umgesetzr: Am 17. November 1945 ordnete Warnke die Entlassung aller noch beschäftigten NS-belasteten Spezialkräfte an. ${ }^{383}$ Eine weitere Beschäftigung sei höchsten kurz-

Mehrzahl der sowjetischen Anweisungen an deutsche Funktionsträger mündlich erfolgte (Foitzik, Sowjetische Militäradministration; Foitzik, Inventar). Höckers Mitschrift ist daher ein historiographischer Glücksfall, da neben den bekannten numerierten Befehlen verschiedener Kommandanturen nur wenig Material über die Kommandanturen überliefert ist. Im Vergleich zu den Unterlagen im BAP über die Zusammenarbeit zwischen SMAD und Deutschen Zentralverwaltungen ist die Situation für Mecklenburg-Vorpommern sehr dürftig: Schon 1945 reißen die Mitschriften von Höcker über seine Treffen mit der SMAM ab; von Warnke, dem wichtigsten Verbindungsmann zur Schweriner Kommandantur, sind gar keine Notizen dieser Art bekannt; und in der zentralen Dolmetscherabteilung der Landesverwaltung finden sich nicht viel mehr als die erwähnten Befehle sowie deutsche Vorlagen für die sowjetische Zensur. Ein ähnliches Beispiel wie Höckers Mitschrift ist der Bericht der Justizverwaltung vom 30. 8. 1947 an Höcker über eine "Ländertagung" am 29. 8. 1947, bei der Oberstleutnant Jakubow den SMADBefehl Nr. 204 bekanntgab und erläuterte (MLHA, MinPräs 1479); auch dieses Protokoll bestätigt die mündliche Befehlserteilung selbst bei gesellschaftlich zentralen Fragen.

${ }^{380}$ Eine Folge war die im Januar 1946 erlassene Kontrollratsdirektive Nr. 24 (Henke, Säuberung, S. 46f.; Friedrich u. a., American, S. 259-263).

${ }^{381}$ Da die Entnazifizierung in Thüringen und Sachsen bereits Anfang November 1945 durch präsidiale Erlasse verschärft wurde und teilweise der 15. 11. 1945 als Stichtag angegeben war, scheint die Konferenz in Karlshorst nicht der einzige Anstoß gewesen zu sein (Welsh, Wandel, S. 48, 53, 179); der Stichtag mußte bis zum 31. 12.1945 verlängert werden (Meinicke, Entnazifizierung [Diss], S. 103), wurde dann aber auch in Sachsen und Thüringen nicht eingehalten (Welsh, Wandel, S. 49, 55f.; Meinicke, Entnazifizierung [Diss], S. XXXVIf. [Tabelle Nr. 3]; Errichtung, S. 9397). Im Entnazifizierungsabschlußbericht an die SMAM vom 27. 11. 1945 verschwieg Höcker die Initiative der SMAD und stellte die Verschärfung als Folge des Beschlusses der Blockparteien vom 30. 10. 1945 dar (MLHA, MdI 752). Anders als in Schwerin hatten die Präsidenten von Sachsen und Thüringen die Entnazifizierung vor dieser Verschärfung noch nicht für beendet erklärt.

${ }^{382}$ Auf einer erweiterten Sitzung des ZK der KPD am 19./20. 11. 1945 unterbrach Ulbricht zweimal Kurt Bürgers Bericht über die zu „weitherzige“ Differenzierung zwischen aktiven und bloß nominellen NSDAP-Mitgliedern mit dem Hinweis, „daß alle Mitglieder der NSDAP und ihrer Gliederungen aus der Verwaltung entfernt werden sollen“, denn so stehe es ,im Befehl des Marschalls Schukow" (SAPMO-BA, RY 1/I2/5, 40, Bl. 178). Bürgers Kritik zeugt wiederum von seiner geringen Kenntnis der Landespolitik, da die von ihm beklagte Differenzierung zu diesem Zeitpunkt bereits durch die Landesverordnung vom 17. 11. 1945 aufgehoben war. 
fristig zur Einarbeitung der Dienstnachfolger möglich, statt dessen sei „energisch“ nach neuen „aufbauwilligen Kräften“ zu suchen, die auch „aus den Reihen der dort beschäftigten Handarbeiter" rekrutiert werden könnten. Drei Gründe führte er für diesen Wandel an: Erstens sei es nach den bisherigen Erfahrungen mit der vorläufigen Beschäftigung NS-Belasteter „zweifelhaft [...], ob mit einem Verwaltungsapparat, in dem noch Faschisten sitzen, das angestrebte Ziel eines schnellen Wiederaufbaus zu erreichen ist" - ein Gedanke, den er bereits am 30 . August 1945 geäußert hatte. Zweitens sei den Weiterbeschäftigungsanträgen zu entnehmen, daß der NSDAP-Eintritt meistens „aus egoistischen Gründen“ vollzogen worden sei: „weil sie eine Benachteiligung in ihrem beruflichen Fortkommen befürchteten ", hätten sie „den Kriegswillen der früheren Machthaber bestärkt und sind somit als mitschuldig an der Katastrophe anzusehen ". ${ }^{384}$ Angesichts der tiefgreifenden gesellschaftlichen Umwälzungen des Jahres 1945, die Abertausende von Berufsverboten und -wechseln mit sich brachten, überrascht Warnkes Zurückweisung der angenommenen Normalität dieser Arbeitsverhältnisse und Karrieremuster keineswegs; ${ }^{385}$ damit reagierte er vielmehr auf die nicht nur in den Westzonen früh feststellbare Tendenz, die eigene Kompromittierung im ,Dritten Reich' zu privatisieren und zu verharmlosen. Mit dem dritten Grund verwies Warnke auf die sowjetischen Machthaber: Es müsse „alles vermieden werden [...], was dazu führen könnte, den Besatzungsbehörden Anlaß zu einem Einschreiten zu geben, wie es bereits örtlich der Fall gewesen ist“. Damit benannte Warnke die Sowjets als treibende und entscheidende Kraft, verwies aber gleichzeitig durch die intendierte Vorwegnahme auf eine gewisse Autonomie der Landesverwaltung. Die Einflußnahme der Sowjets versuchte er nicht zu verschweigen. Ebensowenig intendierte er, den Anschein von Sympathie zu erwecken.

Dieser Hinweis auf die Sowjets, deren Intervention verhindert werden sollte, bleibt unklar. Für das Jahresende 1945 liegen noch keine Hinweise dafür vor, daß die Erwähnung der sowjetischen Besatzungsmacht einem strategischen Kalkül unterlag. Anders als die später üblichen Versuche, die Präsenz der Sowjets dadurch verborgen zu halten, daß sie gar nicht erwähnt werden durften, ${ }^{386}$ ist hier das Bemühen Warnkes offensichtlich, die Landesverwaltung als selbständig agierendes politisches Subjekt vorzuführen. Er führte die Besatzungsmacht zuerst auf, um dann ihre Einflußnahme zu negieren. Da ihre Präsenz und ihr maßgeblicher Einfluß auf alle politischen Entwicklungen in der SBZ allgemein bekannt waren, ${ }^{387}$ suchte Warnke eine punktuelle Selbständigkeit nachzuweisen: Durch den expliziten Verweis auf ihre Eingriffskompetenzen suggerierte er Ehrlichkeit, durch die vermeintlich selbständige Initiative im Entnazifizierungsbereich Eigenständigkeit.

${ }^{383} \mathrm{Ihm}$ sei bis zum 1. 12. 1945 über jede Entlassung zu berichten (MLHA, IHK Mecklenburg 152).

${ }^{384}$ Anders als die meisten Politiker, die sich seit den letzten Monaten des Jahres 1945 zunehmend mehr um eine Differenzierung der Schuldfrage bemühten, um nicht diejenigen vor den Kopf zu stoßen, die im Laufe der nächsten Jahre gesellschaftlich reintegriert werden sollten, formulierte Warnke hier auffällig krude; damit entsprach er fast bis in die Formulierung den von Höcker protokollierten Ausführungen Schukows.

${ }^{385}$ Siehe Anmerkung 239 in Kapitel I.2.

${ }^{386}$ Beispielsweise beschloß der Ministerrat am 25. 4. 1946 und am 10.12. 1946, daß sowjetische Befehle nur mit Sondergenehmigungen in der Presse zu veröffentlichen seien und Rundschreiben an nachgeordnete Behörden keine Bezugnahmen auf die SMAM enthalten sollten (MLHA, 
Aber Warnkes Darstellung war nicht nur hinsichtlich der Initiative falsch, auch die Durchführung unterstand einer genauen Beobachtung der Kommandantur. Trotz der rigorosen Entlassungsanordnung vom 17. November 1945 beantragte der stellvertretende Leiter des Sektors für Innere Angelegenheiten der SMAM, Oberstleutnant Milowanow, am 21. November 1945 bei Höcker Maßnahmen zur Realisierung des bislang nicht ausgeführten sowjetischen Befehls zur Entnazifizierung der örtlichen Verwaltungsorgane. ${ }^{388}$ Alle "faschistischen Elemente" in allen Verwaltungsbereichen des ganzen Landes seien „zu ergreifen und [...] durch vollwertige Personen, die der Arbeit in diesen Organen würdig sind, zu ersetzen“. Bereits Entlassene dürften auch dann nicht wieder eingestellt werden, wenn sie "neuerdings in eine andere Partei aufgenommen worden ${ }^{\text {“ }}$ seien; in sieben Tagen müßten der SMAM die Listen der Entlassenen vorliegen. Gemäß seiner personalpolitischen Unkenntnis und Passivität übertrug Höcker die Verantwortung an Ballerstaedt von der Abteilung Innere Verwaltung. Die doppelte sowjetische Anweisung - Schukow am 13./14. November 1945 in Karlshorst und Milowanow eine Woche später in Schwerin - zeigt den mehrfach verwobenen deutsch-sowjetischen Herrschaftsapparat. Der in Karlshorst mündlich vorgetragene Befehl wurde in Schwerin wiederholt und mit einem systematischen und ortsnahen Kontrollverfahren verbunden: ein Beispiel für die Doppelung und Kreuzung von Kompetenzen zwischen deutschen und sowjetischen Stellen verschiedener geographischer Einheiten. ${ }^{389}$ Am 24 . November 1945 schickte das Personalamt das von Milowanow geforderte Telegramm ins ganze Land, das die Entlassung aller ehemaligen NSDAP-Mitglieder und die telegraphische Mitteilung darüber bis zum Mittag des 26. November 1946 verfügte. ${ }^{390}$ Die sowjetische Anweisung änderte nicht, daß das Personalamt für die Entnazifizierung innerhalb der Verwaltung allein verantwortlich blieb. Neben diesem Amt gab es keine Instanz, die ähnliche Anweisungen geben konnte. ${ }^{391}$

MinPräs 642, Bl. 121f., 132ff.). Es schien auch ein ungeschriebenes Gesetz zu sein, daß die bei fast allen Treffen anwesenden Vertreter der Besatzungsmacht fast niemals auf Teilnehmerlisten auftauchen durften, obwohl ihre Redebeiträge dann dennoch teilweise protokolliert wurden (z. B. MLHA, RdK Güstrow 878, Bl. 20ff.).

${ }^{387}$ Die Auskunft von Ministerialdirektor Wilhelm Heinrich auf einer Justiztagung im September 1946, daß die Vertreter der Landesverwaltung ,in Schwerin nicht nur Tür an Tür, sondern auch von Mann zu Mann in nächster Zusammenarbeit mit der SMA[M] stehen “, zeichnet ein Bild der alltäglichen Arbeit, das in der Aktenüberlieferung getilgt ist, wohl aber den Erinnerungsberichten weiterer damaliger Funktionsträger entspricht (MLHA, MinPräs HA Justiz 180).

${ }^{388}$ MLHA, MdI 752. Am selben Tag informierte auch der Chefdolmetscher des Präsidenten, Berner, Warnke und Höcker von dieser Entnazifizierungs- und Berichtsanforderung, wobei einige terminliche und sachliche Unterschiede auszumachen sind, ohne daß sie in der Landesverwaltung Unklarheiten gestiftet zu haben scheinen (MLHA, MinPräs 1023).

${ }^{389}$ Die komplizierten Unterordnungsverhältnisse und Befehlskompetenzen innerhalb der Besatzungsmacht lassen ahnen, daß diese polykratischen Strukturen fast zwangsläufig in die schon im SMAD-Befehl Nr. 33 vom 22. 8. 1945 beklagte Anarchie führten (Foitzik, Inventar; BAP, DX1, SMAD-Befehl Nr. 33/45).

390 MLHA, MdI 761. Die in Schwerin angesiedelten Fachabteilungen hatten sogar ${ }_{n}$ bis heute mittag 1 Uhr unter Angabe der Namen der Entlassenen mitzuteilen, daß diese Maßnahme restlos durchgeführt ist“".

${ }^{391}$ Dadurch existierten auch bis 1946 keine eigenen Entnazifizierungskommissionen, die den Grad der NS-Belastung evaluierten und über Entlassungen oder Weiterbeschäftigungen entschieden eine bedeutende Differenz gegenüber dem Sequestrierungsverfahren, wo zahlreiche ehrenamtli- 
Einige Fachabteilungen teilten dem Personalamt unverzüglich mit, daß die erneute Entnazifizierungsanordnung für ihre Abteilung samt nachgeordneten Behörden keine Relevanz habe, da alle Pgs bereits entlassen seien. ${ }^{392}$ Die restlichen Fachabteilungen, Kreise und kreisfreien Städte meldeten die unverzüglich durchgeführten Entlassungen in den folgenden Tagen. Nachdem die Möglichkeit, ehemalige NS-Mitglieder als Spezialisten weiterzubeschäftigen, nun nicht mehr existierte, ließ die Entnazifizierung nichts an Klarheit zu wünschen übrig: Sämtliche Pgs waren aus sämtlichen Behörden zu entlassen. Und dem wurden die Behörden in Mecklenburg-Vorpommern tatsächlich gerecht: Die im Anhang aufgeführten Statistiken zeigen verstärkte Entlassungen von NS-Mitgliedern während der Konstituierungsphase nach Kriegsende und im November/Dezember 1945 infolge dieser SMAD-Initiative. Während in den Abteilungen der Landesverwaltungen die Gesamtzahl der Beschäftigten zwischen dem 30. Oktober 1945 und dem 30. November 1945 von 445 auf 487 zunahm, sank die Zahl der Pgs zur gleichen Zeit von 25 auf zwei. Damit waren alle ehemaligen Mitglieder der NSDAP bis auf einen promovierten Statistiker in der Statistikabteilung beim Präsidialamt und einen Mechaniker in der Hausverwaltung (Abteilung Finanzen) entlassen. Seitdem blieb die Zahl der Pgs trotz der zahlreichen Neueinstellungen und des starken Personalzuwachses mit abfallender Tendenz unter 0,5 Prozent der Dienstkräfte.

Auch in den Kreisen und kreisfreien Städten fiel die Zahl der Pgs durch diese Verschärfung der Entnazifizierung zum Jahresende 1945 auf Null, weil alle im November 1945 noch beschäftigten 278 beziehungsweise 289 NS-Belasteten bis Anfang Dezember 1945 entlassen wurden. Die weiterhin aufgeführten $\mathrm{Pgs}^{393}$ waren sämtlich im Gesundheitsdienst tätig oder mit Schmutz- oder Schwerstarbeiten beschäftigt; seit diesem Ende der Entnazifizierung wurden sie in jeder der folgenden Statistiken einzeln aufgeführt und vom Personalamt besonders beobachtet. Von den 98 Pgs am 9. Dezember 1945 arbeiteten beispielsweise vierzig im Gesundheitsdienst, während die 58 anderen im „Holzeinschlag" oder anderweitig "im Arbeiterverhältnis beschäftigt“ waren; von den 46 beziehungsweise 45 Pgs am 25. Dezember 1945 und 9. Januar 1946 waren zuerst zwei und dann drei im Veterinärbereich und alle anderen im regulären Gesundheitsdienst tätig; am 25. Januar 1946 (9. Februar 1946) arbeiteten alle dreißig (38) Pgs im Gesundheitsdienst. Seit dem 24. Februar 1946 wurden dann bis zum Ende dieser statistischen Reihe im September 1948 etwa 16 Theaterleute aus Stralsund als Pgs aufgeführt. 1946 tritt neben die zahlreichen Personen aus dem Gesundheitsbereich auch wieder die erste ehemals NSbelastete Fachkraft (hier für Vermessungsarbeiten) auf; die Anzahl der Fachkräfte nahm im Laufe der folgenden Jahre und der veränderten politischen Ausrichtung von Entnazi-

che deutsche Parteivertreter in Kommissionen in den Kreisen, Städten, Gemeinden und auf Landesebene über die Belastung anderer Deutscher entschieden. Diese Verantwortlichkeit des Personalamtes für die Entnazifizierung machte auch die Fragebögen überflüssig, die ihre große Berühmtheit aus der US-Zone gewannen: Anstatt alle Erwachsenen zu überprüfen, beschränkte sich das Personalamt - unter Hinzuziehung der Arbeitsämter - auf Überprüfungen bei jedem. Stellenwechsel und benutzte dafür einen Personalbogen, der auch alle entnazifizierungsrelevanten Daten abfragte.

392 MLHA, MinPräs HA Justiz 79; BAP, DR2, 421, Bl. 61-64.

${ }^{393}$ Am 9. 12. 1945: 98; am 25. 12. 1945: 46; am 9. 1. 1946: 45 etc. 
fizierung und Antifaschismus dann sehr langsam zu. ${ }^{394}$ Damit war die Entnazifizierung in der staatlichen Verwaltung beendet. Abgesehen von den Heilberufen und Schmutzarbeiten, die ausdrücklich thematisierte Ausnahmebereiche darstellten, ${ }^{395}$ gab es keine Mitarbeiter mehr, die durch ihre Mitgliedschaft in einer NS-Organisation belastet waren.

Den Vollzug der von Schukow und Milowanow angestoßenen Entlassungsaktion meldete Lau der Präsidialabteilung am 27. November 1945:396 Die letzten noch im Amt befindlichen ehemaligen NSDAP-Mitglieder seien entlassen. Schon am selben Tag meldete Höcker der SMAM den Erfolg: Die Entfernung aller NSDAP-Mitglieder - inklusive der schon in den neuen antifaschistischen Parteien Aufgenommenen - „ist in allen mir unterstellten Verwaltungen durchgeführt “ ${ }^{397}$ Nicht ohne Stolz nutzte Höcker den Bericht auch zu einer Darstellung der Geschichte der Entnazifizierung der Verwaltung, bei der er das Potsdamer Abkommen, die Verordnung vom 30. August 1945, den Beschluß der Blockparteien vom 30. Oktober 1945 und die Behandlung der NS-belasteten Spezialisten hervorhob. Bis zum September seien bei der Zentralverwaltung in Schwerin rund 260, bei den Kreisverwaltungen und kreisfreien Städten rund 3000 Personen entlassen worden. Nach dem Parteienbeschluß vom 30. Oktober 1945, nominelle Pgs nur noch dann in den öffentlichen Verwaltungen zu beschäftigen, wenn es keine vergleichbar qualifizierten Bewerber gäbe, habe Höcker am 17. November 1945 auch die Weiterbeschäftigung der „durchweg [...] schwer ersetzbare[n] Fachkräfte“ zur Bewährung untersagt. ${ }^{398}$ Aufgrund der SMAM-Anweisung vom 21. November 1945 sei „nunmehr die Bereinigungsaktion, deren Entwicklung mehr und mehr auf eine radikale, aber gerechte Lösung hinausdrängte, zu einem schnellen Abschluß gekommen“. Mit diesem Resümee wollte Höcker einen Strich unter die Geschichte der Entnazifizierung der Verwaltung ziehen: Er betrachtete sie, teils unter Druck anderer, teils auf eigene Initiative, als beendet und erhoffte sich ruhige Verhältnisse für die weitere Verwaltungs- und Regierungsarbeit. Den Brief schloß er mit der Hoffnung, daß „gewisse Störungen, die naturgemäß bei einer so plötzlichen Entfernung zahlreicher Fachkräfte unvermeidlich sind, durch den Eifer und den Aufbauwillen der Amtsnachfolger der Entlassenen überwunden werden“. Zum zweiten Mal wurde die Entnazifizierung damit in Mecklenburg-Vorpommern offiziell beendet; der Landespräsident hoffte, „daß der Aufbau unseres demokratischen Deutschlands sich nunmehr reibungslos vollziehen“" werde.

394 Siehe Kapitel II.3. Die Pgs, die nach dem im November 1945 verkündeten Ende der Entnazifizierung angestellt wurden, waren so fest etabliert, daß sie von der Wiederaufnahme der Entnazifizierung nicht gefährdet wurden; siehe Kapitel III und die nicht mehr ansteigende Anzahl von Entlassungen im statistischen Anhang.

395 Siehe zu den Heilberufen Kapitel I.2, S. 117f. Die Schmutzarbeiten dienten der Strafe und Sühne; Warnke forderte z. B. am 10.12. 1945 alle Kreise auf, ehemalige Pgs im Falle ihrer Arbeitslosigkeit zu Drainage-, Kanalisations-, Trümmerentfernungs- und anderen Schmutzarbeiten zu verpflichten (MLHA, MdI 761).

${ }^{396}$ MLHA, MdI 752.

397 Ebenda.

398 Diese Version Höckers ist unwahrscheinlich, da der Schweriner Landesverwaltung dieser Beschluß schon seit Anfang August bekannt war (siehe Kapitel I.2, S. 98) und zudem viel weniger rigorose Entlassungen forderte als der Befehl Schukows vom 13./14. 11. 1945. 
Landesverwaltung und Besatzungsmacht hatten die Entnazifizierung abgeschlossen. Trotz des überdurchschnittlichen Rigorismus im Vergleich zu den anderen Ländern und Provinzen der SBZ, in denen die NS-bedingten Überprüfungen und Entlassungen in den Verwaltungen noch bis ins Frühjahr 1946 andauerten, ${ }^{399}$ gab es auch in Mecklenburg-Vorpommern Bereiche, die nur peripher von der Entnazifizierung betroffen waren. Dies belegt ihre doppelte Ausrichtung: Es ging nicht nur um die Ahndung der NSVergangenheit, sondern auch um den gesellschaftlichen Neuaufbau. Im Verwaltungsbereich war dafür ein Neuanfang intendiert, der neben der neuen politischen Ausrichtung auch die zahlreichen Entlassungen notwendig machte. Dadurch schuf sich die als Regierung tätige Spitze der Landesverwaltung ein willfähriges Instrumentarium, mit dem sie die gesellschaftlichen Neuordnungspläne realisieren und die eigene Herrschaft absichern konnte. Die Entnazifizierung förderte nicht zuletzt die Loyalität des neuen Verwaltungsapparates: die Loyalität der übernommenen Dienstkräfte aufgrund der abschreckenden Wirkung der weitreichenden Entlassungsanordnungen; die der Neuen aufgrund ihres Eifers zum Ausgleich mangelhafter Qualifizierung, aufgrund des mit dem Beginn der Verwaltungstätigkeit möglich gewordenen sozialen Aufstiegs und aufgrund der für zahlreiche von ihnen durch alte Sozial- und Bildungsschranken bis dahin unvorstellbaren Partizipation an der Herrschaft. ${ }^{400}$ Die neuen Dienstkräfte, die die Stellen besetzten, die durch die Entnazifizierung frei geworden waren, verdankten ihre Stellung ausschließlich dem neuen politischen System und wurden von diesem schon bald durch die Mitgliedschaft in Parteien und Massenorganisationen aktiv eingebunden. Dabei wurde die reale NS-Vergangenheit zunehmend unwichtiger. Damit wiederholte sich das politische Desinteresse an einzelnen Lebensläufen, weil die einzelnen Menschen nur als funktionierende oder zu verwerfende Teile der großen gesellschaftlichen Maschine galten. Diese Tendenz hatte sich bereits zuvor durch die oberflächliche Entnazifizierung der Ortsfremden angekündigt.

Pragmatismus außerhalb des Verwaltungsapparates

Die Entnazifizierung der Flüchtlinge. Am 27. August 1945 befahl die SMAD, daß sich alle ehemaligen Wehrmachtsangehörigen „im Range eines Leutnants und höher sowie ohne Ausnahme alle ehemaligen Angehörigen der SS und SA, Mitarbeiter der Gestapo und Mitglieder der NSDAP“ innerhalb eines Monats bei den Kommandanturen registrieren lassen müßten. 401 Weil die Mitgliedschaft in den genannten NS-Organisationen 1945 das entscheidende Kriterium der Entnazifizierung war, wurden so alle Betroffenen registriert, in die Illegalität abgedrängt oder zur Flucht in den Westen gezwungen. Die Erfassung intendierte einen Überblick in dem durch die Bevölkerungsbewegungen unüberschaubar gewordenen Chaos, denn allgemein war bekannt, daß unter den Orts-

${ }^{399}$ Errichtung, S. 93-97; Meinicke, Entnazifizierung (Diss), S. XXXVIf., Tabelle Nr. 3; Welsh, Wandel, S. 49, 55f.

${ }^{400}$ Niethammer, Erfahrungen, S. 104-108; Niethammer, Glasnost, S. 44f.

401 SMAD-Befehl Nr. 42 (MLHA, MinPräs 1458, Bl. 53). Bereits in den ersten Wochen der Besatzung waren wiederholt ähnliche Registrierungsbefehle lokaler Kommandanturen ergangen; in Berichten von Internierten taucht wiederholt auf, daß sich die Betroffenen aufgrund solcher Befehle zu den Kommandanturen begeben hätten und von dort in Gefängnisse und Lager gebracht worden seien. 
fremden noch zahlreiche unerkannte Nazis waren. ${ }^{402}$ Trotz der mit strengen Strafandrohungen verbundenen Registrierungsbefehle blieb es ein schwieriges Unterfangen, unerkannte Pgs zu entdecken. ${ }^{403}$ Die Erfolge dieser Befehle sind unbekannt, da sie nicht an deutschen, sondern an sowjetischen Schreibtischen bearbeitet wurden. Im Laufe der nächsten Jahre wurden nur in seltenen Fällen Personen entdeckt, die falsche Angaben gemacht hatten. ${ }^{404}$ Dies lag unter anderem an dem in keinem anderen Land der SBZ vergleichbar hohen Anteil der Fremden an der Gesamtbevölkerung; ihre Vielzahl machte nicht nur die Suche schwerer, sondern auch das Problem gewichtiger.

Fast die Hälfte der mecklenburgischen Bevölkerung im Frühjahr 1945 lebte noch nicht lange in diesem Land. ${ }^{405}$ Während die Fremden aufgrund ihrer Mittellosigkeit nicht von Sequestrierungen und Enteignungen betroffen waren, ist es bemerkenswert, daß sie auch in den Entnazifizierungsunterlagen nicht als eigene Gruppe auftauchen. Immerhin war die Entnazifizierung in allen Zonen Deutschlands stark von „lokalem Filz $^{{ }^{4} 06}$ geprägt, der durch die neuen Mitbürger eine eigene Färbung bekam. Trotz der zahlreichen Schwierigkeiten mit ihnen finden sich fast nirgends Anklagen oder Beschwerden gegen Ortsfremde, die sie als NS-belastet denunzieren - eine immerhin denkbare Reaktion auf die Probleme und den Unwillen in weiten Teilen der, Altbevölkerung'. Neuankommende Flüchtlinge wurden in Ankunftslagern auf Formblättern nach ihrer NSDAP-Mitgliedschaft befragt; die Zahlenangaben tendierten dabei stark gegen Null, so daß viele Kreisbehörden die Spalte mit Kommentaren versahen wie: „Angabe nicht möglich, da Aussagen der Umsiedler offensichtlich falsch“; „Vermerk: Von den Flüchtlingen will niemand der NSDAP angehört haben. ${ }^{{ }^{407}}$

Die Entnazifizierung der Flüchtlinge stellte ein spezifisches Problem dar, das der Umsiedlerabteilung und dem Personalamt auch bekannt war; dennoch wurden keine Wege

${ }^{402}$ Siehe beispielsweise den Bericht der Landesverwaltung vom 21. 7. 1945 (MLHA, MdI 345) oder den Hinweis des ersten KPD-Bezirkssekretärs aus Pommern, Kollwitz, vom 15. 8. 1945 an die KPD-Landesleitung: „Es ist aber ohne Zweifel so, daß noch viele bekannte Faschisten an anderen Orten im Staatsapparat arbeiten" (MLHA, LL KPD I/1a, Bl. 250).

${ }^{403}$ Daher wurden weiterhin ähnliche Registrierungsbefehle erlassen; siehe z. B. Mitteilungsblatt Güstrow, Nr. 7 (1945).

404 Ein Beispiel sind die zwischen dem 31. 12. 1946 und 28. 2. 1947 entlassenen sechs Pgs in Schweriner Ministerien, deren Partei-Mitgliedschaft zuvor nicht bekannt war, da sie sonst in den vorhergehenden Statistiken oder bei der Einstellung benannt worden wären. Diese geringe Zahl zeigt aber, daß ihre Enttarnung eher ein Zufall als der Erfolg einer systematischen Suche war (siehe statistischen Anhang). Als Begründung bei Entlassungen, die auf dieses Problem hinweist, hieß es „Angabe einer falschen eidesstattlichen Erklärung“, wobei die Abweichungen nicht spezifiziert wurden (z. B. MLHA, MinPräs 611, Bl. 83).

${ }^{405}$ Grundlegende Informationen über das Flüchtlingsland Mecklenburg-Vorpommern 1945 in Kapitel I.1, S. 42-45.

406 Woller, Gesellschaft, S. 147.

407 MLHA, Landesbehörde der Volkspolizei 400, passim. Beispielsweise meldete sich im Landkreis Rostock am 5. 11. 1945 von insgesamt 6269 Flüchtlingen niemand als NSDAP-Mitglied. Daher füllten viele Bearbeiter die Spalten nicht aus. In den meisten Informationserhebungen wurde gar nicht erst nach der NS-Belastung gefragt; siehe z. B. die Tagesprotokolle vom Heimkehrerlager Bützow von Ende 1947 bis September 1948 mit der Anzahl der Aufgenommenen und Angaben zum Geschlecht, zu verlorenen oder mitgebrachten Dokumenten, mitgebrachten Lebensmitteln, dem Zustand der Kleidung und Schuhe, Krankheiten, Anzahl der "Verlausten“ (MLHA, RdK Güstrow 133). 
zu einer systematischen Überprüfung der Ortsfremden und ihrer Angaben über die eigene Vergangenheit gesucht. ${ }^{408}$ Dies war kein Zufall, sondern dem Umstand geschuldet, daß sich unter den Umsiedlern zahlreiche Menschen befanden, die sich die Landesverwaltung und die Parteien für den Neuanfang zunutze machen konnten: Zahlreiche derjenigen, die an ihren neuen Wohnorten heimisch wurden, durch die Bodenreform Land erhielten oder andere Arbeit fanden, entwickelten Loyalität und Dankbarkeit gegenüber den entscheidenden politischen Kräften des gesellschaftlichen Neuaufbaus, weil diese den Betreffenden angesichts des Verlustes der Heimat und des allgemeinen gesellschaftlichen Chaos eine Alternative boten. ${ }^{409}$ Viele Entlassene und Geflohene konnten durch ortsfremde Fachkräfte ersetzt werden; so forderte der Parteienblock in Laage am 19. Oktober 1945 von Warnke die Absetzung eines Revierförsters, der Mitglied der NSDAP gewesen war: „Außerdem ist hier festzustellen, daß sich hier in Laage als Ostflüchtling aus dem östl. Pommern der frühere Revierförster L. aufhält, der nicht Mitglied der NSDAP war, sondern sich immer schon und jetzt wieder zur SPD bekannt hat. [...] Es wäre unseres Erachtens doch das Einfachste, ihn mit der Stelle in Kronskamp zu betrauen. " 410 Nach Barthel waren von 1946 bis 1949 elf bis 14 Prozent aller Erwerbstätigen der SBZ im öffentlichen Dienst beschäftigt; die Zahl der 1947 im öffentlichen Dienst tätigen Flüchtlinge war mit 18,2 Prozent auffällig höher. ${ }^{411} \mathrm{Da}$ sie als Neue keinen Rückhalt in bestehenden gesellschaftlichen Strukturen hatten und eigene Organisationen wie Landsmannschaften nicht zugelassen wurden, bildeten sie eine sichere Klientel der neuen Parteien und der neuen Herrscher innerhalb und außerhalb der Verwaltungen. Daher war eine rigorose Untersuchung der Flüchtlinge von seiten der KPD und des Personalamts nicht intendiert.

Am 9. Februar 1946 informierte Höcker das Personalamt, daß die SPD-Zugehörigkeit der Flüchtlinge aus Danzig anhand dort ausgestellter und von der „polnischen SPD“ [sic] bestätigter Ausweise nachprüfbar sei; dasselbe nahm Höcker für die KPD an. Alle staatlichen Dienstkräfte, die die frühere Zugehörigkeit zu einer der Arbeiterparteien angegeben hätten, seien daraufhin zu überprüfen, ob sie „im Besitze einer solchen Bescheinigung sind". ${ }^{412}$ Nachdem die gesamte Mitgliederkartei der NSDAP und zahlreicher weiterer NS-Organisationen in der US-Zone gefunden worden war und ein hervorra-

${ }^{408}$ Das Desinteresse an einer ernsthaften Überprüfung der Flüchtlinge beschränkte sich nicht nur auf Mecklenburg; Moltmann stellte auf einer Konferenz der SMAD, des Präsidiums der Deutschen Verwaltung für Arbeit und Sozialfürsorge und der Leiter der Landes- und Provinzialämter am 11./12. 7. 1946 in Berlin auf die Frage nach der Anzahl der zu Sonderarbeitseinsätzen erfaßten NSDAP-Mitglieder nur lakonisch fest: „Unter den 1 Mill. Umsiedlern, von denen natürlich keiner Nazi sein will, ist die Kontrolle sehr schwer" (BAP, DQ2, 1, BI. 93).

${ }^{409}$ Die Abteilung Arbeit und Sozialfürsorge berichtete z. B. am 4. 12. 1945 von der Meldepflicht der Flüchtlinge bei den Arbeitsämtern und damit zusammenhängenden umfangreichen Umschulungstätigkeiten in Mangelberufen als Maurer, Krankenschwester, Schlosser, Dreher, Elektroschweißer und landwirtschaftliche Maschinenschlosser (MLHA, Min. f. Soz. 228).

410 MLHA, MdI 210b.

${ }^{411}$ Barthel, Ausgangsbedingungen, S. 67.

412 MLHA, MdI 759. Höcker gab keine Quelle für diese Information an, und es erscheint fragwürdig, ob eine solche bürokratische Aktion im Zuge von Flucht und Vertreibung möglich gewesen war. Unklar ist weiterhin, wieso Höcker von der angenommenen Praxis der Danziger SPD auf die der Danziger KPD, nicht aber auf die in anderen Städten des ehemaligen deutschen Ostens rückschloß. 
gendes Mittel zur Suche NS-Belasteter darstellte, schlug Höcker gleichzeitig wegen seines Mißtrauens hinsichtlich der bislang nicht überprüfbaren Angaben der Flüchtlinge vor, eidesstattliche Erklärungen ${ }^{413}$ zu verlangen, kein NSDAP-Mitglied gewesen zu sein, und sie dabei auf die Folgen von Falschaussagen „hinzuweisen und ausdrücklich zu verwarnen. Ich kann mich nicht des Eindrucks erwehren, daß viele frühere Mitglieder der NSDAP ihre Mitgliedschaft aus dem Grunde verschweigen, weil sie glauben, eine Nachprüfung sei nicht möglich. Nachdem die Zentralkartei der NSDAP gefunden ist, wird auch eine solche Nachprüfung bei jedem aus dem Osten stammenden Angestellten erfolgen, sobald dies möglich ist. Die Gerechtigkeit erfordert es, daß auch diese Faschisten rücksichtslos aus der Verwaltung entfernt werden. “ Die Antwort des Personalamtes fiel recht skeptisch aus:414 Die Nachweise der SPD- oder KPD-Zugehörigkeit seien von Dienstkräften in der Landesverwaltung „nur in Ausnahmefällen“ beizubringen; die von Höcker vorgeschlagene Einführung einer eidesstattlichen Erklärung über die NS-Zugehörigkeit sei überflüssig, weil sie - mitsamt dem Hinweis auf die strafrechtliche Ahndung falscher Angaben - schon im Fragebogen enthalten sei. ${ }^{415}$ Auch der Hinweis des Präsidenten auf die Zentralkartei der NSDAP begeisterte nicht: Die Nachprüfung der Dienstkräfte aus dem Osten solle zwar „sobald als möglich erfolgen“, doch zuerst werde „in einigen Zweifelsfällen um Auskunft gebeten“, um „das richtige Funktionieren der Zentralkartei festzustellen".

Trotz der präsidialen Anregung und obwohl OMGUS sie ausdrücklich einer weiteren Öffentlichkeit zur Verfügung stellte, ${ }^{416}$ wurde die NSDAP-Mitgliederkartei von Dienststellen der sowjetischen Besatzungsmacht nicht genutzt. ${ }^{417}$ Damit setzte sich die Linie des Personalamtes durch: Das Mißtrauen und der Widerwillen gegen die von der USamerikanischen Besatzungsmacht verwalteten Auskünfte waren größer als das Interesse

${ }^{413}$ Die Zuverlässigkeit eidesstattlicher Erklärungen vor allem der Ortsfremden war so mangelhaft, $\mathrm{da}$ ß auf der DJV-Länderkonferenz am 1./2.2. 1946 ein Verordnungsentwurf „über die Bestrafung falscher Angaben über die Zugehörigkeit zur ehemaligen NSDAP und zu ihren Gliederungen" eingereicht wurde, der eine Höchststrafe von einem Jahr und bei eidesstattlichen Stellungnahmen eine Mindeststrafe von drei Monaten vorsah (BAP, DP1 [Verwaltungsarchiv], 6957, Bl. 103).

${ }^{414}$ MLHA, MdI 759.

${ }^{415}$ Lau hatte allen Behörden am 19. 9. 1945 einen Musterfragebogen geschickt, auf dem der Unterschrift ein eidesstattlicher Charakter zugesprochen wurde und hinzugefügt war: "Ich bin mir bewußt, daß unrichtige Angaben strafrechtliche Ahndung zur Folge haben" (MLHA, MinPräs 947, Bl. 28; siehe Kapitel II.2, S. 152-155). Auch entlassene Kriegsgefangene mußten bei ihrer Rückkehr eidesstattliche Erklärungen abgeben, keiner NS-Organisation angehört zu haben; im Falle der Mitgliedschaft wurden sie vom Dienststellenleiter vorläufig ohne Bezüge beurlaubt: siehe eine solche Anordnung für die Dienststellen der Abteilung Landwirtschaft und Forsten vom 15. 9. 1945 (MLHA, MinPräs 752).

${ }^{416}$ Lucius D. Clay nannte es das Ziel einer 1947 von OMGUS zur Erleichterung der allgemeinen Benutzung herausgegebenen Broschüre, "die in diesen Akten verfügbaren Informationen einer weiten Öffentlichkeit bekannt zu machen, damit ihr Wert von den interessierten Einrichtungen vollständig ausgeschöpft wird “ (IfZ, OMGUS, 7771 Document Center, Who was a Nazi? Facts about the membership procedure of the Nazi Party. Berlin 1947, S. 3, in: PRO-FO 371, 64747).

${ }^{417}$ Briefliche Auskunft von Kurt Rosenow, seit der Gründung Mitarbeiter und von 1947 bis 1953 Leiter des Berlin Document Center, vom 12. 9.1996 an den Verfasser; gleichzeitig teilt Rosenow mit, daß Juristen und Militärs verschiedener osteuropäischer Länder die BDC-Unterlagen intensiv und ergiebig zur Vorbereitung von Kriegsverbrecherprozessen genutzt haben. 
an einer zuverlässigen Überprüfung der Flüchtlinge. Das war nicht nur ein antiwestlicher Vorbehalt noch vor Beginn des Kalten Krieges, da US-Amerikaner die Kartei verwalteten. Das Personalamt fürchtete vielmehr jeden fremden Einfluß auf sein Ressort, der die weitgehend unangefochtene personalpolitische Stellung im Land hätte gefährden können. Und die Mitgliederkartei enthielt Informationen, deren Inhalt und Dosierung nicht im Belieben des Personalamtes standen. Damit wäre eine Instanz akzeptiert worden, die aufgrund ihrer Unabhängigkeit nicht der Weisungskompetenz des Personalamtes, der KPD/SED oder der Besatzungsmacht zu unterwerfen war. ${ }^{418}$ Durch ihre Anerkennung hätte das Personalamt seine absolute Stellung verloren, die es seinem Informationsmonopol verdankte. ${ }^{419}$

Neben diesem kurzen Schriftwechsel zwischen Personalamt und Höcker wurde das Thema nicht wieder aufgegriffen: weder in Briefen, Protokollen oder anderen der zeitgenössischen Öffentlichkeit unzugänglichen Akten noch in Gesetzen, Verordnungen oder Verlautbarungen. Auch statistische Erhebungen brachten die massenweise Migration nicht mit der Entnazifizierung in Verbindung: in Flüchtlingsstatistiken keine Angaben über die Entnazifizierung, in Entnazifizierungsstatistiken keine spezifischen Angaben über Umsiedler. Dieses in auffälligem Gegensatz zur sonstigen Akribie des Personalamtes stehende Desinteresse unterstreicht, daß es bei der Beurteilung der Dienstkräfte nur sekundär auf die tatsächliche NS-Belastung ankam. Durch diese Handhabung blieb beinahe die Hälfte der formal betroffenen Bevölkerung von der Entnazifizierung unberücksichtigt. Ihr Rigorismus richtete sich vor allem gegen die einheimische Bevölkerung und dabei primär gegen die Dienstkräfte derjenigen Behörden, die 1945 nicht aufgelöst, sondern weitgehend unverändert übernommen wurden. Die Migranten wurden nicht zufällig übersehen, und ihre Überprüfung wäre auch keineswegs unmöglich gewesen. Dies zeigen die Ende 1946 in der SED eingerichteten Kommissionen, welche die Flüchtlinge in den eigenen Reihen parteiintern untersuchten. ${ }^{420}$ Die Entnazifizierung der Ver-

418 Systematische Anfragen hätten OMGUS und die US-Geheimdienste zudem mit wertvollen Informationen über die Personalstruktur der SBZ informiert, für die sie sich ebenso wie die Briten bereits seit den vierziger Jahren interessierten (IfZ, OMGUS 3/162-1/9; IfZ, OMGUS 7/28-3/ 24; PRO-FO 1005, 1633; PRO-FO 1005, 1741; PRO-FO 1005, 1747; PRO-FO 1005, 1748; PRO-FO 1005, 1749; PRO-FO 1005, 1750; PRO-FO 1030, 110; PRO-FO 1050, 467; PRO-FO 1051, 1088; PRO-FO 1056, 456).

${ }^{419}$ Nicht nur die US-Amerikaner sollten von jedem Einfluß auf die Entnazifizierung in der SBZ ferngehalten werden: Der Leiter der mecklenburgischen Justizverwaltung, Heinrich, unterband im Juni 1946 auch die Möglichkeit von Privatpersonen in der SBZ, Verfahren im Rahmen der bereits für beendet erklärten Entnazifizierung zu initiieren. Anlaß war eine Anfrage des Schweriner Amtsgerichts vom 24. 5. 1946, wie mit den zahlreichen Anschuldigungen von zivilen Prozeßparteien vor Gericht umzugehen sei, die eine NS-Belastung ihrer Gegner behaupteten. Heinrichs von Höcker genehmigter Vorschlag, "solche Privatklagen grundsätzlich abzulehnen“, entsprang nicht nur dem Mißtrauen gegen die vor allem bei Prozeßgegnern zu vermutenden Denunziationen, sondern dem politischen Desinteresse an einer Fortsetzung der Entnazifizierung (MLHA, MinPräs HA Justiz [Mischbestand], 666b).

${ }^{420}$ MLHA, LL SED IV/2/5/158, Bl. 140. Noch vor der Vereinigung der Arbeiterparteien war ein leicht gangbarer Weg vorgeschlagen worden, um Überprüfungen näher zu kommen: Ein Sozialdemokrat riet in Güstrow dazu, „die Namen der politischen Freunde aus den einzelnen ausgesiedelten Orten zu sammeln, um sich dann bei diesen über verdächtige Personen aus diesen Orten evtl. Auskunft holen zu können" (MLHA, MdI 197, Bl. 330-334). Auch wenn es nicht in systematische politische Schritte umgewandelt wurde, blieb das Mißtrauen gegenüber den 
waltungsstellen galt Ende November 1945 als beendet, und nunmehr ging es - entsprechend Höckers Formulierung an die SMAM ${ }^{421}$ - um den reibungslosen Aufbau der neuen Verwaltung. Der Wert der Dienstkräfte bemaß sich an ihrer gegenwärtigen Aufbau- und Integrationsbereitschaft, nicht mehr an der Vergangenheit. ${ }^{422}$

Weitere Ausnabmebereiche. Nicht nur die unerkannten Nazis, von denen zahlreiche unter den Flüchtlingen vermutet werden müssen, bildeten Ausnahmen der Entnazifizierung. Auch in anderen Bereichen wurde die Weiterbeschäftigung ehemaliger Pgs mal offen, mal in verdeckter Weise gestattet, sofern sie für den Neuaufbau unersetzbar waren. Der bislang dargestellte Rigorismus bei der Entnazifizierung in Mecklenburg-Vorpommern betraf die staatliche Verwaltung; als Trägerin staatlicher Autorität in einem hochgradig etatistisch ausgerichteten Gesellschaftsprojekt wurde von ihr ein hohes Maß an Loyalität und widerspruchsfreier Durchführung politischer Anweisungen erwartet. Dies galt außerhalb der Verwaltung nicht genauso, selbst wenn diese Bereiche partiell oder ganz in staatlichen Händen lagen. ${ }^{423}$

Die Entnazifizierung von Privatbetrieben richtete sich vor allem in den ersten Wochen, in denen NS-Belastete vornehmlich auf Orts- und Betriebsebene untersucht wurden, auf Einzelpersonen. Schon bald ging es aber nicht mehr um Entlassungen und um Degradierungen zu subalternen Arbeiten, sondern fast ausschließlich um Eigentumsfragen. Bereits die Verordnung Nr. 12a vom 29. August 1945 beschäftigte sich hinsichtlich der „politische[n] Bereinigung der Wirtschaft“ nicht mit Entlassungen einzelner Betriebsmitglieder, sondern mit Beschlagnahmungen, Treuhandverwaltung und der Fortsetzung der Produktion. Daß die politische Belastung innerhalb von Betrieben häufig nur von untergeordnetem Interesse war, belegt auch die fortgesetzte Beschäftigung von zahlreichen fachlich qualifizierten NS-Belasteten durch die Besatzungsmacht in den für sie produzierenden Betrieben.424 Auch bei großen staatlichen Apparaten wie Reichsbahn und Reichspost wurde nur zögernd und unübersichtlich entnazifiziert. Ihre Bedeutung für die Aufrechterhaltung und Wiederherstellung von Mobilität und Information und ihre vor allem bei der Bahn mit großen Sicherheitsrisiken verbundene Tätigkeit

Flüchtlingen erhalten: Die Personalabteilung des SED-Landesvorstandes informierte beispielsweise die entsprechende Abteilung beim Zentralsekretariat im Februar 1947 über die 38 NSDAP-Vertreter im Danziger Volkstag des Jahres 1933; daß diese Angaben aus dem veröffentlichten Handbuch für den Danziger Volkstag erst 1947 erfaßt wurden, zeugt wiederum von dem diesbezüglich geringen Engagement in der SBZ (MLHA, LL SED IV/2/5/155, Bl. 51ff.). Erst am 1.6. 1947 regte Ulbricht auf einer SBZ-Innenministerkonferenz die Errichtung einer entsprechenden Personalkartei bei der DVdI an (SAPMO-BA, DY 30/IV2/13, 109, Bl. 41).

${ }^{421}$ MLHA, MdI 752.

${ }^{422}$ Dies entspricht auch der Beobachtung, daß die Ende 1945/Anfang 1946 durchgeführte Kampagne zum ersten Nürnberger Kriegsverbrecherprozeß von den Belastungen unterhalb der strafrechtlich relevanten Ebene absah und die Entnazifizierung als beendet betrachtete; siehe Kapitel II.3, S. $183-187$.

${ }^{423}$ Die seit 1946/47 tätigen Entnazifizierungskommissionen verhandelten vorwiegend gegen Personen aus Wirtschaftsbetrieben, gegen Selbständige, Landwirte etc. Dies zeigt, daß die 1945 außerhalb des unmittelbaren Staatsapparates fast ausschließlich berufsbezogene Entnazifizierung viele Personen unbehelligt ließ, sofern sie keine Ambitionen hatten, beispielsweise als Lehrer, Verwaltungsangehörige oder Justizmitarbeiter in den Staatsdienst einzutreten. Die Schulen, die Polizei und die Justiz wurden in Mecklenburg-Vorpommern ähnlich schnell von Pgs befreit wie 
trugen dazu ebenso bei wie ihre länderübergreifende Organisation, die wiederholt Kompetenzrivalitäten zwischen Schweriner und Berliner Stellen hervorrief. ${ }^{425}$ Aber nicht nur große Betriebe erfuhren eine andere Behandlung, auch bei kleinen Berufsgruppen wie Professoren und bei jahreszeitlich bedingten Engpässen ${ }^{426}$ wurden differenziertere Maßstäbe angelegt, sofern kein Ersatz zur Verfügung stand: „Die Zahl der Schornsteinfegermeister ist beschränkt. Der überwiegende Teil war Mitglied der NSDAP, daher sind die nominellen Mitglieder anders zu beurteilen als die aktiven." 427

Durch die Probleme und Notstände der Zusammenbruchgesellschaft erfüllten zahllose Berufstätige lebensnotwendige Aufgaben. Mit dem bedrohten menschlichen Leben unmittelbar konfrontiert waren die medizinisch Tätigen. ${ }^{428}$ Ihre Arbeit zu unterbinden, konnte mit keiner grundsätzlichen politischen oder gesellschaftlichen Neuorientierung begründet werden, da dadurch gegenwärtiges Leben zerstört worden wäre; selbst bei ähnlich niedrigen Qualitätsanforderungen wie für die neuen Lehrer und Juristen wären Schnellkurse nicht möglich gewesen. Entsprechend gab es neben den Pfarrern keine Berufsgruppe, die derart zurückhaltend überprüft wurde wie Ärzte und anderes Pflegepersonal:429 Im Telegramm vom 24 . November 1945,430 mit dem das Personalamt die Entlassung aller NSDAP-Mitglieder anordnete, wurden sämtliche „Gesundheitsämter und [...] Heilanstalten“ ausdrücklich ausgenommen; kurz darauf wurden Landräte und

die Verwaltung (Zur Geschichte der Rechtspflege, S. 43, 54f., 68-72; Bessel, Police; MLHA, MinPräs 1032/1, Bl. 14; MLHA, RdK Wismar 768; MLHA, RdK Neustrelitz 306).

${ }^{424}$ Karlsch, Allein, S. 123f., 128; siehe den Entnazifizierungsbericht des Landespersonalamtes vom 5. 12. 1946 an Höcker (MLHA, MinPräs 1375). Nach Zank, Wirtschaft, S. 55f., hatte die Entnazifizierung "so gut wie gar keine Auswirkungen" auf die sowjetischen Betriebe in der SBZ.

${ }^{425}$ Meinicke, Entnazifizierung (Diss), S. 16f.; zum Schienenverkehr im Norden der SBZ siehe die Besprechung zwischen Skossyrew, Höcker und Warnke Ende 1945 mit den beiden Reichsbahnpräsidenten von Schwerin und Greifswald, Jeß und Hoffmann. Die zurückhaltende Entnazifizierung der Bahn wurde einerseits damit begründet, daß die Pgs für die Sicherheit des Schienenverkehrs unabkömmlich seien, andererseits führte Skossyrew einige Bahnunfälle mit mehreren Dutzend Toten auf die „Mitarbeit von diesen faschistischen Elementen“ zurück (MLHA, MinPräs 1309, Bl. 46-56).

${ }_{426}$ Siehe z. B. kurzfristige Sondergenehmigungen für Waldarbeiter (MLHA, MdI 753).

427 Warnke am 3. 11. 1945 (MLHA, RdK Güstrow 42, Bl. 21); ähnlich zurückhaltend wurden die spezialisierten und im Zuge der Bodenreform sehr bedeutsamen Vermessungstechniker entnazifiert (Warnke am 27. 1. 1947, in: MLHA, MdI 762; Brebach/Koch, Bewährung, S. 30f.).

${ }^{428}$ Hinsichtlich der katastrophalen hygienischen Situation und der mangelhaften medizinischen Versorgung in allen Besatzungszonen, die durch Zerstörungen, Materialmangel und fehlendes Personal verursacht waren, siehe Kleßmann, Staatsgründung, S. 51; Sons, Gesundheitswesen, S. 83-223. Zu Mecklenburg-Vorpommern siehe: Eggert, Ende, S. 166-173; MLHA, RdK Güstrow 878 und 880; Stadtarchiv Stralsund, Rep 50-19.

429 Die Kirchen waren die einzigen großen Institutionen, die Krieg und ,Drittes Reich' weitgehend intakt überlebt hatten. Da Besatzungsmacht und KPD/SED zu Beginn der Besatzungszeit keine Konfrontationen mit ihnen beabsichtigten, wurde die Entnazifizierung ihrer Hauptamtlichen erst seit 1946/47 verstärkt gefordert; dazu gehörten auch die aus allen Zonen bekannten Konflikte, ob die staatliche Entnazifizierung ein illegitimer Eingriff in innerkirchliche Angelegenheiten sei (Vollnhals, Kirche; umfangreiche Unterlagen zur Entnazifizierung der mecklenburgischen Landeskirche in: Landeskirchliches Archiv, Bestand Oberkirchenrat, II 1/O, 1, 2; zur Entnazifizierung der Mediziner in der SBZ/DDR siehe: Kleßmann, Relikte; Kleßmann, Sozialgeschichte; Domeinski, Ärzteschaft).

${ }^{430}$ MLHA, MdI 761. 
Oberbürgermeister nach einer Entscheidung von Warnke und Höcker telegraphisch noch einmal darüber informiert, daß „auf dem Gebiet des Gesundheitswesens tätige Personen und Veterinärärzte [...] von dieser Maßnahme nicht berührt" würden. ${ }^{431}$ Entsprechend wurden auf allen staatlichen Verwaltungsebenen Mediziner beschäftigt, die durch ihre NS-Organisationsmitgliedschaft belastet waren: Im Mai 1946 wurde beispielsweise ein Arzt in der Umsiedlerabteilung eingestellt, der seine Tätigkeit bis zum Ende der statistischen Erhebungen behielt, und auf Kreis- und Stadtebene waren es stets mehrere Dutzend Pgs, die in Gesundheitsämtern, Krankenhäusern und anderen staatlichen Einrichtungen tätig waren. ${ }^{432}$

Trotz dieser Großzügigkeit wurde die NS-Belastung von Personen in Heilberufen nicht vollkommen ausgeblendet. Entsprechend den „Richtlinien über die Reinigung der selbständigen Heilberufe" der Deutschen Zentralverwaltung für das Gesundheitswesen vom 13. November 1945 wurde einigen schwer Belasteten ihre Tätigkeit generell untersagt; alle anderen NS-Belasteten hatten sich einer besonderen Weisungsbefugnis der Gesundheitsbehörden zu unterstellen, deren Einsatzanforderungen „jederzeit nachzukommen" sei. ${ }^{433}$ Diese Weisungsbefugnis verdeutlicht, daß ein spezifischer Nutzen der NSBelastung und der damit einhergehenden Erpreßbarkeit von Fachkräften schon früh erkannt wurde: Die belasteten Mediziner wurden nicht nur zu besonders unangenehmen Aufgaben herangezogen, sondern auch schon bald verpflichtet, durch ihre Arbeit den Aufbau neuer Gesundheitsstrukturen zu stärken. Der behutsamen und zurückhaltenden Entnazifizierung des medizinischen Personals entsprach der Versuch, die Ärzte in ein neues und staatsnahes Gesundheitssystem einzubinden. Neben der Überführung der medizinischen Infrastruktur in staatliche Hände, die beispielsweise durch die Auflösung des Deutschen Roten Kreuzes forciert wurde, ${ }^{434}$ gehörte dazu auch die Arbeitsverpflichtung von medizinischem Personal in Flüchtlings- oder Seuchenlagern, an abgelegenen Orten oder zum Ausbau der Polikliniken.435

431 Am 24. 11. 1945 an die Landräte, am 27. 11. 1945 an die Oberbürgermeister (MLHA, MdI 761).

${ }^{432}$ Siehe statistischen Anhang.

${ }^{433}$ MLHA, Min. f. Soz. 13. Das Ministerium für Sozialwesen schickte diese Verordnung am 10. 12. 1945 an alle Gesundheitsämter und verlangte die Einordnung aller Betroffenen nach den vorgegebenen Kategorien sowie Vorschläge für ihre weitere Verwendung (MLHA, Min. f. Soz. 2314). Siehe auch eine leicht abweichende Verordnung der Zentralverwaltung für das Gesundheitswesen vom 17. 10. 1945, die das Ministerium für Sozialwesen am 7.11. 1945 an alle Gesundheitsämter geschickt hatte (MLHA, RdK Güstrow 879, Bl. 122).

434 Am 10. 9. 1945 hatte Warnke die Amtsärzte zu Leitern der Kreisstellen des Roten Kreuzes ernannt und diese damit der staatlichen Kontrolle unterstellt, wodurch die häufig geforderte Einbindung des Gesundheitspersonals in die neue Gesellschaft erleichtert wurde (MLHA, MdI 345). Skossyrew forderte von Höcker Anfang 1946, daß alle DRK-Gesundheitseinrichtungen von den Stadtverwaltungen zu übernehmen seien; "medizinische mittlere Lehranstalten“ des Roten Kreuzes seien zu schließen, die Teilnehmer zu entlassen und alle DRK-Verbände und die DRK-Schwesternschaft aufzulösen (MLHA, MdI 345). Am 17. 1. 1946 wurde das Krankenhaus des Roten Kreuzes vom Schweriner Kreiskommandanten, Tscheprassow, beschlagnahmt (MLHA, MinPräs 1022). Noch am 31. 10. 1945 war dem Leiter des Güstrower Gesundheitsamtes in Schwerin versichert worden, daß „entgegen der Ansicht einiger Güstrower Stellen [...] das Rote Kreuz weiterhin als Abzeichen und Kennzeichnung seine Gültigkeit hat “ (MLHA, RdK Güstrow 878, Bl. 26).

${ }_{435}$ Am 26. 9. 1946 erließ Höcker eine entsprechende Verordnung zur „Einberufung von Ärzten und anderen Angehörigen der Heilberufe zu fachlichen Dienstleistungen“, die Möglichkeiten 


\section{Das Ende für einen Neuanfang}

Schon 1945 zeigte sich in Mecklenburg-Vorpommern die Priorität des gesellschaftspolitischen Neuanfangs vor einer sorgfältigen Abrechnung mit der NS-Vergangenheit. Nach dem Abschluß der Entnazifizierung stellte die Landesverwaltung die Wiederherstellung geordneter gesellschaftlicher Verhältnisse und die Konsolidierung der Verwaltung in den Mittelpunkt ihres Interesses. Die Entnazifizierung beschränkte sich im folgenden darauf, bei Einzelfällen Einstellungen zu verweigern, Entlassungen auszusprechen oder die juristische Ahndung in Gang zu setzen.

Einen Hinweis dazu gab die SMAM bereits am 27. November 1945, also an dem Tag, als Höcker ihr den Abschlußbericht zur Entnazifizierung vorlegte. ${ }^{436}$ Aufgrund einer vergleichbaren, allerdings mehrere Personen betreffenden Einzelfallmeldung ${ }^{437}$ wurde eine Kommission eingesetzt, die den Verbleib zahlreicher NSDAP-Mitglieder im Schweriner Wasser- bzw. Elektrizitätswerk untersuchte. In ihrem Bericht legte sie die Schwierigkeiten einer vollständigen Entnazifizierung dar. In der Stadtküche seien Personen ehrenamtlich tätig, "die sich nicht polizeilich gemeldet hatten und auf diese Art und Weise einfach untertauchten. Sie sind durch ihre Tätigkeit bei der Stadtküche der Notwendigkeit enthoben, sich um Lebensmittelkarten zu kümmern, da ihnen die Küche ausreichende Versorgung gewährt, und gehen auf diese Weise auch der polizeilichen Meldepflicht aus dem Wege." ${ }^{438}$ Dieses Beispiel zeigt, daß die vollständige Registrierung und Kontrolle der Bevölkerung nicht möglich war, da nicht einmal das zentrale Mittel zur Erfassung der Bevölkerung, die Ausgabe der Lebensmittelkarten, zur Meldung aller Personen führte. ${ }^{439}$ Die Entnazifizierung wurde zwar zentral geleitet, aber dennoch blieben viele Entscheidungen von den Gegebenheiten vor Ort abhängig, die ein Schutz für Pgs oder eine Gefährdung anderer Personen sein konnten. ${ }^{440}$ Wiederholt äußerten sich

zur Arbeitsverpflichtung von medizinischem Personal bestimmte (MLHA, Min. f. Soz. 13). Der forcierte Ausbau der Polikliniken fand erst ab 1947/48 statt. Daß dafür gezielt NS-Belastete rekrutiert wurden, zeigt der Behandlungsvorschlag Warnkes vom 2. 7. 1948 im Falle des Masseurs O., dem die Entnazifizierungskommission ein selbständiges Gewerbe untersagt hatte: „Von seiten der Hauptabteilung Gesundheitswesen wird dazu mitgeteilt, [...] daß sich gerade staatlich geprüfte Masseure weigern, eine Anstellung bei der Poliklinik, wo ebenfalls Masseure benötigt werden, anzunehmen. Es wäre daher zu empfehlen, den Beschluß der Entnazifizierungskommission aufrecht zu erhalten, um dadurch der Hauptabteilung Gesundheitswesen die Möglichkeit zu geben, O. als Masseur bei der Poliklinik einzusetzen“ (MLHA, MinPräs 184).

${ }^{436}$ MLHA, MinPräs 1023; siehe auch MLHA, MinPräs 1485, Bl. $136 \mathrm{ff}$.

${ }^{437}$ MLHA, MinPräs 1485, Bl. $169 \mathrm{ff}$.

${ }^{438}$ MLHA, LL KPD I/28, Bl. 59.

${ }^{439}$ Die Ausgabe der Lebensmittelkarten wurde wiederholt als Druckmittel eingesetzt (MLHA, RdK Güstrow 266, Bl. 31R; BAP, DX1, SMAD-Befehl Nr. 153/45, 29. 11. 1945, Bl. 2; MLHA, MinPräs 1462, Bl. 5).

${ }^{440} \mathrm{Da}$ die vorliegende Arbeit die Landespolitik untersucht, werden Ausmaß und Bedeutung von Denunziationen nicht behandelt; die dafür entscheidenden personenbezogenen Entnazifizierungskommissionsakten sind zudem unzugänglich (siehe die Hinweise in der Einleitung). Rückblickend ist die Grenze zwischen Denunziation und berechtigter Anklage besonders schwer zu ziehen. Allerdings tauchen auch in den Kreisakten einige Personen notorisch mit Berichten an die neue Obrigkeit auf, die andere Personen strafrechtlicher Delikte oder politischer Belastungen bezichtigten. Einzelne davon wurden der Falschaussage überführt (siehe z. B. MLHA, RdK Güstrow 95, Bl. 27-30; MLHA, RdK Güstrow 42, Bl. 59ff.; MLHA, RdK Gü- 
dabei ,kleine Leute gegen die alten örtlichen Funktionsträger, nachdem ihnen in der umfassenden politischen Rhetorik und Agitation im Zuge des Neuaufbaus und vor allem der Bodenreform Mut gemacht worden war, das neue Gesellschaftssystem selbst tragen und mitbestimmen zu können. Beispielhaft ist die handschriftlich und in fehlerhaftem Deutsch verfaßte Beschwerde des Neubauern J. vom 10. Dezember 1945 an Vizepräsident Warnke über namentlich genannte NSDAP-Mitglieder, die noch nicht aus ihren Ämtern entfernt seien: „Hoch erfreut war ich als Neubauer in Wilh., alz sie am 2.12. in der Versammlung in die Schauburg sagten, alle Pgs würden aus die Behörden rausgeschmissen. [...] Wie sieht es in de Wirklichkeit aus? [...] Diese zind wie mich erzählt wurde, entlassen den Landesverwaltung gegenüber. Aber ist nur Tarnung, sitzen noch anselben Stelle, angeblich privat, machen dasselbe, geben uns Auskunft wie vorher. Wie ist sowas möglich? Muss an Ort und Stelle gekärt werden, nicht brieflich. Hier muss Bereinigung geschehen, dass kann nicht so weiter gehen, es ist schon Erbitterung bei uns Landarbeiter deswegen. [...] Hoffentlich verschwinden diese bald, bevor die Wut bei uns Neubauern noch grösser wird, vor allem aus den Ämtern. “441 Der Verweis auf die Rede Warnkes und die stolze, vor der Unterschrift wie ein Titel wiederholte Selbstbezeichnung als ,Neubauer' zeugen von der verbreiteten Hoffnung auf einen Neuanfang. Hervorgerufen wurde sie vor allem durch die von KPD, Landesverwaltung und Besatzungsmacht erzeugte soziale Dynamik. Wie die Beschwerde des Neubauern zeigt, gehörte dazu auch die Forderung einer Abrechnung mit NS-,Gockeln' und anderen Repräsentanten des alten Systems. In der von Warnke daraufhin veranlaßten Untersuchung stellte der Landrat in wenigen Worten nur fest, daß die genannten Personen inzwischen entlassen, verstorben oder laut Fragebogen gar keine Pgs gewesen seien. ${ }^{442}$

Etwa sechs Monate nach dem Ende des Faschismus war die Entnazifizierung der Verwaltung weitgehend beendet. Die Behörden sollten nun konsolidiert und die neuen Dienstkräfte eingearbeitet werden. Trotz der weiterhin beibehaltenen AntifaschismusRhetorik war die Vergangenheit abgeschlossen und das politische Interesse so stark auf die Zukunft ausgerichtet, daß die neuen Funktionsträger und Politiker alle Unterbrechungen und Störungen des Neuaufbaus zu verhindern suchten. Das von der Besatzungsmacht installierte Herrschaftssystem hatte sich so weit etabliert, daß es sich.auf einen festen Verwaltungsapparat stützen konnte, für dessen Personalauswahl und Arbeitsweise verbindliche Regeln aufgestellt waren.

Die Entnazifizierung hatte damit ihren Zweck erfüllt: Zahlreiche Personen waren aus dem öffentlichen Dienst entlassen worden. Als Anlaß und Begründung hatte das Kriterium der Parteimitgliedschaft gedient, obwohl allen Zeitgenossen bewußt war, daß ge-

strow 138, Bl. 31). Wie mit unklaren Belastungsmomenten andere Interessen verfolgt werden konnten, zeigt ein Konflikt zwischen Sozialdemokraten und Kommunisten über die Zusammenarbeit von SPD und KPD in Boltenhagen, der dazu führte, daß zwei Altkommunisten vorgehalten wurde, einige Male mit NSDAP-Parteiabzeichen gesehen worden zu sein (SAPMOBA, RY 1/I3/15, 38, Bl. 3-6). Auch das Beispiel des bereits erwähnten Steuerinspektors in Schwerin ist nicht unbedingt ein Exempel tatsächlicher Denunziation, wohl aber der damit verbundenen sozialen Aufstiegsmöglichkeiten (MLHA, LL KPD I/28, Bl. 107).

441 MLHA, MdI 210b.

${ }^{442}$ MLHA, MdI $210 \mathrm{~b}$. 
rechte Beurteilungen differenziertere Maßstäbe vorausgesetzt hätten. ${ }^{443}$ Der Rigorismus und die Geschwindigkeit, mit denen die Entlassungen durchgeführt und die Rückkehr aller, auch der eventuell unrechtmäßig Entlassenen in ihre alten Stellungen verhindert wurden, und das ausdrückliche Desinteresse an einer Überprüfung der Flüchtlinge zeigen, daß nicht die individuelle Belastung das ausschlaggebende Entnazifizierungskriterium im öffentlichen Dienst war. Wichtiger war vielmehr die mit der Entnazifizierung und dem Herrschaftswechsel verbundene Möglichkeit einer strukturellen Veränderung des Verwaltungsapparates, der zu einem effizienten und willfährigen Instrument der neuen politischen Herrschaft um- und ausgebaut wurde.

${ }^{443} 1946$ stellten die Kontrollratsdirektiven Nr. 24 und Nr. 38 mehrere hundert Kriterien zur politischen Beurteilung bereit und gaben auch differenzierte Sanktionsmöglichkeiten vor (Rößler, Entnazifizierungspolitik, S. 64-81, 97-124; siehe Kapitel III). 
